Aus der Klinik für Neurologie

(Prof. Dr. med. M. Bähr)

der Medizinischen Fakultät der Universität Göttingen

\title{
Der Einfluss von humanem $\alpha$-Synuclein-Wildtyp und der Mutanten A30P und A53T auf die Autophagie und den Transport synaptischer Vesikel in primären Mittelhirnneuronen der Ratte
}

\author{
INAUGURAL-DISSERTATION \\ zur Erlangung des Doktorgrades \\ der Medizinischen Fakultät der \\ Georg-August-Universität zu Göttingen
}

vorgelegt von

Florian Bitow

aus

Sömmerda

Göttingen 2019 
Dekan:

Referent:

Ko-Referent:

Datum der mündlichen Prüfung:
Prof. Dr. med. W. Brück

PD Dr. med. J. C. Koch

Prof. Dr. Thomas Dresbach

07.10 .2020 
Hiermit erkläre ich, die Dissertation mit dem Titel „Der Einfluss von humanem a-SynucleinWildtyp und der Mutanten A30P und A53T auf die Autophagie und den Transport synaptischer Vesikel in primären Mittelhirnneuronen der Ratte" eigenständig angefertigt und keine anderen als die von mir angegebenen Quellen und Hilfsmittel verwendet zu haben.

Göttingen, den 16.09.2019

(Florian Bitow) 


\section{Inhaltsverzeichnis}

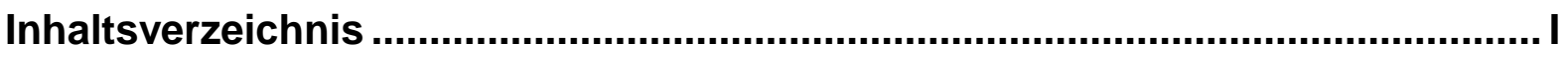

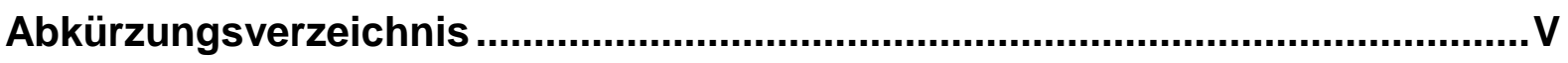

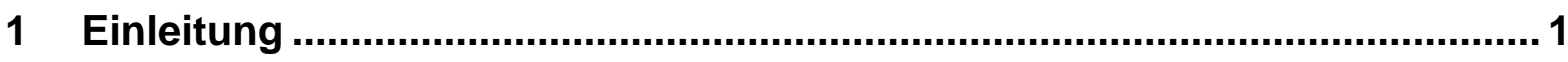

1.1 Das idiopathische Parkinsonsyndrom ............................................... 1

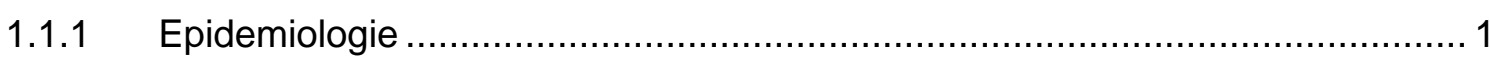

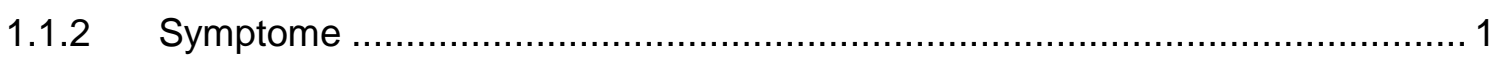

1.1.3 Pathogenetische Grundlagen............................................................ 2

1.1.3.1 Umweltfaktoren und toxische Einflüsse als Auslöser des zellulären

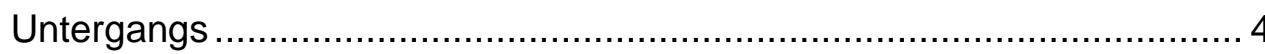

1.1.4 Mechanismen des zellulären Untergangs - oxidativer Stress, mitochondriale und proteasomale Dysfunktion und Störung der Autophagie .......................... 4

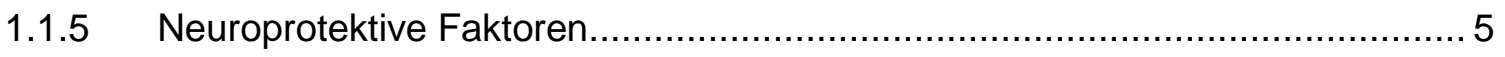

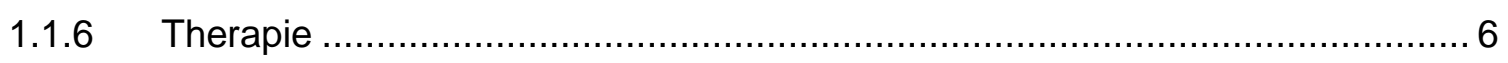

1.1.6.1 Aktuelle Therapie des Parkinsonsyndroms ...................................... 6

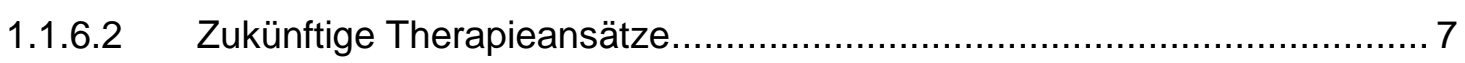

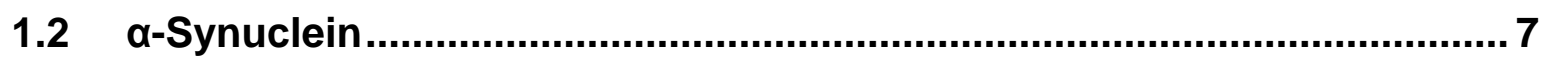

1.2.1 Proteinstruktur und Funktion ................................................................ 8

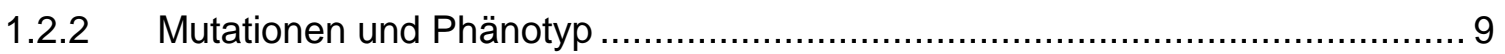

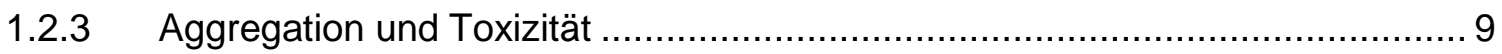

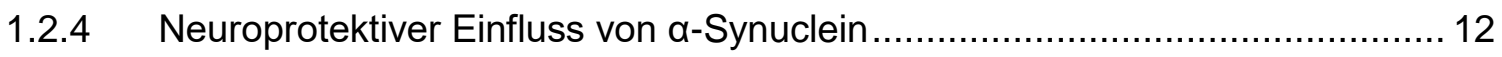

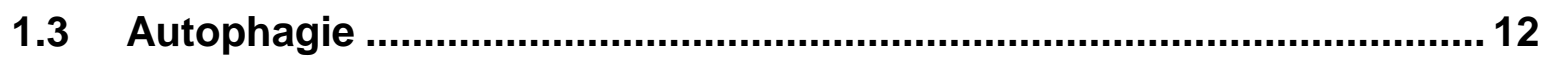

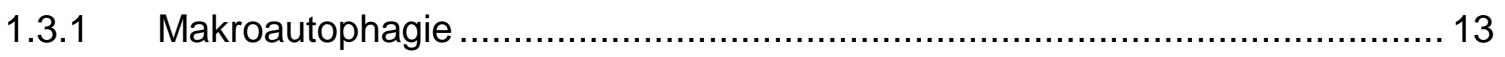

1.3.1.1 Mikrotubulin-assoziiertes Leichtketten-Protein 3 ................................. 14

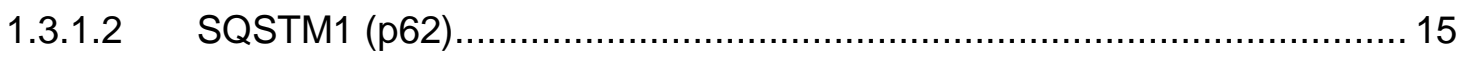

1.3.1.3 Monitoring des autophagischen Flusses ........................................... 15

1.3.2 Chaperon-vermittelte Autophagie........................................................ 16

1.3.2.1 Lysosomal-assoziiertes Membranprotein-2A .................................... 18

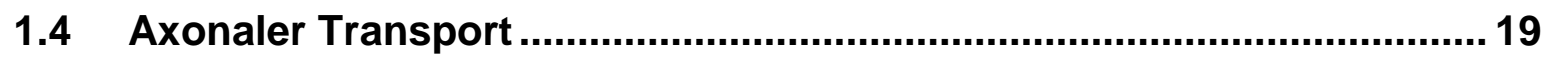

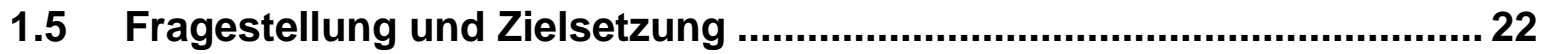




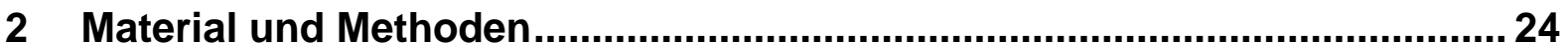

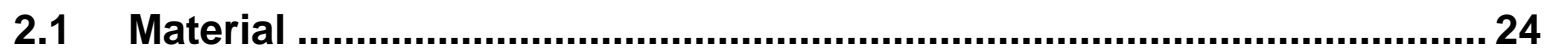

2.1.1 Chemikalien, Reagenzien und Kits .................................................... 24

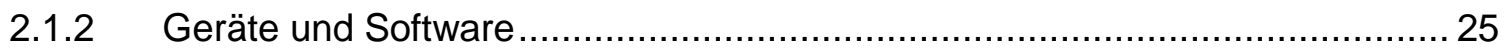

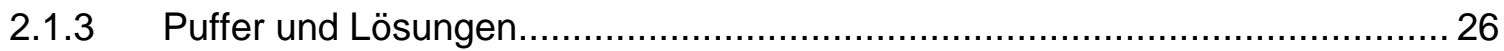

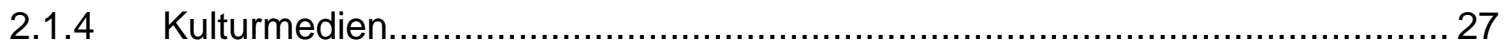

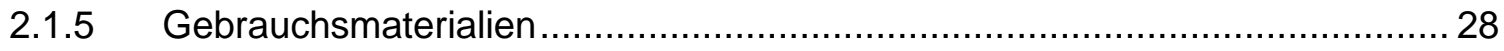

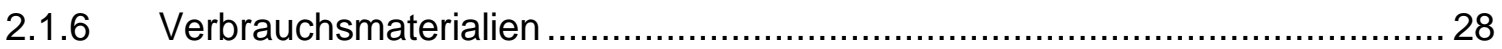

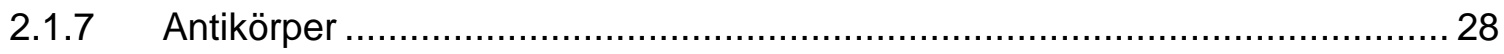

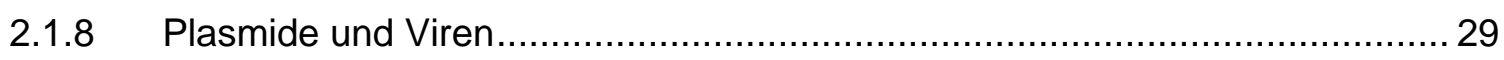

2.1.8.1 a-Synuclein-Plasmide (WT, A30P, A53T) ......................................... 29

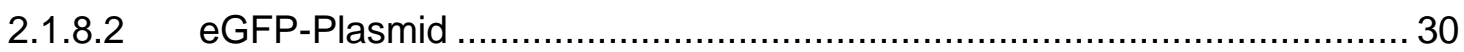

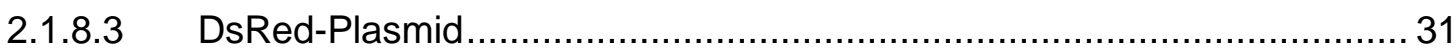

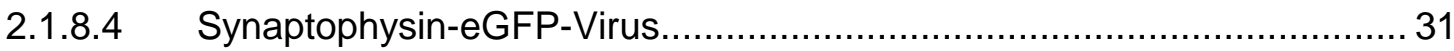

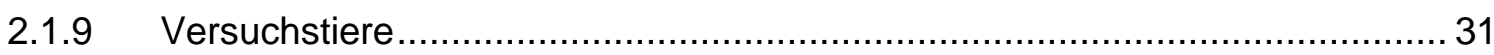

2.2 Primäre Mittelhirnneuronenzellkultur.................................................. 31

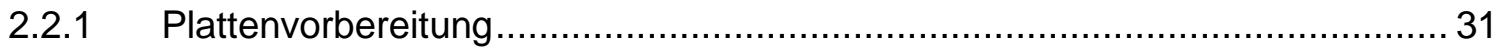

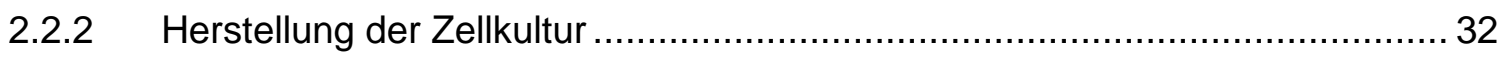

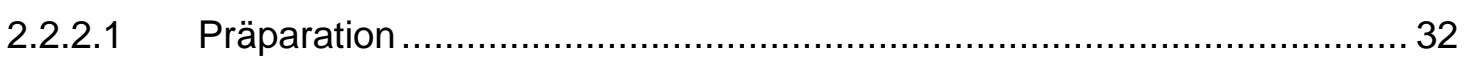

2.2.2.2 Lösung des Zellverbandes ................................................................... 33

2.2.2.3 Berechnung der Zellmenge und Zellaussaat......................................... 34

2.2.2.4 Kultivierung ............................................................................ 35

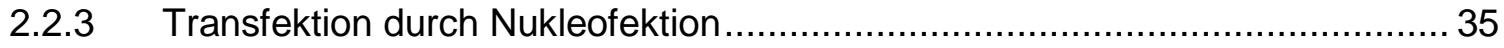

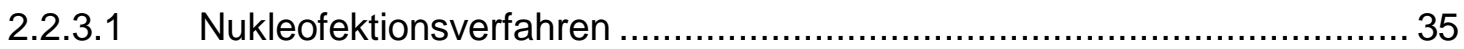

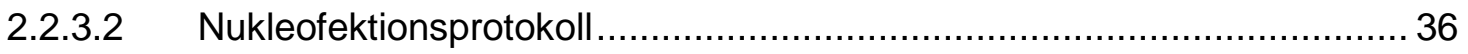

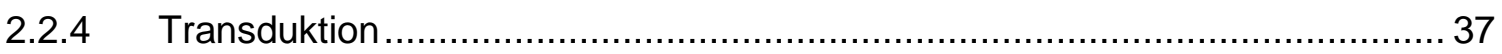

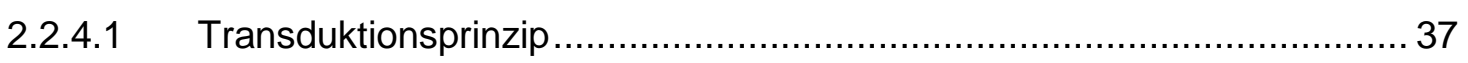

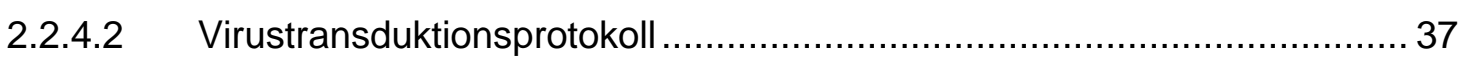

2.2.5 Plasmidamplifikation und Restriktionsenzymverdau..................................... 38

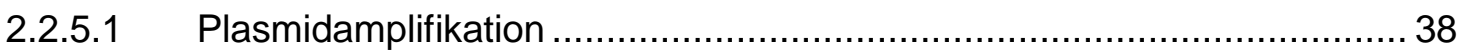

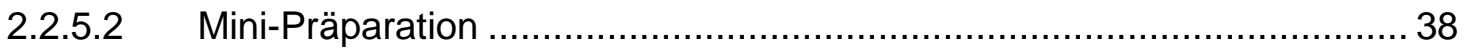

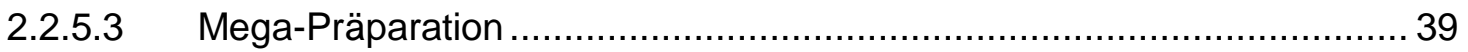

2.2.5.4 DNA-Konzentration und Reinheit (OD-Bestimmung) .............................. 39

2.2.5.5 Restriktionsenzymverdau und Agarosegelelektrophorese ...................... 40

2.2.6 Bafilomycin $A_{1}$-Behandlung................................................................ 42 


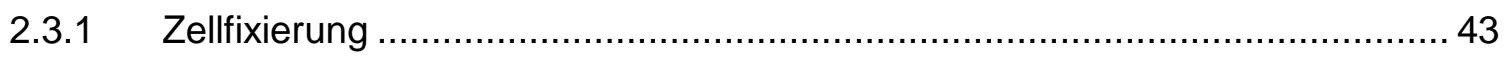

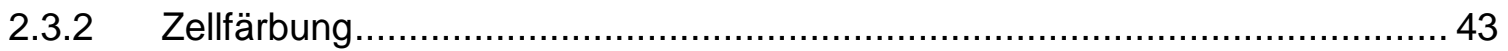

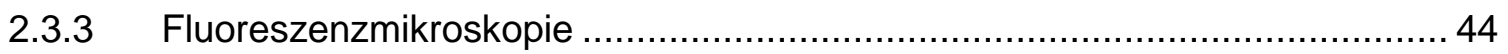

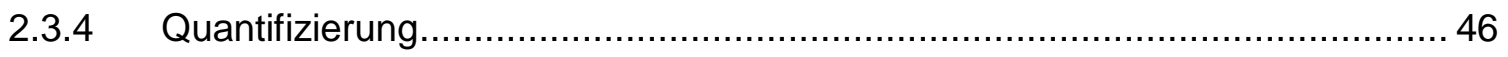

2.3.4.1 Anzahl LC3-positiver Autophagosomen ............................................... 46

2.3.4.2 Anzahl LAMP-2A-positiver Lysosomen und deren Verteilung ................. 48

2.4 Analyse des axonalen Vesikeltransportes..........................................50

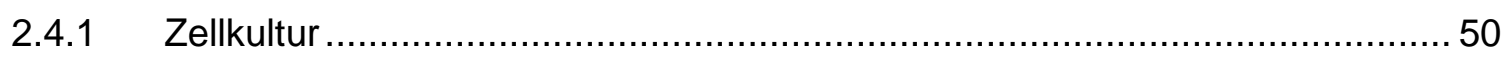

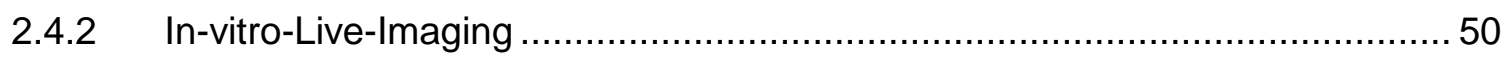

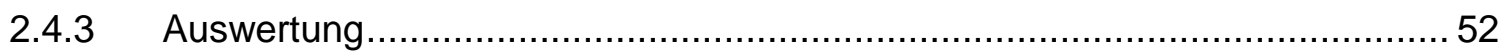

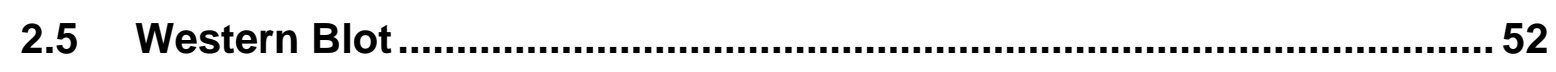

2.5.1 Ermittlung der Proteinkonzentration …………...................................... 52

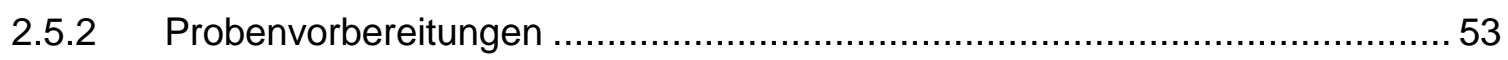

2.5.3 SDS-Polyacrylamid-Gelelektrophorese …………................................... 53

2.5.4 Proteintransfer (Blotten) auf eine Nitrozellulosemembran ............................. 54

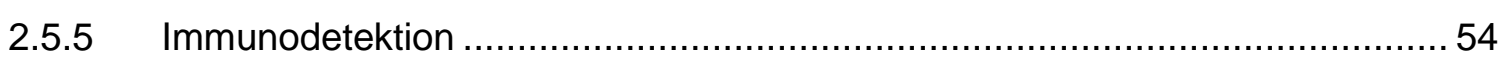

2.5.6 Quantifizierung der Western Blots............................................................. 55

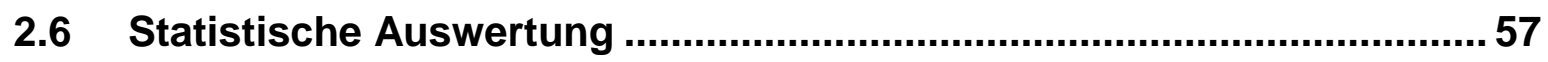

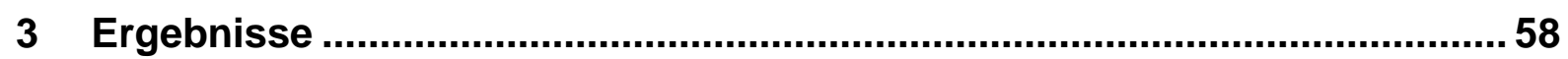

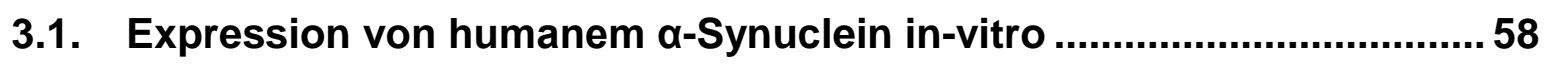

3.1.1 Quantitative $\alpha$-Synuclein-Expression im Western Blot....................................58

3.1.2 Immunzytochemische Kontrolle der $\alpha$-Synuclein-Transfektion .......................60

3.2 Makroautophagie in primären Mittelhirnneuronen ............................... 62

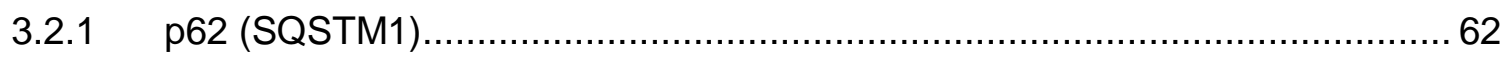

3.2.2 Analyse des Autophagie-Flusses im Western Blot ...................................... 63

3.2.2.1 Veränderungen von LC3 im Western Blot ohne Bafilomycin $A_{1}-$

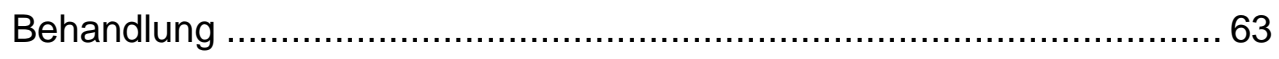

3.2.2.2 Vorversuche zur Ermittlung der optimalen Bafilomycin $A_{1}$-Dosis .............. 65

3.2.2.3 Bafilomycin $A_{1}$-Behandlung der $\alpha$-Synuclein- und eGFP-transfizierten Mittelhirnneurone zur Bestimmung des Autophagie-Flusses im Western Blot

3.2.3 Analyse des Autophagie-Flusses mittels der Anzahl LC3-positiver Autophagosomen in immunzytochemischen Färbungen 70 
3.2.3.1 Tyrosinhydroxylase-positive (dopaminerge) Neurone ........................... 71

3.2.3.2 Tyrosinhydroxylase-negative Mittelhirnneurone .................................... 75

\subsection{Chaperon-vermittelte Autophagie in primären dopaminergen}

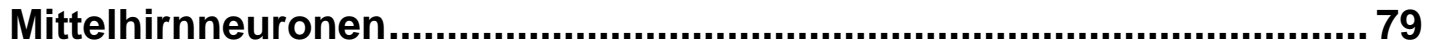

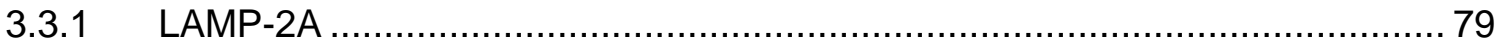

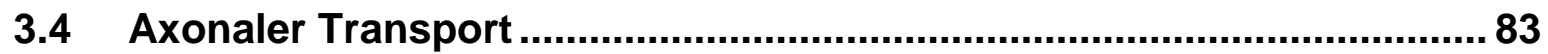

3.4.1 Visualisierung des axonalen Transportes - Synaptophysin.......................... 83

3.4.2 Optimierung des Versuchsaufbaus ............................................................ 83

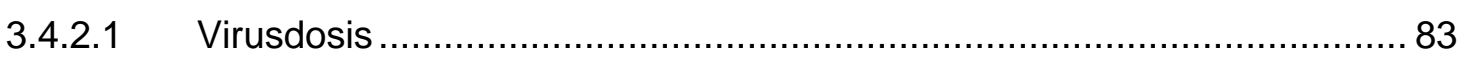

3.4.2.2 Co-Transfektion von $\alpha-S y n u c l e i n$ und DsRed ..................................... 85

3.4.3 Vesikeltransport in $\alpha$-Synuclein-transfizierten Mittelhirnneuronen .................. 86

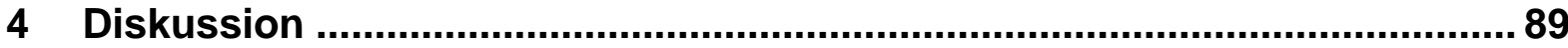

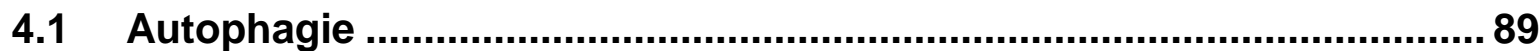

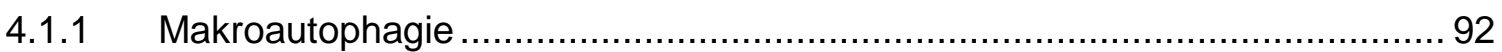

4.1.1.1 Veränderungen der Proteinmenge von SQSTM1 (p62).......................... 92

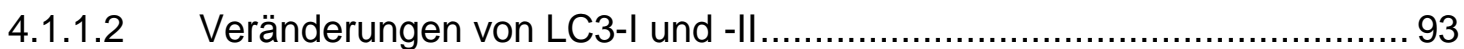

4.1.2 Chaperon-vermittelte Autophagie............................................................... 97

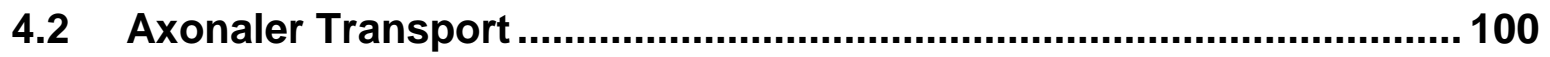

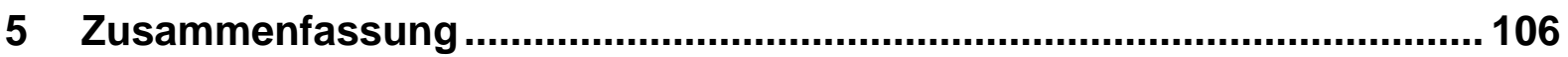

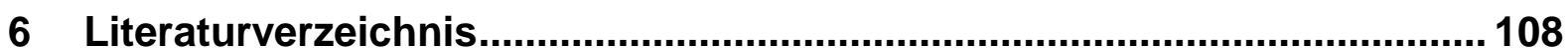




\section{Abkürzungsverzeichnis}

a. u.

A30P

A53T

AAV

AK

ATG

ATP

BCA

bp

BSA

CMA

CSPa1

Cy3

Cy5

DAPI

DIV

DNA

DsRed

E14

E46K

ECL

eGFP

G51D

GAPDH

H50Q

HRP

Hsc70

iPS

$\mathrm{KHC}$

KIF

KLC

LAMP-2A

LB

LC3 arbitrary unit

Alanin zu Prolin bei Aminosäure 30 Punktmutation von a-Syn

Alanin zu Threonin bei Aminosäure 53 Punktmutation von a-Syn

Adeno-assoziierter Virus

Antikörper

Autophagie-assoziierte Gene

Adenosintriphosphat

Bicinchoninsäure (bicinchonin acid)

Basenpaare

bovines Serumalbumin

Chaperon-vermittelte (mediated) Autophagie

Cystein-String-Protein- $\alpha-1$

Indocarbocyanin 3

Indocarbocyanin 5

4',6-Diamidin-2-phenylindol

days in-vitro

Desoxyribonukleinsäure

Discosoma sp. rot fluoreszierendes Protein

Embryonaltag 14

Glutaminsäure zu Lysin bei Aminosäure 46 Punktmutation von a-Syn

enhanced chemiluminescence

verstärkt (enhanced) grün fluoreszierendes Protein

Glycin zu Asparaginsäure bei Aminosäure 51 Punktmutation von a-Syn

Glycerinaldehyd-3-phosphat-Dehydrogenase

Histidin zu Glutamin bei Aminosäure 50 Punktmutation von a-Syn

horseradish Peroxidase

heat shock cognate protein of $70 \mathrm{kDa}$

idiopathisches Parkinsonsyndrom

kinesin heavy chains

kinesin family member

kinesin light chains

lysosomal-assoziiertes Membranprotein-2A

Luria Bertani

Mikrotubulin-assoziiertes Leichtketten-Protein 3 


\begin{tabular}{|c|c|}
\hline L-Dopa & L-3,4-Dihydroxyphenylalanin (Vorstufe des Dopamins) \\
\hline LK & Lewy-Körperchen \\
\hline MAP2 & Mikrotubuli-assoziiertes Protein 2 \\
\hline Mef2d & myocyte enhancer factor-2d \\
\hline $\mathrm{MPP}^{+}$ & 1-Methyl-4-Phenyl-Pyridin \\
\hline MPTP & 1-Methyl-4-Phenyl-1,2,3,6-Tetrahydropyridin \\
\hline mTOR & mechanistic target of rapamycin \\
\hline PBS & Phosphat-gepufferte Salzlösung \\
\hline PC12 & Phäochromozytomzellreihe 12 \\
\hline PE & Phosphatidylethanolamin \\
\hline PFA & Paraformaldehyd \\
\hline RNA & Ribonukleinsäure \\
\hline $\mathrm{RT}$ & Raumtemperatur \\
\hline SDS & Sodiumdodecylsulfat \\
\hline SH-SY5Y & Zellreihe humaner Neuroblastomzellen \\
\hline SNARE & $\begin{array}{l}\text { soluble } N \text {-ethylmaleimide-sensitive factor attachment protein } \\
\text { receptor }\end{array}$ \\
\hline SNpc & Substantia nigra pars compacta \\
\hline SQSTM1/p62 & Sequestosom 1 \\
\hline SV 40 & Simian Virus 40-Promotor \\
\hline TBS & Tris-gepufferte Salzlösung \\
\hline TBS-T & Tris-gepufferte Salzlösung mit Tween \\
\hline TH & Tyrosinhydroxylase \\
\hline TU & transfection unit \\
\hline VPS35 & vacuolar protein sorting-associated protein 35 \\
\hline WB & Western Blot \\
\hline WT & Wildtyp-Form von alpha-Synuclein \\
\hline a-Syn & alpha-Synuclein \\
\hline$\alpha-S y n-W T$ & Wildtyp-Form von alpha-Synuclein \\
\hline
\end{tabular}




\section{$1 \quad$ Einleitung}

\subsection{Das idiopathische Parkinsonsyndrom}

\subsubsection{Epidemiologie}

Bereits im Jahr 1817 wurde die Erkrankung, die heute als idiopathisches Parkinsonsyndrom (iPS) bekannt ist, durch den britischen Arzt und Apotheker James Parkinson (1755-1824) in seiner Veröffentlichung „An Essay on the Shaking Palsy“ (dt. „Eine Abhandlung über die Schüttellähmung") beschrieben (Parkinson 1817). Hierin schilderte Parkinson erstmals die klassischen Symptome der später nach ihm benannten Erkrankung.

Heutzutage ist das iPS - nach der Alzheimerschen Erkrankung - die zweithäufigste neurodegenerative Erkrankung mit einer Prävalenz von ungefähr 1,8\% in der Gruppe der über 65-Jährigen bis 2,6 \% bei den über 85-Jährigen (de Rijk et al. 2000). Jährlich erkranken ca. 0,1-0,2\% der Bevölkerung neu am iPS, wobei eine Zunahme der Inzidenz in Abhängigkeit vom Alter zu verzeichnen ist (Driver et al. 2009). In Deutschland lag die Erkrankungsrate schätzungsweise bei 110000 Fällen im Jahr 2005 (Dorsey et al. 2007).

\subsubsection{Symptome}

Die klassischen Symptome der Erkrankung bestehen aus einer Trias, welche sich aus Rigor, Tremor und Bradykinese zusammensetzt (Blaszczyk 1998, Fearnley und Lees 1991, Parkinson 1817). Je nach Ausprägungsgrad dieser Symptome wird das iPS in verschiedene Subtypen eingeteilt, wobei der Äquivalenz-Typ, mit etwa gleichstarker Ausprägung der drei oben genannten Symptome, der häufigste ist, gefolgt vom akinetischrigiden und Tremor-dominanten Verlaufstyp. Ein weiteres Kardinalsymptom des iPS, welches in der Erstbeschreibung nicht erwähnt wurde, ist die posturale Instabilität als Ausdruck des Verlustes der Halte- und Stellreflexe (Bloem et al. 1992).

Neben diesen typischen Merkmalen der Erkrankung gibt es noch weitere Symptome, die zum Teil den klassischen Anzeichen der Erkrankung um Jahre vorausgehen und als Prodromalsymptome retrospektiv betrachtet werden können. Häufig sind hierbei die Symptome ausgelöst durch eine Störung der Innervation des vegetativen Nervensystems, wie bspw. eine Motilitätsstörung des Magens (Gastroparese), aber auch Obstipation oder Diarrhoen (Chaudhuri und Schapira 2009), die ihrerseits die Medikamentenresorbtion beeinflussen und somit im Verlauf die Wirksamkeit der Therapie einschränken können. Des Weiteren kommt es hierdurch auch zu einer Talgüberproduktion der Haut (insbesondere im Gesicht - „Salbengesicht“), sexueller Dysfunktion und Temperaturregulationsstörungen, die zu einer Hyperthermie führen und somit akut lebensgefährlich sein können. 
Darüber hinaus bilden sich auch Störungen des sensiblen/sensorischen Nervensystems, allen voran eine Verminderung des Geruchsinns (Hyposmie) (Herting et al. 2008) oder Dysästhesien und Schmerzen der Muskulatur und Gelenke als frühe Hinweise eines beginnenden Rigors, aus. Zusätzlich kann auch das visuelle System, bspw. durch eine Konvergenz-, Akkomodations- oder Farbsinnstörung vor allem im Blau-Grün-Bereich, betroffen sein (Rodnitzky 1998, Bodis-Wollner und Tagliati 1993).

Letztlich kann die Parkinsonerkrankung auch die psychische und kognitive Leistungsfähigkeit beeinflussen (Narayanan et al. 2013), was sich in der Ausbildung von demenziellen Symptomen, Halluzinationen und Depressionen zeigt (Slaughter et al. 2001). Schlafstörungen in Form einer REM-Schlafverhaltensstörung gehen häufig dem Krankheitsbeginn voraus und mit einer über 40\%igen Wahrscheinlichkeit einher, dass der betroffene Patient innerhalb der nächsten 10 Jahre ein iPS oder eine Demenz mit Lewy-Körperchen entwickelt (French und Muthusamy 2016, Postuma et al. 2009).

\subsubsection{Pathogenetische Grundlagen}

Das pathologische Korrelat der extrapyramidal-motorischen Symptome zu Beginn der Krankheit ist der Untergang dopaminerger Neurone im Bereich der Substantia nigra pars compacta (SNpc) und ihrer neuronalen Projektionen in das Striatum, was dort zum Mangel an Dopamin mit folgender Störung des biochemischen Gleichgewichts führt (Dauer und Przedborski 2003). Aber auch andere Hirnareale sind im Rahmen des iPS in ihrer Funktionsfähigkeit gestört. Erwähnenswert hierbei sind die olfaktorischen Regionen (Braak et al. 2006), das visuelle System (Bodis-Wollner und Tagliati 1993), aber auch serotonerge Areale wie die Raphe-Kerne und präfrontale Hirnregionen (Narayanan et al. 2013), der noradrenerg projezierende Locus coeruleus oder Bereiche des retikulären Systems. Je nach Beteiligung der einzelnen Hirnareale sind die zugehörigen Symptome mehr oder weniger ausgeprägt, wobei das dopaminerge Defizit des Striatums als das wesentliche pathogenetische Korrelat der Erkrankung anzusehen ist, da es auch ursächlich für die Ausbildung der klassischen motorischen Symptome ist.

Interessanterweise konnte gezeigt werden, dass erst ein Verlust von ca. $60 \%$ der striatalen dopaminergen Terminalen zum Auftreten der typischen Parkinsonsymptome führt (Brooks 1998). Die Degeneration der nigralen Zellsomata beträgt zu diesem Zeitpunkt erst ca. $40 \%$, was einen Beginn der Pathogenese in den axonalen Terminalen, gefolgt von einer rückwärts gerichteten Ausbreitung auf das Soma (sog. dying back), impliziert (Burke und O’Malley 2013).

Neben den sporadisch auftretenden Parkinsonfällen, die ca. 90-95 \% aller Parkinsonerkrankungen ausmachen, können genetisch determinierte Parkinsonsyndrome diagnostiziert werden, die einem monogenetischen Erbgang folgen. Bisher wurden 18 
verschiedene Genorte (PARK 1-18, s. Tab. 1), deren Mutationsformen zur definitiven Ausbildung eines Parkinsonsyndroms führen, entdeckt (Spatola und Wider 2014). Diese sog. familiären Parkinsonsyndrome haben im Vergleich zu den sporadisch auftretenden Fällen häufig klinische Besonderheiten, wie ein früheres Erkrankungsalter, eine schnell einsetzende demenzielle Entwicklung oder begleitende Dystonien. Darüber hinaus finden sich auch mutationsspezifische pathologische Besonderheiten bei einigen genetischen Formen, wie bspw. das Fehlen von Proteinaggregat-Ablagerungen (Gasser 2001). Aufgrund der kausalen Verknüpfung der familiären Parkinsonsyndrome mit determinierten genetischen Veränderungen wurden weitere genetische Analysen durchgeführt und mittlerweile 16 Risikogene identifiziert (Singleton et al. 2013), die das Erkrankungsrisiko erhöhen und so zur pathogenetischen Klärung sporadischer Erkrankungen beitragen können. Hieraus können ggf. weitere therapeutische Strategien entwickelt werden. Letztlich scheinen neben den genetischen Veränderungen auch Umweltfaktoren Einfluss auf die Entstehung eines iPS zu nehmen (Braak und Del Tredici 2008, Wider und Wszolek 2008).

\begin{tabular}{|c|c|c|c|}
\hline Bezeichnung & Gen & Chromosom & Erbgang \\
\hline PARK1/PARK4 & a-Synuclein & $4 q 21.3-q 22$ & $A D$ \\
\hline PARK2 & Parkin & 6q25.2-q27 & AR \\
\hline PARK3 & n. n. & $2 p 13$ & $A D$ \\
\hline PARK5 & UCH-L1 & $4 p 14$ & $A D$ \\
\hline PARK6 & PINK1 & $1 p 35-36$ & AR \\
\hline PARK7 & DJ-1 & $1 p 36$ & $\mathrm{AR}$ \\
\hline PARK8 & LRRK2 & $12 q 12$ & $A D$ \\
\hline PARK9 & ATP13A2 & $1 p 36$ & AR \\
\hline PARK10 & AAOPD & $1 p 32$ & unklar \\
\hline PARK11 & GIGYF2 & $2 q 36-37$ & $A D$ \\
\hline PARK12 & n. n. & Xq21-q25 & X-chromosomal \\
\hline PARK13 & OMI/HTRA2 & $2 p 12$ & $A D$ \\
\hline PARK14 & PLA2G6 & $22 q 13.1$ & AR \\
\hline PARK15 & FBXO7 & 22q11.2-qter & AR \\
\hline PARK16 & n. n. & $1 q 32$ & $A D$ \\
\hline PARK17 & VPS35 & $16 q 12$ & $A D$ \\
\hline PARK18 & EIF4G1 & $3 q 27.1$ & $A D$ \\
\hline
\end{tabular}

Tab. $\quad 1.1 \quad$ Tabellarische Auflistung der assoziierten Genloci des familiären Parkinsonsyndroms. AD: autosomal dominant; AR: autosomal rezessiv; n. n.: nomen nominandum. 


\subsubsection{Umweltfaktoren und toxische Einflüsse als Auslöser des zellulären Untergangs}

Da nur ein geringer Teil der Parkinsonerkrankungen monogenetisch determiniert ist, werden auch Umwelteinflüsse als Auslöser eines iPS diskutiert (Thomas und Beal 2007). Unterstützung erfährt diese These durch Zwillingsstudien, in denen gezeigt werden konnte, dass der genetische Einfluss auf die Erkrankung bei einem Erkrankungsalter von über 50 Jahren nur noch eine untergeordnete Rolle spielt (Tanner et al. 1999).

Häufige toxische Auslöser sind Schwermetalle. Exposition mit diesen Stoffen, insbesondere mit Mangan, führt zu einem deutlich erhöhten Erkrankungsrisiko. Pathogenetisch besteht die Toxizität in dem durch Mangan induzierten Dopamin-Abbau mit folgender Ausbildung neurotoxischer Substanzen wie Dopaminquinon und Wasserstoffperoxid (Florence und Stauber 1988). Auch andere Metalle, wie Eisen und Kupfer, werden als Auslöser eines iPS diskutiert (Gorell et al. 1999). Es konnte gezeigt werden, dass diese Metalle zu einer erhöhten Fibrillisation von a-Synuclein führen (Uversky et al. 2001) und so pathogenetisch an der Ausbildung eines Parkinsonsyndroms beteiligt sein können (Carboni und Lingor 2015).

Des Weiteren konnte mittels einer Metaanalyse von Studien aus verschiedenen Ländern (USA, Kanada, China, Spanien, Italien, Taiwan und Australien) gezeigt werden, dass eine Assoziation des Auftretens eines iPS mit dem Wohnen in ländlicher Gegend, dem Trinken von Brunnenwasser und einer langjährigen landwirtschaftlichen Arbeit besteht (Priyadarshi et al. 2001). Ursächlich hierfür kann die erhöhte Exposition mit Pestiziden, wie bspw. Rotenon und Paraquat (Betarbet et al. 2000) oder auch mit Organophosphaten (Kamel und Hoppin 2004), sein.

\subsubsection{Mechanismen des zellulären Untergangs - oxidativer Stress, mitochondriale und proteasomale Dysfunktion und Störung der Autophagie}

Durch zelluläre Prozesse, wie der mitochondrialen Energiegewinnung und -speicherung in Adenosintriphosphat (ATP), entstehen permanent reaktive Sauerstoffmetabolite, die zelluläre Strukturen oxidieren und dadurch die Funktionsfähigkeit der Zelle stören. Proteine werden bspw. durch Änderung ihrer Konformation oder Nitrierung funktionslos, Zellmembranen in ihrer Integrität gestört und Nukleinsäuren, allen voran Desoxyribonukleinsäuren (DNA), geschädigt. Oxidationskatalysatoren, wie bspw. Eisen, welches durch das Eisen-speichernde Neuromelanin in dopaminergen Neuronen angereichert ist, zeigen sich in der SNpc von Parkinsonpatienten erhöht (Fasano et al. 2006, Good et al. 1998, Dexter et al. 1989, Riederer et al. 1989) und tragen zur Entwicklung eines iPS bei (Carboni und Lingor 2015). Auch eine mitochondriale Dysfunktion, wie sie bei 
Parkinsonpatienten festgestellt wurde (Cooper et al. 1995), löst direkt oder durch den Mangel des intrazellulären Energieträgers ATP oxidativen Stress aus, wird aber auch durch oxidativen Stress selbst hervorgerufen (Keeney et al. 2006). Bspw. führt der Energiemangel durch den Funktionsverlust des energieabhängigen Vesikel-Monoamin-Transporters 2 zu einer cytoplasmatischen Kumulation von Dopamin, welches selbst oxidativ wirkt (Andersen 2004). Daneben wirkt oxidiertes Dopamin über dessen Metabolite (5-S-Cysteinyl-DopaminDerivate) inhibitorisch auf die mitochondriale Funktion und kann diesen Effekt verstärken (Andersen 2004, Berman und Hastings 1999, Spencer JP et al. 1998). Zusätzlich konnte gezeigt werden, dass antioxidativwirkende Enzyme, wie die Glutathion-Peroxidase und -Reduktase oder die Superoxiddismutase, in der SNpc von Parkinsonpatienten erniedrigt sind (Pearce et al. 1997) und dies ggf. der mitochondrialen Inhibition durch oxidierte Substanzen vorausgeht (Jha et al. 2000). Tierexperimente unterstützen den für das iPS diskutierten Zusammenhang zwischen Neurotoxizität [z. B. Zelluntergang durch Freiwerden von mitochondrialem Cytochrom C und verschiedenen Caspasen (Smith et al. 2005, Zhivotovsky et al. 1999)], oxidativem Stress durch Eisen, mitochondrialer Dysfunktion und Mangel an antioxidativen Enzymen (Kaur et al. 2003, Przedborski et al. 1992).

Eine weitere wichtige Rolle in der Pathogenese des iPS spielt eine Störung der Autophagie, welche unten ausführlich abgehandelt wird (s. 1.3).

\subsubsection{Neuroprotektive Faktoren}

Trotz der beschriebenen pathogenetischen Einflüsse gibt es auch protektive Faktoren, die das Risiko, an einem iPS zu erkranken, vermindern.

So konnte gezeigt werden, dass Raucher im Vergleich zu Nicht-Rauchern ein deutlich erniedrigtes Risiko haben, an einem iPS zu erkranken (Hernán et al. 2002, Baron 1986), wobei am ehesten Nikotin als schützender Faktor zu nennen ist (Quik et al. 2008). Ähnliches wurde für den Konsum von Kaffee gezeigt (Powers et al. 2008, Hernán et al. 2002).

Weiterhin werden erhöhten Harnsäure- (Shen und Ji 2013, Gao et al. 2008, Kutzing und Firestein 2008, Schlesinger und Schlesinger 2008) und Cholesterin-Serumspiegeln (Huang $X$ et al. 2015, Simon et al. 2007, de Lau et al. 2006) schützende Eigenschaften hinsichtlich der Ausbildung eines iPS zugeschrieben.

Zudem belegen aktuelle Studien einen protektiven Einfluss von körperlicher Aktivität auf die Entwicklung eines iPS. So sollen 6 Stunden moderate Bewegung pro Woche das relative Risiko bereits um ca. 45 \% senken können (Yang F et al. 2015, Xu et al. 2010). 


\subsubsection{Therapie}

\subsubsection{Aktuelle Therapie des Parkinsonsyndroms}

Die derzeit verfügbaren und klinisch erprobten Therapieansätze des Parkinsonsyndroms wirken rein symptomatisch. Dabei rücken neben den klassischen motorischen Symptomen auch die nicht-motorischen Symptome sowie die Alltagskompetenz und der Erhalt der Selbstständigkeit mehr in den Fokus der therapeutischen Strategien.

Klassische medikamentöse Ansätze zielen auf eine Erhöhung der pathologisch reduzierten Dopamin-Konzentration im zentralen Nervensystem ab. Allen voran ist die Behandlung mit L-3,4-Dihydroxyphenylalanin (L-Dopa, Vorstufe des Dopamins) zu nennen, dessen Wirksamkeit in den 1960ern erstmals beschrieben wurde (Carlsson 1964) und noch heute als potentestes Medikament gilt (Parkinson Study Group 2004, Levine et al. 2003). Im Verlauf wurden ergänzend synthetische Dopaminagonisten entwickelt. Hierbei unterscheidet man Ergot- und nicht-Ergot-Dopaminagonisten, wobei die Ergot-Dopaminagonisten - aufgrund ihres ausgeprägten Lungenfibrose-Risikos - nur noch selten, bspw. bei Unverträglichkeiten gegenüber den übrigen Medikamenten, unter regelmäßigen klinischen Kontrollen Anwendung finden. Daneben werden Substanzen eingesetzt, deren primäre Wirkung eine Hemmung der Dopamin abbauenden Enzyme ist. Hierzu zählen Monoaminoxidase B- und Catechol-O-Methyltransferase-Inhibitoren. Sofern die klinische Symptomatik eine Therapie notwendig macht, sollte diese frühzeitig und individuell unter Berücksichtigung von Alter, Komorbiditäten, Schwere der Erkrankung sowie Wirkungs- und Nebenwirkungsprofil eingeleitet werden. Vor allem bei jungen Patienten wird die initiale Therapie mit nicht-Ergot-Dopaminagonisten aufgrund des verzögerten Auftretens motorischer Spätkomplikationen (Dyskinesien) empfohlen. Bei älteren Patienten wird dagegen die primäre L-Dopa-Therapie aufgrund des ungünstigeren Nebenwirkungsprofils der Dopaminagonisten hinsichtlich psychotischer Ereignisse sowie der besseren symptomatischen Wirksamkeit bevorzugt.

Im Verlauf der Erkrankung kommt es häufig zu Komplikationen in Form von Wirkungsfluktuationen, die zunehmend schlechter auf eine klassische orale Medikation ansprechen. Vor allem ein plötzlicher Wirkungsverlust mit ausgeprägten Akinesien (Freezing-Phänomen) bis hin zu starken Dyskinesien ist zu verzeichnen. In dieser z. T. Medikamenten-refraktären Phase, aber auch bei jüngeren, medikamentös schwer einstellbaren Patienten stellen neben der Kombinationstherapie verschiedener dopaminagonistischer Substanzen die kontinuierliche intrajejunale L-Dopa-Infusion, die subkutane Apomorphin-Gabe mittels Pumpensystem sowie die tiefe Hirnstimulation ergänzende Therapiealternativen dar. Durch stereotaktische Implantation von Elektroden im Bereich des Nucleus subthalamicus oder selten im Nucleus ventralis intermedius des Thalamus kann ein funktionelles Neurotransmitter-Gleichgewicht im Bereich der Basalganglien hergestellt und 
so die Symptome trotz mangelnden medikamentösen Ansprechens reduziert werden (Follett et al. 2010, Williams et al. 2010, Deuschl et al. 2006).

\subsubsection{Zukünftige Therapieansätze}

Letztlich sind die oben beschriebenen Therapieverfahren nur auf die Kontrolle der Symptome ausgerichtet. Deswegen verwundert es nicht, dass intensivste Forschung zur Entwicklung einer kausalen Therapie betrieben wird. Hierfür ist es notwendig, die pathophysiologischen Abläufe noch besser zu verstehen. Erste Ansätze sind die neuroprotektive Gentherapie und die Transplantation embryonaler Stammzellen.

Im Rahmen der neuroprotektiven Gentherapie können bspw. apoptotische Prozesse durch Überexpression anti-apoptotischer Proteine, wie der B-cell-lymphoma 2-ProteinFamilie, gehemmt werden (Malik et al. 2005, Azzouz et al. 2000). Aber auch andere pathogene Mechanismen, wie die Fehlfaltung von Proteinen, wurden als Therapieansatz aufgegriffen. So konnte gezeigt werden, dass eine Steigerung der Expression von Chaperonen ebenfalls neuroprotektiv ist (Dong et al. 2005). Zusätzlich gibt es eine Phase I/II-Studie, in der virale Vektoren eingesetzt werden, um die enzymatische Produktion von Dopamin zu steigern, was wiederum zu einer Besserung der motorischen Symptome führte (Palfi et al. 2014). Solche viralen Vektoren werden auch zur Modulation neuronaler Wachstumsfaktoren [bspw. CNTF (ciliary neurotrophic factor), Wachstumsfaktoren der GDNF-Familie (glial-derived neurotrophic factor) oder Neurturin] eingesetzt, worüber das Überleben dopaminerger Neurone gefördert wird. Grundlage für diesen Therapieansatz ist der Mangel an neurotrophen Substanzen in der SNpc von Parkinsonpatienten (Decressac et al. 2012, Chauhan et al. 2001, Howells et al. 2000, Mogi et al. 1999).

Eine weitere kurative Therapieoption besteht in der Transplantation embryonaler Stammzellen. Bereits 1992 wurden erste Studien hierüber begonnen (Spencer DD et al. 1992, Widner et al. 1992), jedoch aufgrund sehr unterschiedlicher Ergebnisse nicht ausgeweitet. Erst nachdem es gelang, embryonale Stammzellen isoliert zu kultivieren, erfolgte die weitere Erforschung und vielversprechende präklinische Ergebnisse wurden bereits publiziert (Hallett et al. 2015, Grealish et al. 2014).

\section{$1.2 \quad \alpha$-Synuclein}

Das pathologische Hauptmerkmal des iPS auf zellulärer Ebene ist das Vorliegen von intraneuronalen eosinophilen Einschlusskörperchen, den sog. Lewy-Körperchen (LK). Diese bestehen zu einem Großteil aus dem aggregierten Protein $\alpha$-Synuclein ( $\alpha$-Syn) (Spillantini et al. 1997), dem eine zentrale Rolle in der Pathophysiologie des iPS zugeschrieben wird. 


\subsubsection{Proteinstruktur und Funktion}

$\alpha$-Syn ist, neben $\beta$ - und $y$-Synuclein, ein Protein der Synuclein-Familie und wurde erstmals 1991 beschrieben (Maroteaux und Scheller 1991). Eine wesentliche Gemeinsamkeit dieser Proteinfamilie ist ein hochkonserviertes helikales Amino-Ende und ein weniger konserviertes saures Carboxyl-Ende (George 2002). Mit ca. 15 kDa Molekulargewicht ist das 140 Aminosäuren lange Protein verhältnismäßig klein und sowohl zytoplasmatisch als auch nukleär zu finden (Gonçalves und Outeiro 2013). Das entsprechende humane Gen ist auf dem Chromosom 4q21.3-q22 lokalisiert und setzt sich aus insgesamt 7 Exons zusammen, wobei durch alternatives Splicing mit Verlust von Exon 3 oder Exon 5 weitere Isoformen entstehen können (Beyer 2006, Uéda et al. 1994). Trotz seiner geringen Größe liegt es, im Gegensatz zu vielen anderen Proteinen dieser Größe, nativ zum Teil in einer löslichen und ungefalteten Form vor (Conway et al. 1998). Darüber hinaus neigt es als $\beta$-Faltblattstruktur zur Oligomerisierung, wohingegen in a-helikaler Form eine MembranAssoziation beobachtet werden konnte (Cookson 2009). Die Frage nach der physiologisch dominierenden Konformation von $\alpha$-Syn wird weiterhin kontrovers diskutiert, so lassen sich je nach Nachweismethode vorrangig Tetramere (Bartels et al. 2011) oder Monomere (Burré et al. 2013) nachweisen.

Zwar wird a-Syn nahezu in allen menschlichen Geweben exprimiert, dennoch ist das Vorkommen im Gehirn (dort vor allem im Neokortex, Hippokampus, Striatum, Thalamus und Cerebellum) von besonderer Wichtigkeit und macht ca. $1 \%$ aller zytosolischen Proteine neuronaler Zellen aus (Iwai et al. 1995). Besondere Anreicherung findet sich in präsynaptischen Axonterminalen, sodass ihm eine wesentlich Rolle in präsynaptischen und Membran-assoziierten Prozessen zugeschrieben wird (George 2002). So konnte gezeigt werden, dass es für die Ausbildung des an der Membranfusion präsynaptischer Vesikel beteiligten soluble $\mathrm{N}$-ethylmaleimide-sensitive factor attachment protein receptor (SNARE-)Komplexes beteiligt ist (Chandra et al. 2005). Weiterhin führte die experimentelle Verminderung von a-Syn zu einer Reduktion und Umverteilung der synaptisch lokalisierten Vesikel (Nemani et al. 2010), sodass a-Syn einen Einfluss auf die Größe des präsynaptisch gelegenen Vesikel-Pools nimmt (Murphy DD et al. 2000). Im Bereich dopaminerger Neurone konnte gezeigt werden, dass a-Syn die Aktivität des Dopamin-Transporters und somit die zelluläre Dopamin-Wiederaufnahme verringert (Wersinger und Sidhu 2003).

Insgesamt wird $\alpha$-Syn daher eine Rolle als negativer Regulator der neuronalen Transmission mit inhibitorischer Wirkung auf die Exozytose Neurotransmitter-haltiger Vesikel in Nervenzellen zugeschrieben (Nemani et al. 2010, Larsen et al. 2006). So konnte bspw. an a-Syn-defizienten Mäusen eine schnellere Freisetzung von Dopamin im Vergleich zu $\alpha$-SynWT-Versuchstieren gezeigt werden (Abeliovich et al. 2000). 


\subsubsection{Mutationen und Phänotyp}

Durch Polymeropoulos et al. konnte erstmals das a-Syn-Gen als ein Locus des familiären Parkinsonsyndroms identifiziert werden. Des Weiteren wurde die A53T-Mutation von ihm beschrieben (Polymeropoulos et al. 1997), die in ca. 30 Familien beobachtet und auf einen initialen Überträger griechisch-italienischen Ursprungs zurückgeführt werden konnte. 2009 konnte ergänzend eine de-novo-A53T-Mutation in einer schwedischen Familie entdeckt werden (Puschmann et al. 2009). Daneben gibt es 4 weitere $\mathrm{N}$-terminal gelegene Punktmutationen: A30P (Krüger et al.1998), E46K (Zarranz et al. 2004), H50Q (AppelCresswell et al. 2013) und G51D (Lesage et al. 2013), die mit einem hereditären Parkinsonsyndrom assoziiert sind. Insgesamt sind diese monogenetischen familiären Formen jedoch sehr selten (Berg et al. 2005).

Neben diesen strukturellen Proteinveränderungen konnte auch gezeigt werden, dass Duplikationen und Triplikationen des a-Syn-Gens zum autosomal-dominant vererbten Parkinsonsyndrom führen (Chartier-Harlin et al. 2004, Singleton et al. 2003), was einen GenDosis-Effekt als Krankheitsursache nahelegt. Diese Annahme wird gestärkt durch PromotorPolymorphismen im a-Syn-Gen, die als Risikofaktor des iPS gelten (Tan et al. 2003) und zu einer Herabsetzung des durchschnittlichen Erkrankungsalters führen (Hadjigeorgiou et al. 2006).

\subsubsection{Aggregation und Toxizität}

In iPS-Patientengehirnen konnten a-Syn-haltige, ubiquitinierte Proteinaggregationen zytoplasmatisch in neuronalen Zellsomata (Spillantini et al. 1997) und innerhalb dystropher Neuriten (Takeda et al. 1998), entsprechend LK und Lewy-Neuriten, gefunden werden. Auch bei anderen Erkrankungen, wie bspw. dem Morbus Alzheimer, der Multisystematrophie (Aggregate in Oligodendrozyten), der neurodegenerativen Erkrankung mit Eisenablagerung im Gehirn oder der Lewy-Body-Demenz, konnten solche Aggregate beobachtet werden. Bestandteil dieser Aggregate ist vor allem die unphysiologische $\beta$-Faltblattstruktur des a-Syns, die durch Änderung der Proteinkonformation zur Ausbildung unlöslicher Proteinfibrillen führt und sich in LK ablagert. Normalerweise sind $\beta$-Faltblatt-Monomere instabil und werden durch zelluläre Proteine, sog. Chaperone, wieder in ihre ursprüngliche, native Form rückgefaltet (Goldberg und Lansbury 2000). Die Änderungen der Quartärstruktur mit Zusammenlagerung zu Oligomeren und folgender Fibrillisierung verleiht dem fehlgefalteten $\alpha$-Syn Stabilität und ermöglicht die Ablagerung in LK (Modler et al. 2003, Conway et al. 1998). Toxisch scheinen jedoch nicht die gebildeten LK zu sein (George 2002), sondern die Zwischenprodukte bis zur Ausbildung höhermolekularer Fibrillen (Peelaerts et al. 2015, Goldberg und Lansbury 2000). Dies wird unterstützt durch 
Untersuchungen der a-Syn-Mutationen A30P und A53T. Die A30P-Mutation führt zu einer Hemmung der Konversion von Protofibrillen zu Fibrillen, wohingegen die A53T-Mutation, wie auch eine stark erhöhte Konzentration der a-Syn-Wildtypform ( $\alpha-S y n-W T, W T$ ), zu einer vermehrten Fibrillenbildung führt. Beide Mutationsformen zeigen eine erhöhte Oligomerisierung mit einer elevierten Anzahl an Oligomeren bei der A30P-Mutation (Conway 2000). Die a-Syn-Mutation H50Q zeigt ebenso eine beschleunigte Fibrillenbildung (Khalaf et al. 2014, Ghosh et al. 2013). Auch posttranslationale Veränderungen, wie alternatives Splicing oder Phosphorylierung, erhöhen die Fibrillisierung von a-Syn und konnten vermehrt in Lewy-Körperchen nachgewiesen werden (Chen und Feany 2005, Li W et al. 2005, Fujiwara et al. 2002). Ergänzend konnte ein toxischer Effekt der $\alpha$-Syn-Präfibrillen durch Zerstörung vesikulärer Strukturen mittels Ausbildung von Membranporen (Kim et al. 2009) und Freisetzung intravesikulärer Proteine, wie oxidationsanfälliges Dopamin, gezeigt werden (Karpinar 2009) (s. Abb. 1.1).

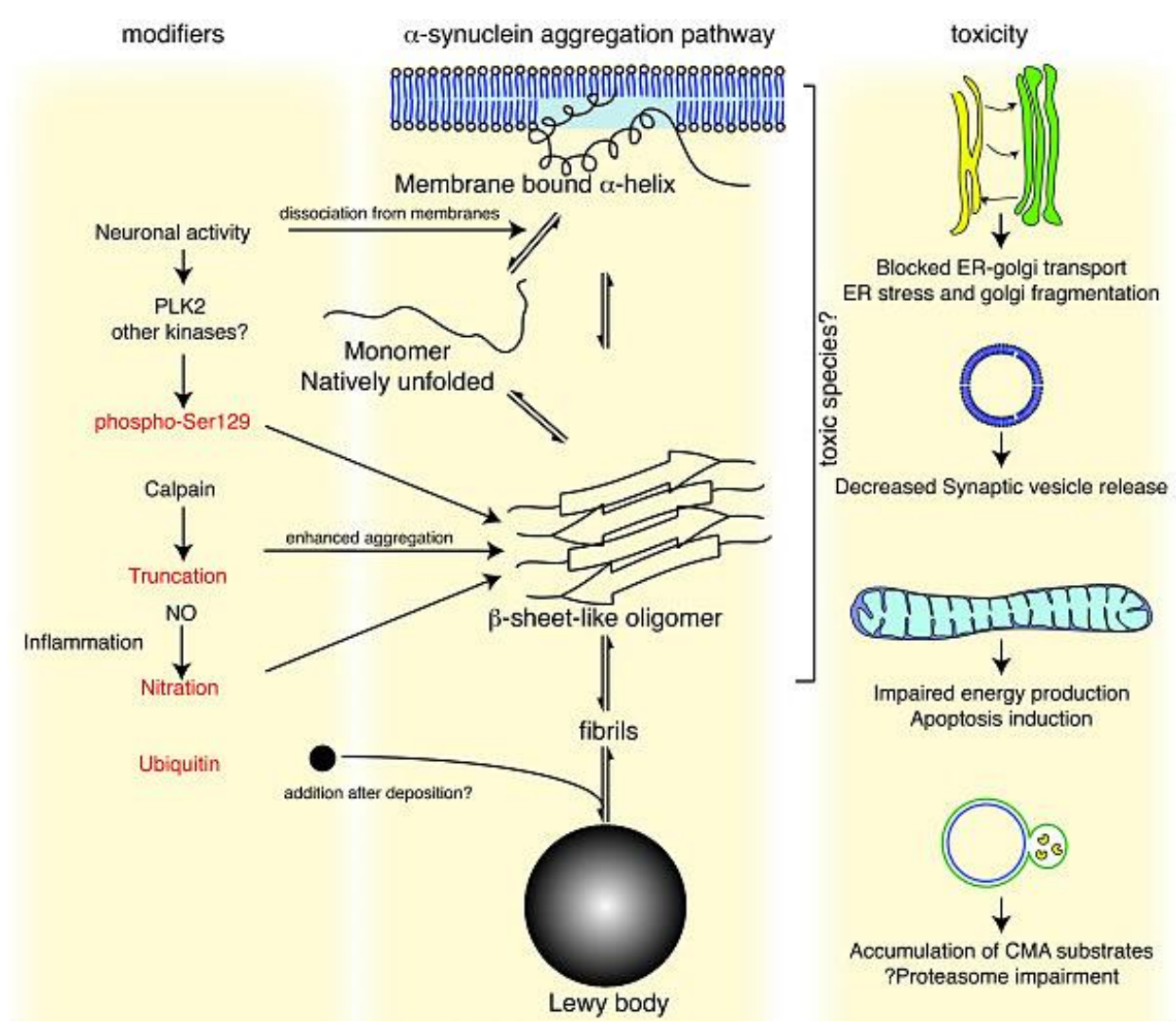

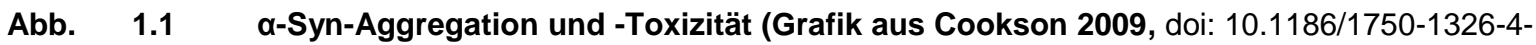
9). Die mittlere Spalte zeigt den Ablauf der a-Syn-Aggregation. Ausgehend von zytoplasmatisch gelöstem oder in $\alpha$-helicaler Form natürlicherweise vorkommendem $\alpha$-Syn kann es über ungefaltete $\alpha$-Syn-Monomere zur Ausbildung von Oligomeren kommen, welche durch $\beta$-Faltblatt-Strukturen stabilisiert werden. Hieraus entstehen höhermolekulare Fibrillen, die im Verlauf in Lewy-Körperchen deponiert werden. Die linke Spalte zeigt verschiedene an diesem Prozess beteiligte Vorgänge (bspw. a-Syn-Phosphorylierung oder Inflammation). Rechtsseitig werden verschiedene zelluläre Prozesse dargestellt, die die Toxizität von $\alpha$-Syn vermitteln (bspw. Apoptose-Induktion oder Autophagie-Dysfunktion). CMA: Chaperon-vermittelte Autophagie, NO: Stickstoff-monoxid, ER: endoplasmatisches Reticulum, PLK2: polo like Kinase 2. 
Eine für die Pathogenese des iPS entscheidende Beobachtung ist die Ausbreitung (spreading) von pathologischem a-Syn (gemessen an der LK-Dichte) von einem Neuron zum anderen gemäß eines reproduzierbaren anatomischen Musters ausgehend von primären Läsionen im Hirnstamm bis zum Neocortex. Initial zeigen sich Veränderungen im Bereich der dorsalen Nuclei des Nervus glossopharyngeus und des Nervus vagus (Hirnstamm, Stadium 1), welche gut die Frühsymptome wie bspw. Gastroparese erklären. Über pontine Veränderungen (Stadium 2) kommt es im Stadium 3 zu den pathognomonischen Läsionen in der SNpc und folgend zur Ausbreitung über Areale des Prosencephalons, Mesocortex und Allocortex hin zu neokortikalen Bereichen des sensorischen und motorischen Assoziationscortex und letztlichem Befall der primären sensorischen und motorischen Areale (Stadium 4-6) (Braak und Del Tredici 2009). Hierbei ist jedoch zu erwähnen, dass die Stadien 1 und 2 histopathologische Beobachtungen einer LK-Pathologie sind und an asymptomatischen Menschen erforscht wurden. Erst ab Stadium 3 ist von einer typischen Symptomatik auszugehen, sodass der postulierte dynamische Prozess der beschriebenen Pathologie nicht endgültig auf die Entwicklung eines iPS übertragen werden kann. Zusätzlich wurde an zwei Parkinsonpatienten nach Transplantation fetaler dopaminerger Neurone gezeigt, dass nach mehr als 10 Jahren auch die transplantierten Neurone eine LK-Pathologie aufwiesen (Li JY et al. 2008). Ursächlich hierfür könnte die Ausbreitung der toxischen a-Syn-Formen mit Ausbildung von LK über verschiedene Nervenzellpopulationen sein (Desplats et al. 2009).

Eine Störung des intrazellulären Proteinabbaus trägt ebenso zur Toxizität von $\alpha$-Syn bei. So konnten an postmortalen Untersuchungen von Parkinsonpatienten Veränderungen in diesem Prozess festgestellt werden (Anglade et al. 1997). Ob hierbei jedoch eher eine Steigerung des Abbaus oder eine Inhibition durch a-Syn erfolgt, konnte aufgrund widersprüchlicher Ergebnisse bisher nicht abschließend geklärt werden (Details s. auch Diskussion).

Ein weiterer zellulärer Prozess, welcher durch $\alpha$-Syn beeinflusst wird, ist der Transport entlang neuronaler Axone. Bereits 1998 ergaben sich erste Hinweise, dass die toxische Akkumulation von a-Syn auf Defekten des axonalen Transportes beruht (Jensen $\mathrm{PH}$ et al. 1998). Sowohl an postmortalen Hirnuntersuchungen als auch an in-vitro und in-vivo Modellen konnten diese Hinweise bestätigt werden, und es wurde im Folgenden vor allem der Transport von a-Syn selbst untersucht. Auch hierbei ergaben sich zum Teil kontroverse Ergebnisse und die Auswirkungen von a-Syn auf den Transport anderer Strukturen, wie synaptische Vesikel, wurden nur unzureichend analysiert, sodass im Rahmen der vorliegenden Arbeit dieser Bereich des Transportes besonders beobachtet wurde (Details s. auch Diskussion). 


\subsubsection{Neuroprotektiver Einfluss von $\alpha$-Synuclein}

Neben den oben genannten toxischen Einflüssen ergibt sich auch Evidenz für einen neuroprotektiven Effekt von a-Syn. Es konnte in-vitro und in-vivo gezeigt werden, dass a-Syn-WT in der Lage ist, Neurone vor oxidativem Stress, bspw. durch die Neurotoxine Paraquat, 6-Hydroxydopamin, 1-Methyl-4-phenyl-1,2,3,6-tetrahydropyridin (MPTP) oder auch Dopamin selbst, zu schützen, wohingegen mutierte Formen dazu nicht in der Lage waren (Monti et al. 2007, Choi et al. 2006, Colapinto et al. 2006, Jensen PJ et al. 2003). Es werden hierbei verschiedene Mechanismen diskutiert. Zum einen erhöht $\alpha$-Syn die Expression des Chaperons Hitzeschockprotein-70 (Choi et al. 2006), zum anderen werden sog. Stress-kinasen, wie z. B. die c-Jun N-terminalen Kinasen, inaktiviert (Hashimoto et al. 2002). Darüber hinaus konnte gezeigt werden, dass $\alpha$-Syn mit ebenfalls präsynaptisch lokalisiertem Cystein-String-Protein- $\alpha-1$ (CSPa1) interagiert. Dieses Protein fungiert als CoChaperon und ist, ebenso wie a-Syn, an der Ausbildung des SNARE-Komplexes beteiligt. In CSPa1-defizienten Mäusen ist eine rapid progressive Neurodegeneration zu verzeichnen, die durch $\alpha$-Syn aufgehoben werden kann (Chandra et al. 2005).

\section{$1.3 \quad$ Autophagie}

Die Autophagie ist ein degradierender Prozess, der sich in allen eukaryotischen Zellen findet. Er ist notwendig, um zytoplasmatische Proteine zu recyceln, funktionsunfähige Organellen zu beseitigen und die zelluläre Homöostase zu gewährleisten. Zusätzlich ist Autophagie ein zellulärer Schutzfaktor, der die Akkumulation toxischer Stoffe verhindert und an der Elimination invasiver Mikroben, der Antigenpräsentation sowie der Energiegewinnung beteiligt ist (Klionsky 2005, Yorimitsu und Klionsky 2005). Autophagie ist jedoch kein einzelner Prozess, sondern ein Oberbegriff für mehrere separate zelluläre Vorgänge, die als Ganzes die autophagische Kapazität ausmachen. Man unterscheidet dabei die Makroautophagie, Mikroautophagie und die Chaperon-vermittelte Autophagie (Klionsky et al. 2007).

Autophagie kann dabei ein selektiver, aber auch ein nicht-selektiver Prozess sein (Shintani und Klionsky 2004). Im Rahmen der nicht-selektiven Autophagie wird Zytoplasma, welches bspw. durch Energiemangel dysfunktional geworden ist, beseitigt. Von selektiver Autophagie spricht man dagegen, wenn bestimmte zelluläre Bestandteile, wie Mitochondrien (= Mitophagy), Peroxisomen (= Pexophagy) oder Teile der nukleären Membran, recycelt werden (Reggiori und Klionsky 2013, Deffieu et al. 2009, Dunn et al. 2005). 


\subsubsection{Makroautophagie}

Makroautophagie ist charakterisiert durch die Bildung sog. Autophagosomen. Dies sind Vesikel mit einer Doppelmembran, die aus Phagophoren entstehen und in denen abzubauende Substrate aus dem Zytosol eingeschlossen werden (siehe Abb. 1.2).

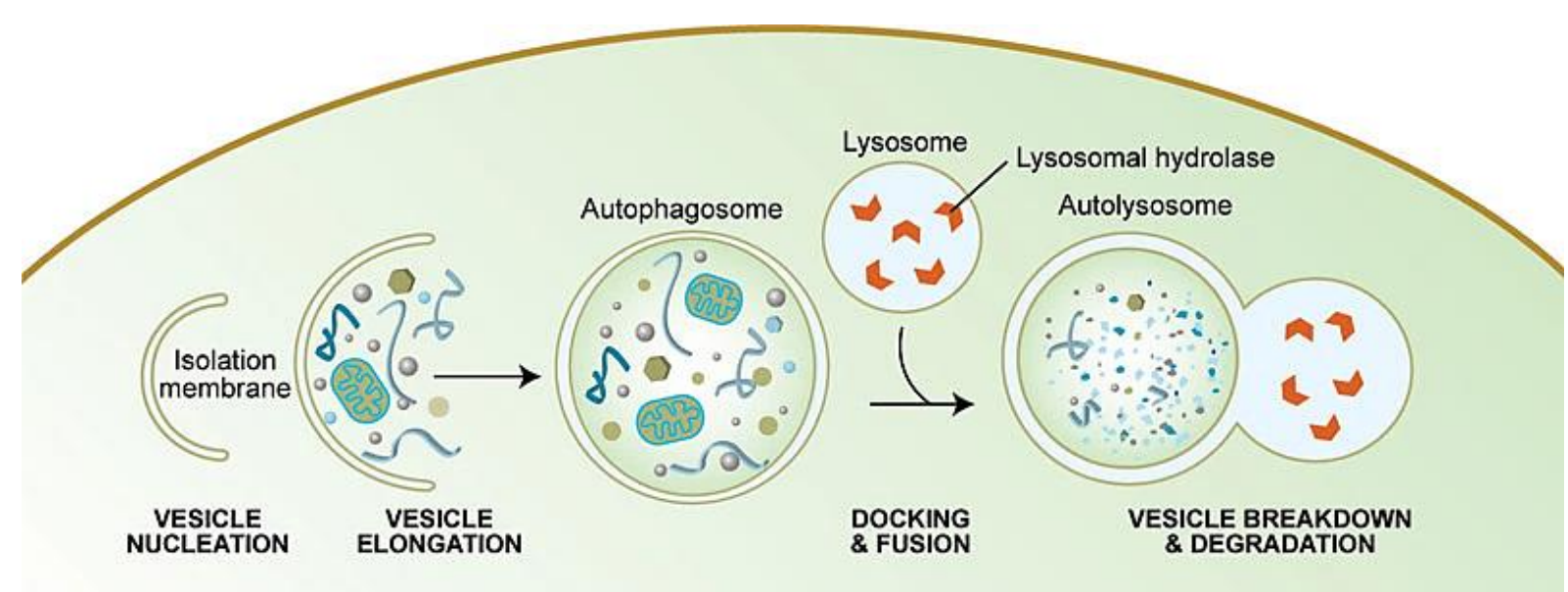

Abb. $\quad 1.2$ Schematische Darstellung der Makroautophagie-Schritte (Grafik aus Meléndez und Levine 2009, doi: 10.1895/wormbook.1.147.1). Erläuterungen: s. Text.

Die Membrananteile der Phagophoren stammen aus den Membranen von endoplasmatischem Reticulum, Mitochondrien, Golgi-Apparat und Plasmamembran (Taylor R et al. 2012, Mari et al. 2010, van der Vaart et al. 2010, Yen et al. 2010, Geng und Klionsky 2008) sowie aus sog. Omegasomen, welche als Omega-geformte Membranstrukturen einer Phosphatidylinositol-3-Phosphat-reichen Subdomäne des endoplasmatischen Reticulums entspringen (Axe et al. 2008). Es kommt zunächst zu einer Elongation der Phagophoren (Gordon und Seglen 1988), wodurch Zytoplasma mit den darin enthaltenen Proteinbestandteilen und Organellen unspezifisch vom Rest der Zelle abgetrennt wird. Bei voranschreitender Elongation kommt es zum Zusammenschluss beider Phagophor-Enden zu einem Vesikel, dem sog. Autophagosom, welches die abzubauenden Zellbestandteile beinhaltet. Für die Elongation des Phagophors ist eine spezielle Proteinfamilie notwendig, die sog. ATG-Gene (autophagy-related genes), die initial in Hefen beschrieben wurden und konservierte Homologe in Eukaryoten besitzen (Klionsky et al. 2003, Harding et al. 1995, Thumm et al. 1994, Tsukada und Ohsumi 1993). Mittlerweile sind mehr als 37 verschiedene dieser Gene bekannt (Feng et al. 2014, Ohsumi 2014). Hierbei können funktionell verschiedene Subpopulationen der ATG-Gene gebildet werden:

1. der Atg1/ULK-Komplex (bestehend aus Atg1, Atg11, Atg13, Atg17, Atg29 und Atg31), welcher für die Induktion der Autophagosomen zuständig ist, 
2. das Atg9-System, welches für die Anlieferung neuer Membranbestandteile des Phagophors notwendig ist,

3. der Ptdlns-3-Kinase-Komplex, welcher an der Rekrutierung weiterer Membranbestandteile beteiligt ist und

4. zwei Ubiquitin-ähnliche Konjugationssysteme, die eine Rolle in der Vesikel-Elongation spielen (Mizushima et al. 2011, Mizushima 2007, Suzuki et al. 2007, Xie und Klionsky 2007), von denen eines als Schlüsselprotein das Mikrotubulin-assoziierte 1A/1B-LeichtkettenProtein 3 (microtubule-associated protein 1A/1B-light chain $3=$ LC3) beinhaltet (Feng et al. 2014), welches aufgrund des experimentellen Interessen im Rahmen dieser Abhandlung gesondert erläutert werden soll (s. 1.3.1.1).

Neben dieser unspezifischen Degradation intrazellulärer Bestandteile gibt es spezifische Abbauprozesse in Autophagosomen, bspw. von Mitochondrien (= Mitophagie), Peroxysomen (= Pexophagie) oder invasiven Mikroben (Deffieu et al. 2009, Dunn et al. 2005). Hierbei verbinden spezielle Proteine, darunter p62 (s. 1.3.1.2), die spezifischen Abbauprodukte mit Proteinen des Autophagiesystem, so z. B. auch mit LC3, wodurch eine Internalisierung der abzubauenden Zellbestandteile in das Autophagosom erfolgen kann (Xilouri et al. 2016).

Anschließend erfolgt die Verschmelzung des Autophagosoms mit einem Lysosom zum sog. Autolysosom. Die im Lysosom enthaltenen Enzyme zur Proteindegradation beginnen nach Senkung des $\mathrm{pH}$-Wertes mit der Hydrolyse der im Autophagosom enthaltenden Zellbestandteile zu Aminosäuren, welche im weiteren Verlauf der Zelle zur erneuten Proteinsynthese wieder bereitgestellt werden (Xilouri et al. 2016, Feng et al. 2014).

\subsubsection{Mikrotubulin-assoziiertes Leichtketten-Protein 3}

Das Mikrotubulin-assoziierte Leichtketten-Protein 3 (LC3) ist ein zentrales Protein der Makroautophagie. Es handelt sich um das Säugetier-Homolog von Atg8. LC3 ist ein Ubiquitin-ähnliches Protein, an welches im Rahmen der intrazellulären Autophagie mit Phosphatidylethanolamin (PE) konjugiert und somit eine Möglichkeit der Membranbindung hergestellt werden kann (Sou et al. 2006). PEs sind chemisch betrachtet Phosphoglyceride und stellen einen wichtigen Baustein von Biomembranen dar (Gibellini und Smith 2010). Aufgrund dessen unterscheidet man ein natives LC3 (LC3-I) und ein PE-konjugiertes LC3 (LC3-II), welches membrangebunden ist. Nach der Membranbindung dient LC3 am Autophagosom als ein Rezeptor für abzubauende ubiquitinierte Zellbestandteile.

Die Synthese von LC3 erfolgt zunächst in Form der Vorstufe pro-LC3. Im Rahmen der posttranslationellen Prozessierung kommt es zur proteolytischen Abspaltung am C-Terminus durch die Protease Atg4 und damit zur Bildung von LC3-I mit einem Molekulargewicht von $\sim 18 \mathrm{kDa}$. Dieses kann bei Aktivierung der Autophagie durch PEKonjugation zu LC3-II (erscheint bei $\sim 16 \mathrm{kDa}$ im Western Blot) modifiziert werden, wonach 
es nicht mehr löslich, sondern membrangebunden, intrazellulär an Autophagosomen aber auch an Phagophoren vorliegt. Aufgrund dieser Membranbindung wird es aktuell als spezifischer Marker für Autophagosomen angesehen (Klionsky et al. 2012). Im weiteren Verlauf kommt es zur Ausbildung von Autolysosomen. Hierin erfolgt sowohl der Abbau der im Autophagosom zuvor eingeschlossen zytoplasmatischen Bestandteile als auch von LC3-II, sodass dessen Proteinmenge, bspw. gemessen im Western Blot oder in immunzytochemischen Färbungen, Aufschluss über die Aktivität der Makroautophagie geben kann. Dabei ist jedoch zu beachten, dass nicht die alleinige Bestimmung von LC3-II ausreichend für die Beurteilung ist (s. 1.3.1.3).

\subsubsection{SQSTM1 (p62)}

Sequestosom 1 (= SQSTM1 oder p62, namensgebend ist das Molekulargewicht von ca. $62 \mathrm{kDa}$ ) ist ein multifunktionelles Protein, das sowohl an LC3 als auch an zytosolische poly-ubiquitinierte Substrate bindet und diese hierdurch dem Autolysosom zuführt (Bjørkøy et al. 2005). Hierfür besitzt dieses Protein eine LC3-Interaktionsdomäne sowie eine Ubiquitin-Bindungsstelle. Die p62-gebundenen poly-ubiquitinierten Proteine werden nach der Bindung an LC3 in das Autophagosom internalisiert und durch Ausbildung des Autolysosoms den abbauenden Proteasen zugänglich gemacht. Hierbei kommt es zur Degradation von p62, wobei ein geringer Teil auch über das Ubiquitin/Proteasom-System degradiert werden kann (Komatsu et al. 2012). Daneben hat p62 aktivierende Wirkung auf den nukleären Faktor kappa-B (NF-kB), worüber eine Interaktion mit Apoptoseregulierenden Signalwegen besteht.

\subsubsection{Monitoring des autophagischen Flusses}

Die Aktivität der Autophagie entsprechend der Menge an Substraten, die intrazellulär autophagisch degradiert werden, wird als Autophagie-Fluss bezeichnet (Loos et al. 2014). Der Autophagie-Fluss kann, neben anderen, technisch aufwendigeren Methoden, an der Dynamik des spezifisch mit Autophagosomen gebundenen LC3-II abgeschätzt werden, allerdings erlaubt die alleinige Bestimmung der nativen LC3-II-Proteinmenge in einem biologischen System keine valide Aussage über den Funktionsstatus der Makroautophagie, da hierdurch nur die aktuelle Menge an Autophagosomen und nicht der Fluss durch das autophagische System ermittelt wird. So ist eine vermehrte LC3-II-Menge sowohl durch einen gesteigerten Autophagie-Fluss mit mehr Produktion von Autophagosomen als auch durch einen verminderten Autophagie-Fluss mit gestörtem Abbau von Autophagosomen erklärbar. Daher muss eine vergleichende Bestimmung des Autophagie-Flusses anhand der LC3-II-Konzentration stets eine Inhibition der Degradation von Autophagosomen beinhalten, um dadurch die wirklich durch das autophagische System "fließende“ Menge an Autophagosomen zu fixieren. Allein hierdurch kann der Autophagiefunktionsstatus ermittelt 
werden (Klionsky et al. 2016, Bartlett et al. 2011, Cui et al. 2012, Nezis et al. 2008, Wang QJ et al. 2006). Diese Inhibition erfolgt mittels verschiedener Hemmstoffe, welche bspw. zu einer Erhöhung des lysosomalen pH-Wertes führen und darüber die proteolytische Funktion des Lysosoms blocken. Um einen solchen Inhibitor handelt es sich bei Bafylomycin $A_{1}$. Bafilomycin $A_{1}$ führt zu einer Blockade intrazellulärer $\mathrm{H}^{+}$-ATPasen und dadurch zu einer Inhibition der Ansäuerung lysosomaler Strukturen, wodurch die $\mathrm{pH}$-abhängigen lysosomalen Proteasen und damit verbunden das Voranschreiten der Autophagie geblockt werden (Klionsky et al. 2012, Yoshimori et al. 1991). Darüber hinaus werden Fusionsproteine der Verschmelzung von Autophagosomen und Lysosomen durch die pH-Absenkung gestört, wodurch ein Fusionsstopp und somit eine Blockade der Autophagie zusätzlich erzielt wird (Jahreiss et al. 2008, Klionsky et al. 2008, Yamamoto et al. 1998). Eine Behandlung mit Bafilomycin $A_{1}$ bewirkt dadurch eine komplette Blockade der Autophagosomendegradation und ermöglicht somit die sichere Bestimmung der Menge der über einen bestimmten Behandlungszeitraum hinweg gebildeten LC3-II positiven Autophagosomen. Auch die Betrachtung weiterer, relativ spezifisch im Autolysosom degradierter Proteine, wie bspw. p62, trägt zum Gesamtverständnis des Funktionsstatus der Makroautophagie bei (Germain et al. 2011, Mizushima und Yoshimori 2007).

\subsubsection{Chaperon-vermittelte Autophagie}

Die Chaperon-vermittelte Autophagie (chaperone-mediated autophagy =CMA) ist eine weitere Möglichkeit der intrazellulären Proteindegradation. Das grundlegende Merkmal und gleichzeitig wichtigstes Unterscheidungskriterium zur Makro- oder Mikroautophagie liegt in der nicht bestehenden Notwendigkeit intermediäre Vesikelstrukturen zu bilden, um Proteine in Lysosomen einzuschleusen (Arias und Cuervo 2011, Kaushik et al. 2011). Vielmehr werden die lysosomalen Substrate mit Hilfe des zytosolisch oder an der lysosomalen Membran gebundenem Hsc70 (heat shock cognate protein of $70 \mathrm{kDa}$ ) direkt Rezeptor-vermittelt in Lysosomen transportiert (s. Abb. 1.3). 


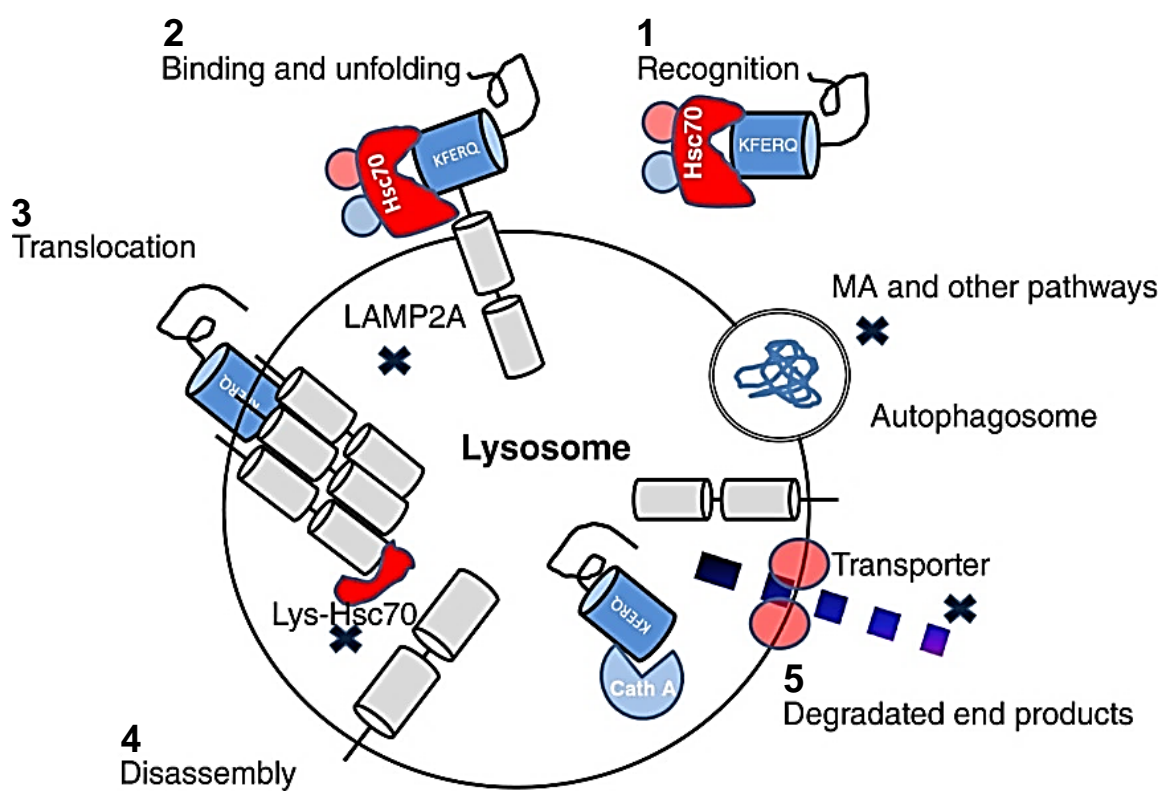

Abb. 1.3 Ablauf der CMA (Grafik aus Wang G und Mao 2014, doi: 10.1186/2047-9158-3-20). (1) Erkennung zu degradierender Proteine mit einer KFERQ-Pentapeptidsequenz durch zytoplasmatisches Hsc70. (2) Bindung des Hsc70-Substrat-Komplexes an den lysosomalen Rezeptor LAMP-2A. (3) Translokation des abzubauenden Proteins durch einen Membrankanal gebildet aus LAMP-2A-Multimeren in das Lysosom. (4) Auflösung des Translokationskomplexes. (5) Nach Wirkung der lysosomalen Enzyme erfolgt die Freisetzung der Abbauprodukte ins Zytoplasma, dort kann eine Wiederverwertung der Aminosäuren erfolgen.

Als erster Schritt der CMA erfolgt die Bindung des zu degradierenden Proteins an die zytosolisch vorliegende Form des Hsc70 über eine KFERQ-Pentapeptidsequenz (LysinPhenylalanin-Glutamat-Arginin-Glutamin) der potentiellen Substrate (Dice 1990, Chiang und Dice 1988). Interessanterweise wurde gezeigt, dass über $30 \%$ aller zytosolischen Proteine dieses Pentapeptid-Motiv zur Bindung des CMA-Mediators Hsc70 in ihrer Primärsequenz besitzen (Chiang und Dice 1988) und dieses durch posttranslationale Modifikation (z. B. Phosphorylisation) zu einem atypischen Erkennungsmotiv mit teilweise besserer Erkennbarkeit verändert werden kann (Quintavalle et al. 2014, Lv et al. 2011, Thompson et al. 2009). Unter physiologischen Bedingungen wird diese Bindungsstelle im Rahmen der Proteinfaltung unzugänglich für Hsc70. Erst unter zellulärem Stress kommt es zu einer partiellen Proteinumfaltung, welche das Bindungsmotiv für Hsc70 freilegt und somit die Substrate der CMA zugänglich macht, was als Folge die Aktivierung der CMA hat (Bandhyopadhyay und Cuervo 2007, Massey et al. 2006, Cuervo 2004).

Nach erfolgter Translokation kommt es im Lysosom zur enzymatischen Degradation der angelieferten Proteine und im Weiteren zur Freisetzung der Abbauprodukte, welche anschließend wiederverwertet werden können. 


\subsubsection{Lysosomal-assoziiertes Membranprotein-2A}

Das lysosomal-assoziierte Membranprotein-2A (LAMP-2A) stellt neben Hsc70 das zweite Schlüsselprotein der CMA dar. Als integrales Membranprotein Typ I besteht es aus einer luminal glykolisierten Region (lysosomal gelegen), einer Transmembranregion sowie einem kurzen zytosolisch gelegenen Anteil (Eskelinen et al. 2003). Als eine von drei SpliceVarianten des LAMP2-Gens (Tanaka et al. 2000) erfüllt es über den zytosolischen Teil die Funktion eines lysosomalen Rezeptors für die mittels Hsc70 angelieferten Degradationssubstrate. Daneben wirkt es gegenüber den intralysosomalen Proteasen membranprotektiv am Lysosom und ist beteiligt an der Entwicklung von Lysosomen, dem CholesterolStoffwechsel (Eskelin et al. 2004) und der lysosomalen Bewegung entlang von Mikrotubuli (Huynh et al. 2007). Im Ruhezustand liegt LAMP-2A als Monomer in der lysosomalen Membran vor und kann über seinen zytosolisch gelegenen C-Terminus Proteine binden. Die eigentliche Internalisierung ins Lysosom erfolgt jedoch erst nach Ausbildung eines Komplexes bestehend aus mehreren LAMP-2A-Monomeren. Nachdem die Substrate in das Lysosom abgegeben wurden, erfolgt der Zerfall des Komplexes, und LAMP-2A liegt wieder als Monomer vor (Bandyopadhyay et al. 2008, Eskelinen et al. 2004). Diese LAMP-2Avermittelte Translokation ist letztlich der geschwindigkeitslimitierende Prozess der CMA (Cuervo und Dice 2000).

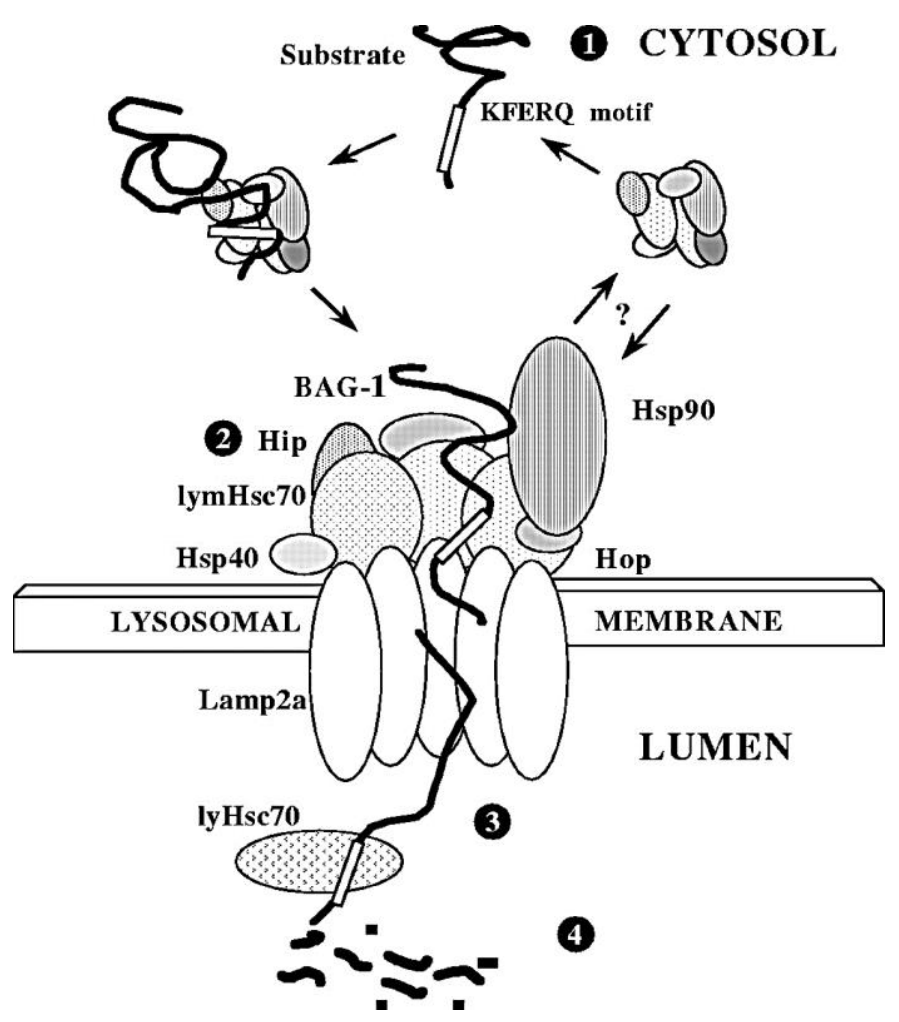

Abb. 1.4 Detaillierte Darstellung des Translokationsprozesses sowie der beteiligten Proteine (Grafik aus Agarraberes und Dice 2001). Vergleiche Abb. 1.3. Details s. Text. 


\section{$1.4 \quad$ Axonaler Transport}

Besondere Charakteristika von Neuronen sind ihre ausgeprägte Polarität und die weitreichende Länge ihrer Zellfortsätze in Relation zum Soma (insbesondere der Axone), die im Falle von Motorneuronen eine Länge von über 1 Meter erreichen können. Daher stellt der aktive Transport von molekularen Substraten und Zellorganellen entlang der langen Neuronenfortsätze einen essentiellen Prozess zum Erhalt der neuronalen Integrität dar. Zusammenfassend wird dieser komplexe Prozess bezogen auf Axone als axonaler Transport bezeichnet. Ähnliche Mechanismen sind jedoch auch in dendritischen Ausläufern zu beobachten. Dabei werden die Nervenendigungen mit Proteinen, Lipiden oder Zellorganellen, wie bspw. Mitochondrien, versorgt, im Gegenzug aber auch verbrauchte Stoffe oder fehlgefaltete Proteine vom terminalen Ende der Neuriten zum Soma rückgeführt, um durch deren Abbau im Soma den Erhalt der zellulären Homöostase zu gewährleisten (Maeder et al. 2014, Chia et al. 2013, Perlson et al. 2010). Daneben erfüllt der axonale Transport durch die Beförderung synaptischer Vesikel zur Präsynapse auch eine entscheidende Rolle im Rahmen der neuronalen Transmission und hat aufgrund dieser vielfältigen Funktionen Einfluss auf verschiedene neurodegenerative Erkrankungen, darunter auch auf das Parkinsonsyndrom (Saha et al. 2004).

Allgemein unterscheidet man einen langsamen von einem schnellen axonalen Transport, definiert nach der durchschnittlichen Geschwindigkeit der transportierten Stoffe. Von einem schnellen Transport wird bei einer durchschnittlichen Geschwindigkeit über $1 \mu \mathrm{m} / \mathrm{s}$ und von einem langsamen Transport unter 0,1 $\mu \mathrm{m} / \mathrm{s}$ gesprochen ( $\mathrm{Li} \mathrm{W}$ et al. 2004, Wang $L$ und Brown 2001, Allen et al. 1982, Brady et al. 1982). Geschwindigkeiten dazwischen werden nicht näher klassifiziert. Dabei muss jedoch beachtet werden, dass der axonale Transport sehr heterogen mit Wechseln von hohen Geschwindigkeiten zu Pausen unterschiedlicher Dauer verläuft (Roy et al. 2000, Wang L et al. 2000) und je nach Auswertungsmethode die durchschnittliche Geschwindigkeit nicht das Resultat einer konstanten Bewegung der transportierten Stoffe entlang der Mikrotubuli ist. Darüber hinaus unterscheiden sich beide Transportformen auch in der Art der transportierten Stoffe. So werden im Rahmen des schnellen Transportes vornehmlich Komponenten der Synapse, wie bspw. Vesikelvorstufen oder Membranbestandteile, dagegen über den langsamen Transportweg bspw. Neurofilamente oder Mikrotubuli-Bestandteile transportiert (Gunawardena und Goldstein 2004).

Neben der Unterteilung des Transportes anhand der Durchschnittsgeschwindigkeiten erfolgt die Klassifizierung weiterhin nach der Richtung des Transportes. Man unterscheidet einen anterograden (zur Axonterminalen/Plusende der Mikrotubuli) von einem retrograden (zum Zellkörper/Minusende der Mikrotubuli) Transport (Hirokawa et al. 2010). Dabei unterscheiden sich auch die jeweiligen für die Bewegung notwendigen Motorproteine. So ist 
Kinesin das Motorprotein des anterograden Transportes und Dynein das des retrograden (Kapitein und Hoogenraad 2011). Diese beiden Proteine sind vor allem für den langen Transport vom Soma zum Axonende und umgekehrt zuständig (Vale 2003). Daneben ist Myosin Va ein weiteres Transportprotein, welches jedoch vornehmlich im Rahmen kurzer Transportwege in Verbindung mit dem Aktinskelett (Ali et al. 2007) seine Funktion erfüllt (Hammer und Sellers 2011, Rao et al. 2011), jedoch auch in der Lage ist, den Mikrotubuliassoziierten Transport durch direkte Bindung an Mikrotubuli oder Kinesin zu unterstützen (Cao et al. 2004, Huang JD et al. 1999).

Ein weiterer wesentlicher Baustein des axonalen Transportes sind Mikrotubuli. Hierbei handelt es sich um die Hauptkomponente des Zytoskeletts, welche eine tubulärhelikale Struktur von ca. $25 \mathrm{~nm}$ Durchmesser aufweist, aus $\alpha$ - und $\beta$-Tubulin-Heterodimeren aufgebaut ist und einem kontinuierlichen Auf- (=Polimerisation) und Abbauprozess (= Depolimerisation) unterliegt (Perlson et al. 2010). Mikrotubuli sind in Axonen polarisiert aufgebaut. Dabei überwiegt am Minusende (zum Zellkörper gerichtet) die Depolymerisation und am schnell wachsenden Plusende (distal gerichtet) die Polymerisation. Entlang dieser Mikrotubuli erfolgt der Transport mittels spezieller Motorproteine unter Energieverbrauch (ATP).

Motorproteine sind in ihrer Grundstruktur ähnlich aufgebaut. Sie bestehen aus zwei wesentlichen Anteilen: 1.) einer Motordomäne, welche die eigentliche Funktion der energieabhängigen Bewegung entlang der Mikrotubuli erfüllt und 2.) einer Schwanzregion, welche die Verbindung mit den zu transportierenden Stoffen herstellt. Daneben gibt es zusätzliche Adaptorproteine an der Schwanzregion, welche vor allem im Rahmen der Bindung spezifischer Stoffe an das jeweilige Motorprotein assistieren (Schlager und Hoogenraad 2009, Hirokawa und Takemura 2005). Kinesine, die Motorproteine des anterograden Transportes, bilden eine Proteinfamilie mit 40 verschiedenen Proteinen (Stokin et al. 2005). Sie bestehen aus 2 Kinesin-Schwerketten (kinesin heavy chains $=\mathrm{KHC}$ ) und zwei Kinesin-Leichtketten (kinesin light chains $=\mathrm{KLC}$ ). Die KHCs bilden dabei die Motordomäne sowie den Verbindungsteil zu den KLCs, welche über Adapterproteine mit der Bindung der zu transportierenden Stoffe assoziiert sind (Hirokawa et al. 2010). Genetische Grundlage sind Gene, welche für verschiedene KHC-Untereinheiten codieren (KIF1A, KIF5A, KIF5B und KIF5C). KIF5B wird dabei in allen Zelltypen exprimiert, wogegen KIF1A, KIF5A und KIF5C nur in Neuronen exprimiert werden (Hirokawa und Noda 2008, Okada et al. 1995). Die Bewegung erfolgt durch wechselseitige Bindung der Motordomänen-Köpfe zu den Mikrotubuli. Dabei wird ATP durch den gebundenen Kopf hydrolysiert, was zu einer Bewegung des ungebundenen Kopfes in Richtung Plusende der Mikrotubuli führt und hier die Bindung mittels Tubulin-Acetylierung hergestellt wird (Reed et al. 2006). Dadurch entwickelt sich eine "gehende“ Fortbewegung (Millecamps und Julien 2013). Dynein, als 
wesentlichstes Protein des retrograden Transportes, ist dagegen als Komplex aus mehreren Untereinheiten aufgebaut, bestehend aus zwei Schwerketten, zwei Intermediärketten, vier Intermediär-Leichtketten und mehreren Leichtketten (Eschbach und Dupuis 2011). Dabei haben die Schwerketten (cytoplasmic dynein 1 heavy chain 1 = DYNC1H1) Motordomänen mit ATPase-Aktivität und binden hierüber auch an Intermediär- und Leichtketten (Eschbach und Dupuis 2011), über welche mit Hilfe von Dynactin die Bindung der Transportstoffe erfolgt. Die Bewegung von Dynein entlang der Mikrotubuli ähnelt der von Kinesin mit einem energieabhängigen Bindungswechsel der Motordomänen in Richtung des Minusendes der Mikrotubuli.

Die folgende Abbildung fasst die wichtigsten am axonalen Transport beteiligten Proteine zusammen (s. Abb. 1.5).
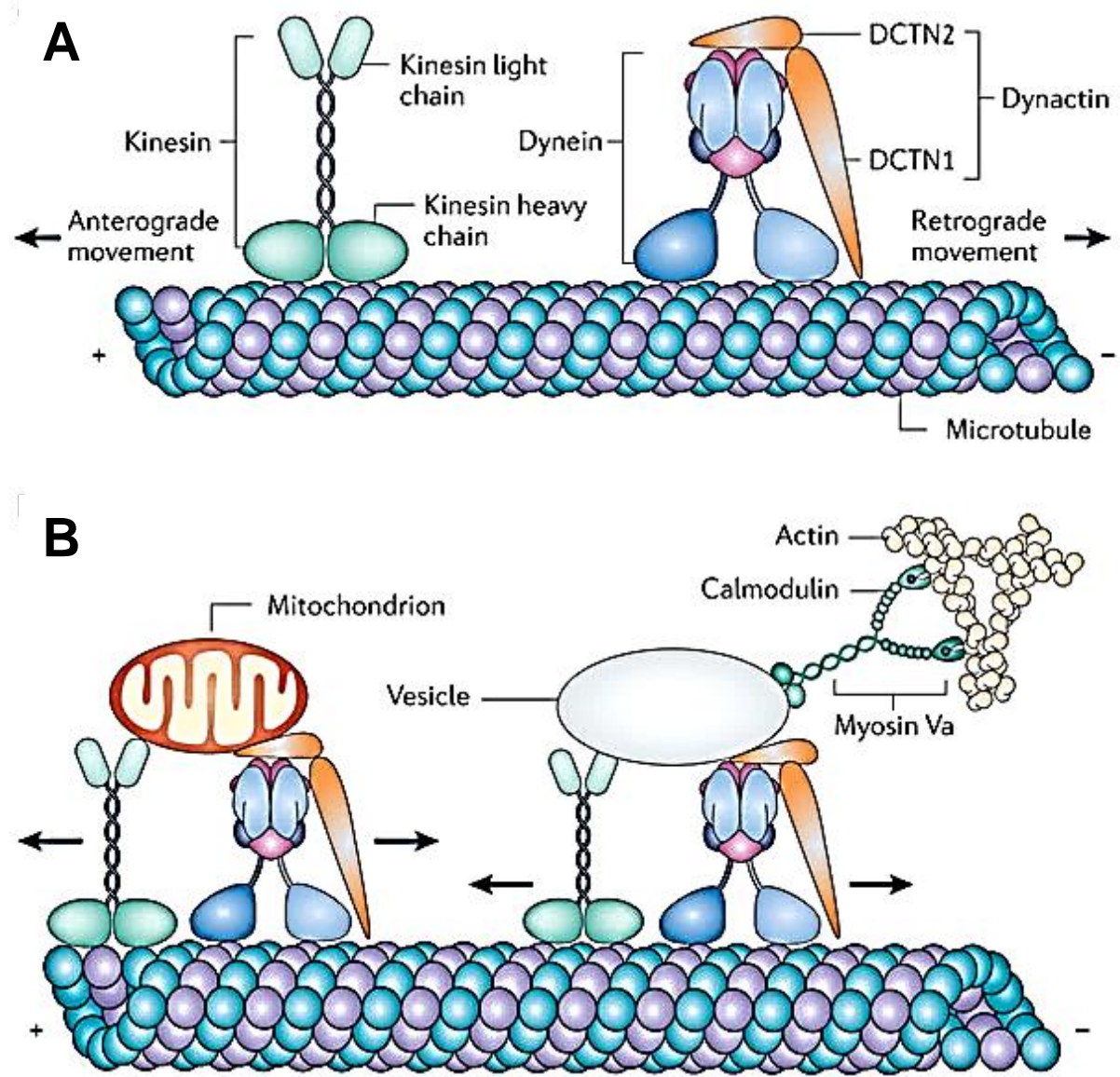

Abb. $\quad 1.5$ Bestandteile des Mikrotubuli-assoziierten axonalen Transportes (Grafik aus Millecamps und Julien 2013, doi: 10.1038/nrn3380). (A) Zusammenfassende Darstellung der einzelnen Bestandteile von Kinesin (2 Schwerketten und 2 Leichtketten) und des Dynein-Komplexes [Schwer-, Intermediär-, Intermediär-Leicht- und Leichtketten sowie Dynactin-Untereinheiten (DCTN1 und 2)]. (B) Darstellung der Bindung von Stoffen (bspw. Mitochondrien oder Vesikel) an Kinesin (über Leichtketten) oder Dynein mit Hilfe von Dynactin. Zusätzlich erfolgt die Darstellung des Myosin Va-vermittelten Transportes an Aktinfilamenten zur Verteilung der mittels Mikrotubuli und deren Motorproteine angelieferten Stoffe. 


\section{$1.5 \quad$ Fragestellung und Zielsetzung}

Das idiopathische Parkinsonsyndrom ist eine chronisch progrediente und bislang nicht kausal therapierbare Erkrankung mit weitreichenden Folgen für das Leben der betroffenen Patienten. Auch ökonomisch stellt die Erkrankung aufgrund der hohen Prävalenz eine Belastung der Gesamtbevölkerung dar. Trotz intensivster Bemühungen in den letzten Jahrzehnten basiert die aktuelle Therapie lediglich auf der Symptomkontrolle ohne die Möglichkeit, krankheitsmodifizierend eingreifen zu können. Fundamental für die zukünftige Entwicklung von kurativen oder neuroprotektiven Therapien ist daher ein detailliertes Verständnis der Pathogenese des iPS, um gezielt therapeutische Strategien entwickeln zu können. Hierbei soll die vorliegende Arbeit einen Beitrag leisten, indem die Fragestellung bearbeitet wird, welche Effekte das pathogenetisch wichtige Protein $\alpha$-Syn auf zwei wesentliche Pathomechanismen, die Autophagie und den axonalen Transport, hat.

In den letzten beiden Jahrzehnten wurden bereits entscheidende Erkenntnisse über die pathologischen Veränderungen auf histologischer und molekularer Ebene gewonnen. Zentral war dabei die Entdeckung des Proteins a-Syn und seiner direkt krankheitsbedingenden Mutationen. Es konnte gezeigt werden, dass $\alpha$-Syn der wesentliche Bestandteil der für das iPS pathognomonischen neuronalen Ablagerungen, der sog. LewyKörperchen, ist. Darauf basierend konnten Versuchsmodelle entwickelt werden, die ein Verständnis der zugrundeliegenden Pathogenese des iPS ermöglichten. Ein wesentliches Modell stellt hierbei die Überexpression von a-Syn sowohl in-vitro als auch in-vivo dar.

Ferner sind in den letzten Jahren zunehmend die intrazelluläre Proteindegradation und deren mögliche Dysfunktion in den Fokus der Forschung geraten. Ein zentraler Mechanismus der Proteindegradation ist die Autophagie. Bezüglich der Frage nach Effekten der $\alpha$-Syn-Überexpression auf die Autophagie wurden bislang widersprüchliche Ergebnisse veröffentlicht, die auch auf unvollständigen Versuchsreihen und Betrachtung der Effekte in unterschiedlichen Zellsystemen beruhen. So wurde sowohl eine verstärkte (Choubey et al. 2011, Ebrahimi-Fakhari et al. 2011, Spencer B et al. 2009, Xilouri et al. 2009, Cuervo et al. 2004) als auch eine reduzierte Aktivität der Autophagie unter Einfluss von $\alpha$-Syn (Winslow et al. 2010) beschrieben. Die hier vorliegende Arbeit untersucht erstmals umfassend die Effekte einer Überexpression von a-Syn und seiner pathogenen Mutationen A30P und A53T auf die Autophagie in primären dopaminergen Mittelhirnneuronen der Ratte. Diese Zellen wurden gewählt, da das Mittelhirn bei Menschen mit iPS am eindrücklichsten betroffen ist.

Auf zellulärer Ebene ist die Pathologie des iPS zuallererst in den Axonen und deren Endigungen, den sog. Präsynapsen, zu erkennen. Die folgende axonale Degeneration ist somit ein früher Prozess in der Erkrankung, der erst später in den neuronalen Zelltod mündet. Die Mechanismen, die zur axonalen Degeneration beim iPS führen, sind bislang nicht bekannt. Möglich ist eine Störung des axonalen Transportes, da dieser eine zentrale 
Rolle für die Integrität der Axone spielt. Inzwischen gibt es erste Publikationen, die belegen, dass der axonale Transport früh bei der Entwicklung eines iPS gestört ist. Allerdings ist unklar, wie es zu dieser Störung kommt und welche Rolle sie in der Pathogenese des iPS spielt. Bezüglich einer Interaktion von $\alpha$-Syn und dem axonalen Transport gibt es bereits Untersuchungen, die jedoch vor allem den Transport von $\alpha$-Syn selbst entlang der axonalen Ausläufer analysierten und zu teils widersprüchlichen Ergebnissen kamen. Sicherlich kommt a-Syn und somit auch seinem Transport eine entscheidende Rolle in der synaptischen Funktion zu, dennoch ist für die Integrität des Neurons der axonale Transport insbesondere synaptischer Vesikel und der bspw. darin lokalisierten Neurotransmitter ebenso von entscheidender Bedeutung, sodass dieser Prozess an primären dopaminergen Mittelhirnneuronen im Rahmen der vorliegenden Arbeit umfassend untersucht wurde.

Durch die gewonnenen Erkenntnisse dieser Arbeit sollen sich neue Verknüpfungen und Forschungsansätze ergeben, die zu einem noch detaillierteren Verständnis der Pathogenese des iPS führen mit dem letztendlichen Ziel einer zielgerichteten und vor allem kausal-heilenden Therapieoption. 


\section{Material und Methoden}

\section{$2.1 \quad$ Material}

\subsubsection{Chemikalien, Reagenzien und Kits}

\section{Substanz}

\section{Agarose}

Ammoniumperoxidisulfat

Ampicillin

Ampuwa- $\mathrm{H}_{2} \mathrm{O}$

Bafilomycin $\mathrm{A}_{1}$

BCA (Bicinchonininsäure-)-Assay

Borsäure

Bromphenolblau

BSA (Bovines Serumalbumin-)-Standardprotein

BSA-Mediumzusatz

CPI (complete proteinase inhibitor)

Dako Antibody Diluent

DAPI (4',6-Diamidin-2'Phenylindoldihydrochlorid)

DMEM IF-12 (Dulbecco's modified eagle medium)

DNase

DTT (Dithiothreitol)

Dual $\AA$ Color Marker

EGTA (Ethylenglycol-bis(aminoethylether)-N,N'tetraessigsäure)

Enzym BgllI

Enzym Notl

Enzym Smal

Ethanol absolut

Ethidiumbromid

FCS (Fötales Rinderserum)

Glucoselösung $45 \%$

Glycin

Glycerol/Glycerin

HBSS (Hank's balanced salt solution)

HEPES (2-(4-(2-Hydroxyethyl)-1-Piperazinyl)-

Ethansulfonsäure)

Igepal

Insulin

Isopropanol

$\mathrm{KCl}$ (Kaliumchlorid)

Laminin

LB-Agar

LB-Pulver

L-Glutamin $(200 \mathrm{mM})$

Luminol

Methanol

$\mathrm{MgCl}_{2}$ (Magnesiumchlorid)

Milchpulver

Mowiol@ 4-88 Reagent, Calbiochem $\AA$

N1 Medium Supplement 100x

Natriumacetat

Natriumhydrogenkarbonat

Natriumchlorid

\section{Hersteller}

AppliChem, Darmstadt, Deutschland

Roth, Karlsruhe, Deutschland

Roth, Karlsruhe, Deutschland

Fresenius Kabi, Bad Homburg, Deutschland

Sigma-Aldrich, Taufkirchen, Deutschland

Thermo Scientific, Rockford, IL USA

AppliChem, Darmstadt, Deutschland

SERVA, Heidelberg, Deutschland

Sigma-Aldrich, Taufkirchen, Deutschland

Sigma-Aldrich, Taufkirchen, Deutschland

Roche, Mannheim, Deutschland

Dako, Hamburg, Deutschland

Sigma-Aldrich, Taufkirchen, Deutschland

Gibco, Karlsruhe, Deutschland

Roche, Mannheim, Deutschland

Sigma-Aldrich, Taufkirchen, Deutschland

Bio-Rad, München, Deutschland

Sigma-Aldrich, Taufkirchen, Deutschland

New England Biolabs, Frankfurt am Main,

Deutschland

New England Biolabs, Frankfurt am Main,

Deutschland

New England Biolabs, Frankfurt am Main,

Deutschland

AppliChem, Darmstadt, Deutschland

Sigma-Aldrich, Taufkirchen, Deutschland

PAA, Pasching, Österreich

Sigma-Aldrich, Taufkirchen, Deutschland

AppliChem, Darmstadt, Deutschland

Roth, Karlsruhe, Deutschland

Gibco, Karlsruhe, Deutschland

AppliChem, Darmstadt, Deutschland

Sigma-Aldrich, Taufkirchen, Deutschland

Sigma-Aldrich, Taufkirchen, Deutschland

AppliChem, Darmstadt, Deutschland

AppliChem, Darmstadt, Deutschland

Sigma-Aldrich, Taufkirchen, Deutschland

AppliChem, Darmstadt, Deutschland

AppliChem, Darmstadt, Deutschland

PAA, Pasching, Österreich

Sigma-Aldrich, Taufkirchen, Deutschland

AppliChem, Darmstadt, Deutschland

AppliChem, Darmstadt, Deutschland

Roth, Karlsruhe, Deutschland

Roth, Karlsruhe, Deutschland

Sigma-Aldrich, Taufkirchen, Deutschland

Roth, Karlsruhe, Deutschland

Gibco, Karlsruhe, Deutschland

AppliChem, Darmstadt, Deutschland 
PBS (Phosphat-gepufferte physiologische Kochsalzlösung)-Pulver

p-Coumarsäure

PFA (Paraformaldehyd)

Poly-L-Ornithin-Hydrobromid

Propylgallat

PSN Antibiotic Mixture 100x

QIAprep Spin Miniprep Kit

Qiagen Plasmid Mega Kit

Rotiphorese (30\%)

SDS (Natriumdodecylsulfat)

Sucrose $(\mathrm{D}(+)$ Saccharose)

TEMED (Tetramethylethylendiamin)

Tris

Trypsin

Tween

Wasserstoffperoxid $30 \%$

Xylenxyanol
AppliChem, Darmstadt, Deutschland

Sigma-Aldrich, Taufkirchen, Deutschland

AppliChem, Darmstadt, Deutschland

Sigma-Aldrich, Taufkirchen, Deutschland

Sigma-Aldrich, Taufkirchen, Deutschland

Gibco, Karlsruhe, Deutschland

Qiagen, Hilden, Deutschland

Qiagen, Hilden, Deutschland

Roth, Karlsruhe, Deutschland

AppliChem, Darmstadt, Deutschland

Roth, Karlsruhe, Deutschland

Sigma-Aldrich, Taufkirchen, Deutschland

AppliChem, Darmstadt, Deutschland

Sigma-Aldrich, Taufkirchen, Deutschland

AppliChem, Darmstadt, Deutschland

Roth, Karlsruhe, Deutschland

Merck, Darmstadt, Deutschland

\subsubsection{Geräte und Software}

\section{Geräte und Software}

Autoklav; Systec 5075 ELV

AxioCam HRM (Kamera)

AxioVision 4.8 Software-Paket

Eismaschine, Scotsman $\AA$

Elektrophoresekammer für Western Blots,

Mini-PROTEAN® 3 Cell-System

Elektrophoresekammer für DNA-Auftrennung,

(Mini-Sub-Cell GT)

Entwicklungsmaschine für Röntgenfilme,

Curix 60

Feinwaage; BL210S

Fluoreszenzlichtquelle HXP 120 (KüblerCodix)

Fluoreszenz Mikroskop; Axioplan

Fluoreszenz Mikroskop; Axiovert 40C

Fluor-S ${ }^{\mathrm{TM}}$-Multilmager (UV-Gerät)

Gefrierschrank $-20^{\circ} \mathrm{C}$

Gefrierschrank $-80^{\circ} \mathrm{C}$

Heizblock; ThermoStat plus

Inkubator für Bakterienkulturen $37^{\circ} \mathrm{C}$

Inkubator für Zellkulturen $37^{\circ} \mathrm{C}, 5 \% \mathrm{CO}_{2}$

Kühlschränke

Kyplot 2.0

Magellan 3

Messzylinder

Microsoft Office Excel 2007

Microsoft Office PowerPoint 2007

Microsoft Office Word 2007

Mikrowelle silver edition

Motor-Pipettierhelfer; accu-jet@ pro

Neubauer-Zählkammer

Nucleofector ${ }^{\mathrm{TM}}$ II Device

pH-Meter

Photometer (Biophotometer)

Photometer
Hersteller

Systec, Wettenberg, Deutschland

Zeiss, Jena, Deutschland

Zeiss, Jena, Deutschland

Frimont, Mailand, Italien

Bio-Rad, München, Deutschland

Bio-Rad, München, Deutschland

AGFA, Düsseldorf, Deutschland

Sartorius, Göttingen, Deutschland

Zeiss, Jena, Deutschland

Zeiss, Jena, Deutschland

Zeiss, Jena, Deutschland

Bio-Rad, München, Deutschland

Liebherr, Biberach, Deutschland

Heraeus, Hanau, Deutschland

Eppendorf, Hamburg, Deutschland

GFL (Gesellschaft für Labortechnik), Burgwedel,

Deutschland

Heraeus, Hanau, Deutschland

Liebherr, Biberach, Deutschland

Kyenslab Incorporated, Tokyo, Japan

Tecan, Crailsheim, Deutschland

Duran, Wertheim, Deutschland

Microsoft, Unterschleißheim, Deutschland

Microsoft, Unterschleißheim, Deutschland

Microsoft, Unterschleißheim, Deutschland

Bosch, Stuttgart, Deutschland

Brand, Wertheim, Deutschland

Roth, Karlsruhe, Deutschland

Lonza, Basel, Schweiz

Sartorius, Göttingen, Deutschland

Eppendorf, Hamburg, Deutschland

Bio-Rad, München, Deutschland 
Photometer; ELISA-Photometer Tecan RainBow

Petrischalen (Durchmesser $10 \mathrm{~cm}$ und $20 \mathrm{~cm}$ )

Pipetten

Präparationsbesteck;

Cohan-Vannas Spring Scissors $(5,7 \mathrm{~cm})$

Dumont \#5-Mirror Finish Forceps $(11 \mathrm{~cm})$

Quantity One 4.2.1

Rollmixer

Sauger

Schüttler; Gyro rocker Stuart SSM3 3D mini

Schüttler (Amplifikation Mini)

Schüttler (Amplifikation Mega-Präp)

Sonificator

Stereoskop; Stemi 2000 (Binokularmikroskop)

Sterilbank mit Abschirmung; LaminAir HB 2448

Sterilbank ohne Abschirmung; Hera guard

Spannungsquelle; EPS 301

Transferkammer;

Mini-PROTEAN® Elektrophorese-System

Vortex-Mixer 7-2020

Waage; LE6202S Präzisionswaage

Wasserbad

Wasserreiniger; PureLab plus

Wippschüttler

Zellschaber

Zentrifuge; Biofuge fresco

Zentrifugen; Centrifuge 5415R, 5810R, 5415D
Tecan, Crailsheim, Deutschland

Roth, Karlsruhe, Deutschland

Gilson, Villiers le Bel, Frankreich

FST (Fine Science Tools), Heidelberg,

Deutschland

Bio-Rad, München, Deutschland

Dynalab Corp., Rochester, NY USA

Schütt Labortechnik, Göttingen, Deutschland

Dynalab Corp., Rochester, NY USA

Heidolph Instruments, Schwabach, Deutschland

New Brunswick Scientific, Enfield, USA

Bandelin, Berlin, Deutschland

Zeiss, Jena, Deutschland

Heraeus, Hanau, Deutschland

Heraeus, Hanau, Deutschland

Amersham Pharmacia Biotech, Freiburg,

Deutschland

Bio-Rad, München, Deutschland

neoLab, Heidelberg, Deutschland

Sartorius, Göttingen, Deutschland

GFL (Gesellschaft für Labortechnik), Burgwedel,

Deutschland

Elga Labwaters, Ransbach-Baumbach,

Deutschland

neoLab, Heidelberg, Deutschland

Sarstedt, Nümbrecht, Deutschland

Heraeus, Hanau, Deutschland

Eppendorf, Hamburg, Deutschland

\subsubsection{Puffer und Lösungen}

\section{Puffer / Lösungen}

\begin{tabular}{l}
\hline Agarosegel \\
\hline BCA-Farblösung \\
\hline Boratpuffer \\
\hline BSA-Standardprotein \\
\hline CPI 25x \\
\hline DAPI-Lösung \\
\hline DNA-Ladepuffer 6-fach \\
\hline DNase-Lösung \\
\hline ECL (enhanced chemiluminiscence)-Lösung
\end{tabular}

Elektrophoresepuffer (10x)

\section{Herstellung}

$1 \%$ Agarose (1,5 g), 1,3\% Ethidiumbromid (2 $\mu \mathrm{l})$ in $150 \mathrm{ml}$ TBE-Puffer

$2 \%$ Reagenz $B$ in Reagenz $A$

$150 \mathrm{mM}$ Borsäure in $\mathrm{H}_{2} \mathrm{O}_{\text {dest. }}$; $\mathrm{pH} 8,4$

steril filtrieren

$10 \mu \mathrm{g} / \mu \mathrm{l} \mathrm{BSA}$ in Lysepuffer

1 Tablette CPI in $2000 \mathrm{ml}$ Ampuwa- $\mathrm{H}_{2} \mathrm{O}$

$20 \mu \mathrm{g} \mathrm{DAPI}+180 \mu \mathrm{l} \mathrm{CH} \mathrm{CH}_{3}+39,8 \mathrm{ml}$ PBS

$0,15 \%$ Bromphenolblau, $0,15 \%$ Xylencyanol, $40 \%$ Saccharose in $\mathrm{H}_{2} \mathrm{O}_{\text {dest }}$

DNase in CMF lösen (Endkonzentration $5 \mathrm{mg} / \mathrm{ml}$ ) Lösung 1:

$2,5 \mathrm{mM}(100 \mu \mathrm{l})$ Luminol

$0,4 \mathrm{mM}(44 \mu \mathrm{l}) \mathrm{p}$-Coumarsäure

$0,1 \mathrm{M}(1 \mathrm{ml})$ Tris-Chlorid in $\mathrm{H}_{2} \mathrm{O}_{\text {dest }}(8,85 \mathrm{ml})$; $\mathrm{pH} 8,5$

Lösung 2: $\quad 6 \mu \mathrm{l} 30 \%$ iges $\mathrm{H}_{2} \mathrm{O}_{2}$

$0,1 \mathrm{M}$ Tris-Chlorid

in $9 \mathrm{ml} \mathrm{H} \mathrm{O}_{2}$ dest.; $\mathrm{pH} \mathrm{8,0}$

Direkt vor dem Gebrauch werden beide

Lösungen im Verhältnis 1:1 gemischt.

250 mM Tris, 1,9 M Glycin, 1 \% SDS in $\mathrm{H}_{2} \mathrm{O}_{\text {dest. }}$. zur Gelelektrophorese 1:10 mit $\mathrm{H}_{2} \mathrm{O}_{\text {dest. }}$ mischen ( $=1 \mathrm{x}$ Elektrophoresepuffer) 
Glucoselösung $5 \%$

\begin{tabular}{l}
\hline $\mathrm{H}_{2} \mathrm{O}_{\text {dest. }}$ \\
\hline HKME-Puffer \\
\hline Lysepuffer für Zelllysate \\
\hline Milchlösung $5 \%$ \\
\hline Mowiol@ (coverslip mounting solution)
\end{tabular}

Paraformaldehyd-Lösung (4 \%)

$5 \mathrm{ml} 45$ \%ige Glucoselösung, $45 \mathrm{ml} \mathrm{H}_{2} \mathrm{O}$-Ampuwa Wasserreiniger PureLab Plus aufgereinigtes $\mathrm{H}_{2} \mathrm{O}$ $10 \mathrm{mM}$ HEPES (pH 7,2), $142 \mathrm{nM} \mathrm{KCl,} 5 \mathrm{mM}$ $\mathrm{MgCl}_{2}, 1 \mathrm{mM}$ EDTA in $\mathrm{H}_{2} \mathrm{O}_{\text {dest. }}$. $940 \mu \mathrm{l}$ HKME-Puffer, $40 \mu \mathrm{l}$ CPI (25x), $10 \mu \mathrm{l}$ $100 \mathrm{mM}$ DTT, $10 \mu \mathrm{l}$ lgepal

$5 \mathrm{~g}$ Milchpulver in $100 \mathrm{ml}$ TBS-T

$5 \mathrm{~g}$ Mowiol $\AA \mathrm{A}+20 \mathrm{ml}$ PBS $1 \mathrm{~h}$ bei $40^{\circ} \mathrm{C}$ rühren, $+10 \mathrm{ml}$ Glycerin $1 \mathrm{~h}$ bei RT rühren,

Zentrifugation bei $500 \mathrm{rpm} 15 \mathrm{~min}, \mathrm{pH} 8,0$

$+0,3 \mathrm{ml} 2 \% \mathrm{NaN}_{3}+$ Propylgallat (1 Spatel-spitze auf $10 \mathrm{ml}$ ), rühren bei RT über Nacht, Zentrifugtion bei $4000 \mathrm{rpm} 20 \mathrm{~min}$

\begin{tabular}{|c|c|}
\hline Paraformaldehyd-Lösung (4 \%) & $\begin{array}{l}40 \mathrm{~g} \text { Paraformaldehyd in } 1000 \mathrm{ml} \text { PBS } \\
1 \mathrm{~h} \text { bei } 60^{\circ} \mathrm{C} \text { rühren; filtrieren, } \mathrm{pH} 7,4 \text { (mit } 1 \mathrm{M} \\
\mathrm{NaOH} \text { einstellen) }\end{array}$ \\
\hline PBS & $\begin{array}{llll}9,55 \mathrm{~g} & \text { PBS-Pulver in } 1000 \mathrm{ml} & \mathrm{H}_{2} \mathrm{O}_{\text {dest. }} \\
\text { steril filtrieren }\end{array}$ \\
\hline $\begin{array}{l}\text { Sammelgel für Western-Blots }(1,14 \%) \\
\text { Angaben für } 2 \text { Gele }\end{array}$ & $\begin{array}{l}3,05 \mathrm{ml} \mathrm{H}_{2} \mathrm{O}_{\text {dest., }} 1,25 \mathrm{ml} \text { Tris/SDS-Puffer } 4 \mathrm{x} \\
\text { (pH 6,8), 0,65 ml } 30 \% \text { Rotiphorese-Gel, 0,025 ml } \\
10 \% \text { Ammoniumperoxidsulfat, 0,005 ml TEMED }\end{array}$ \\
\hline TBE 10x (Tris-Borsäure-EDTA-Puffer) & $\begin{array}{l}\text { 0,45 M Tris, } 0,45 \mathrm{M} \text { Borsäure, } 0,1 \% 1 \mathrm{M} \text { EDTA } \\
\text { (pH 8.0) in } \mathrm{H}_{2} \mathrm{O}_{\text {dest. }} \\
\text { Direkt vor Gebrauch } 1: 10 \text { mit } \mathrm{H}_{2} \mathrm{O}_{\text {dest. }} \\
\text { verdünnen, um eine } 1 \mathrm{x} \text { konzentrierte } \\
\text { Lösung zu erhalten. }\end{array}$ \\
\hline TBS (Tris-gepufferte Salzlösung) & $150 \mathrm{mM} \mathrm{NaCl}, 50 \mathrm{mM}$ Tris in $\mathrm{H}_{2} \mathrm{O}_{\text {dest. }}$ \\
\hline TBS-T (TBS mit Tween) & $0,1 \%$ Tween in TBS $(\mathrm{pH} 7,6)$ \\
\hline Transferpuffer & $\begin{array}{l}25 \mathrm{mM} \text { Tris-Chlorid, } 192 \mathrm{mM} \text { Glycin, } 20 \% \\
\text { Methanol in } \mathrm{H}_{2} \mathrm{O}_{\text {dest. }}(\mathrm{pH} 8,3)\end{array}$ \\
\hline $\begin{array}{l}\text { Trenngel für Western-Blots (15\%) } \\
\text { Angaben für } 2 \text { Gele }\end{array}$ & $\begin{array}{l}4,25 \mathrm{ml} \quad \mathrm{H}_{2} \mathrm{O}_{\text {dest. }}, 4,25 \mathrm{ml} \text { Tris/SDS-Puffer } 4 \mathrm{x} \\
(\mathrm{pH} 8,8), \quad 8,5 \mathrm{ml} 30 \% \text { Rotiphorese-Gel, } 85 \mu \mathrm{l} \\
\text { 10\%ige Ammoniumperoxidsulfat-Lösung, } 8,5 \mu \mathrm{l} \\
\text { TEMED }\end{array}$ \\
\hline Tris/SDS-Puffer 4x (pH 6,8) & $\begin{array}{c}0,5 \mathrm{M} \text { Tris, } 0,4 \% \text { SDS in } \mathrm{H}_{2} \mathrm{O}_{\text {dest. }} \\
\text { pH auf } 6,8 \text { einstellen }\end{array}$ \\
\hline Tris/SDS-Puffer 4x (pH 8,8) & $\begin{array}{c}0,5 \mathrm{M} \text { Tris, } 0,4 \% \text { SDS in } \mathrm{H}_{2} \mathrm{O}_{\text {dest. }} \\
\text { pH auf } 8,8 \text { einstellen }\end{array}$ \\
\hline Trypsin-Lösung & $0,25 \%$ Trypsin in CMF $(\mathrm{pH} 7,4)$ \\
\hline
\end{tabular}

\subsubsection{Kulturmedien}

\section{Bezeichnung}

CMF-Ampuwa ( $\mathrm{Ca}^{2+}$, $\mathrm{Mg}^{2+}$-frei; CMF)

CMF-Medium

LB-Medium

LB-Agar

MDN-Medium

MDN-Medium mit FCS

\section{Herstellung}

$10 \%$ HBSS (10x) in Ampuwa- $\mathrm{H}_{2} \mathrm{O}(\mathrm{pH}$ auf 7,4 mittels Natriumhydrogenkarbonat einstellen) 50 ml HBSS (10x) in sterilem $\mathrm{H}_{2} \mathrm{O}_{\text {dest. }}(\mathrm{pH}$ auf 7,4 mittels Natriumhydrogenkarbonat einstellen $25 \mathrm{~g}$ LB-Pulver in $1000 \mathrm{ml} \mathrm{H} \mathrm{H}_{2} \mathrm{O}_{\text {dest., }}(\mathrm{pH} 7,0)$; autoklavieren und mit Ampicillin $100 \mu \mathrm{g} / \mathrm{ml}$ versetzen

$11,2 \mathrm{~g}$ LB-Agar in $350 \mathrm{ml} \mathrm{H} \mathrm{H}_{2}$ dest.; autoklavieren und auf ca. $60^{\circ} \mathrm{C}$ abgekühlen, mit Ampicillin $100 \mu \mathrm{g} / \mathrm{ml}$ versetzen

94,09 ml DMEM IF-12, $2 \mathrm{ml}$ Glucose $5 \%, 0,71 \mathrm{ml}$ BSA für Zellkultur, $1 \mathrm{ml}$ PSN, $1 \mathrm{ml} \mathrm{N} 1,1 \mathrm{ml}$ Glutamin, $200 \mu \mathrm{l}$ Insulin 


\subsubsection{Gebrauchsmaterialien}

Material

Blotting-Filterpapiere

Blotting-Schwämme

Glasplatten

Glasspaltplatten

Kämme
Hersteller

Roth, Karlsruhe, Deutschland

Bio-Rad, München, Deutschland

Bio-Rad, München, Deutschland

Bio-Rad, München, Deutschland

Bio-Rad, München, Deutschland

\subsubsection{Verbrauchsmaterialien}

\section{Material}

Auslaufpipetten $(5 \mathrm{ml}, 10 \mathrm{ml}, 25 \mathrm{ml})$

Chemiluminiszenzfilme,

(Amersham Hyperfilm ${ }^{\text {TM }}$ ECL)

Deckgläser rund (Coverslips)

Filter, steril (Filtropur S 0.2)

Glaskammer-Zellkulturplatten (chamber slides)

Mikroplatte (96-well-plate)

Nitrozellulosemembran

Nukleofektions-Kit (Nukleofektionslösung,

sterile Küvetten und Transferpipetten)

Objektträger

Parafilm

Pipettenspitzen (div. Größen)

Pipettenspitzen mit Filter

Biosphere

Reaktionsgefäße (0,5 ml, 1,5 ml, $2 \mathrm{ml})$ (Epicup)

Reaktionsgefäße $(10 \mathrm{ml}, 15 \mathrm{ml}, 50 \mathrm{ml}$ ) (Falcon-

Röhrchen)

Spritze $20 \mathrm{ml}$

Zellkulturplatten (6 Well, 24 Well)

\section{Hersteller}

Sarstedt, Nümbrecht, Deutschland GE Healthcare, München, Deutschland

R. Langenbrinck, Emmendingen, Deutschland Sarstedt, Nümbrecht, Deutschland Thermo Fisher Scientific, Waltham, MA USA Sarstedt, Nümbrecht, Deutschland

Lonza, Rockland, ME USA

Knittel Glass, Braunschweig, Deutschland Pechiney Plastic Packaging, Menesha, WI USA

Sarstedt, Nümbrecht, Deutschland

(div. Größen), Sarstedt, Nümbrecht, Deutschland

Eppendorf, Hamburg, Deutschland

Sarstedt, Nümbrecht, Deutschland

BD, Heidelberg, Deutschland

Sarstedt, Nümbrecht, Deutschland

\subsubsection{Antikörper}

\section{Antikörper}

Anti-human- $\alpha$-Synuclein-Maus-Antikörper

Anti-Ratten-\&-human- $\alpha$-Synuclein-Maus-

Antikörper

Anti-Aktin-Maus-Antikörper

Anti-Lamp2-Kaninchen-Antikörper

Anti-LC3-Maus-Antikörper

Anti-P62-Ratten-Antikörper

Anti-Tyrosinhydroxylase-Kaninchen-Antikörper

Anti-GAPDH-Maus-Antikörper

Anti-Tubulin-Maus-Antikörper

Anti-Maus-IgG-Cy3-Ziegen-Antikörper

Anti-Kaninchen-IgG-Cy3-Ziegen-Antikörper

Anti-Maus-IgG-Cy5-Ziegen-Antikörper

Anti-Maus-IgG-HRP-Ziegen-Antikörper

Anti-Ratten-IgG-HRP-Ziegen-Antikörper

\section{Hersteller}

Invitrogen, Karlsruhe, Deutschland

BD Biosciences, Heidelberg, Deutschland

Invitrogen, Karlsruhe, Deutschland

Invitrogen, Karlsruhe, Deutschland

NanoTools, Teningen, Deutschland

Sigma-Aldrich, Taufkirchen, Deutschland

Zytomed, Berlin, Deutschland

Biotrend, Köln, Deutschland

Sigma-Aldrich, Taufkirchen, Deutschland

Dianova, Hamburg, Deutschland

Dianova, Hamburg, Deutschland Invitrogen, Karlsruhe, Deutschland Santa Cruz Biotechnology, Santa Cruz, CA USA Santa Cruz Biotechnology, Santa Cruz, CA USA 


\subsubsection{Plasmide und Viren}

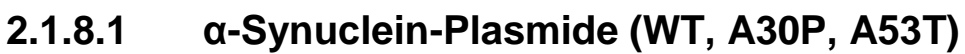

Diese Plasmide wurden uns freundlicherweise von der Arbeitsgruppe Dr. S. Kügler (AG Bähr, Göttingen, Deutschland) bereitgestellt. Sie exprimieren humanes $\alpha$-Syn in seiner Wildtyp-Form sowie in zwei Parkinson-relevanten Mutationen (A30P und A53T). Sämtliche Plasmide sind in ihrer Grundstruktur (siehe Abb. 2.1) gleich aufgebaut und beinhalten einen humanen Synapsin-Promotor, der die Expression der Proteine reguliert. Zusätzlich ist auf allen Plasmiden eine Ampicillin-Resistenz codiert (AMP), um im Rahmen der bakteriellen Vervielfältigung eine Selektion der korrekten Plasmide mittels Antibiotika-Behandlung zu ermöglichen. Lediglich die zu transkribierenden Proteine unterscheiden sich (WT, A30P oder A53T). Durch die A30P-Mutation entsteht eine neue Schnittstelle für das Restriktionsenzym Smal, sodass das Vorhandensein dieser Mutation in der restriktionsenzymatischen Verdauung nachgewiesen werden kann (s. Abb. 2.1 und s. 2.2.5.5).

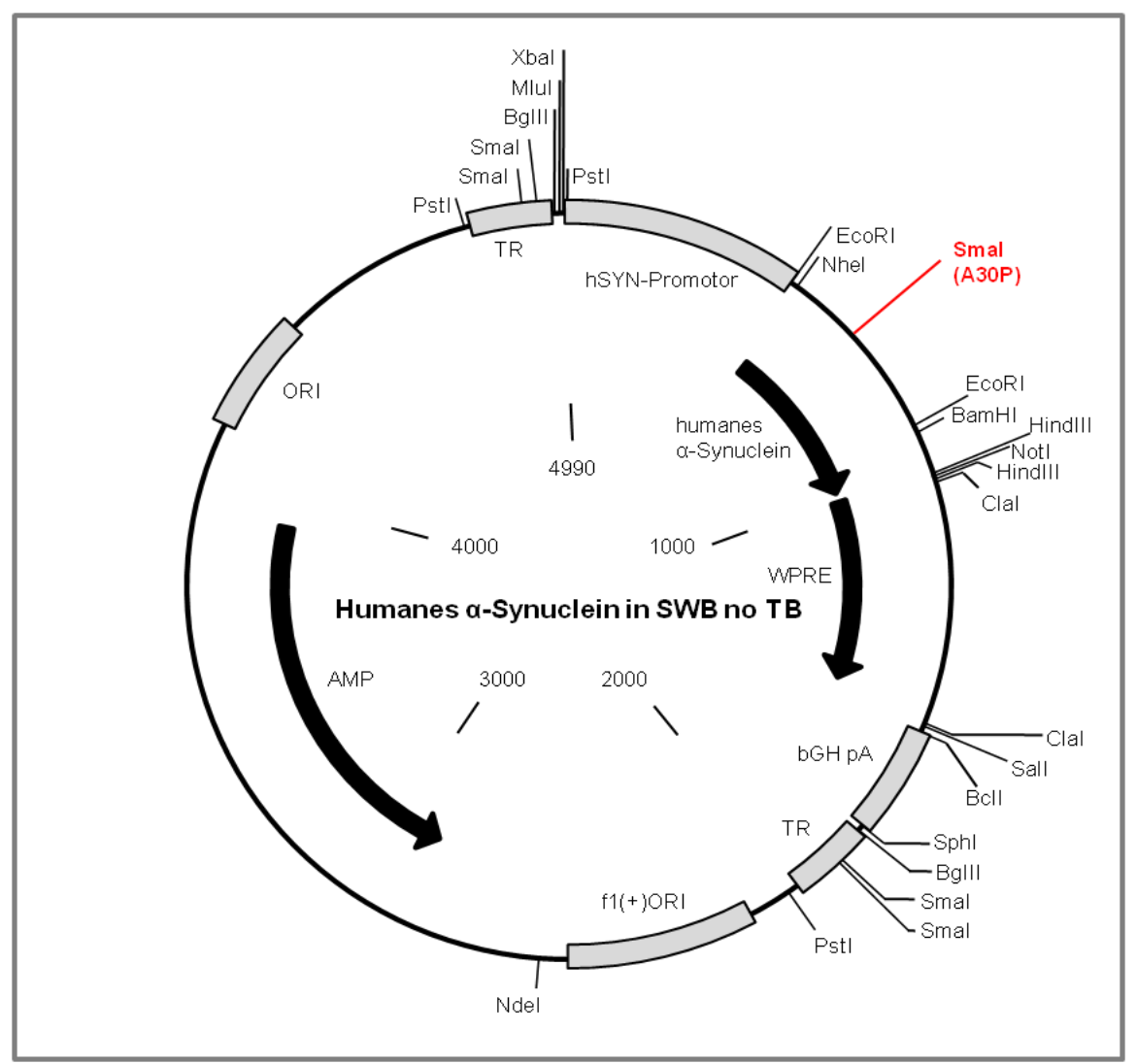

Abb. $2.1 \quad$ humanes $\alpha$-Syn-exprimierendes Plasmid. Zahlen entsprechen Basenpaaren (bp); AMP: Ampicillin-Resistenz; WPRE: Woodchuck Hepatitis Virus posttranskriptionelles Regulationselement; ORI: Replikationsursprung (origin of replication); f1(+) ORI: Replikationsursprung zur einzelsträngigen Replikation von f1-Phagen; TR: endständige Wiederholung (terminal repeat); bGH pA: bovines Wachstumshormon (bovine growth hormone) mit Polyadenylat-Sequenz; hSYN: humaner Synapsin-Promotor. In die Plasmidkarte sind die Schnittstellen verschiedener Restriktionsenzyme eingezeichnet. Die durch die A30P-Mutation neu entstehende Smal-Schnittstelle ist rot hervorgehoben. 


\subsubsection{2 eGFP-Plasmid}

Das eGFP-Plasmid, welches freundlicherweise von der Arbeitsgruppe Prof. U. Michel (AG Bähr, Göttingen, Deutschland) bereitgestellt wurde, konnte zur Co-Transfektion der Mittelhirnneurone genutzt werden, um durch die Eigenfluoreszenz des exprimierten Proteins (eGFP = verstärkt [enhanced] grün fluoreszierendes Protein) transfizierte Zellen schnell und einfach fluoreszenzmikroskopisch darstellen zu können. Das Plasmid (Gen-Bank-ID: HQ416702) besitzt eine Gesamtgröße von 7098 bp und die Expression steht unter Kontrolle eines humanen Synapsin- sowie eines Simian Virus 40-Promotors, welcher der Steigerung der Transkription dient (Koch et al. 2011). Darüber hinaus weist es eine Ampicillin-Resistenz auf, welche im Rahmen der Amplifikation die Selektion der korrekten Plasmide ermöglichen soll (s. Abb. 2.2).

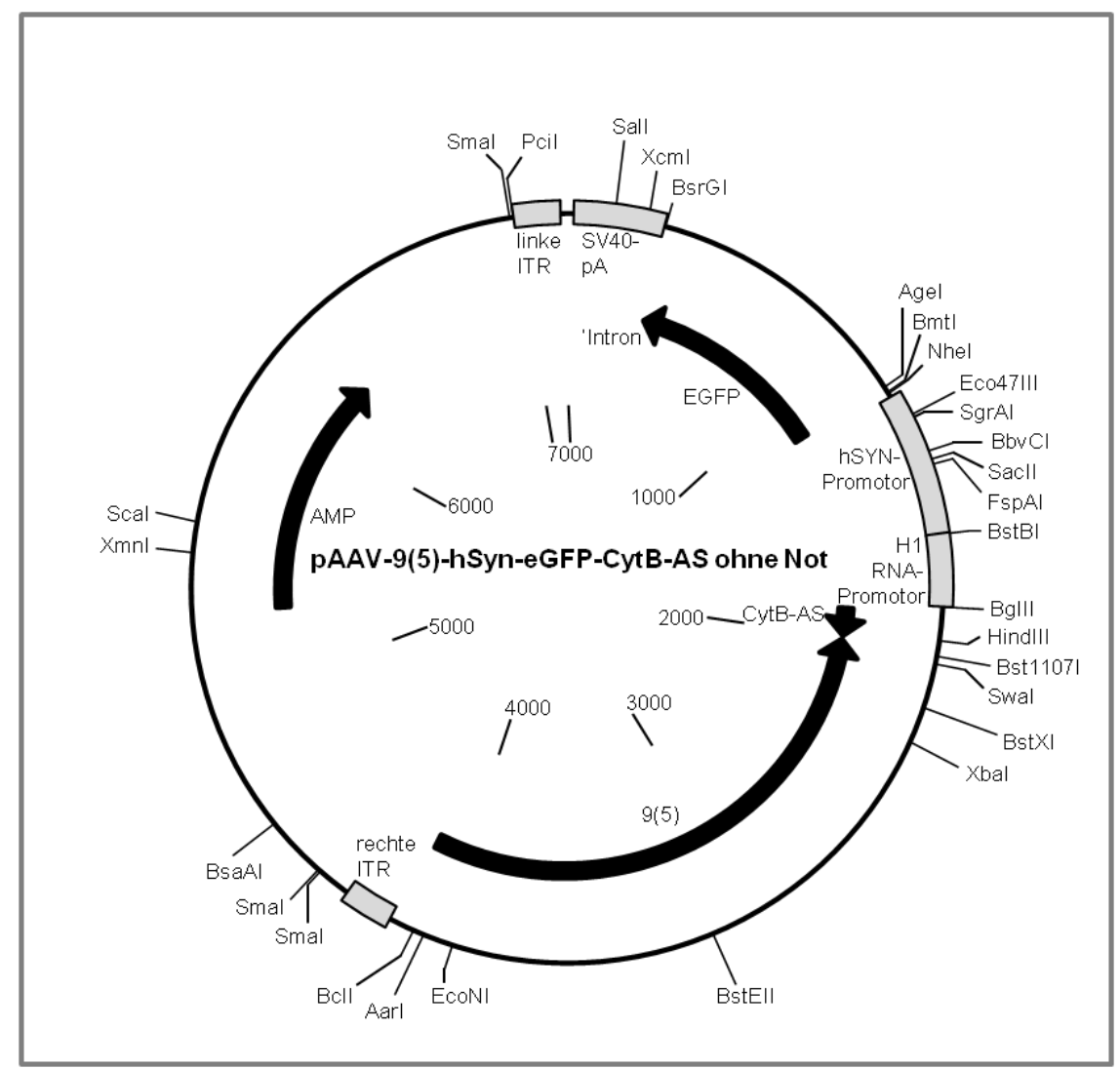

Abb. $\quad 2.2 \quad$ eGFP-exprimierendes Plasmid. Zahlen entsprechen Basenpaaren (bp); AMP: AmpicillinResistenz; hSYN: humaner Synapsinpromotor; ITR: umgekehrte endständige Wiederholung (inverted terminal repeat); SV40 pA: Simian Virus 40 Polyadenylat-Sequenz; H1 RNA-Promotor: Polymerase III H1 RNA Promotor-Sequenz; CytB-AS: partielle Sequenz von Cytochrom B. In die Plasmidkarte sind die Schnittstellen verschiedener Restriktionsenzyme eingezeichnet. 


\subsubsection{DsRed-Plasmid}

Durch dieses Plasmid (Gen-Bank-ID: AY640633) wird ein Protein mit rot fluoreszierender Eigenschaft exprimiert. Ursprünglich wurde dieses Protein in Discosoma sp. entdeckt und bekam daher den Namen DsRed. Die Expression wird durch einen humanen Synapsin-Promotor reguliert und die Transkription durch einen SV 40-Promotor verstärkt. Die Gesamtgröße des Plasmids beträgt $7058 \mathrm{bp}$, und neben DsRed beinhaltet es zur Selektion im Rahmen der Vervielfältigung auch eine Ampicillin-Resistenz.

\subsubsection{Synaptophysin-eGFP-Virus}

Um den axonalen Transport in primären Mittelhirnneuronen zu visualisieren, erfolgte die Transduktion mittels eines Synaptophysin-eGFP-exprimierenden Adeno-assoziierten Virus (AAV). Dieser exprimiert das ubiquitär in synaptischen Vesikeln vorkommende Synaptophysin, an welches eGFP gekoppelt wurde und somit die Vesikel leicht visualisiert werden konnten. Die Expression des Synaptophysin-eGFP unterliegt der Kontrolle eines chicken- $\beta$-actin-Promotors und wird durch einen Cytomegalie-Virus-Verstärker unterstützt (Klonierung und Herstellung durch Jan Koch und Uwe Michel, Göttingen, Deutschland). Die Herstellung des AAV erfolgte nach dem Protokoll von Zolotukhin (Zolotukhin et al. 1999).

\subsubsection{Versuchstiere}

Zur Herstellung der Mittelhirnzellkulturen wurden Embryonen (E14) aus trächtigen Wistar-Ratten verwendet. Sämtliche Versuche erfolgten in Einklang mit den Tierschutzrichtlinien des Landes Niedersachsen (AZ: T10/28).

\subsection{Primäre Mittelhirnneuronenzellkultur}

\subsubsection{Plattenvorbereitung}

Je nach Versuch wurden 6-Kavitäten-Zellkulturplatten (6-well-plates, Wachstumsfläche ca. $9,5 \mathrm{~cm}^{2} /$ Kavität) für Western Blot-Analysen oder 24-Kavitäten-Zellkulturplatten (24-well-plate, Wachstumsfläche ca. $2 \mathrm{~cm}^{2} /$ Kavität) für immunzytochemische Färbungen benutzt. Darüber hinaus wurden sterile Glasplättchen (Coverslips), auf denen die Zellen zur immunzytochemischen Färbung wachsen mussten, in die 24-Loch-Zellkulturplatten eingelegt. Diese wurden durch eine Poly-Ornithin/Laminin-Behandlung zur Erzeugung eines optimalen Wachstums- und Adhäsionsmilieus für primäre neuronale Zellkulturen vorbereitet (Gstraunthaler und Lindl 2013, Flanagan et al. 2006).

Zunächst wurden die Kulturplatten unter sterilen Bedingungen mit Ampuwa-Wasser gewaschen und nachfolgend mit in Boratpuffer gelöstem Poly-Ornithin (Konzentration: 1:50) 
für mindestens 4 Stunden (meist über Nacht) bei Raumtemperatur inkubiert. Das negativ geladene Poly-Ornithin stellte die Grundverbindung zur Zellkulturplatte und den Glasplättchen her. Einen Tag vor der Präparation der Mittelhirnneurone wurden die Platten mit Laminin, einem Bestandteil der zellulären Basalmembran, welches für eine optimale Haftung der Zellen an der Zellkulturplatte sorgen sollte, behandelt. Hierfür wurden die Platten zweimal mit Ampuwa gewaschen, anschließend mit Laminin [in CMF $\left(\mathrm{Ca}^{2+}-\mathrm{Mg}^{2+}\right.$ freie Hank's balanced salt solution) gelöst, Konzentration 1:1000] mit $500 \mu \mathrm{l} /$ Kavität für immunzytochemische (24-Kavitäten-Zellkulturplatten) bzw. $2000 \mu \mathrm{l} /$ Kavität für Western BlotAnalysen (6-Kavitäten-Zellkulturplatten) bedeckt und bei $37^{\circ} \mathrm{C}$ über Nacht inkubiert. Unmittelbar vor der Präparation wurden die vorbereiteten Platten dreimal mit CMF gewaschen und abschließend mit $400 \mu \mathrm{l} /$ Kavität MDN-Kulturmedium in einer 24-KavitätenZellkulturplatte bzw. $2000 \mu \mathrm{l} /$ Kavität in einer 6-Kavitäten-Zellkulturplatte befüllt.

\subsubsection{Herstellung der Zellkultur}

\subsubsection{Präparation}

Durch die Präparation sollte eine Mittelhirnzellkultur hergestellt werden, die eine möglichst hohe Anzahl an dopaminergen, also Tyrosinhydroxylase-positiven Neuronen enthielt. Ungefähr $90 \%$ aller dopaminergen Neurone des Rattengehirns sind im rostral gelegenen Mittelhirn, dem sog. Tegmentum, zu finden (Shimoda et al. 1992) und konnten in Abwandlung des 1992 von Shimoda et al. veröffentlichten Protokolls zur Isolation von primären dopaminergen Mittelhirnneuronen gewonnen werden (Krieglstein et al. 1995). Durch die durchgeführte Präparation enthielt die Zellkultur keine Gliazellen (Saal et al. 2015)

Sämtliche Versuche erfolgten in Einklang mit den Tierschutzrichtlinien des Landes Niedersachsen.

Zunächst wurden die trächtigen Rattenweibchen (E14) mittels $\mathrm{CO}_{2}$ narkotisiert und anschließend getötet. Direkt nach Eintritt des Todes wurde die ventrale Rumpfseite der Ratte großzügig mit 70\%igem Ethanol desinfiziert und durch eine mediane Längslaparotomie eröffnet. Mit frisch desinfiziertem Präparationsbesteck wurde der Uterus mit den enthaltenen Embryonen von den Bandstrukturen, die den Uterus an der Körperhinterwand fixieren, gelöst, um die Embryonen entnehmen zu können. Diese wurden in eine sterile Petrischale mit $4{ }^{\circ} \mathrm{C}$ kaltem CMF, die sich unter einer offenen Sterilbank ohne Abschirmung befand, überführt und von rückständigem Fettgewebe und Blut mittels steriler Schere und Pinzette befreit. Nach dieser Reinigung wurden die Fruchtblasen eröffnet, die Embryonen befreit und steril in eine weitere, auf Eis gekühlte, sterile Petrischale überführt.

Unter stereoskopischer Sicht (Stereoskop Stemi 2000, Zeiss, Jena, Deutschland) wurde das Mittelhirn der Embryonen identifiziert und keilförmig herausgeschnitten (s. 
Abb. 2.3). Das so gewonnene Stück wurde an der konvexen, meningeal geschlossenen Seite mit einem gezielten Scherenschnitt eröffnet (s. Abb. $2.4(\mathrm{a})$ ) und schonend aufgeklappt. Dadurch zeigte sich das Mittelhirn medial als eine schmetterlingsförmige Figur, die lateral durch weiteres neuronales Gewebe begrenzt wurde (s. Abb. 2.4 (b)). Dieses und das auf der Rückseite des Präparates befindliche meningeale Gewebe wurden weiter getrennt, sodass nur noch das schmetterlingsförmige Mittelhirn zur weiteren Herstellung einer möglichst reinen und viele dopaminerge Neurone enthaltenden Zellkultur genutzt werden konnte (s. Abb. 2.4 (b-e)). Das separierte Mittelhirngewebe wurde danach in ein mit $4{ }^{\circ} \mathrm{C}$ kalten CMF-Ampuwa gefülltes Falcon-Röhrchen überführt und auf Eis gekühlt. Danach wurden weitere Embryonen gleichartig präpariert, um die nötige Anzahl an Zellen für eine Kultur zu gewinnen. Pro Muttertier konnten max. 20 Embryonen gewonnen und aus diesen pro Embryo durchschnittlich 500000 Mittelhirnneurone isoliert werden.

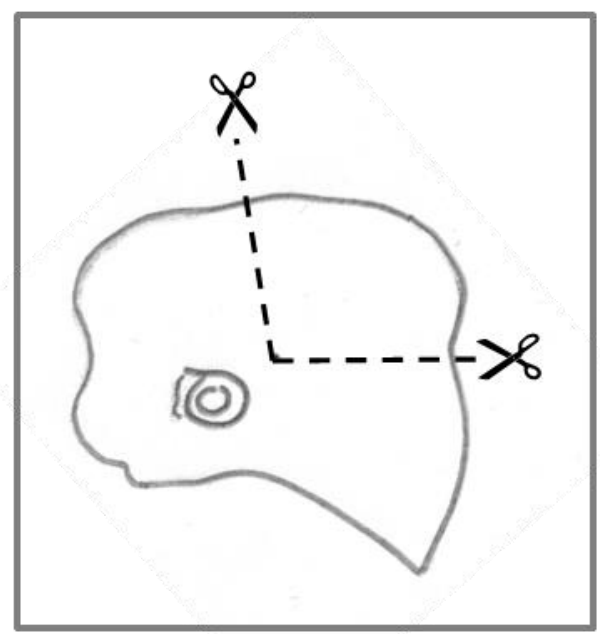

Abb. $\quad 2.3 \quad$ Zeichnerische Darstellung des Craniums eines Rattenembryos E14. Eingezeichnet ist die keilförmige Schnittührung zur Isolation des Mittelhirns (eigene Abbildung).

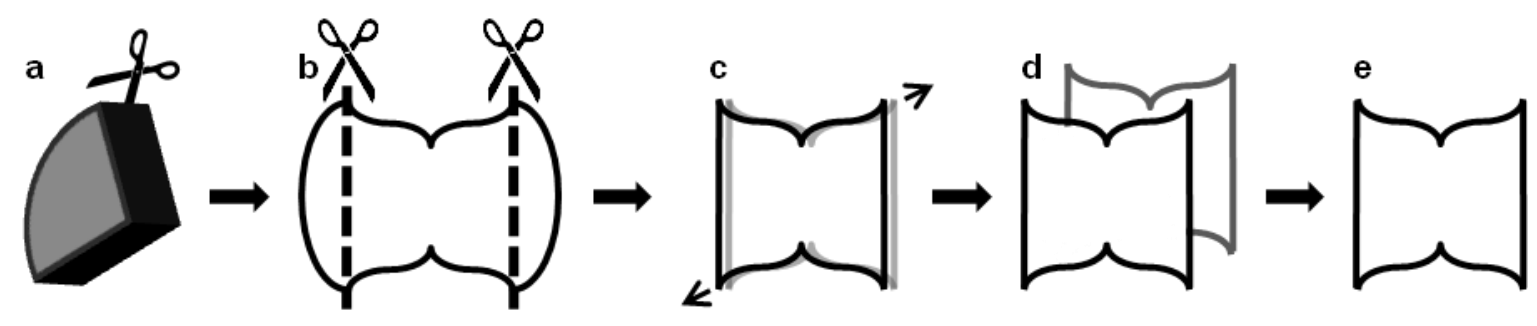

Abb. 2.4 Schematische Darstellung der Präparationsschritte nach Mittelhirn-Exzision (s. Abb. 2.3). Erläuterungen zu (a) bis (e) siehe Text oben.

\subsubsection{Lösung des Zellverbandes}

Anschließend an die Präparation der Mittelhirnneurone mussten diese zur Kultivierung im Nährmedium in mehreren Schritten vorsichtig aus ihrem Zellverband gelöst 
werden. Dazu wurden die Zellen zunächst in einem Falcon-Röhrchen, welches während der Präparation auf Eis gelagert wurde, für 1 Minute bei $800 \mathrm{rpm}$ und $20^{\circ} \mathrm{C}$ zentrifugiert und der CMF-Überstand unter einer abgeschirmten Sicherheitswerkbank mit einem Sauger und einer Pasteurpipette abgenommen. Das so entstandene Zellpellet wurde mit $1 \mathrm{ml}$ TrypsinLösung wieder aufgelöst und für genau 11 Minuten bei $37^{\circ} \mathrm{C} \mathrm{im}$ Wasserbad behandelt. Hierdurch kam es durch Degradation von Proteinen der Extrazellulärmatrix zur Auflösung der interzellulären Verbindungen und Herauslösen der Zellen aus dem Zellverband. Anschließend wurden $60 \mu \mathrm{l}$ DNase zur Zellösung gegeben und erneut für 1 Minute bei $20{ }^{\circ} \mathrm{C}$ und $800 \mathrm{rpm}$ zentrifugiert. Der Überstand aus DNase und Trypsin wurde wieder entfernt, die Zellen mit ca. $900 \mu$ l FCS durch 3-5 maliges, vorsichtiges Auf- und Abpipettieren, sog. Triturieren, mit einer $1000 \mu \mathrm{l}$ fassenden Pipette resuspendiert und für eine Minute zur Sedimentation der Zellen stehen gelassen. Anschließend wurde der Überstand in ein neues, steriles Falcon-Röhrchen überführt, das zurückgebliebene Zellpellet mit $900 \mu \mathrm{l}$ Nährmedium versetzt und mit einer Spezialglaspasteurpipette (Öffnung: 100 $\mu \mathrm{m}$ ) ca. $4 x$ trituriert, bis sich eine homogen gelöste Zellsuspension ergab. Die so gelösten Zellen wurden zu dem zuvor gewonnenen FCS-Überstand zugefügt und ein weiteres Mal bei $800 \mathrm{rpm}$ und $20^{\circ} \mathrm{C}$ für 4 Minuten zentrifugiert, der entstandene Überstand verworfen und die Zellen in genau $1000 \mu \mathrm{l}$ Nährmedium durch 1-2 maliges Triturieren gelöst.

\subsubsection{Berechnung der Zellmenge und Zellaussaat}

Um vergleichbare Zellkulturen herzustellen, war es nötig kontinuierlich die gleiche Anzahl an Zellen pro Kavität einer 6- oder 24-Kavitäten-Zellkulturplatte auszusäen. Hierfür wurden die nach der Präparation in $1000 \mu$ I Nährmedium befindlichen Zellen gezählt und die zu entnehmende Menge Nährmedium mit den darin enthaltenen Zellen berechnet.

Zunächst wurden $10 \mu \mathrm{l}$ der Zelllösung in $90 \mu \mathrm{l}$ PBS (1:10) verdünnt und daraus jeweils $10 \mu \mathrm{l}$ in die obere und untere Tasche einer Neubauerzählkammer pipettiert, alle 8 Eckfelder (je $1 \mathrm{~mm}^{2}$ ) gezählt und anschließend der Mittelwert berechnet. Dieser wurde mit $10^{5}$ multipliziert, um die Gesamtzellzahl in $1000 \mu \mathrm{l}$ Nährmedium zu ermitteln. Anhand dessen konnte die benötigte Menge der Nährmedium-Zellösung für jede Versuchsgruppe berechnet werden. Im Allgemeinen wurden für eine 24-Kavitäten-Zellkulturplatte 800000 Zellen/Kavität und für eine 6-Kavitäten-Zellkulturplatte 3200000 Zellen/Kavität benötigt.

Die so errechnete Menge der Nährmedium-Zelllösung wurde mit Nährmedium ergänzt, damit pro Kavität einer 24-Kavitäten-Zellkulturplatte insgesamt $100 \mu \mathrm{l}$ ausgesät werden konnten und sich somit zusammen mit dem in die Kulturplatten bereits vorgelegten Nährmedium ein Gesamtvolumen von $500 \mu \mathrm{l}$ ergab. Bei 6-Kavitäten-Zellkulturplatten wurde ein auszusäendes Volumen von $500 \mu \mathrm{l}$ gewählt, sodass sich pro Kavität ein Gesamtvolumen von $2500 \mu$ l ergab. 
Zur optimalen Aussaat wurden die Zellen langsam in kreisförmigen Bewegungen in die einzelnen Kavitäten pipettiert und im Anschluss durch vorsichtiges Kreisen der Zellkulturplatte möglichst gleichmäßig verteilt.

\subsubsection{Kultivierung}

Die Zellkulturen wurden in einem Inkubator bei $37^{\circ} \mathrm{C}, 5 \% \mathrm{CO}_{2}$ und in Wasserdampfgesättigter Atmosphäre für insgesamt 5 Tage kultiviert ( 5 Kulturtage $=$ days in-vitro = DIV5). Während dieser Wachstumsphase wurden die Zellkulturen je nach Versuch unterschiedlich behandelt.

Bei nativen Zellkulturen, d.h. ohne Transfektion, oder bei allein Virus-behandelten Zellen genügte ein Austausch des Nährmediums am ersten und dritten Tag nach der Präparation. Hierfür wurden $250 \mu \mathrm{l}$ Nährmedium entnommen und die äquivalente Menge wieder hinzugefügt. Bei Virus-behandelten Zellkulturen wurden zusätzlich 4 Stunden nach der Herstellung der Zellkultur $250 \mu \mathrm{l}$ Nährmedium für 24 Stunden entnommen, der Virus hinzugefügt und anschließend das Nährmedium wieder ergänzt.

Bei Zellkulturen, die durch Elektroporation mit Plasmiden transfiziert wurden, war es nötig das Nährmedium häufiger zu wechseln. Bereits 3-4 Stunden nach der Präparation wurden ungefähr 2/3 des Mediums entfernt und durch frisches ersetzt. Hierdurch sollte der toxische Effekt der Nukleofektionslösung reduziert und die Zellkultur von möglichst vielen avitalen Zellen gereinigt werden, um optimale Wachstumsbedingungen für die übrigen vitalen Neurone zu gewährleisten. An den folgenden 3 Tagen wurden täglich $250 \mu \mathrm{l}$ Nährmedium ausgetauscht und die Zellen bis zum fünften Tag weiter kultiviert.

Anschließend an diese jeweils 5-tägige Kultivierung wurden die Zellen je nach beabsichtigtem Versuch entweder für immunzytochemische Versuche fixiert oder für quantitative Proteinanalysen im Rahmen eines Western Blots lysiert.

\subsubsection{Transfektion durch Nukleofektion}

\subsubsection{Nukleofektionsverfahren}

Durch die Nukleofektion war es möglich die a-Syn-exprimierenden Plasmide in die Zellkerne der Mittelhirnneurone einzubringen und hierdurch eine stabile Expression des humanen a-Syns in seinen verschiedenen Ausführungen (WT, A30P- und A53T-Mutation) sowie der Kontrollplasmide, welche eGFP oder DsRed exprimierten, zu erzielen.

Die Transfektion wurde stets als Co-Transfektion durchgeführt, d.h. die Versuchsgruppen, in denen a-Syn exprimiert werden sollte, wurden immer mit $3 \mu \mathrm{g}$ a-Syn-Plasmid und $2 \mu \mathrm{g}$ eGFP-/DsRed-Plasmid transfiziert. Hierdurch konnte stets eine erfolgreiche Transfektion mittels der Expression von eGFP/DsRed und der damit verbundenen 
Autofluoreszenz überprüft werden. Da die Expression von eGFP/DsRed keinen toxischen Einfluss auf Zellen oder eine Veränderung des zellulären Stoffwechsels zur Folge hat (Chalfie et al. 1994), konnte die Transfektion mit $5 \mu \mathrm{g}$ eGFP/DsRed-Plasmid als Kontrollgruppe fungieren.

Die Nukleofektion stellt einen speziellen Fall der Elektroporation dar. Hierbei gelangt das zu transfizierende Plasmid nicht nur in das Zytoplasma der Zielzelle, sondern unter Zuhilfenahme einer speziellen Nukleofektionslösung auch direkt in den Zellkern (Zeitelhofer et al. 2009, Maasho et al. 2004), wo es in das Genom eingebaut und das codierte Protein exprimiert werden kann. Die Durchlässigkeit der zellulären Membran wird hierbei durch ein angelegtes elektrisches Feld erzielt, welches für einen sehr kurzen Moment die Anordnung der zellulären Phospholipid-Doppelschicht verändert, woraufhin Plasmide in die Zelle und den Zellkern eindringen können. Durch diese Behandlung können toxische Substanzen in die Zelle gelangen aber auch wertvolle Zellbestandteile die Zelle verlassen und dadurch die Zelle anhaltend geschädigt oder sogar zerstört werden. Aufgrund dessen musste die Mindestzellzahl 3,2 × $10^{6}$ Zellen pro Transfektion betragen.

Zur Erzeugung des notwendigen elektrischen Feldes wurden der Nucleofector ${ }^{\mathrm{TM}}$ II Device (Lonza, Basel, Schweiz) in Kombination mit dem Basic Primary Neurons Nucleofector $^{\circledR}$-Kit (VPI-1003), welches speziell für primäre Neurone entwickelt wurde, eingesetzt. Die Parameter zur Erzeugung unterschiedlicher elektrischer Felder konnten durch die Auswahl eines Nukleofektionsprogrammes verändert werden. Das für primäre Mittelhirnneurone beste Programm wurde durch Frau Jessica Haack im Rahmen ihrer Dissertationsarbeit über den Einfluss von $\alpha$-Syn auf Wachstum und Regeneration von primären dopaminergen Mittelhirnneuronen der Ratte optimiert und stellt die Grundlage für die Wahl des Nukleofektionsprogrammes G-013 in der vorliegenden Arbeit dar (Haack 2019).

\subsubsection{Nukleofektionsprotokoll}

Die Elektroporation erfolgte direkt im Anschluss an die Präparation der primären Mittelhirnneurone noch bevor die Zellen in die einzelnen Kavitäten der Zellkulturplatten ausgesät wurden. Hierfür wurde die benötigte Zellzahl pro Versuchsgruppe (ca. 3,2-5 × $10^{6}$ Zellen pro Versuchsgruppe) in $1,5 \mathrm{ml}$ fassende Reaktionsgefäße (Epicups) überführt und anschließend für 90 Sekunden bei 800 rpm zentrifugiert. Im nächsten Schritt wurde das gesamte Nährmedium entfernt, um zellschädigende Interaktionen zwischen Nukleofektionslösung und Resten des Nährmediums zu reduzieren. Das so gewonnene Zellpellet wurde daraufhin mit $90 \mu \mathrm{l}$ der fertigen Nukleofektionslösung (Nucleofector ${ }^{\mathrm{TM}}$ Solution 2,25 $\mathrm{ml}+$ Supplement aus dem Basic Primary Neurons Nucleofectorß-Kit) resuspendiert und das zu transfizierende Plasmid (gelöst in $10 \mu \mathrm{l}$ Ampuwa) hinzugefügt. Das Gesamtvolumen von $100 \mu \mathrm{l}$ wurde in eine sterile Elektroporationsküvette überführt, und es erfolgte 
die Elektroporation mit dem Programm G-013. Im Anschluss an die Elektroporation wurde direkt in die Küvette die benötigte Menge 10\%iges FCS-Nährmedium (z. B. $300 \mu \mathrm{l}$ Nährmedium $+100 \mu \mathrm{l}$ zellhaltige Nukleofektionslösung $=400 \mu \mathrm{l}$ Gesamtvolumen um 4 Kammern einer 24-Kavitäten-Zellkulturplatte zu befüllen) mit einer mitgelieferten Plastikpipette pipettiert, die Gesamtlösung aus der Küvette herausgeholt und in ein steriles Reaktionsgefäß überführt. Dieser Vorgang wurde für alle Versuchsgruppen in gleicher Weise wiederholt. Während dessen wurden die bereits elektroporierten Zellen im Inkubator bei $37^{\circ} \mathrm{C}$ bis zur Aussaat und der anschließenden Kultivierung gelagert (s. 2.2.2.3 und 2.2.2.4).

\subsubsection{Transduktion}

\subsubsection{Transduktionsprinzip}

Eine weitere Methode genetisches Material in eukaryotische Zellen einzubringen und eine stabile Expression des Genproduktes zu erreichen, ist die virale Transduktion. Hierbei dienen Adeno-assozierte Viren (AAV) als Vektoren (Muzyczka 1992). Da AAV selbst nicht alle Proteine in ihrem Genom codieren, die sie zur Vervielfältigung benötigen, sind sie auf die Hilfe anderer Viren, wie bspw. Adenoviren oder auch humane Herpesviren, angewiesen (Büning et al. 2008, McPherson et al. 1985, Buller et al. 1981) und gehören daher zur Virusfamilie der Dependoviren. Diese Helferviren liefern die Proteine, wie z. B. die adenoviralen Proteine E1A, E2A, E4 und VA-RNA, zur Replikation. Dies bedeutet, dass sich $A A V$ in Abwesenheit dieser Helferviren nicht replizieren und die Behandlung der Zellkultur schonend und nicht toxisch für die Zielzellen ist. Es wird die DNA der AAV entweder in das Genom der Zelle eingebaut (z. B. in Chromosom 19 des Menschen) oder liegt in den meisten Fällen als Episom neben dem übrigen Genom der Zielzelle vor, und dessen codiertes Protein wird im Verlauf durch die zelleigenen Mechanismen der Proteinbiosynthese exprimiert.

\subsubsection{Virustransduktionsprotokoll}

Die virale Transduktion wurde im Rahmen der Versuche zum axonalen Transport zur Erzeugung Synaptophysin-eGFP-markierter Vesikel benutzt. Hierbei wurden zunächst mit a-Syn und DsRed transfizierte Zellkulturen hergestellt (s. 2.2.2 und 2.2.3). In diesen Versuchen musste DsRed als Marker der erfolgreichen Transfektion eingesetzt werden, da der Synaptophysin-Virus eGFP zur Visualisierung der Vesikel nutzte. Auch zwischen DsRed und a-Syn wurde die Co-Transfektionsrate zuvor bestimmt, um zu ermitteln, ob - analog zu den Versuchen mit eGFP - ebenfalls eine annähernd 100\%ige Co-Transfektion erzielt werden konnte (s. auch 3.4.1.2). 4 Stunden nach Fertigstellung erfolgte die virale 


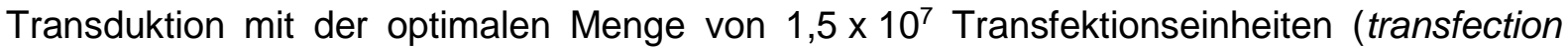
unit $=\mathrm{TU}$ ) an Synaptophysin-eGFP-Virus (s. auch 3.4.1.1). Die Kultivierung der Zellkultur erfolgte wie unter 2.2.2.4 beschrieben.

\subsubsection{Plasmidamplifikation und Restriktionsenzymverdau}

\subsubsection{Plasmidamplifikation}

Zur Amplifikation der Plasmide wurde das Bakterium Escherichia coli (E. coli) genutzt, da es ringförmige DNA (Plasmide) unabhängig seines eigenen Genoms vermehren kann. Die E. coli-Stämme wurden zuvor mit dem jeweiligen Plasmid transformiert und konnten dieses daraufhin vervielfältigen. Zur Selektion der korrekten Bakterienklone wurden die LB-Agar-Nährböden (LB: Luria Bertani) mit Ampicillin im Verhältnis 1:1000 versetzt, da die korrekt transformierten Bakterien eine durch das Plasmid codierte Ampicillin-Resistenz aufweisen und somit nur diese Bakterienstämme wachsen konnten. Anschließend wurde die beimpfte LB-Agarplatte bei $37^{\circ} \mathrm{C}$ über Nacht inkubiert. Nachdem ein sichtbares koloniales Wachstum der Bakterien eingetreten war, wurden je Plasmid 4 Kolonien mit einer sterilen Pipette in ein ebenfalls mit Ampicillin 1:1000 versetztes, $2,5 \mathrm{ml}$ flüssiges LB-Medium enthaltendes Falcon-Röhrchen überführt und bei $37^{\circ} \mathrm{C}$, etwas schräg stehend und schüttelnd bei $180 \mathrm{rpm}$ für 12-16 Stunden inkubiert. Anschließend wurde eine Hälfte der Bakterien-haltigen Lösung zur Plasmid-DNA-Extraktion einer Mini-Präparation (Plasmidisolierung, s. 2.2.5.2) zugeführt und die andere Hälfte für eine größere Plasmidamplifikation mit folgender Maxi-Präparation (s. 2.2.5.3) bei $4^{\circ} \mathrm{C}$ aufbewahrt.

\subsubsection{Mini-Präparation}

Mittels Plasmid-Präparation werden die vervielfältigten Plasmide (s. 2.2.4.1) aus dem Bakterium isoliert und anschließend aufgereinigt. Durch eine Mini-Präparation können ca. $20 \mu \mathrm{g}$ reines Plasmid gewonnen werden. Aufgrund dieser geringen Menge diente die MiniPräparation lediglich zur Kontrolle der korrekten Amplifikation im Rahmen eines durchgeführten Restriktionsenzymverdaus. Anschließend musste bei korrektem Ergebnis noch eine Mega-Präparation durchgeführt werden, um ca. $2000 \mu \mathrm{g}$ Plasmid gewinnen zu können (s. 2.2.4.3). Die Mini-Präparation wurde mit dem QIAprep Spin Miniprep Kit (Qiagen, Hilden, Deutschland) nach dem beiliegendem Protokoll durchgeführt.

Aus den Falcon-Röhrchen, die zur Amplifikation der Plasmide genutzt wurden, wurden als erstes $2 \mathrm{ml}$ in ein steriles Epicup überführt und bei $13000 \mathrm{rpm}$ für 1 Minute zentrifugiert. Der gebildete Überstand wurde verworfen und das Bakterien-haltige Pellet am Boden des Epicups mit $250 \mu \mathrm{l}$ Puffer P1 resuspendiert, anschließend mit $250 \mu \mathrm{l}$ Puffer P2 versetzt und maximal 5 Minuten bei Raumtemperatur unter kontinuierlichem Schwenken des 
Reaktionsgefäßes inkubiert. Dadurch wurden die bakteriellen Hüllstrukturen lysiert. Danach wurden $350 \mu$ l Puffer N3 zur Präzipitation der bakteriellen DNA hinzugefügt, 5x geschwenkt und bei 13000 rpm für 10 Minuten zentrifugiert, um im Überstand das freie Plasmid zu gewinnen. Dieser wurde in spezielle Säulen (QIA spin column®) gegeben und ein weiteres Mal für 1 Minute bei 13000 rpm zentrifugiert. Dadurch wurde die Plasmid-DNA in einer speziellen Membran der Säule gebunden und der Durchfluss konnte entfernt werden. Durch die Zugabe von $500 \mu \mathrm{l}$ Puffer PB und anschließender 1-minütiger Zentrifugation bei 13000 rpm wurde die DNA gereinigt und eventuell enthaltene Nukleasen inaktiviert. Der Durchfluss wurde wiederum verworfen. Danach wurde die Säule mit $750 \mu$ Puffer PE für einen weiteren Reinigungsvorgang befüllt und abermals bei 13000 rpm für 1 Minute zentrifugiert. Der Durchfluss wurde wieder verworfen und die Säule ohne Befüllung noch einmal zentrifugiert, um letzte Rückstände der zuvor benutzten Lösungen zu entfernen. Abschließend wurde die Säule in ein neues, steriles Epicup gegeben, $50 \mu$ Puffer AE hinzugefügt und letztmalig zentrifugiert. Dadurch wurde die noch in der Säule gebundene Plasmid-DNA eluiert.

\subsubsection{Mega-Präparation}

Im Rahmen einer Mega-Präparation Plasmid-haltiger Bakterien konnten insgesamt ca. $2000 \mu \mathrm{g}$ des benötigten Plasmids isoliert werden. Zunächst wurde, wie unter 2.2.5.2 beschrieben, eine Mini-Präparation durchgeführt, wobei nur ein Teil der kultivierten Bakterien zur Plasmid-Gewinnung genutzt und der andere bei $4^{\circ} \mathrm{C}$ gelagert wurde. Nachdem die isolierten Plasmide der Mini-Präparation durch einen restriktionsenzymatischen Verdau (s. 2.2.5.5) auf ihre Korrektheit geprüft wurden, konnte die noch gelagerte Bakterienlösung als Ausgangspunkt für die Mega-Präparation genutzt werden. Die Bakterien wurden in $2000 \mathrm{ml}$ Ampicillin-haltigen LB-Flüssigmedium (Dilution 1:1000) überführt und zu je $500 \mathrm{ml}$ in Kolbenflaschen aufgeteilt. Diese wurden für ca. 14 Stunden bei $37^{\circ} \mathrm{C}$ und 180 rpm in einem Schüttler inkubiert. Die Präparation wurde mit dem Qiagen Plasmid Mega Kit entsprechend dem beiliegendem Herstellerprotokoll durchgeführt. Letztlich wurden hierbei die gleichen Schritte analog zur Mini-Präparation lediglich mit anderen Volumina der einzelnen Lösungen durchgeführt. Zusätzlich wurde nach Eluierung der Plasmid-DNA aus den Säulen diese durch Isopropanol präzipitiert, in einem zusätzlichen Reinigungsschritt mit $70 \%$ igem Ethanol weiter aufbereitet und anschließend zur Lagerung bei $4^{\circ} \mathrm{C}$ in Tris-Puffer gelöst. Auch diese Plasmide wurden durch einen Restriktionsenzymverdau erneut kontrolliert und die DNA-Konzentration und Reinheit durch ein Bio-Photometer bestimmt.

\subsubsection{DNA-Konzentration und Reinheit (OD-Bestimmung)}

Um vergleichbare Mengen Plasmid zur Transfektion der Zellkulturen einsetzen zu können, war es nötig die Konzentrationen der verschiedenen Plasmide durch Messung der 
optischen Dichte (=OD) zu ermitteln. Darüber hinaus konnte hierbei auch die Reinheit der hergestellten Plasmide bestimmt werden, da eine erfolgreiche, möglichst atoxische Zelltransfektion nur durch eine praktisch kontaminationsfreie Plasmidlösung gewährleistet werden kann.

Die Konzentration der Nukleinsäuren wurde photometrisch bei einer Wellenlänge von $260 \mathrm{~nm}$ in einer Quarzküvette ermittelt. Anhand der einzelnen Extinktionen konnten die Konzentrationen der Plasmidlösungen ermittelt werden. Das Absorptionsmaximum für Proteine liegt bei $280 \mathrm{~nm}$, sodass das Verhältnis OD260/OD280 zur Abschätzung der Reinheit einer Plasmidlösung genutzt werden kann (Sambrook und Russell 2001, Wilfinger et al. 1997). Hierbei spricht ein Wert von ca. 1,8 für eine reine, nahezu kontaminationsfreie Plasmidlösung.

Zunächst wurde eine Leerwertmessung einer mit $100 \mu \mathrm{l}$ Ampuwa befüllten Küvette durchgeführt. Der hierbei ermittelte Wert wurde anschließend vom Plasmidwert subtrahiert. Die Plasmide wurden 1:100 in Ampuwa verdünnt und ebenfalls gemessen. Anhand dieser Werte konnten dann die Konzentrationen bestimmt werden.

\subsubsection{Restriktionsenzymverdau und Agarosegelelektrophorese}

Dieser Versuch diente der Kontrolle der vervielfältigten Plasmide. Hiermit konnten Fehler im Rahmen der Amplifikation der neu produzierten Plasmide, wie Veränderungen der Plasmidlänge oder Punktmutationen, welche die Schnittstellen für Restriktionsenzyme verändern oder sogar neue entstehen lassen, ausgeschlossen werden.

Bei Restriktionsenzymen handelt es sich um Restriktionsendonukleasen, die in der Lage sind, DNA an ganz bestimmten, sog. palindromischen Sequenzen, zu zerschneiden (Mülhardt 2009). Palindromische Sequenzen sind Basenabfolgen eines DNA-Stranges, dessen Komplementärstrang die gleiche Abfolge der Basen jedoch gespiegelt aufweist. Dadurch dienen sie als Erkennungssequenz für DNA-modifizierende Proteine.

$$
\begin{aligned}
& \text { Beispiel: } \quad 5^{\prime} \text {-CCCGGG- 3، } \\
& \text { 3"-GGGCCC- 5“ }
\end{aligned}
$$

Dieses Beispiel ist gleichzeitig die palindromische Sequenz des Restriktionsenzyms Smal, welches in der vorliegenden Arbeit auch benutzt wurde. Restriktionsenzyme sind primär in Bakterien und Archaeen zu finden und dienen dort der Degradation von eingedrungenen Bakteriophagen.

Durch Sequenzierung der benötigten Plasmide, die durch die Arbeitsgruppen Dr. S. Kügler (AG Bähr, Göttingen, Deutschland; $\alpha$-Syn-Plasmide) und Prof. U. Michel (AG Bähr, Göttingen, Deutschland; eGFP- und DsRed-Plasmid) zur Verfügung gestellt wurden und bei denen eine 100\%ige Übereinstimmung der Sequenzen zur Literaturreferenz bestand, konnten multiple Schnittstellen für verschiedene Restriktionsenzyme ermittelt und somit auch die erwarteten Fragmentlängen errechnet werden (s. 2.1.8). 
Für die Kontrolle der $\alpha$-Syn-Plasmide wurde zum einen das Restriktionsenzym Smal und zum anderen eine Kombination der Endonukleasen Bglll und Notl verwendet. Interessanterweise entsteht durch die A30P-Mutation eine weitere Schnittstelle für Smal, sodass diese Mutation über den Restriktionsverdau ebenfalls nachgewiesen werden konnte. Das produzierte eGFP-Plasmid wurde allein mit Smal geprüft.

Für den Restriktionsverdau wurden jeweils $200 \mathrm{ng}$ der Plasmid-DNA mit 0,5 $\mu \mathrm{l}$ des jeweiligen Enzyms, $1 \mu$ eines Enzympuffers (nach Angabe des Herstellers New England Biolabs; Smal: Puffer 4, Bglll/Notl: Puffer 3) und Ampuwa zusammengeführt, um ein Gesamtvolumen von $10 \mu \mathrm{l}$ zu erhalten. Als Kontrolle dienten Lösungen ohne Beigabe der Enzyme. Anschließend wurden die Smal-haltigen Ansätze bei Raumtemperatur und die Bglll/Notl-haltigen Ansätze bei $37^{\circ} \mathrm{C}$ für 30 Minuten inkubiert und danach zu jeder Probe 2,5 $\mu \mathrm{l}$ eines 5x DNA-Puffers hinzugefügt. Anschließend wurden $10 \mu \mathrm{l}$ der jeweiligen Probe sowie $5 \mu$ l einer DNA-Leiter auf ein Agarosegel aufgetragen und die entstandenen DNAFragmente durch Gelelektrophorese aufgetrennt. Hierbei wanderte die negativ geladene DNA durch das angelegte elektrische Feld in Richtung des positiven Pols. Die Auftrennung erfolgte bei $100 \mathrm{~V}$ und dauerte je nach gewünschten Abständen der einzelnen Fragmente bis zu 2 Stunden.

Abschließend konnten die so separierten und durch Ethidiumbromid-Interkalierung (dem Agarosegel zugesetzt) unter UV-Licht (Fluor-S ${ }^{T M}$-Multilmager) sichtbar gemachten Fragmente betrachtet, mit Hilfe der Software Quantity One 4.2.1 fotografiert und die Fragmentgrößen durch die bekannte DNA-Leiter semiquantitativ erfasst werden.

Es stellten sich die anhand der Plasmidkarte (s. 2.1.8) zu erwartenden DNAFragmente bei Smal-Verdau mit einer Größe von ungefähr 3000 bp und 2000 bp für $\alpha$-SynWT und die A53T-Mutation dar. Berechnet wurden Fragmente mit einer Größe von 3013 bp und 1955 bp. Durch die a-Syn-Mutation A30P bildet sich eine weitere Schnittstelle für das Restriktionsenzym Smal, sodass ein zusätzliches Fragment entsteht und sich DNAFragmente mit 3000 bp, 1200 bp und 700 bp (3013 bp, 1265 bp und 690 bp) ergaben. Beim Restriktionsverdau mit den Enzymen Bglll/Notl ergaben sich für alle verwendeten $\alpha$-SynVarianten gleichlange DNA-Fragmente mit 3100 bp (3173 bp), 1000 bp (959 bp) und 900 bp (858 bp) (s. Abb. 2.5).

Gleiches wurde für das eGFP-Plasmid durchgeführt, bei dem sich ebenfalls die anhand der Plasmidkarte berechneten DNA-Fragmente von 4406 bp und 2861 bp zeigten. Darüber hinaus gibt es ein weiteres, 11 bp großes Fragment, welches durch zwei direkt zueinander benachbarte Schnittstellen für das verwendete Restriktionsenzym Smal entsteht, jedoch aufgrund seiner minimalen Größe nicht dargestellt werden kann (s. Abb. 2.6). Anhand dieser Ergebnisse sowie der nachgewiesenen Proteinexpression (Western Blot, Immunzytochemie) konnte eine korrekte Amplifikation der Plasmide nachgewiesen werden. 


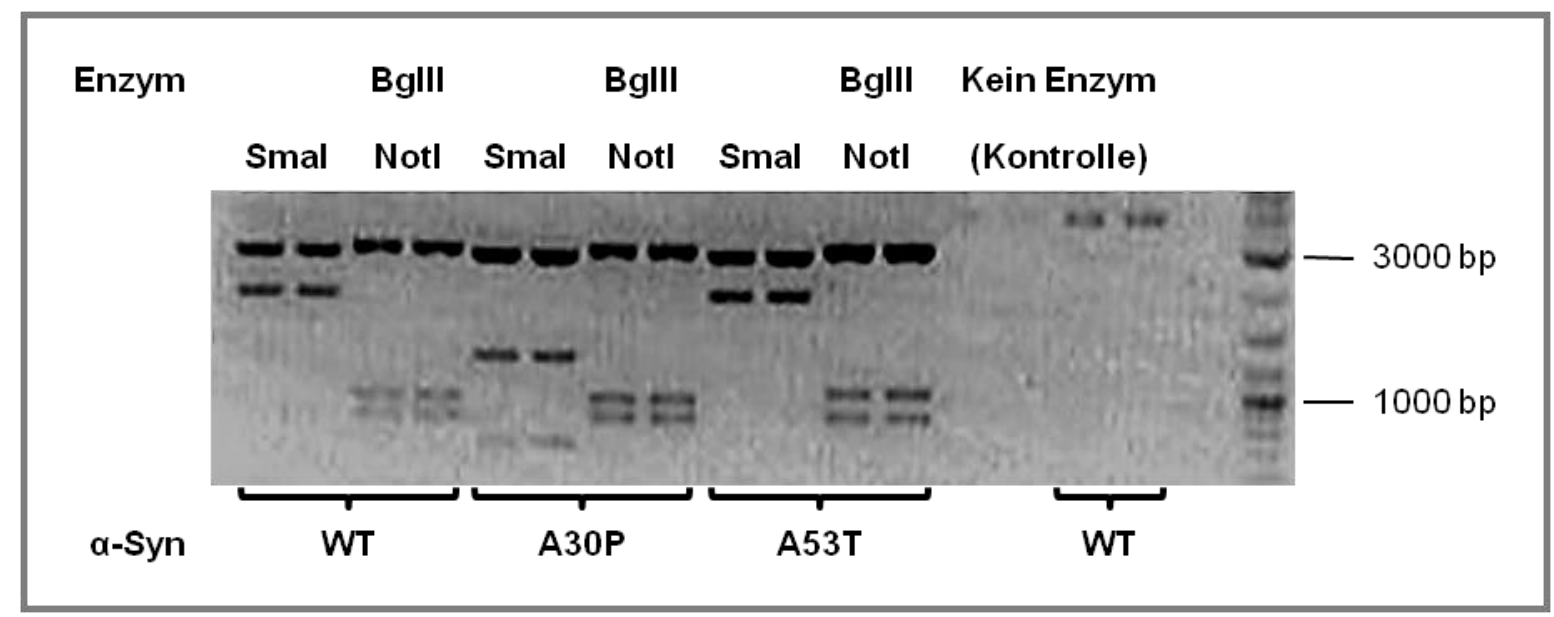

Abb. 2.5 Darstellung eines Restriktionsenzymverdaus der $\alpha$-Syn-Plasmide. Die zuvor berechneten Fragmentgrößen konnten semiquantitativ bestätigt werden. $\mathrm{Zu}$ beachten ist die durch die Punktmutation A30P entstandene Schnittstelle für Smal mit folglich 3 DNA-Fragmenten.

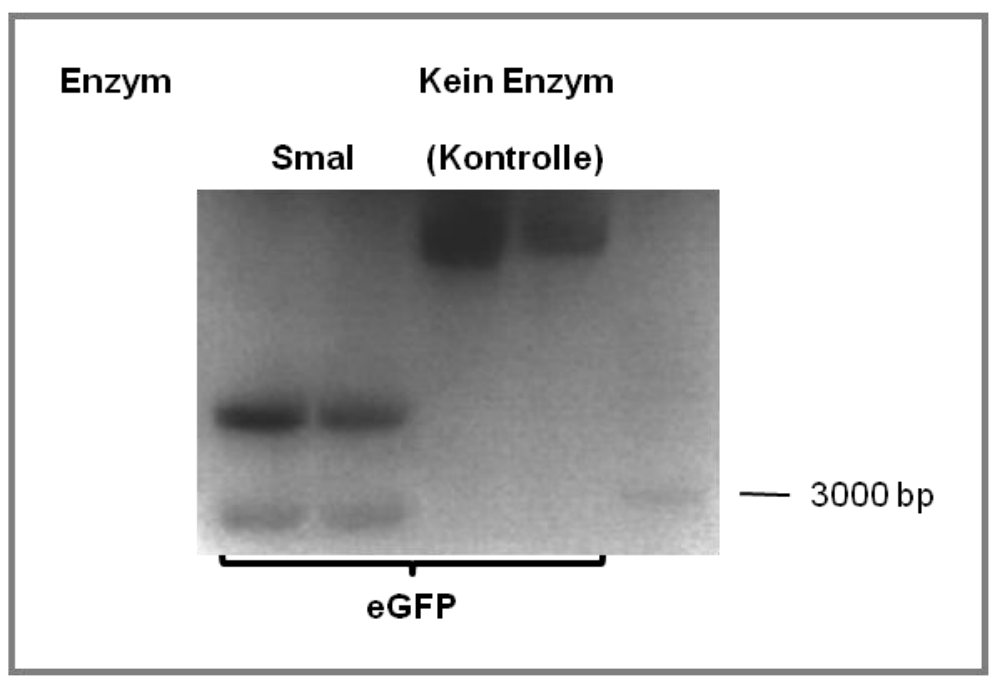

Abb. 2.6 Darstellung eines Restriktionsenzymverdaus des eGFP-Plasmids. Die zuvor berechneten Fragmentgrößen konnten semiquantitativ bestätigt werden.

\subsubsection{Bafilomycin A 1 -Behandlung}

Zur Ermittlung des Einflusses von $\alpha$-Syn auf die Autophagie primärer Mittelhirnneurone war es nötig, neben transfizierten Zellkulturen, die keiner weiteren Behandlung unterlagen, auch Zellkulturen mit dem Makroautophagie-Inhibitor Bafilomycin $A_{1} z u$ behandeln. Hierfür wurden die Zellkulturen am 5. Tag nach der Präparation 6 Stunden vor der Herstellung von Zelllysaten oder der Fixierung behandelt. Dafür wurde zunächst sämtliches Nährmedium vollständig entfernt, durch frisches, mit $1 \mathrm{nM}$ Bafilomycin $A_{1}$ versetztes Medium ersetzt und die Neurone für weitere 6 Stunden kultiviert, um anschließend lysiert oder fixiert zu werden. 


\subsection{Immunzytochemische Färbung}

Für immunzytochemische Färbungen wurden die hergestellten Zellkulturen auf gläsernen Deckgläschen (Coverslips) in 24-Kavitäten-Zellkulturplatten für 5 Tage kultiviert (s. 2.2.2.4). Für die Färbung der Zielproteine wurde zunächst ein spezifischer, gegen dieses Protein gerichteter Antikörper (primärer Antikörper), welcher in einem Spezies-fremden Lebewesen hergestellt wurde, eingesetzt. Anschließend wurde ein zweiter Antikörper (sekundärer Antikörper), der gegen den Erstantikörper gerichtet und an dem ein Fluorochrom gebunden war, ergänzt. Bestrahlung mit einem Fluoreszenzlicht bestimmter Wellenlänge führte zur Lichtemission des Fluorochroms, wodurch die indirekt markierten Proteine dargestellt werden konnten.

\subsubsection{Zellfixierung}

Die Zellfixierung erfolgte am 5. Tag nach Herstellung der Zellkultur. Dafür wurde zunächst das Nährmedium mit einer Plastikpasteurpipette aus den einzelnen Kavitäten der Kulturplatte entnommen und anschließend mit auf $37^{\circ} \mathrm{C}$ vorgewärmten PBS (500 $\left.\mu \mathrm{l}\right)$ befüllt, um Rückstände des Mediums entfernen zu können. Das PBS wurde wieder entfernt, durch $500 \mu$ l\%iges Paraformaldehyd (PFA) ersetzt und für 10 Minuten bei $4{ }^{\circ} \mathrm{C}$ inkubiert. Zuletzt wurde das PFA entnommen und die Platten dreimal mit PBS gewaschen.

\subsubsection{Zellfärbung}

Im Anschluss an die Waschgänge wurden die Coverslips vorsichtig mit einer Pinzette aus den Kammern entnommen und auf eine umgedrehte, mit Parafilm überzogene Lochplatte überführt. Die Zwischenräume der Lochplatte wurden mit destilliertem Wasser gefüllt und der Parafilm leicht gelocht, um bei den folgenden Inkubationsschritten ein Austrocknen der Zellen zu verhindern. Anschließend wurden sämtliche PBS-Reste entfernt, die Neurone der einzelnen Coverslips mit reinem Aceton unter einem Abzug schockgefroren und für 10 Minuten bei $-20^{\circ} \mathrm{C}$ inkubiert, um die Zellmembranen permeabel zu machen. Nachdem das Aceton entfernt und die Deckgläschen erneut mit PBS dreimal gewaschen wurden, konnten sie mit $\mathrm{DAKO}^{\circledR}$ diluent für 20 Minuten bei Raumtemperatur bedeckt werden. Dieses diente der Blockierung unspezifischer Proteinbindungen, sodass in den anschließenden Antikörper-Behandlungen die spezifischen Proteine dargestellt werden konnten. Zunächst wurden die Zellen mit dem ersten Antikörper (AK), der spezifisch für das Zielprotein war, über Nacht bei $4^{\circ} \mathrm{C}$ inkubiert. Nach der Behandlung mit dem Erstantikörper wurden die Coverslips mit PBS dreimal für je 5 Minuten auf dem mini gyro-rocker (Stuart®) gewaschen und anschließend mit dem passenden Zweitantikörper in entsprechender 
Verdünnung für 30 Minuten bei $37^{\circ} \mathrm{C}$ und lichtgeschützt inkubiert (s. Tab. 2.1). Danach wurden die Coverslips erneut dreimal mit PBS für je 5 Minuten gewaschen, um anschließend die Zellkernfärbung mit DAPI durchführen zu können. An ein letztes Mal waschen mit PBS, um Reste der DAPI-Lösung zu entfernen, schloss sich die Einbettung der Coverslips auf einen Objektträger mit auf $37^{\circ} \mathrm{C}$ vorgewärmten Mowiol@ an. Vor der Fluoreszenzmikroskopie mussten die Objektträger bei $4{ }^{\circ} \mathrm{C}$ getrocknet werden und konnten so bis zum Mikroskopieren in Objektträgermappen lichtgeschützt auch gelagert werden.

\begin{tabular}{|c|c|c|c|c|}
\hline \multicolumn{3}{|c|}{ Erstantikörper } & \multicolumn{2}{|c|}{ Zweitantikörper } \\
\hline Antikörper & $\begin{array}{l}\text { Verdünnung (in } \\
\text { DAKO }^{\circledR} \text { diluent) }\end{array}$ & Herkunft & Antikörper & $\begin{array}{l}\text { Verdünnung (in } \\
\text { DAKO }^{\circledR} \text { diluent) }\end{array}$ \\
\hline $\begin{array}{l}\text { anti-human- } \\
\text { a-Syn-AK }\end{array}$ & $1: 250$ & Maus & \multirow{2}{*}{$\begin{array}{c}\text { anti-Maus-Cy5- } \\
\text { AK }\end{array}$} & \multirow{2}{*}{ 1:1000 } \\
\hline $\begin{array}{c}\text { anti-Ratten \& } \\
\text { human- } \alpha-S y n-A K\end{array}$ & $1: 250$ & Maus & & \\
\hline anti-LAMP-2A-AK & $1: 200$ & Maus & $\begin{array}{c}\text { anti-Maus-Cy3- } \\
\text { AK }\end{array}$ & $1: 1000$ \\
\hline anti-LC3-AK & $1: 200$ & Maus & $\begin{array}{c}\text { anti-Maus-Cy3- } \\
\text { AK }\end{array}$ & $1: 1000$ \\
\hline \multirow{2}{*}{ anti-TH-AK } & \multirow{2}{*}{$1: 250$} & \multirow{2}{*}{ Kaninchen } & $\begin{array}{l}\text { anti- Kaninchen - } \\
\text { Cy3-AK }\end{array}$ & $1: 1000$ \\
\hline & & & $\begin{array}{l}\text { anti- Kaninchen - } \\
\text { Cy5-AK }\end{array}$ & 1:1000 \\
\hline
\end{tabular}

Tab. 2.1 Erst- und Zweitantikörper und deren Verdünnung für immunzytochemische Färbungen. Die Wahl des jeweiligen Flourochroms des sekundären Tyrosinhydroxylase (TH)-Antikörpers richtete sich nach dem verwendeten Fluorochrom des Zweitantikörpers des zweiten Proteins bei CoFärbungen.

\subsubsection{Fluoreszenzmikroskopie}

Die gefärbten Präparate wurden am Axioplan-Fluoreszenzmikroskop mikroskopiert und mit Hilfe der Software AxioVision Rel. 4.8 (Carl Zeiss Vision, Jena, Deutschland) über eine spezielle Kamera (Axiocam) fotografiert.

An die sekundären AK sind Fluoreszensfarbstoffe (Fluorochrome), wie bspw. Indocarbocyanin 3 (Су3) oder Indocarbocyanin 5 (Cy5), gebunden. Diese Fluorochrome können nach Anregung mit Licht einer bestimmten Wellenlänge (Absorbtion) selbst Licht spezifischer, jedoch im Vergleich zur Anregung andere Wellenlänge, das visuell oder mit Hilfe einer Kamera wahrgenommen werden kann, aussenden (Emission). Dadurch werden indirekt die Zielproteine durch die Kette aus Erstantikörper (spezifisch für Zielprotein), 
Zweitantikörper (bindet am primären $\mathrm{AK}$ ) und gebundenem Fluorochrom, welches Licht emittiert, sichtbar. Die folgende Tabelle stellt die verwendeten Fluorochrome sowie die fluoreszierenden Stoffe DAPI (interkaliert mit der DNA), eGFP und DsRed mit ihrem Exzitations- und Emissionsmaximum und der visuellen Farbwahrnehmung gegenüber (s. Tab. 2.2). Zu beachten ist, dass das verwendete Cy5 nur sehr schwach bis gar nicht über das menschliche Auge wahrgenommen werden kann, sodass es nur mittels verwendeter Kamera und Software visualisiert werden konnte.

\begin{tabular}{|c|c|c|c|}
\hline $\begin{array}{c}\text { Fluorochrom und } \\
\text { Autofluoreszenz }\end{array}$ & $\begin{array}{c}\text { Exzitationsmaximum } \\
\text { in } \mathbf{~ n m}\end{array}$ & $\begin{array}{c}\text { Emissionsmaximum } \\
\text { in } \mathbf{n m}\end{array}$ & Färbung \\
\hline DAPI & 358 & 461 & blau \\
\hline eGFP & 489 & 508 & grün \\
\hline Cy3 & 550 & 570 & rot \\
\hline DsRed & 558 & 583 & rot \\
\hline Cy5 & 650 & 670 & violett \\
\hline
\end{tabular}

Tab. $2.2 \quad$ Zusammenstellung der verwendeten Fluoreszenzen.

Zur Auswertung der Versuche mussten einzelne dopaminerge, d. h. in der immunzytochemischen Färbung Tyrosinhydroxylase-positive (TH-positive) Zellen fotografiert werden. Hierfür wurde die AxioCam sowie die Software AxioVision benutzt. Aufgrund der insgesamt geringen Anzahl transfizierter dopaminerger Neurone wurden zunächst Übersichtsaufnahmen mit einem 10x-Objektiv gemacht, auf diesen die transfizierten Neurone identifiziert und anschließend in gezielten Detailaufnahmen aufgenommen. Hierfür wurden je nach Versuch entweder ein 63x-vergrößerndes Öl-Objektiv oder ein 20x-Objektiv genutzt.

Im Rahmen der statistischen, standardisierten Auswertung der Co-Transfektion wurden die Bilder, um mögliche systematische Ungleichheiten der Zellverteilung entlang des Durchmessers des Deckgläschens in allen Gruppen gleichermaßen abzubilden (häufig findet sich in der Mitte des Deckgläschens trotz sorgfältiger Zellaussaat eine höhere Zelldichte als am Rand), nach einem objektiven System entlang des größten Durchmessers der Coverslips hintereinander aufgenommen (s. Abb. 2.7). 


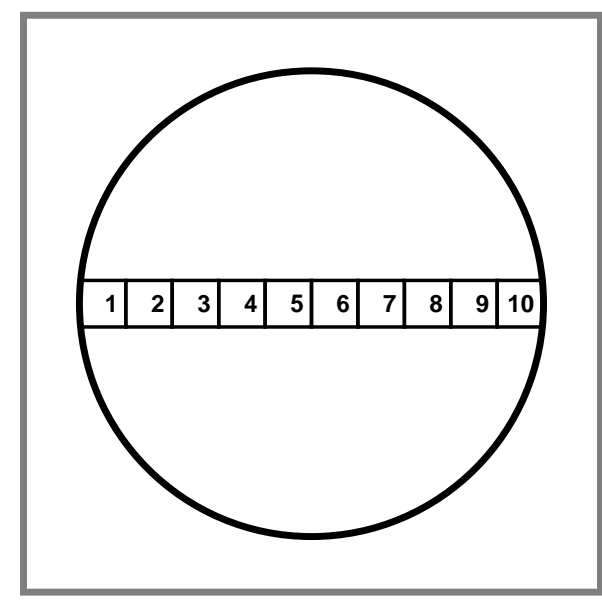

Abb. $\quad 2.7 \quad$ Schematische Darstellung der standardisierten Bildaufnahme. Bei 20x-Vergrößerung konnten ca. 10 Gesichtsfelder aufgenommen werden.

\subsubsection{Quantifizierung}

Die Messung der einzelnen Parameter erfolgte, sofern möglich, automatisiert mit Hilfe der Software ImageJ. Um eine objektive Auswertung der einzelnen Versuche zu gewährleisten, wurden sämtliche Auswertungen verblindet vorgenommen.

\subsubsection{Anzahl LC3-positiver Autophagosomen}

Zur Ermittlung der Anzahl LC3-positiver Autophagosomen wurden die gegen LC3 und Tyrosinhydroxylase (TH) immunzytochemisch gefärbten Neurone über ein 63xvergrößerndes Öl-Objektiv aufgenommen. Zusätzlich wurde bei diesen Aufnahmen das pseudo-konfokale ApoTome (Zeiss) eingesetzt, mit dessen Hilfe fluoreszenzmarkierte Präparate frei von Streulicht in der gewünschten Fokusebene aufgenommen und somit kontrastreicher dargestellt werden können. Es wurde in der Ebene fotografiert, in welcher die Zellkörperfläche am größten war. Zur weiteren Verbesserung des Kontrastes der Zielstrukturen erfolgte zweimal die automatisierte Bildbearbeitung mit Hilfe des Aufnahmeprogrammes Axiovision (Zeiss) (Bildverarbeitung > Bildschärfe > Unscharfmaskierung > OK; voreingestelltes Setting wurde belassen), um durch die Kontrastanhebung an kleinen Strukturen und Kanten optimale Voraussetzungen für die anschließende automatisierte Zählung mit dem Programm ImageJ zu erhalten (s. Abb. 2.8). 
LC3

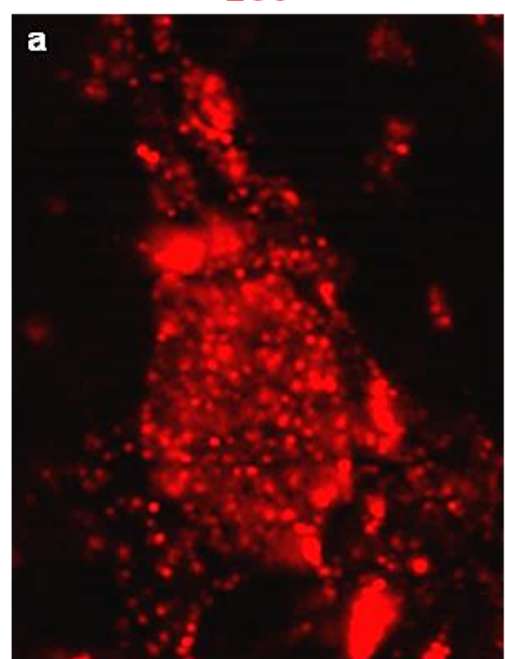

LC3

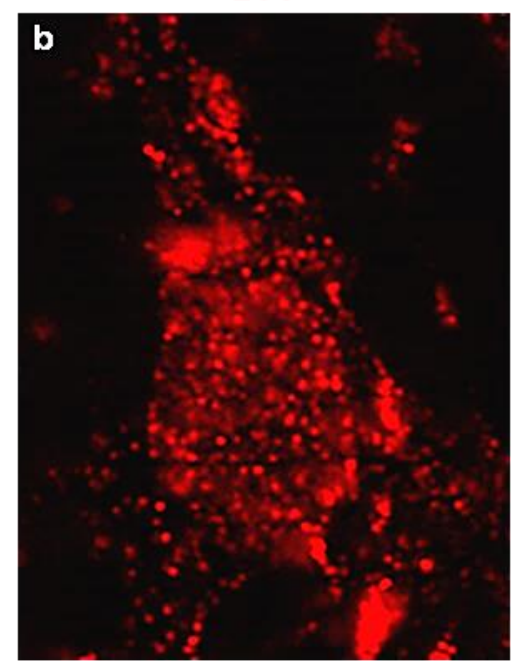

LC3

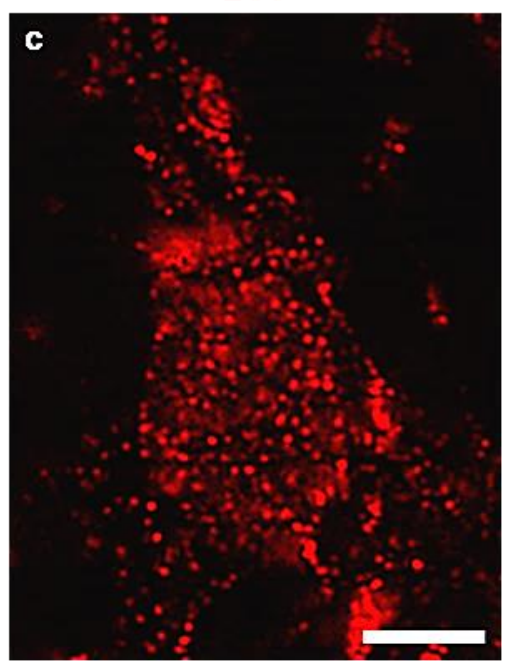

Abb. 2.8 Darstellung der automatisierten Bildbearbeitung mit Axiovision. LC3-Immunzytochemie; (a) Originalaufnahme mit 63x-Öl-Objektiv und ApoTome; (b) nach erster automatisierter Bildbearbeitung; (c) nach zweiter Bildbearbeitung. Die LC3-positiven Autophagosomen konnten durch die Bearbeitung des aufgenommenen Bildes und der daraus resultierenden Kontrastierung wesentlich genauer dargestellt und gemessen werden. Primäres Mittelhirnneuron, DIV5, Maßbalken: 5 m, 63x-Öl-Objektiv.

Die bearbeiteten Bilder wurden anschließend in ImageJ geöffnet (als .zvi-Datei, Dateiformat von Axiovision) und das Soma der Zielzelle entweder in der TH-Färbung (für dopaminerge Neurone) oder in der eGFP-Fluoreszenz (für nicht-dopaminerge Neurone) umrandet (,freehand selections“, s. Abb. 2.9 (a)). Anschließend wurde das Bild der LC3Färbung invertiert (Edit > Invert; s. Abb. 2.9 (b)), die zuvor erarbeitete Zellumrandung auf dieses übertragen (Edit > Selections > Restore Selection; s. Abb. 2.9 (c)) und automatisch ein Schwellenwert der Fluoreszenzintensität festgesetzt (Image > Adjust > Treshold; s. Abb. 2.9 (d)). Die daraufhin markierten Punkte entsprachen den LC3-positiven Autophagosomen, die automatisch (Analyze > Analyze Particles, Einstellung: size (pixel^2): 9-infinity) gezählt wurden.

Da Autophagosomen durchschnittlich einen Durchmesser von ca. $300 \mathrm{~nm}$ (unter zellulärem Stress bis zu $900 \mathrm{~nm}$ ) haben (Jin und Klionsky 2014), wurden nur Punkte gezählt, die mindestens $3 \times 3$ Pixel (1 Pixel entspricht ca. $92,5 \mathrm{~nm}$ bei 63-facher Vergrößerung) groß waren. Darüber hinaus wurden Partikel, die bspw. 18-26 Pixel $^{2}$ groß waren, als zwei einzelne Autophagosomen $(=2 \times 3 \times 3$ große Partikel = 2 Autophagosomen), die durch Autophagieprozesse verschmolzen sind oder räumlich so nah gelegen waren, dass eine automatische Separierung in den Bildern nicht möglich war, gezählt, um so die bestehende Autophagiekapazität korrekt zu ermitteln. Dies wurde bis zu einer Verschmelzung von ca. 22 Autophagosomen entsprechend 198 Pixel $^{2}$ aufgetrennt. Größere Partikel wurden nicht mehr miterfasst. Dadurch konnte gewährleistet werden, dass Zellen, die zwar etwas weniger dafür jedoch wesentlich größere Autophagosomen hatten oder deren kleine Autophagosomen bei der gewählten Vergrößerung sich als ein Autophagosom darstellten, im Vergleich zu 
anderen Neuronen dennoch als Zellen mit größerer Autophagiekapazität und -funktionalität bewertet wurden. Außerdem war es hierdurch möglich mehrere benachbarte Autophagosomen, die durch die automatische Setzung des Schwellenwertes zu einem großen LC3-positiven Partikel verschmolzen sind, wieder zu separieren (s. Abb. 2.9 (c) und (d) schwarzer Kreis) und eine möglichst genaue automatische Zählung zu gewährleisten.

TH

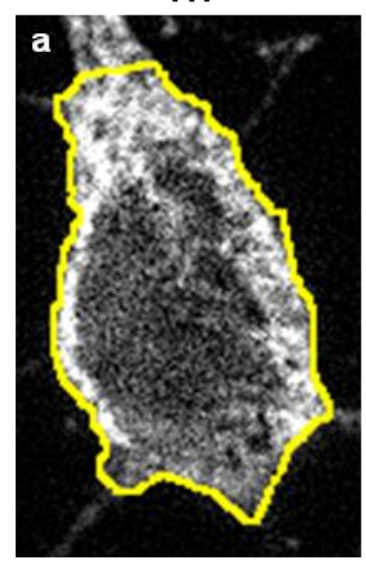

LC3

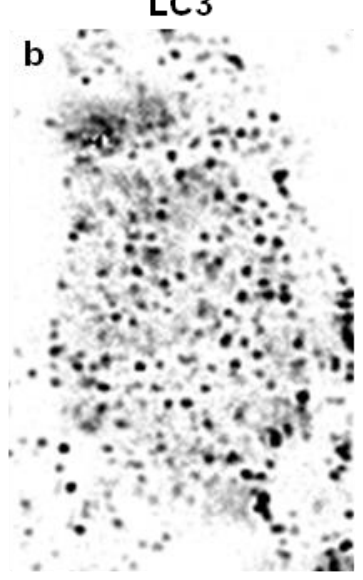

LC3

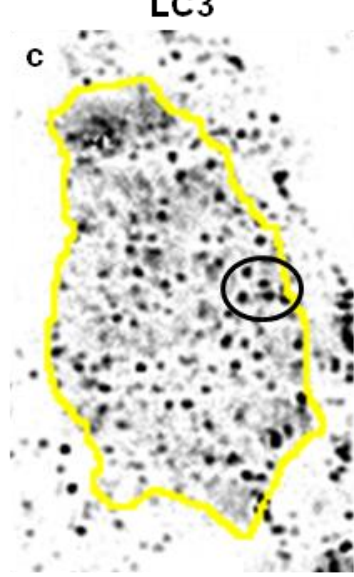

LC3

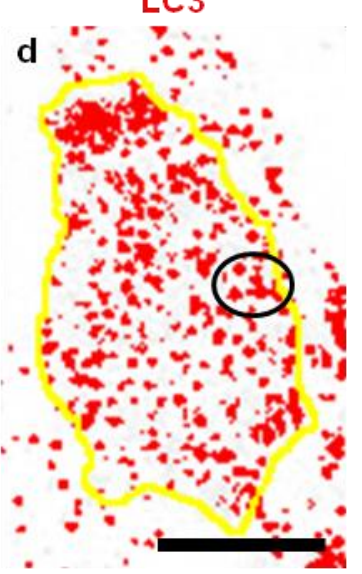

Abb. 2.9 Beispielhafte Darstellung der automatisierten Auswertung LC3-positiver Autophagosomen. (a) Soma-Markierung eines TH-positiven Neurons; (b) invertierte LC3-Färbung; (c) übernommene Markierung aus der TH-Färbung auf LC3-Färbung; (d) über automatischen Schwellenwert markierte LC3positive Autophagosomen. Schwarze Umkreisung: 5 visuell einzeln abgrenzbare Autophagosomen in (c) verschmelzen durch die automatische Schwellenwert-Setzung teilweise zu einem großen Partikel in (d). Rechnerisch (siehe Text oberhalb) wurde dieses Partikel in einzelne Autophagosomen korrigiert. Primäres dopaminerges Mittelhirnneuron. DIV5, Maßbalken: $5 \mu \mathrm{m}, 63 x-O ̈ l-O b j e k t i v$.

\subsubsection{Anzahl LAMP-2A-positiver Lysosomen und deren Verteilung}

Die Aufnahmen und Bearbeitungen der Bilder zur Auswertung der CMA anhand LAMP-2A-positiver Lysosomen erfolgten analog zu den Beschreibungen unter Punkt 2.3.4.1 zur Analyse der Anzahl LC3-positiver Autophagosomen. Im Anschluss erfolgte die Messung der zytoplasmatisch gelegenen, LAMP-2A-positiven Lysosomen mit Hilfe des Programmes ImageJ. Im Rahmen der Aktivierung der CMA kommt es zu einer Verschiebung LAMP-2Apositiver Lysosomen in Richtung des Zellkerns, sodass eine Signalanreicherung in diesem Bereich für eine Funktionssteigerung spricht (Cuervo et al. 2004).

Zunächst wurde ein Überlagerungsbild der TH-Färbung und der DAPI-Zellkernfärbung benutzt, um radiär vom Zellkern ausgehende und bis zum Rand des Zellkörpers reichende Messlinien einzuzeichnen (s. Abb. 2.10 (a)). Erst anschließend wurden diese Messlinien auf das LAMP-2A-Bild übernommen (s. Abb. 2.10 (b)), um diese nicht bewusst durch Lysosomen zu zeichnen. Die Fluoreszenzintensität der LAMP-2A-Färbung wurde dann entlang jeder einzelnen Linie gemessen (ImageJ: Analyze > Plot Profile). 

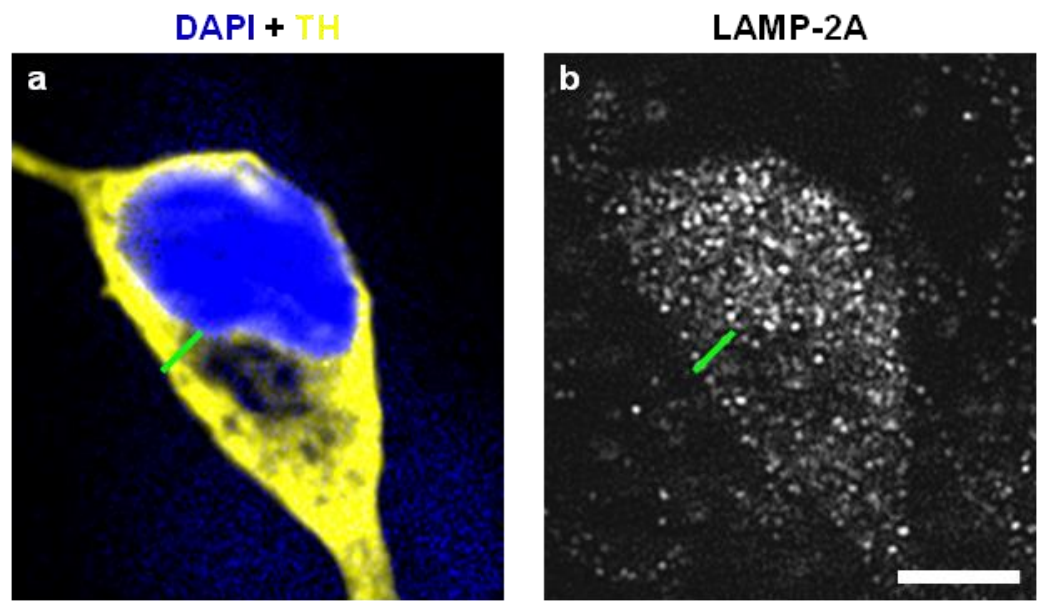

Abb. 2.10 Beispielhafte Darstellung der automatisierten Auswertung LAMP-2A-positiver Lysosomen. (a) TH- und DAPI-Färbung, grüne Linie: Messlinie; (b) LAMP-2A-Färbung mit übernommener Messlinie aus (a). Primäres dopaminerges Mittelhirnneuron, DIV5, Maßbalken: 5 m, 63x-ÖI-Objektiv.

Für jede Zelle wurden hierbei 6 Einzelmessungen durchgeführt. Dadurch entstand entlang jeder Messlinie für jedes Pixel Abstand vom Zellkern ein eigenständiger Fluoreszenzintensitätswert (gemessen als Grauwert), der graphisch aufgezeichnet wurde (s. Abb. 2.11). Sofern die gemessenen Werte eine Grauwertschwelle von 1000000 überschritten, wurde dies als LAMP-2A-positives Lysosom bei einem bestimmten Abstand (zunächst in Pixel) gewertet. Wenn bei mehreren benachbarten Pixeln dieser Schwellenwert überschritten wurde, wurden diese zu einem oder mehreren Lysosomen zusammengefasst oder separiert und pro einzelnem Vesikel der Abstand bei der höchsten Fluoreszenzintensität erfasst. Hierfür wurden 1-4 Überschreitungen als 1 Lysosom, 5-6 als 2 Lysosomen und 7-9 als 3 Lysosomen definiert. Mehr benachbarte Schwellenwertüberschreitungen konnten nicht gesehen werden.
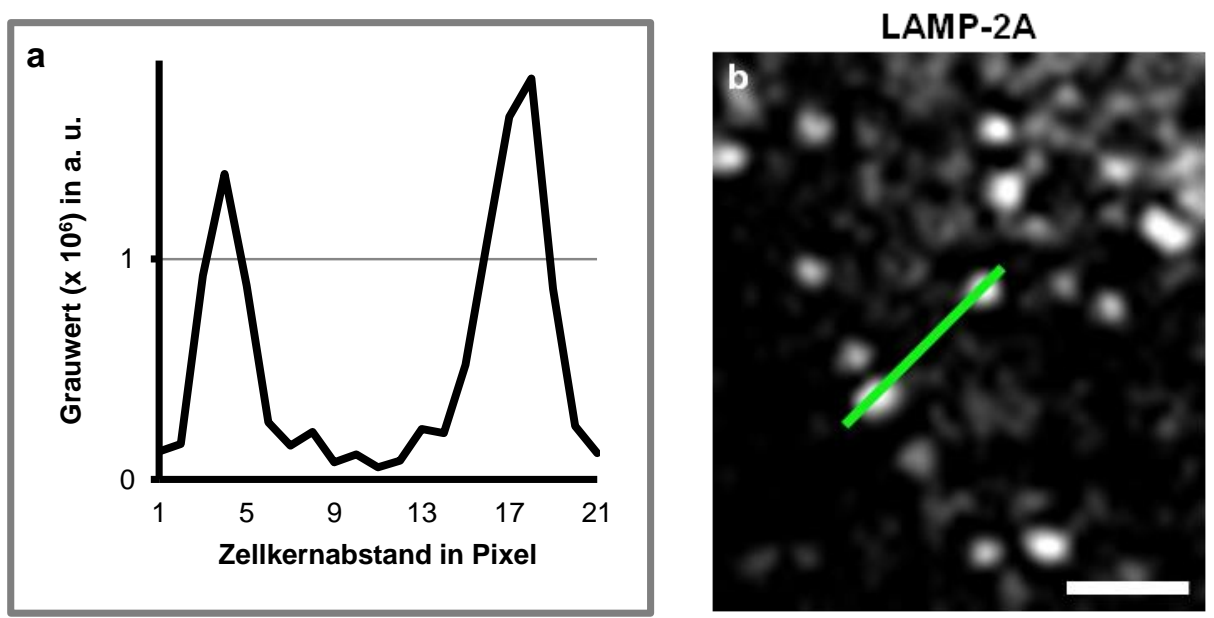

Abb. 2.11 Graphische Darstellung der gemessenen Grauwerte (a) am Beispiel der Messlinie aus Abb. 2.10 in Detailvergrößerung (b). graue Hilfslinie: Schwellenwert für Lysosom-Definition, grün: Messlinie. Es zeigen sich zwei LAMP-2A-positive Lysosomen. a. u. (in a) = arbitrary units (dt. willkürliche Einheit) Maßbalken: $1 \mu \mathrm{m}, 63 x-O ̈ I-O b j e k t i v$. 


\subsection{Analyse des axonalen Vesikeltransportes}

\subsubsection{Zellkultur}

Um die Auswirkungen von $\alpha$-Syn auf den zellulären Vesikeltransport zu beurteilen,

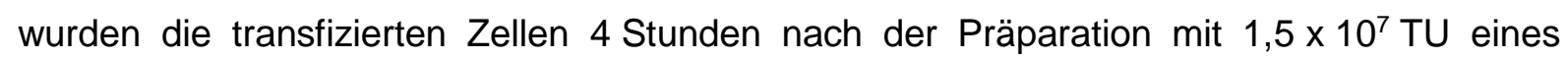
Synaptophysin-eGFP exprimierenden Virus behandelt (s. 2.2.4.2). Durch den Virus wurden Synaptophysin-eGFP-haltige Vesikel produziert, die über die eGFP-Fluoreszenz sichtbar wurden. Dadurch war es möglich den Vesikeltransport zu visualisieren und zu untersuchen.

Damit die Neurone und ihre Transportvorgänge in bestmöglicher Qualität fotografiert werden konnten, war es nötig die Zellen nicht in den gewöhnlichen KunststoffZellkulturplatten zu kultivieren, da diese den Fluoreszenzstrahlengang beeinträchtigten, sondern in speziellen Glaskammern (chamber slides). Die Aussaat erfolgte mit 800000 Zellen/Glaskammer.

Die Visualisierung der transfizierten Neurone erfolgte mittels DsRed-Co-Transfektion, da der Virus selbst eine eGFP-Fluoreszenz nutzte. Die Co-Transfektionsrate mit $\alpha$-Syn lag ebenfalls bei $100 \%$ (s. auch 3.4.1.2).

\subsubsection{In-vitro-Live-Imaging}

Zur Beurteilung des vesikulären Transportes war es nötig die Zellen ohne Fixierung im lebenden Zustand zu fotografieren, um anschließend die so gewonnenen Bilderserien auszuwerten. Dafür wurde das zur Bildgewinnung genutzte Axiovert-Mikroskop zusätzlich mit einer Inkubationskammer erweitert, um während des Live-Imagings optimale Lebensbedingungen $\left(37^{\circ} \mathrm{C}, 5 \% \mathrm{CO}_{2}\right.$, Wasserdampf-teilgesättigte Atmosphäre) für die Zellen zu gewährleisten.

Anschließend wurden unter dem Mikroskop bei 63-facher Vergrößerung DsRedpositive und somit transfizierte Neuriten gesucht und mittels Kamera (AxioCam) und dem Programm Axiovision Bilderserien aufgenommen. Dabei wurde ein Nervenzellfortsatz 20x alle $500 \mathrm{~ms}$ fotografiert, sodass insgesamt für 10 Sekunden der Transport der Synaptophysin-eGFP-markierten Vesikel pro Zelle beurteilt werden konnte (s. Abb. 2.12 (120)). Eine längere Zeitspanne war aufgrund des starken eGFP-Fluoreszenzverlustes nicht möglich. Die Bildbearbeitung erfolgte analog zu den unter 2.3.4.1 beschriebenen Schritten. 

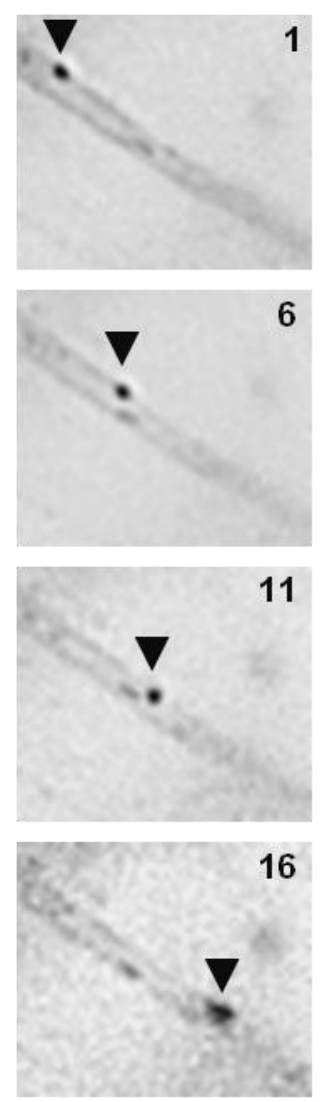

1
2

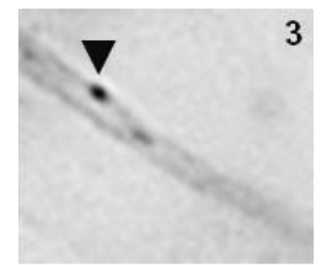

7
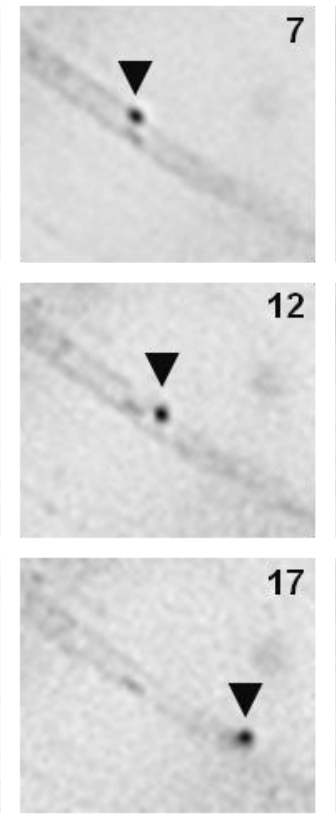

3

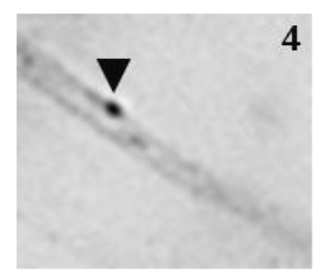

8

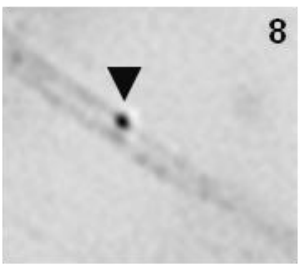

13

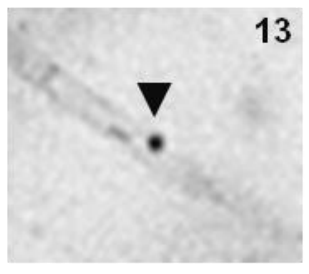

18

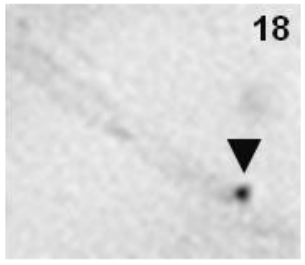

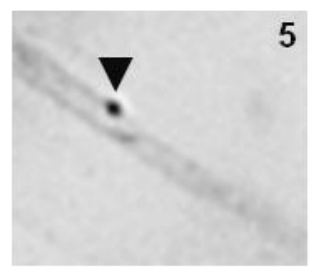

9

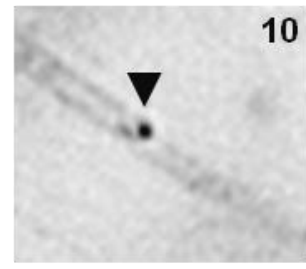

14

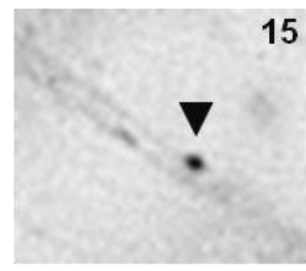

19

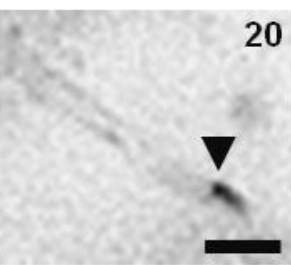

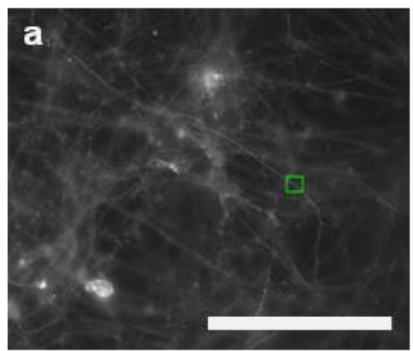

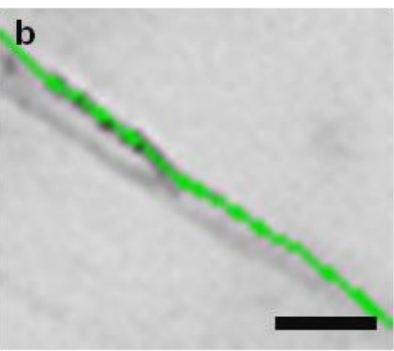

C
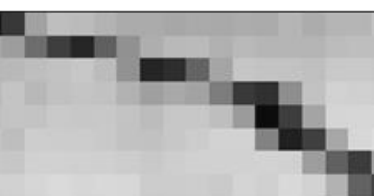

Abb. $2.12 \quad$ Beispieldarstellung der Bildaufnahme sowie der Auswertungsschritte des axonalen Transportes. (1-20) Bildabfolge der Synaptophysin-eGFP-Fluoreszenzaufnahmen (schwarz-weiß invertiert), zwischen jedem Bild liegen 500 ms; Pfeilspitze: bewegendes Vesikel; (a) grün markierter Bildausschnitt des zu untersuchenden Neuriten; (b) Markierung des Neuriten nach Projektion des Z-Stacks auf eine Ebene (schwarz-weiß invertiert); (c) Kymograph des in (b) markierten Neuriten nach Übertragung der Markierung auf die Bilderserie. Es zeigt sich eine deutliche Bewegung des Synaptophysin-eGFP-markierten Vesikels. Darüber hinaus zeigen sich Änderungen der Geschwindigkeit und zuletzt auch der Bewegungsrichtung des Vesikels. Neurit eines primären Mittelhirnneurons, DIV5, Maßbalken: (1-20) und (b) $2 \mu \mathrm{m}$, (a) 100 m, 63x-ÖlObjektiv. 


\subsubsection{Auswertung}

Die so hergestellten Bilderserien der Vesikel wurden mittels ImageJ ausgewertet. Für bessere Kontrastverhältnisse wurden alle Bilder in schwarz-weiß als .zvi-Datei (AxiovisionFormat, s. Abb. 2.12 (a)) evaluiert. Die transfizierten Neuriten wurden nach ihrer visuellen Schärfe ausgewählt, rechteckig markiert (rectangular selections; s. Abb. 2.12 (a)) und anschließend dieser Bereich ausgeschnitten (Image $>$ Crop). Im Anschluss wurde die Bilderserie schwarz-weiß invertiert (Edit $>$ Invert), mit der Funktion $Z$ Project (Image > Stacks $>$ Z Project; Einstellung: max intensity) alle Bilder der Serie übereinander projiziert und in einem Bild zusammengefasst. Dadurch war es einfacher möglich den Verlauf des Neuriten mit der Funktion segmented line nachzuzeichnen (s. Abb. 2.12 (b)) und diese Messlinie wieder auf die Orginal-Bilderserie zu übertragen (Edit > Selection > Restore Selection). Im Anschluss hieran erfolgte die weitere Auswertung durch die Erzeugung eines Kymographen mittels eines ImageJ-Plugins (MultipleKymograph). Dadurch wurden für jedes Einzelbild der Bilderserie die Helligkeitsunterschiede entlang der Messlinie ermittelt und entsprechend dem zeitlichen Verlauf zusammenfassend als Graph dargestellt (s. Abb. 2.12 (c)). Hierdurch war es möglich die Bewegung einzelner Vesikel und Parameter wie die Durchschnittsgeschwindigkeit oder Geschwindigkeitsänderungen zu ermitteln, da nun die zurückgelegte Wegstrecke (horizontal in Pixel) und die Zeit (eine Zeile entsprach $500 \mathrm{~ms}$ ) in Bezug gesetzt wurden.

\subsection{Western Blot}

\subsubsection{Ermittlung der Proteinkonzentration}

Vor Bestimmung der Proteinkonzentration erfolgte am fünften Kulturtag die Lysatgewinnnung aus den primären Zellkulturen. Hierfür wurde das gesamte Nährmedium mit einem Sauger aus der 6-Lochplatte entfernt und unmittelbar danach ein- bis zweimal mit jeweils $2 \mathrm{ml} 5 \%$ iger Glukoselösung pro Well gewaschen. Nach vollständiger Entfernung der Glukose-Lösung wurden die Zellen mit $60 \mu \mathrm{l}$ Lyse-Puffer versetzt, mit einem Zellschaber vom Boden der Well-Platte gelöst und die Zellen samt Lysepuffer in einem 1,5 ml, auf Eis gekühlten Reaktionsgefäß gesammelt. Anschließend wurde jede Lysatprobe insgesamt 30 Sekunden (Einstellung: Power: 40, Cycle: -) mit dem Sonificator behandelt und die Proben für 30 Minuten bei $13000 \mathrm{rpm}$ und $4^{\circ} \mathrm{C}$ zentrifugiert, um den Protein-haltigen Überstand von anderen Bestandteilen zu trennen und diesen in ein neues Reaktionsgefäß zu überführen. Die Proben wurden bis zur weiteren Verarbeitung (BCA-Assay) bei $-20^{\circ} \mathrm{C}$ aufbewahrt.

Zur Bestimmung der Proteinkonzentration jeder lysierten Probe wurde eine BCAAnalyse [Bicinchoninsäure (bicinchoninic acid=BCA)] durchgeführt. Das Prinzip der BCA- 
Analyse beruht auf der Biuret-Reaktion, bei der Proteine $\mathrm{Cu}^{2+}$-Ionen in alkalischer Lösung zu $\mathrm{Cu}^{+}$reduzieren. Unter Zugabe von Bicinchonininsäure entwickelt sich dabei ein violettgefärbter Komplex, dessen optische Dichte photometrisch gemessen werden kann.

Hierfür wurde $1 \mu$ l eines Proteinlysats mit $199 \mu$ ler BCA-Lösung in einer Mikroplatte (96-well-plate) vermischt, zusätzlich eine Proteinstandardreihe mit bekannten BSA (bovines Serumalbumin-)-Konzentrationen $(40 \mu \mathrm{g}, 20 \mu \mathrm{g}, 10 \mu \mathrm{g}, 5 \mu \mathrm{g}, 2,5 \mu \mathrm{g}, 1,25 \mu \mathrm{g}, 0,625 \mu \mathrm{g})$ aufgetragen und anschließend bei $37^{\circ} \mathrm{C}$ für 30 Minuten inkubiert. Danach wurde die optische Dichte aller Proben photometrisch bei einer Wellenlänge von $562 \mathrm{~nm}$ ermittelt. Durch die Standardproteinreihe mit bekannter Proteinkonzentration und dazugehöriger optischer Dichte konnte eine Standardproteinkonzentrationsgerade ermittelt und hierüber die einzelnen Konzentrationen der Proteinlysate berechnet werden konnten.

\subsubsection{Probenvorbereitungen}

Die bei $-20^{\circ} \mathrm{C}$ gelagerten Zelllysate wurden auf Eis aufgetaut, die berechneten Volumina der Proteinlysate in ein hitzebeständiges Epicup pipettiert und mit der berechneten Menge eines 6x SDS (sodium dodecyl sulfate, dt. Natriumdodecylsulfat)-Puffers (= Lysepuffer mit Bromphenolblau versetzt $=$ Leammli-Puffer) versetzt. Im Anschluss wurden die Proben in einem $95^{\circ} \mathrm{C}$ heißen Hitzeblock für 5 Minuten denaturiert. Für Analysen von a-Syn wurde hierbei eine Proteinmenge von $20 \mu \mathrm{g}$ pro Lysat genutzt. Aufgrund der geringen p62- und LC3-Proteinmenge (v. a. LC3-II) in den Lysaten musste eine Gesamtproteinmenge von $60 \mu \mathrm{g}$ für jedes Lysat zur Analyse dieser Proteine eingesetzt werden.

\subsubsection{SDS-Polyacrylamid-Gelelektrophorese}

Bei der SDS-Polyacrylamid-Gelektrophorese (SDS-PAGE) erfolgt die Auftrennung von Proteinen entsprechend ihrem molekularen Gewicht. Durch den Zusatz von SDS werden alle Proteine negativ geladen und somit unabhängig ihrer Ladung nur nach dem Molekulargewicht separiert.

Zunächst wurden hierfür $1,5 \mathrm{~mm}$ dicke $(1,5 \mathrm{~mm}$ spacer) SDS-Polyacrylamid-Gele bestehend aus einem 15\%igem Trenngel (separating gel) und einem 5\%igem Sammelgel (stacking gel) mit 10 Kammern zur Befüllung des Western Blots hergestellt. Anschließend wurde die Elektrophorese-Kammer aufgebaut, jeweils 2 Gele pro Kammer in die vorgesehene Vorrichtung eingespannt und die Kammer entsprechend mit Elektrophoresepuffer gefüllt. In die erste Tasche des Gels wurden bei jeder Analyse $5 \mu$ l einer Proteinleiter (Dual-Color-Marker/Rainbow-Proteinmarker) eingebracht und nach Aufbereitung der Proteinproben wurden diese in die folgenden Taschen des Sammelgels einzeln pipettiert. 
Danach erfolgte die Auftrennung der Proteine bei $4^{\circ} \mathrm{C}$ im Kühlraum zunächst mit einer angelegten Spannung von $75 \mathrm{~V}$ für ca. 15 Minuten (bis die Markerfront in das Trenngel eingedrungen ist) und dann bei $100 \mathrm{~V}$ für ca. 1,5 Stunden.

\subsubsection{Proteintransfer (Blotten) auf eine Nitrozellulosemembran}

Hierbei werden die zuvor mittels Elektrophorese aufgetrennten Proteine durch ein elektrisches Feld aus dem Gel auf eine Nitrozellulosemembran transferiert. Zunächst wird die Nitrozellulosemembran für wenige Minuten in Ampuwa und im Anschluss für weitere 10 Minuten im Transferpuffer äquilibriert, um so für die Aufnahme der Proteine aus dem Gel präpariert zu sein. Ebenfalls in Transferpuffer wurden die Schwämme und Whatman-Papiere eingelegt. Danach wurde das Western Blot-System - nach Lösung des Elektrophoresegels aus den Glaskammern - in typischer schichtweiser Anordnung (s. Abb. 2.13) aufgebaut und in die Blotting-Kammer eingesetzt. Diese wurde mit einem kleinen Eiskanister zur Kühlung des Vorgangs und mit Transferpuffer befüllt, ein elektrisches Feld (1000 mA, $100 \mathrm{~V}, 150 \mathrm{~W}$ ) angelegt und für $90 \mathrm{~min}$ bei $4^{\circ} \mathrm{C}$ in einem Kühlraum die Proteine auf die Nitrozellulosemembran transferiert. Im Anschluss hieran wurde die Membran für 15 min mit TBS-T gewaschen, um Rückstande des Transferpuffers zu entfernen.

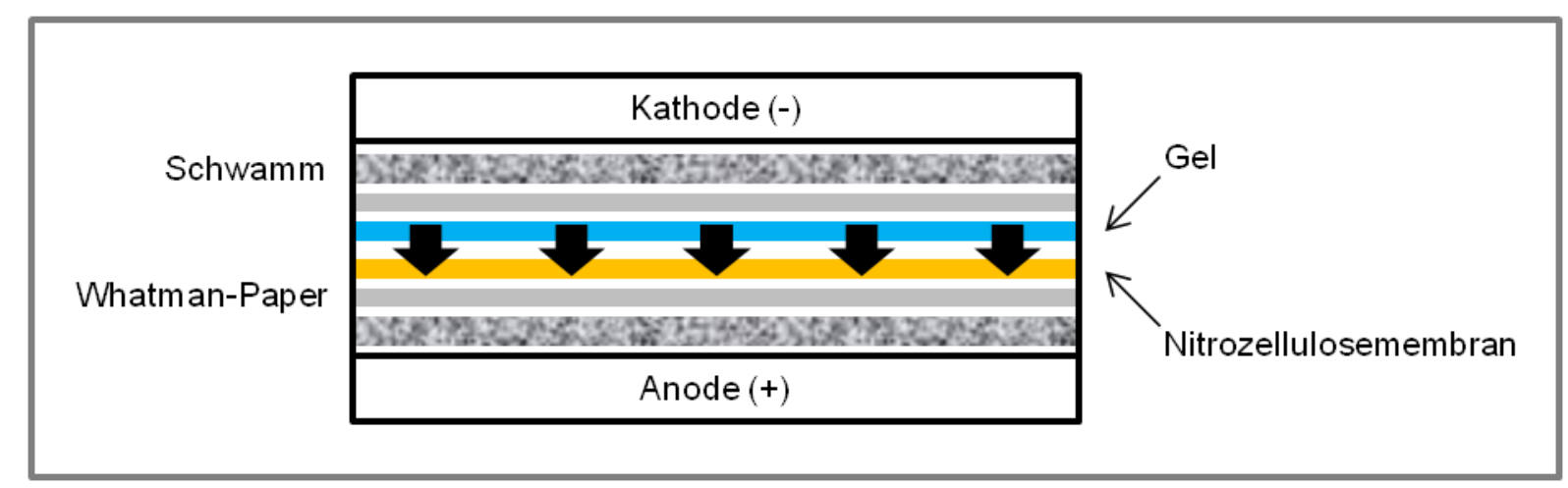

Abb. 2.13 Schematischer Aufbau der Proteintransferkammer. Blockpfeile innerhalb des schematischen Aufbaus zeigen die Richtung des Proteintransfers vom Gel auf die Nitrozellulosemembran.

\subsubsection{Immunodetektion}

Hierbei werden durch Inkubation der Nitrozellulosemembran mit spezifischen, monoklonalen Antikörpern die zu untersuchenden Proteine sichtbar gemacht.

Zunächst wurden die Protein-beinhaltenden Membranen für ca. 1 Stunde in 5\%iger Milchlösung inkubiert, um unspezifische Bindungsstellen für die eingesetzten AK zu blockieren. Dadurch konnten die gegen die Zielproteine gerichteten AK im Wesentlichen nur noch an ihr Zielprotein binden. Im Anschluss hieran wurden die Erstantikörper (AK gegen 
das Zielprotein) in einer 5\%igen Milchlösung in entsprechender Verdünnung (s. Tab. 2.3) zusammen mit der Nitrozellulosemembran bei $4^{\circ} \mathrm{C}$ über Nacht in einem $50 \mathrm{ml}$ FalconRöhrchen inkubiert. Um eine kontinuierliche Benetzung der Membran mit der AK-Lösung zu gewährleisten, erfolgte die Inkubation rotierend. Anschließend wurde die Membran dreimal für je 15 Minuten in TBS-T unter konstanter Bewegung (Kipptisch) gewaschen, um so ungebundene Rückstände des ersten Antikörpers auf der Nitrozellulosemembran zu entfernen. Danach konnte ein passend zum Erstantikörper ausgewählter sekundärer AK entsprechend in 5\%iger Milchlösung verdünnt (s. Tab. 2.3) zusammen mit der gewaschenen Membran in einem weiteren 50 ml Falcon-Röhrchen bei Raumtemperatur für 30-60 Minuten mit $30 \mathrm{rpm}$ rotierend inkubiert werden. Anschließend wurde die Nitrozellulosemembran erneut dreimal für je 15 Minuten in TBS-T gewaschen.

\begin{tabular}{|c|c|c|c|c|}
\hline & \multicolumn{2}{|c|}{ Erstantikörper } & \multicolumn{2}{|c|}{ Zweitantikörper } \\
\hline Zielprotein & Herkunft & Verdünnung & & Verdünnung \\
\hline a-Syn & \multirow{5}{*}{ Maus } & $1: 250$ & \multirow{5}{*}{ Anti-Maus-HRP } & $1: 1000$ \\
\hline LC3 & & $1: 200$ & & $1: 1000$ \\
\hline Tubulin & & $1: 1000$ & & $1: 10000$ \\
\hline GAPDH & & $1: 5000$ & & $1: 5000$ \\
\hline Aktin & & $1: 2500$ & & $1: 5000$ \\
\hline P62 & Kaninchen & $1: 5000$ & $\begin{array}{c}\text { Anti-Kaninchen- } \\
\text { HRP }\end{array}$ & $1: 1000$ \\
\hline
\end{tabular}

Tab. 2.3 Erst- und Zweitantikörperverdünnung für Protein-Immunodetektion nach Western Blot. HRP: Horseradish-Peroxidase

Abschließend wurde die Membran zusammen mit frischer ECL-Lösung für genau 60 Sekunden zwischen einer Kunststofffolie inkubiert. Die an den sekundären AK gebundene Horseradish-Peroxidase (HRP) konnte dadurch die Chemolumineszenzreaktion des in der ECL-Lösung enthaltenen Luminols katalysieren. Die dabei freiwerdende Strahlung wurde auf einem Film aufgenommen (Curix 60, AGFA, Düsseldorf, Deutschland). Diese letzten Schritte erfolgten in einem Dunkelraum.

\subsubsection{Quantifizierung der Western Blots}

Zum Vergleich der einzelnen Proteinmengen zwischen den Versuchsgruppen wurden die entwickelten Western Blot-Röntgenfilme zunächst im .jpeg-Format eingescannt und mit Hilfe der Software ImageJ die optometrische Dichte jeder einzelnen Proteinbande gemessen (Gassmann et al. 2009). 
Hierfür wurde die erste Bande rechteckig markiert (Rectangular selections) und die Auswahl fixiert (Analyze > Gels > Select First Lane). Danach wurde die Markierung auf die nächste Proteinbande gezogen und ebenfalls fixiert (Analyze $>$ Gels $>$ Select Next Lane). Dieser Vorgang wurde für sämtliche Proteinbanden wiederholt (s. Abb. 2.14 (a)). Anschließend wurden die so markierten Banden als Graph dargestellt (Analyze > Gels > Plot Lanes) und an diesen Graphen der Hintergrund durch eine waagerechte Linie im Bereich der Bande eingezeichnet (s. Abb. 2.14 (b)), sodass im nächsten Schritt die Berechnung der Bandenintensität (Anwendung des „Wand (tracing) tool“ in der Graphik) lediglich die rein durch das Protein verursachte Erhöhung der Intensität berücksichtigte. Die so gewonnenen Zahlenwerte der optometrischen Dichte wurden in eine Excel-Tabelle übertragen (s. Abb. 2.14 (c)). Für jeden Western Blot wurden auch die Proteinmengen der Tubulin-, GAPDH- oder Actin-Banden jeder Probe, die als Marker für die möglichst gleiche eingesetzte Proteinmenge zwischen den einzelnen Versuchsgruppen diente, gemessen. Dadurch konnten rechnerisch in allen Versuchsgruppen gleiche Proteinmengen erzielt und minimale Ungenauigkeiten bei der Probenbeladung des Elektrophoresegels korrigiert werden.
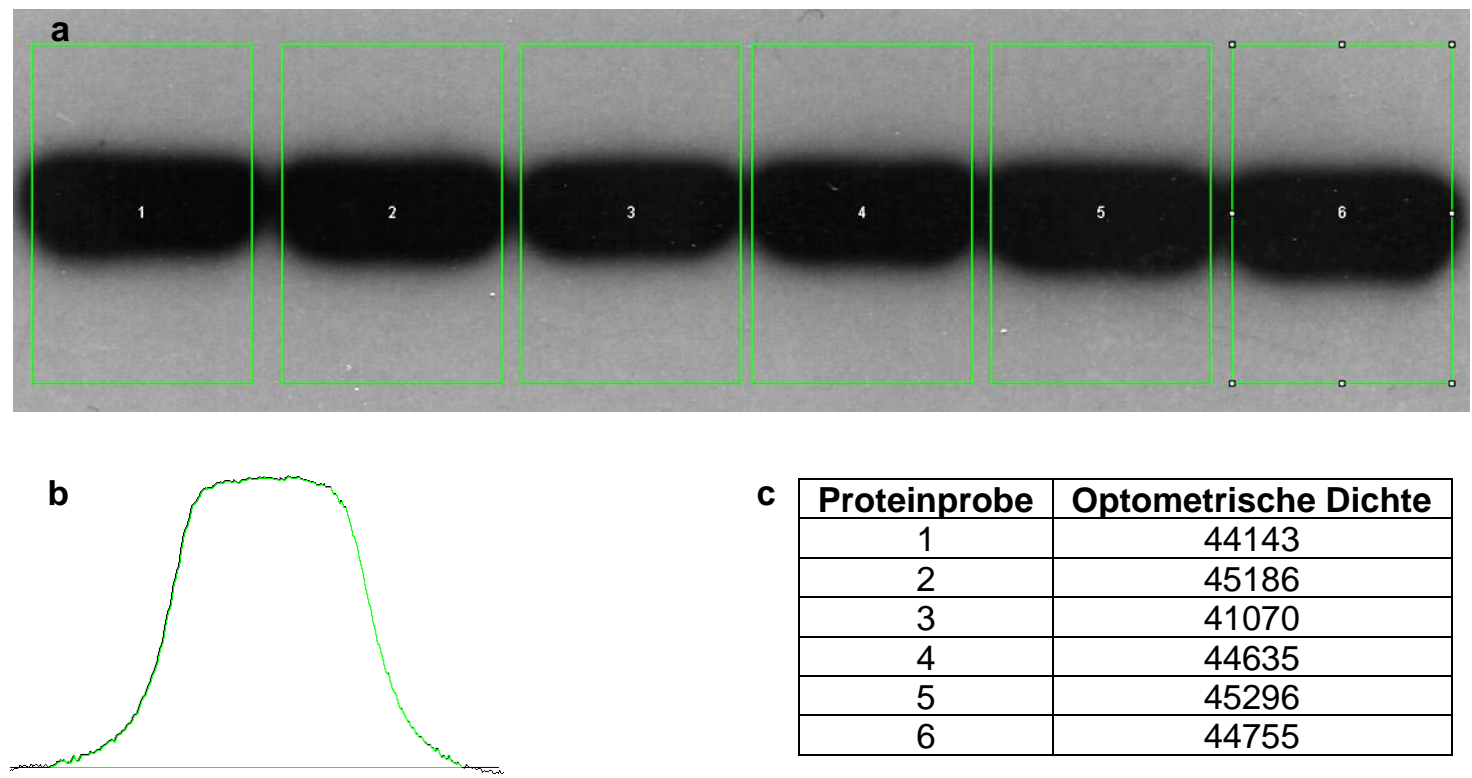

C

\begin{tabular}{|c|c|}
\hline Proteinprobe & Optometrische Dichte \\
\hline 1 & 44143 \\
\hline 2 & 45186 \\
\hline 3 & 41070 \\
\hline 4 & 44635 \\
\hline 5 & 45296 \\
\hline 6 & 44755 \\
\hline
\end{tabular}

Abb. $\quad 2.14 \quad$ Darstellung der Proteinquantifizierung der Western Blots. (a) Markierung der Western Blot-Banden; (b) graphische Darstellung der optometrischen Dichte einer Proteinbande; (c) ermittelte Werte der optometrischen Dichte (in a. u.) der Proteinbanden 1-6 aus (a). Es zeigen sich sowohl visuell als auch in der Messung nahezu identische Werte der optometrischen Dichte aller Versuchsgruppen, was wiederum einer annähernd gleichen Proteinmenge entspricht. Aber auch die visuell marginal sichtbar geringere Proteinmenge in Probe 3 wird anhand der Bestimmung der optometrischen Dichte erkenntlich. 


\subsection{Statistische Auswertung}

Zur statistischen Auswertung der einzelnen Versuche wurde das Programm KyPlot genutzt. In Rücksprache mit der Medizinischen Statistik der Universität Göttingen konnte bei allen Versuchen zunächst eine einfache ANOVA durchgeführt werden, um zu prüfen, ob zwischen den unterschiedlichen Versuchsgruppen ein signifikanter Unterschied zwischen den Mittelwerten bestand, ohne dabei jedoch eine Aussage zu treffen zwischen welchen Gruppen der Unterschied existierte. Ergab sich bei der einfachen ANOVA ein signifikanter Unterschied, wurden anschließend die Versuchsgruppen untereinander mittels TukeyKramer oder Dunnett-Post-hoc-Test auf Signifikanz geprüft, um herauszufinden welche Gruppen zueinander signifikante Unterschiede der bestimmten Messgrößen aufwiesen. Wann welcher Test eingesetzt wurde, ist dem Fließtext und den graphischen Darstellungen im Ergebnisteil zu entnehmen. Der Signifikanzvergleich bei lediglich 2 Versuchsgruppen erfolgte mittels Students t-Test. 


\section{$3 \quad$ Ergebnisse}

\subsection{Expression von humanem $\alpha-S y n u c l e i n$ in-vitro}

\subsubsection{Quantitative $\alpha$-Synuclein-Expression im Western Blot}

Für sämtliche Versuchsreihen und Analysen wurde eine stabile Expression von humanem $\alpha-S y n$ in seinen verschiedenen Varianten in primären embryonalen Mittelhirnneuronen benötigt. Hierfür wurden die Neurone mittels Nukleofektion (s. auch 2.2.3) mit den jeweiligen $\alpha$-Syn-Plasmiden, welche humanes $\alpha$-Syn in seiner Wildtyp-Form sowie den Parkinson-relevanten Mutationen A30P und A53T exprimierten, transfiziert (s. auch 2.1.8).

Zunächst erfolgte die alleinige Darstellung des humanen $\alpha$-Syns mittels eines humanspezifischen AKs (Invitrogen, Karlsruhe, Deutschland) zur Kontrolle der Nukleofektion und Plasmidfunktion/Proteinexpression des humanen $\alpha$-Syns. Es zeigte sich eine deutliche Expression der humanen $\alpha$-Syn-Varianten sowie erwartungsgemäß eine fehlende Proteinbiosynthese in der nur mit dem eGFP-Kontrollplasmid in äquivalenter Menge transfizierten Kontrollgruppe (s. Abb. 3.1 (A)).

Anschließend wurde die Abhängigkeit der Proteinexpression von der bei der Transfektion eingesetzten DNA-Menge mit unterschiedlichen Mengen an a-Synexprimierendem Plasmid untersucht. Hierfür wurde $\alpha$-Syn in Western Blots aus Zelllysaten der primären Mittelhirnzellkulturen durch einen Spezies-unspezifischen AK (BD Biosciences, Heidelberg, Deutschland), welcher sowohl das intrinsische Ratten- $\alpha-S y n$ als auch das vom Plasmid codierte humane $\alpha$-Syn (=Pan- $\alpha-S y n)$ bindet, detektiert. Es zeigte sich eine signifikante Erhöhung der $\alpha$-Syn-Gesamtproteinmenge auf das 1,39 $\pm 0,024$-Fache bei $2 \mu \mathrm{g}$ eingesetztem $\alpha$-Syn-WT-Plasmid ( $p=0,039$, One-Way ANOVA gefolgt von Tukey-KramerPost-hoc-Test) und auf das 1,70 $\pm 0,00054$-Fache bei $4 \mu \mathrm{g}(p=0,00050)$ im Vergleich zur Kontrollgruppe. Die Differenz zur Gesamtproteinmenge der eGFP-Kontrolle entspricht dem exprimierten humanen $\alpha$-Syn. Der Unterschied zwischen $2 \mu \mathrm{g}$ und $4 \mu \mathrm{g}$ eingesetzter Plasmidmenge entsprach ca. einer Verdopplung des exprimierten humanen $\alpha$-Syns (relative Differenzsteigerung von 0,38 [2 $\mu \mathrm{g}]$ auf $0,7[4 \mu \mathrm{g}]$ ) und stelle sich auch signifikant $(p=0,0011)$ dar (s. Abb. $3.1(B))$.

Bei der Quantifizierung der Überexpression mit der für alle Versuche genutzten Standardplasmidmenge für $\alpha$-Syn von $3 \mu \mathrm{g}$ konnte eine durchschnittlich 2,11-fach erhöhte Menge an $\alpha-S y n(\mathrm{WT}: 1,88 \pm 0,2$; A30P: 2,38 \pm 0,36; A53T: 2,08 $\pm 0,09$ ) in den transfizierten Versuchsgruppen im Vergleich zur eGFP-Kontrollgruppe ermittelt werden. Hierbei zeigte sich in allen $\alpha$-Syn-transfizierten Gruppen eine signifikante Erhöhung (WT: $p=0,012$, A30P: $p=0,0019$, A53T: $p=0,0038$ zu eGFP, One-Way ANOVA gefolgt von Tukey-KramerPost-hoc-Test) zur eGFP-Kontrolle (s. Abb. 3.1 (C)). Innerhalb der a-Syn-Versuchsgruppen 

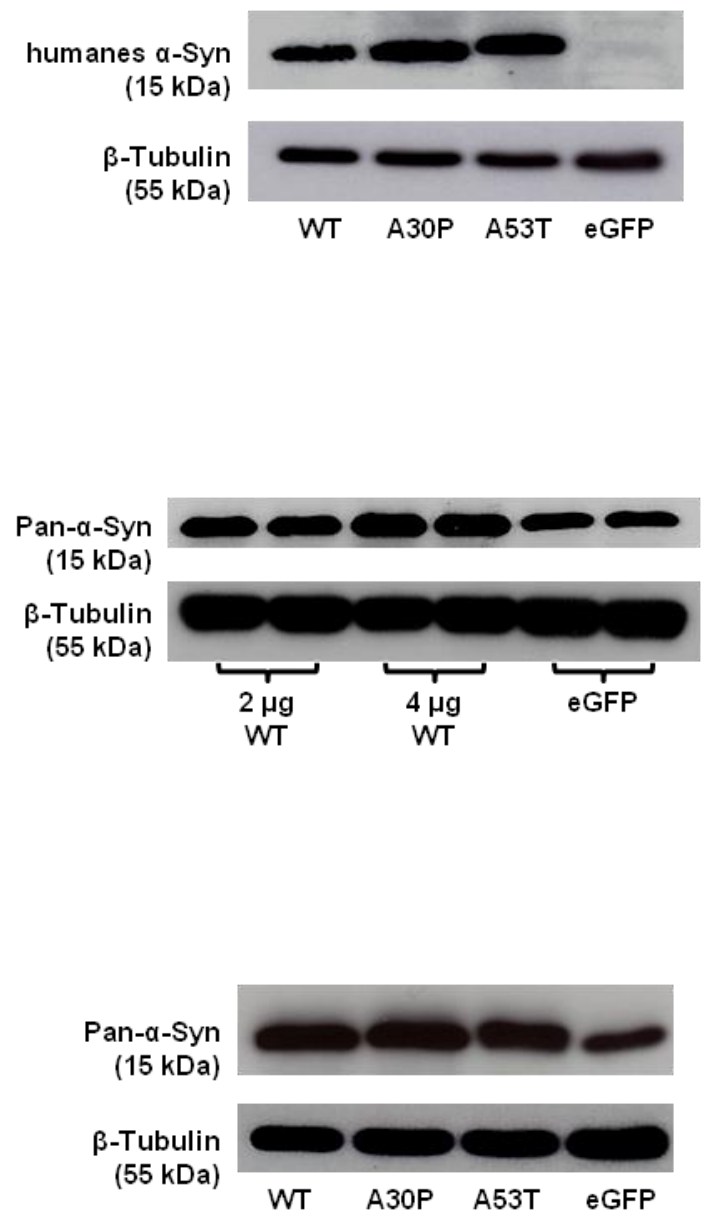

A
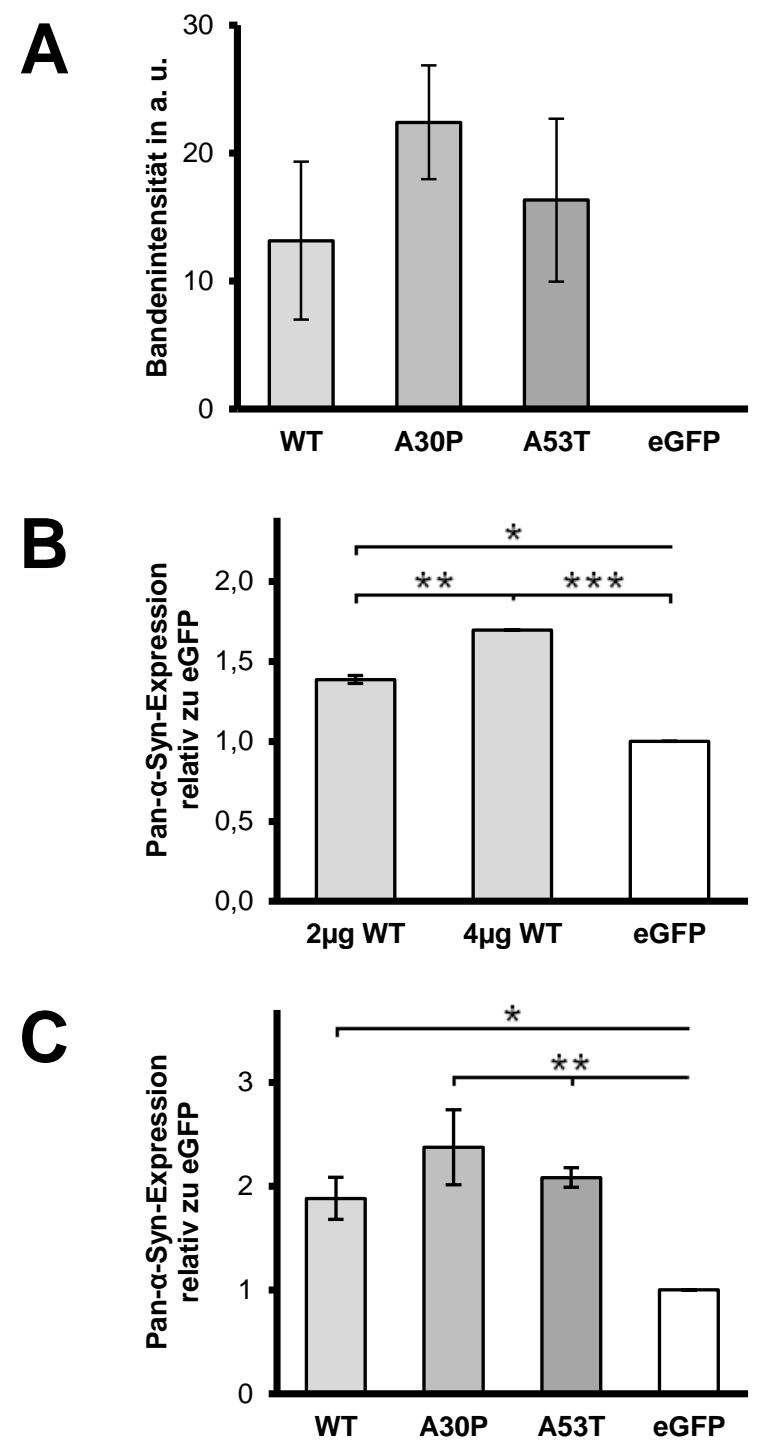

Abb. 3.1 Expression von humanem $\alpha-S y n$ oder Pan- $\alpha-S y n$ nach Transfektion mit Plasmiden, die die humanen $\alpha-S y n-V a r i a n t e n$ WT, A30P und A53T exprimieren im Vergleich zur eGFP-Kontrollgruppe in-vitro. (A) Links: Exemplarischer Western Blot der Expression von humanem $\alpha$-Syn. Erwartungsgemäß zeigt sich keine Expression in der eGFP-Kontrollgruppe. Rechts: Quantifizierung der Bandenintensität des exprimierten humanen $\alpha$-Syns im Western Blot. Es fanden sich keine signifikanten Unterschiede zwischen den a-Syn-Gruppen nach Transfektion der verschiedenen Plasmide. (B) Links: Exemplarischer Western Blot der Plasmidmengen-abhängigen $\alpha$-Syn-Überexpression (Pan- $\alpha-S y n)$. Bereits visuell ist eine Steigerung der Pan-a-Syn-Expression abhängig von der eingesetzten Plasmidmenge zu sehen. Rechts: Quantifizierung der Plasmidmengen-abhängigen Pan- $\alpha$-Syn-Überexpression in Relation zur eGFP-Kontrolle. Es zeigt sich eine signifikante Steigerung der Gesamtexpression von $\alpha$-Syn nach Transfektion mit $\alpha$-Syn-WT-exprimierendem Plasmid, wobei eine Steigerung der Plasmidmenge auch eine weitere, signifikante Erhöhung bewirkt. (C) Links: Exemplarischer Western Blot der $\alpha$-Syn-Überexpression (Pan- $\alpha-S y n)$ nach Transfektion mit $3 \mu \mathrm{g}$ der verschiedenen $\alpha$-Syn-Plasmide im Vergleich zur Kontrolle. Es zeigt sich eine relativ homogene Überexpression in den a-Syn-Versuchsgruppen. Rechts: Quantifizierung der a-Syn-Überexpression in den a-Syn-transfizierten Versuchsgruppen relativ zur eGFP-Kontrolle. Es zeigt sich eine durchschnittlich 2-fache Erhöhung der a-Syn-Gesamtexpression in den a-Syn-transfizierten Gruppen, zwischen denen selbst sich kein signifikanter Unterschied ergab. Primäre Mittelhirnneurone, DIV5, $\mathrm{n}=3$ (A und $C$ ), 2 (B) unabhängige Zellkulturen. a. u. (in $\mathrm{A})=$ arbitrary units (dt. willkürliche Einheit), Fehlerbalken: Standardfehler des Mittelwertes, ${ }^{*}: p<0,05,{ }^{* *}: p<0,01,{ }^{* \star *}: p<0,001$ in One-Way ANOVA gefolgt von Tukey-Kramer-Post-hocTest. 


\subsubsection{Immunzytochemische Kontrolle der $\alpha$-Synuclein-Transfektion}

Mittels immunzytochemischer Färbung der mit $\alpha$-Syn-Plasmiden transfizierten Neurone konnte die Expression von humanem a-Syn qualitativ demonstriert werden. Die folgenden Bilder zeigen die Co-Expression von eGFP und humanem $\alpha$-Syn in primären Mittelhirnneuronen nach Nukleofektion. Zu beachten ist die fehlende Expression in der Kontrollgruppe, welche allein mit $5 \mu \mathrm{g}$ eGFP-Plasmid transfiziert wurde und somit erwartungsgemäß kein humanes a-Syn exprimierte (s. Abb. 3.2).
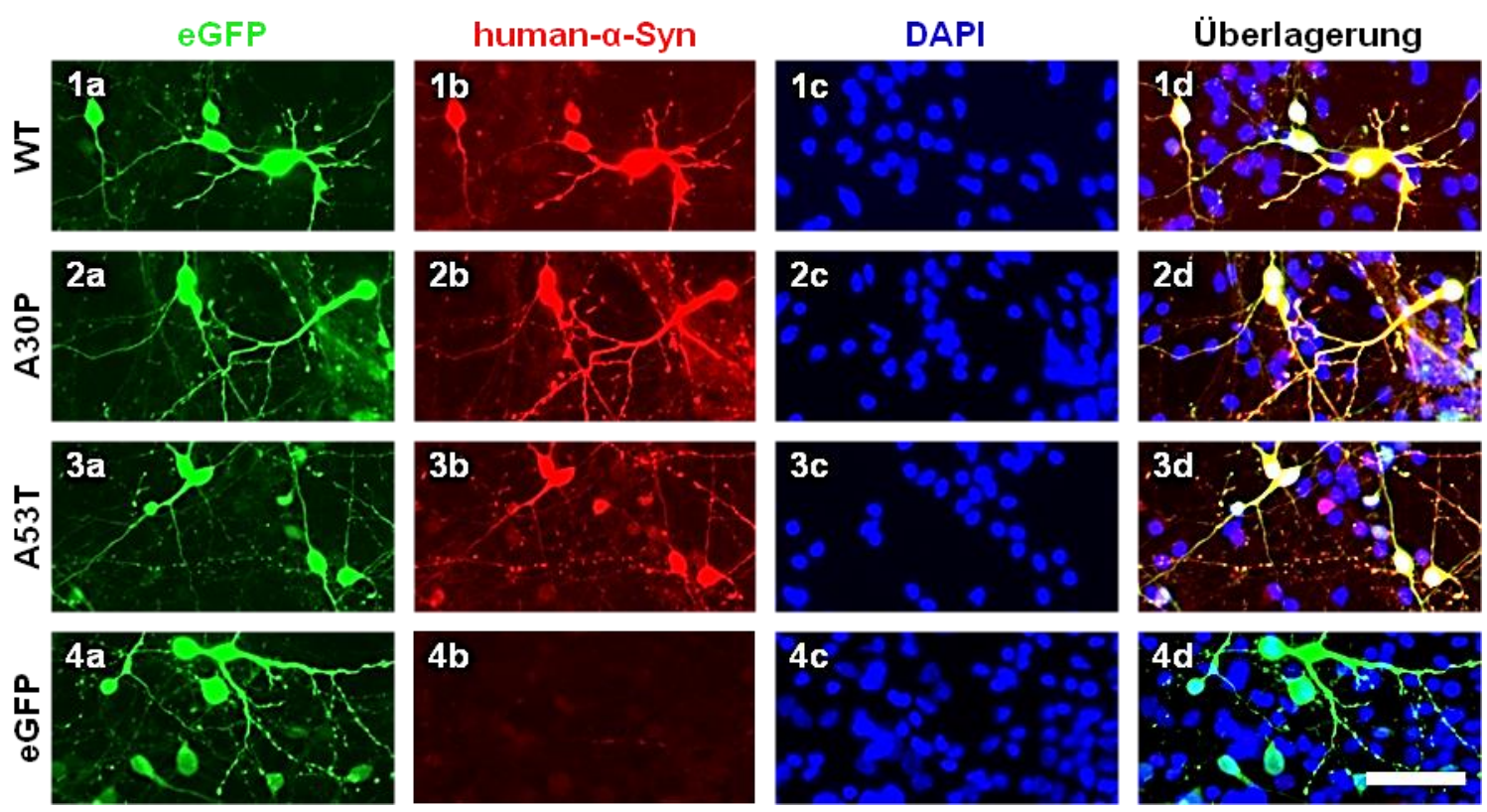

Abb. $\quad 3.2 \quad$ Posttransfektionelle Expression von humanem $\alpha$-Synuclein und eGFP in Immunzytochemie. (a) eGFP-Fluoreszenz, (b) human- - -Syn-Färbung, (c) DAPI-Zellkernfärbung, (d) Überlagerung; 1(a-d) a-Syn-WT, 2(a-d) a-Syn-A30P, 3(a-d) a-Syn-A53T, 4(a-d) eGFP-Kontrollgruppe. Es zeigt sich deutlich die alleinige Expression des humanen $\alpha$-Syns in den mit $\alpha$-Syn- und eGFP-Plasmiden co-transfizierten Zellen, wohingegen in der eGFP-Kontrollgruppe erwartungsgemäß kein human- $\alpha-S y n$ nachgewiesen werden konnte. Primäre Mittelhirnneurone, DIV5, Maßbalken: $50 \mu \mathrm{m}, 20 x-O b j e k t i v$ (Ausschnitt).

Des Weiteren konnte hierbei die Co-Transfektion der Mittelhirnneurone mit dem eGFP-Plasmid, dessen Expressionsprodukt eGFP als Marker für die erfolgreiche Transfektion einer Zelle dienen sollte, und dem $\alpha$-Syn-Plasmid gezeigt werden. Dabei zeigte sich bei der Auswertung von 18 Gesichtsfeldern in 20x-Vergrößerung aus 3 unabhängigen Zellkulturen für den a-Syn-WT eine Co-Transfektionsrate mit EGFP von 98,34 \pm 0,54\%, für die A30P-Mutation von 99,18 $\pm 0,26 \%$ und für die A53T-Mutation von 98,92 \pm 0,38\%, sodass davon auszugehen war, dass eine eGFP-exprimierende Zelle ebenfalls das humane a-Syn produziert und somit eGFP als alleiniger Marker für die gelungene Co-Transfektion dienen kann (s. Abb. 3.3). Dies bestätigte im Wesentlichen auch die vom Hersteller des Transfektionssystems (Lonza, Basel, Schweiz) getroffene Aussage einer 100\%igen Co- 
Transfektionsrate. Zur Darstellung des humanen a-Syns wurde hierbei erneut ein spezifisch gegen das humane $\alpha$-Syn gerichteter AK benutzt.

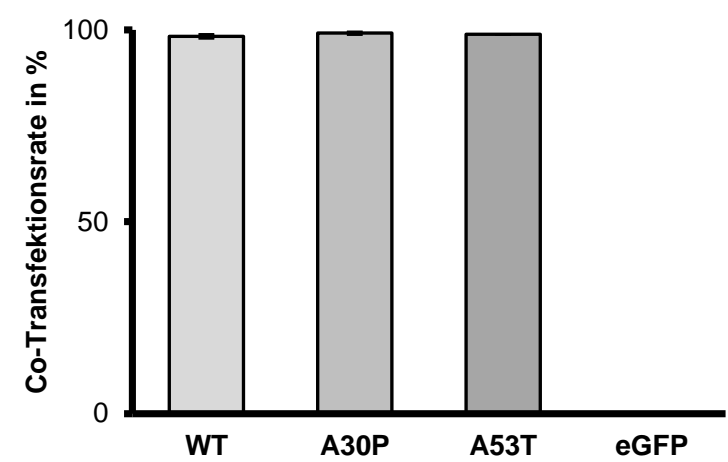

Abb. $\quad 3.3 \quad$ Quantifizierung der Co-Expression von humanem $\alpha$-Synuclein und eGFP in der Gesamtzellkultur nach Plasmid-Transfektion. Es zeigt sich eine annähernd $100 \%$ ige Co-Expression (WT: 98,34\%, A30P: 99,18\%, A53T: 98,92\%) von eGFP und humanem a-Syn in den mit human-a-Syn- und eGFP-Plasmid co-transfizierten Gruppen im Vergleich zur eGFP-Kontrollgruppe, die allein mit 5 ug eGFPPlasmid transfiziert wurde. Primäre Mittelhirnneurone, DIV5, $n=18$ Gesichtsfelder in 10x-Vergrößerung aus 3 unabhängigen Zellkulturen, Fehlerbalken: Standardfehler des Mittelwertes.

Beispielhaft hierfür soll der Vergleich zwischen einem mit $\alpha$-Syn-WT (3 $\mu \mathrm{g}$ Plasmid) und eGFP ( $2 \mu \mathrm{g}$ Plasmid) co-transfizierten und einem mit $5 \mu \mathrm{g}$ eGFP-Plasmid transfizierten und als Kontrolle dienenden dopaminergen Neuron gezeigt werden (s. Abb. 3.4). Gleiches wurde auch für die a-Syn-Mutationen festgestellt. Auch hierbei zeigte sich, dass eGFPtransfizierte dopaminerge Neurone das co-transfizierte a-Syn exprimierten (s. auch Abb. 3.2).
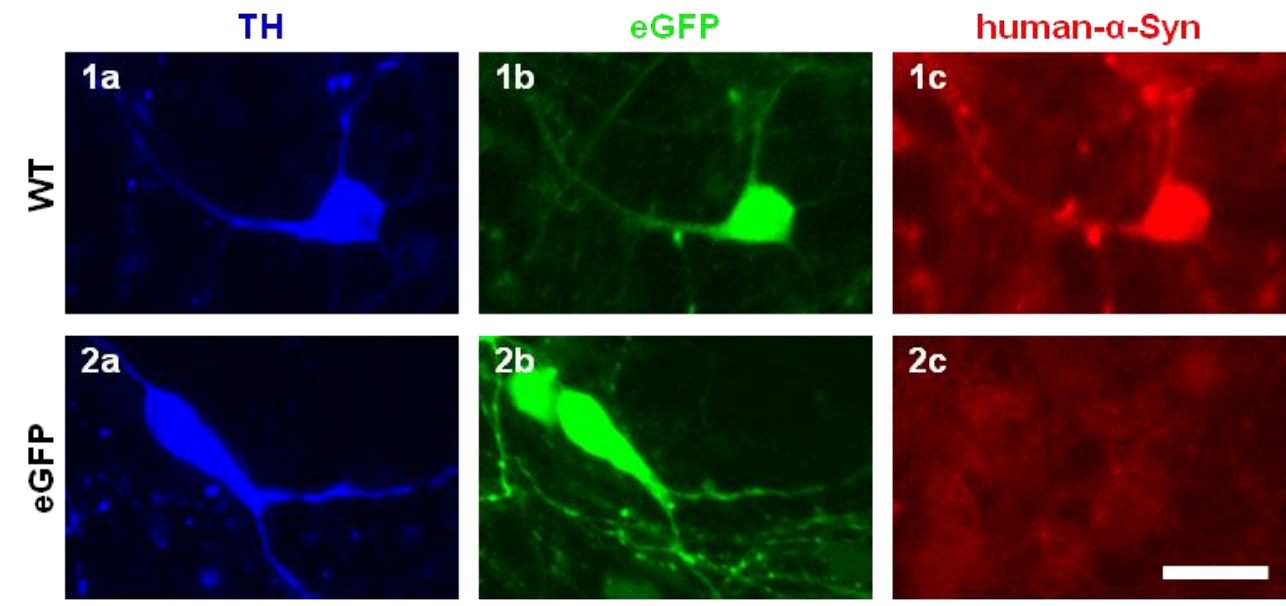

Abb. $\quad 3.4 \quad$ Co-Transfektion und Expression von humanem $\alpha$-Synuclein und eGFP in immunzyto-

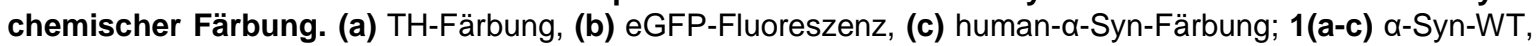
2(a-c) eGFP-Kontrollgruppe. Primäre dopaminerge Mittelhirnneurone, Maßbalken: $20 \mu \mathrm{m}, 20 x-O b j e k t i v$. 


\subsection{Makroautophagie in primären Mittelhirnneuronen}

\subsection{1 p62 (SQSTM1)}

p62 ist ein zytoplasmatisch lokalisiertes Protein, welches physiologisch an der intrazellulären Degradation strukturell geschädigter und in ihrer Funktion gestörter Zellproteine beteiligt ist (s. auch 1.3.1.2). Es vermittelt über eine Interaktion mit LC3 die Aufnahme abzubauender Proteine in Autophagosomen, in denen im weiteren Verlauf der intrazelluläre Abbau der aufgenommenen Proteine aber auch von p62 selbst stattfindet. Veränderungen der p62-Proteinmenge können demzufolge Funktionsänderungen der Autophagie, insbesondere der Makroautophagie, aufzeigen. Es erfolgte daher zunächst die quantitative Bestimmung der p62-Proteinmenge mittels Western Blot der (co-)transfizierten Zellkulturen (s. Abb. 3.5). Die alleinige Transfektion mit eGFP diente als Kontrollgruppe.

Es wurden insgesamt 3 voneinander unabhängige Zellkulturen zur Analyse der p62-

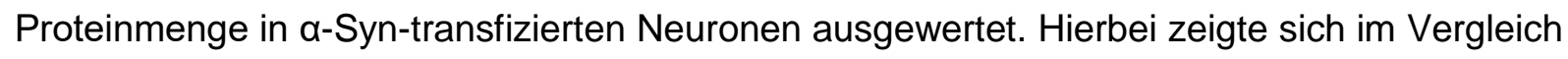
zur eGFP-Kontrollgruppe eine signifikante Reduktion der relativ zur Kontrollgruppe gemessenen Proteinmenge aller a-Syn-transfizierten Versuchsgruppen auf das $0,48 \pm 0,19$-Fache für den $\alpha-S y n-W T(p=0,029$ zu eGFP, One-Way ANOVA gefolgt von Dunnett-Post-hoc-Test), $0,51 \pm 0,06$-Fache für die A30P-Mutation $(p=0,036)$ und für die A53T-Mutation auf das $0,54 \pm 0,11$-Fache $(p=0,049)$. Zwischen den $\alpha$-Syn-Varianten konnte kein signifikanter Unterschied festgestellt werden (s. Abb. 3.5).

A
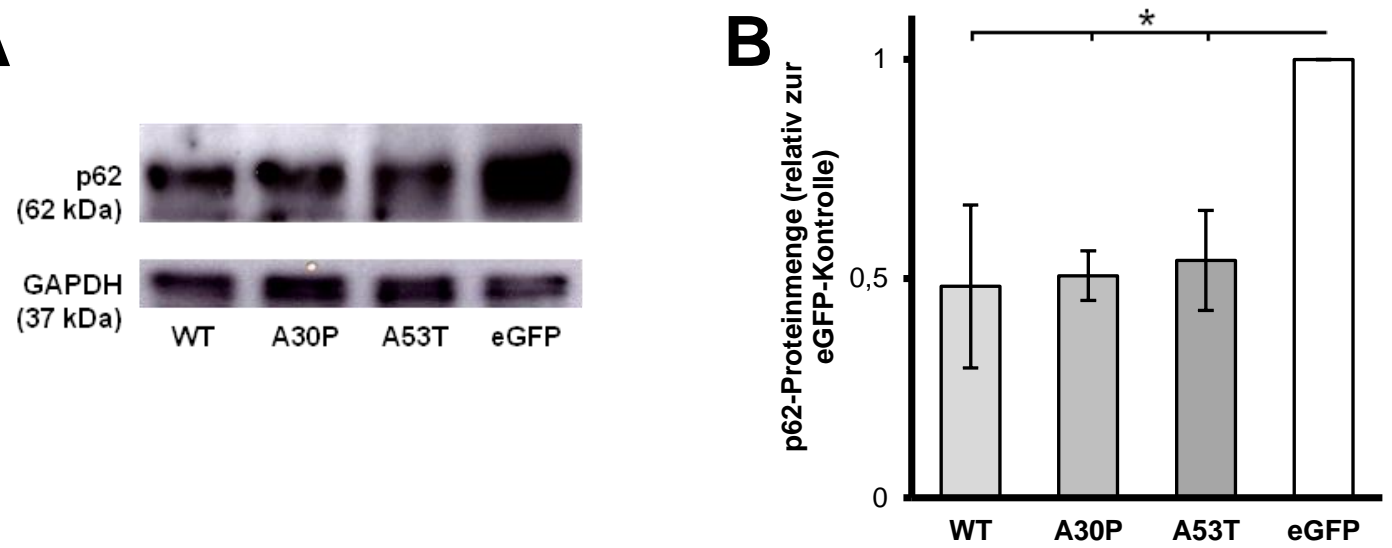

Abb. $\quad 3.5 \quad$ p62-Expression nach Transfektion mit $\alpha$-Synuclein relativ zur eGFP-Kontrollgruppe im Western Blot. (A) Beispielhafter Western Blot der p-62-Proteinmenge. Es ist eine Reduktion der p62Proteinmenge in den mit $\alpha$-Syn-transfizierten Versuchsgruppen zu erkennen. (B) Quantifizierung der p62Proteinmenge. Es zeigt sich eine signifikante Reduktion der p62-Proteinmenge in den mit $\alpha$-Syn-Plasmiden transfizierten Versuchsgruppen in Relation zur eGFP-Kontrollgruppe. Primäre Mittelhirnneurone, DIV5, $n=3$ unabhängige Zellkulturen, Fehlerbalken: Standardfehler des Mittelwertes, ${ }^{*}: p<0,05$ in One-Way ANOVA gefolgt von Dunnett-Post-hoc-Test. 
Ergebnisse

\subsubsection{Analyse des Autophagie-Flusses im Western Blot}

\subsubsection{Veränderungen von LC3 im Western Blot ohne Bafilomycin $A_{1}$ - Behandlung}

Um den Einfluss von a-Syn-WT und den Mutationsformen auf die Autophagie zu beurteilen, wurden die Expressionsmengen der Proteine LC3-I und LC3-II, die als Marker der Makroautophagie dienen, untersucht (s. auch 1.3.1). Hierbei wurde nach Herstellung der Zelllysate aus transfizierten primären Mittelhirnneuronen eine quantitative Messung der Proteinmengen im Western Blot durchgeführt und analysiert. Es zeigten sich die typischen Banden für LC3-I bei ca. 18 kDa und für LC3-II bei 16 kDa (s. Abb. 3.6 (A)).

Hierbei ergaben sich im Rahmen der Quantifizierung von 3 unabhängigen Western Blots keine signifikanten Unterschiede ( $p=0,25$ in One-Way ANOVA) der relativ zur Kontrollgruppe gemessenen LC3-I-Proteinmengen des a-Syn-WT von 0,64 0,2-fach, der A30P-Mutation von 0,79 \pm 0,10-fach und der A53T-Mutation von 0,85 \pm 0,09-fach, auch wenn eine geringe Reduktion insbesondere der a-Syn-WT-Versuchsgruppe zu verzeichnen war.

Es zeigten sich aber signifikant reduzierte LC3-II-Proteinmengen im Vergleich zur eGFP-Kontrollgruppe mit einer Reduktion der LC3-II-Menge auf das 0,13 \pm 0,06-Fache in Relation zur eGFP-Kontrollgruppe für den WT $\left(p=7,04 \times 10^{-6}\right.$ zu eGFP, One-Way ANOVA gefolgt von Tukey-Kramer-Post-hoc-Test), das 0,25 \pm 0,03-Fache für die A30P-Mutation $\left(p=2,50 \times 10^{-5}\right)$ und das $0,39 \pm 0,11$-Fache für die A53T-Mutation $(p=0,00017)$.

Aufgrund des stark reduzierten LC3-II bei im Wesentlichen gleichen LC3-IProteinmengen konnte ein deutlich reduzierter LC3-II/LC3-I-Quotient der $\alpha$-Syn-transfizierten Zellen im Vergleich zur eGFP-Kontrollgruppe ermittelt werden. Durch die Umwandlung von LC3-I zu LC3-II im Rahmen der Autophagie spricht ein erniedrigter Wert für einen beschleunigten Aufbau von Autophagosomen. Dabei zeigte sich der LC3-II/LC3-I-Quotient des a-Syn-WTs mit einem Mittelwert von 0,14 \pm 0,04 am stärksten reduziert und wies somit eine signifikante Reduktion gegenüber der eGFP-Kontrolle mit einem LC3-II/LC3-IQuotienten von $0,71 \pm 0,11$ ( $\mathrm{p}=0,0019$ zu eGFP, One-Way ANOVA gefolgt von TukeyKramer-Post-hoc-Test) auf. Die A30P-Mutation wies ebenso einen signifikant reduzierten Quotienten von 0,23 $\pm 0,04(p=0,0066)$ wie die A53T-Mutation von 0,33 $\pm 0,11(p=0,029)$ gegenüber der Kontrollgruppe auf. Innerhalb der einzelnen $\alpha$-Syn-transfizierten Versuchsgruppen ergaben sich trotz tendenzieller Unterschiede keine signifikanten Differenzen (s. Abb. 3.6 (B-D)). Dennoch kann hierüber keine valide Aussage über den Funktionsstatus der Autophagie erhoben werden, da hierfür der Vergleich mit Autophagie-blockierten Versuchsgruppen erfolgen muss, um die Dynamik in diesem Prozess abzubilden (s. auch 1.3.1.3). 
A
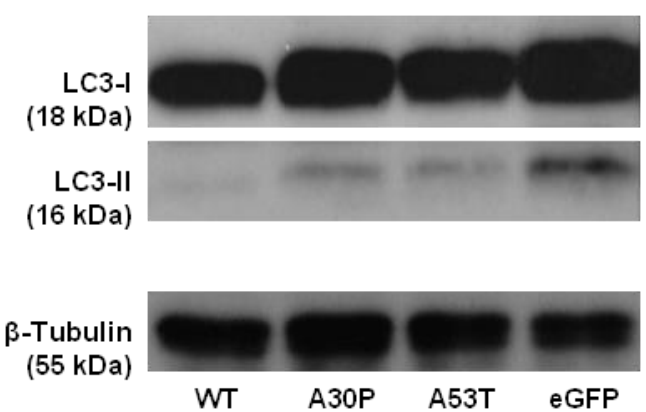

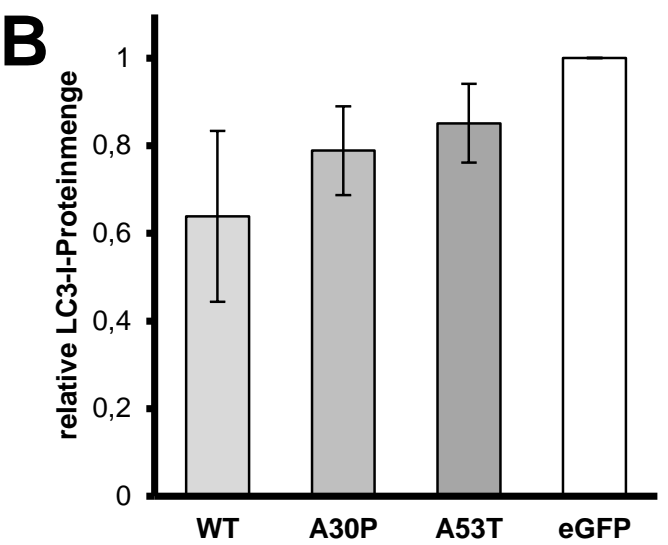

D

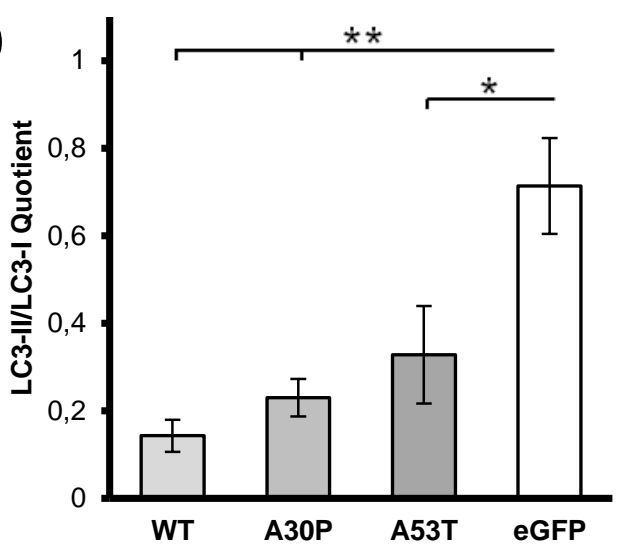

Abb. $\quad 3.6 \quad$ LC3-Expression nach Transfektion mit $\alpha$-Synuclein relativ zur eGFP-Kontrollgruppe im Western Blot. (A) Beispielhafter Western Blot der LC3-Proteinmengen. Es ist eine annähernd konstante LC3-I-Proteinmenge bei ausgeprägter LC3-II-Reduktion in den a-Syn-transfizierten Versuchsgruppen im Vergleich zur eGFP-Kontrolle zu erkennen. (B, C und D) Quantifizierung der LC3-I- und -II-Proteinmenge sowie des LC3-II/LC3-I-Quotienten. Es ergaben sich keine signifikanten Unterschiede in der LC3-I-Expression bei signifikanter Reduktion der LC3-II-Proteinmenge. Hieraus resultierte ein signifikant reduzierter LC3-II/LC3I-Quotient in den $\alpha$-Syn-transfizierten Versuchsgruppen. Primäre Mittelhirnneurone, DIV5, $\mathrm{n}=3$ unabhängige Zellkulturen, Fehlerbalken: Standardfehler des Mittelwertes, ${ }^{*}: p<0,05,{ }^{* *}: p<0,01,{ }^{* * *}: p<0,001$ in OneWay ANOVA gefolgt von Tukey-Kramer-Post-hoc-Test.

Die bisher dargestellten Ergebnisse wären mit einer gesteigerten Makroautophagie nach Transfektion mit $\alpha$-Syn-Plasmiden vereinbar, da die erniedrigte LC3-II-Proteinmenge in Verbindung mit dem dadurch erniedrigten Quotienten aus LC3-II und LC3-I und zusätzlich die erniedrigte Menge an p62, welches im Rahmen der Makroautophagie abgebaut wird, dafür sprechen.

Dennoch können die reduzierten Mengen der gemessenen Proteine auch in einem unterschiedlich schnellem Auf- und Abbau LC3-II-positiver Autophagosomen, ohne dabei die weiteren Schritte einschließlich der lysosomalen Degradation abzubilden, begründet sein. Um dies zu untersuchen und dadurch weitere Rückschlüsse auf die Funktionalität der Makroautophagie innerhalb der unterschiedlich transfizierten Versuchsgruppen zu erhalten, war es nötig, die Neurone mit dem Makroautophagie-Inhibitor Bafilomycin $A_{1}$ (s. auch 1.3.1.3) zu behandeln. Dadurch wird die Verschmelzung der Autophagosomen mit Lysosomen zum Autolysosom blockiert und die tatsächlich vorhandenen LC3-Proteinmengen können 
unabhängig von den dynamischen Degradationsprozessen durch lysosomale Enzyme gemessen werden.

\subsubsection{Vorversuche zur Ermittlung der optimalen Bafilomycin A1-Dosis}

Durch die Behandlung der primären Mittelhirnneurone mit $1 \mathrm{nM}$ Bafilomycin $\mathrm{A}_{1}$ für 6 Stunden direkt vor der Herstellung eines Zelllysats zur Western Blot-Analyse respektive vor der Fixierung zur immunzytochemischen Färbung wird die Makroautophagie am Endpunkt, der Fusion mit dem Lysosom und die lysosomale Enzymfunktion, blockiert. Dadurch ist es möglich, die LC3-Proteinmengen in Bafilomycin $A_{1}$ behandelten und unbehandelten Proben zu vergleichen und die Auswirkung von a-Syn auf die Makroautophagie weiter zu charakterisieren.

Da Bafilomycin $A_{1}$ selbst einen toxischen Effekt auf die Zellen ausüben kann, zum einen durch die blockierte Autophagie, zum anderen durch mögliche direkte toxische Effekte, galt es vor der Behandlung die richtige Menge an Bafilomycin $A_{1}$ herauszufinden. Dabei musste ein Optimum von ausreichender Wirkung und möglichst geringer Toxizität gefunden werden. Hierfür wurden mit $\alpha$-Syn-WT-transfizierte primäre Mittelhirnneurone mit unterschiedlichen Mengen Bafilomycin $A_{1}$ behandelt und hiernach zum einen die Wirkung auf die LC3-Proteinmengen im Western Blot dargestellt und quantifiziert (s. Abb. 3.7 (A-D)) und zum anderen in immunzytochemischer Färbung der prozentuale Anteil an abgestorbenen Zellen festgestellt (s. Abb. 3.7 (E)), um einen Hinweis auf die Toxizität zu erhalten.

Es zeigte sich hierbei ein geringer Anstieg des LC3-I in den mit Bafilomycin $A_{1}$ behandelten Versuchsgruppen im Vergleich zur unbehandelten Kontrollgruppe. Dabei stieg die LC3-I-Proteinmenge der mit $1 \mathrm{nM}$ Bafilomycin $A_{1}$ behandelten Neurone auf das 1,48Fache, bei $10 \mathrm{nM}$ auf das 2,12-Fache und bei $50 \mathrm{nM}$ auf das 1,47-Fache der LC3-IProteinmenge der unbehandelten Kontrollgruppe an (s. Abb. 3.7 (B)).

Die LC3-II-Proteinmenge kumulierte erwartungsgemäß aufgrund der fehlenden Fusion der Autophagosomen mit Lysosomen und der damit fehlenden Proteindegradation besonders ausgeprägt, sodass sich für mit $1 \mathrm{nM}$ Bafilomycin $A_{1}$ behandelte Neurone eine Erhöhung auf das 13,55-Fache, für $10 \mathrm{nM}$ Bafilomycin $\mathrm{A}_{1}$ auf das 14,80-Fache und für $50 \mathrm{nM}$ eine 9,38-Fache Steigerung im Vergleich zur unbehandelten Kontrollgruppe ergab (s. Abb. $3.7(\mathrm{C})$ ).

Dadurch konnte auch ein exponentiell erhöhter LC3-II/LC3-I-Quotient festgestellt werden, der für die $1 \mathrm{nM}$ Versuchsgruppe 9,18-fach, für $10 \mathrm{nM} \mathrm{6,99-fach} \mathrm{und} \mathrm{für} 50 \mathrm{nM}$ 6,34fach im Vergleich zur unbehandelten Versuchsgruppe betrug (s. Abb. 3.7 (D)). Es zeigte sich, dass im Rahmen der gewählten Versuchsreihe $1 \mathrm{nM}$ Bafilomycin $A_{1}$ den besten hemmenden Effekt auf die Autophagie innerhalb der primären Zellkultur hatte und somit für die folgenden Experimente genutzt wurde. Eine Testung weiterer, vor allem auch niedrigerer Bafilomycin-Konzentrationen erschien nicht sinnvoll, da nur im Rahmen einer kompletten 
Blockade der Autophagie valide Aussagen bezüglich des Funktionsstatus der Autophagie getroffen werden können (Klionsky et al. 2012).

Als Grundlage zur Beurteilung der Stofftoxizität von Bafilomycin $A_{1}$ diente die Quantifizierung der überlebenden Zellen nach 5-tägiger Kultivierung mittels immunzytochemischer Färbung der Zellkultur. Es zeigte sich hierbei eine signifikante Verringerung der durchschnittlichen Zellzahl auf $333 \pm 22$ innerhalb der mit $50 \mathrm{nM}$ Bafilomycin $\mathrm{A}_{1}$ behandelten Versuchsgruppe im Vergleich zur unbehandelten Kontrollgruppe mit $481 \pm 47$ zählbaren Zellen ( $p=0,047$ One-Way ANOVA gefolgt von Dunnett-Post-hoc-Test). Darüber hinaus zeigte sich eine nicht signifikante Reduktion der Zellzahl innerhalb der $10 \mathrm{nM}$ Versuchsgruppe auf $401 \pm 37$ Zellen $(p=0,53)$. Zwischen unbehandelter Kontrollgruppe und $1 \mathrm{nM}$ Bafilomycin $\mathrm{A}_{1}$ behandelter Versuchsgruppe mit $486 \pm 47$ Zellen gab es ebenso keinen signifikanten Unterschied ( $p=1,00)$ (s. Abb. $3.7(E)$ ) und somit keinen Hinweis auf eine größere Toxizität der Behandlung.

A
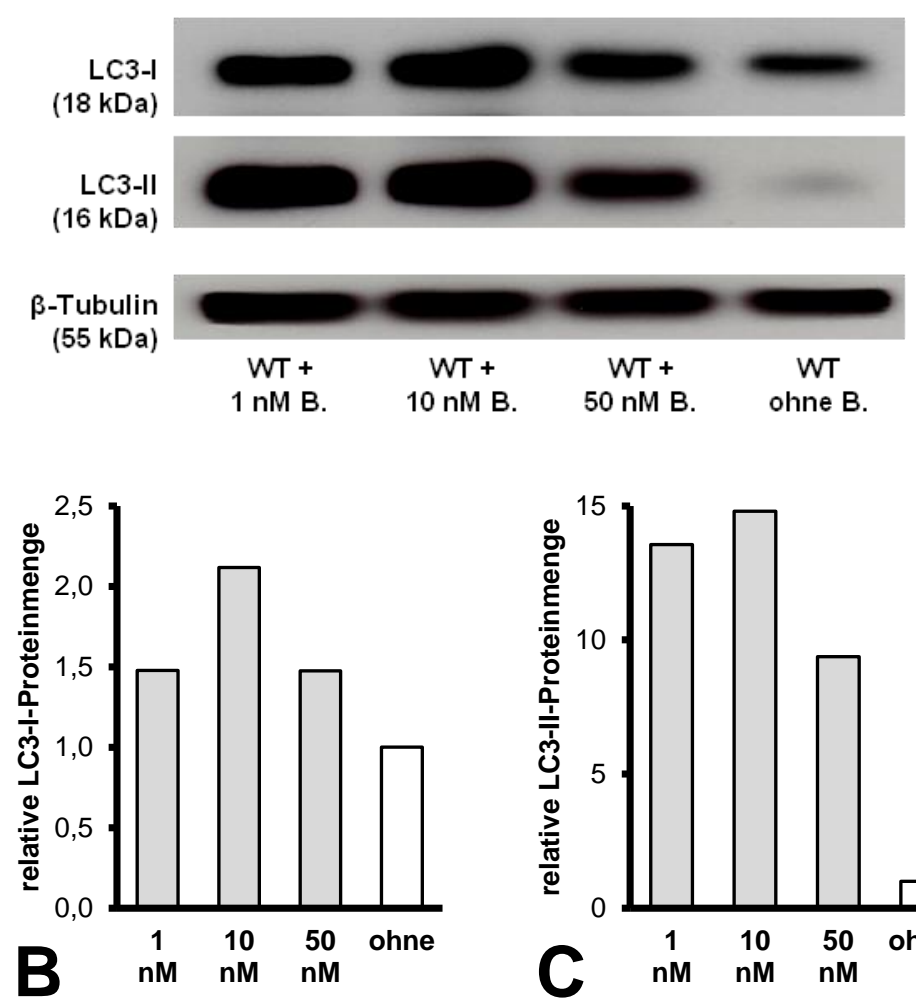
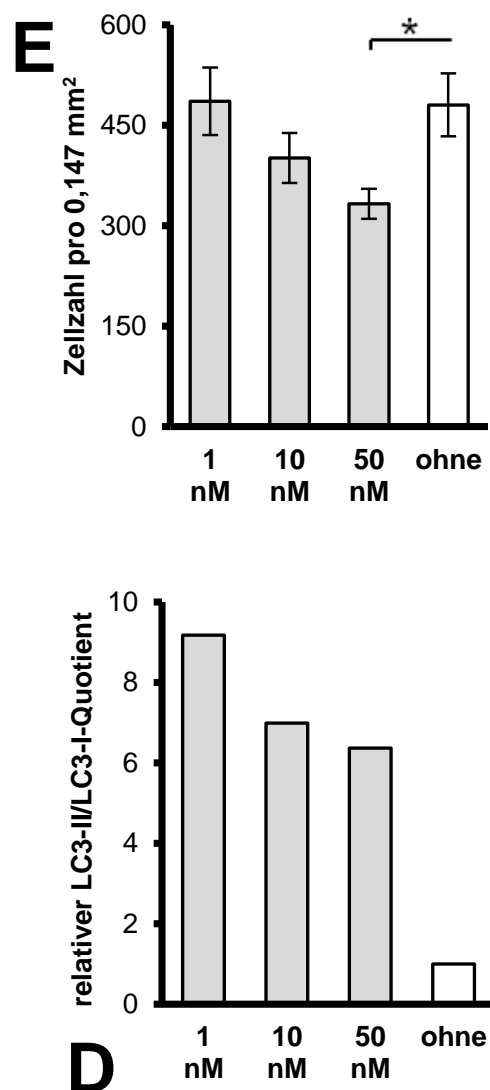

Abb. $\quad 3.7$ Auswirkungen unterschiedlicher Bafilomycin $A_{1}$-Dosen auf die LC3-Proteinmengen (in Relation zur Bafilomycin $A_{1}$ unbehandelten Kontrollgruppe) sowie Bafilomycin $A_{1}$-induzierter Zelltod. (A) Western Blot der Bafilomycin-Dosisfindung. Durch die Bafilomycin $A_{1}$-Behandlung zeigt sich insbesondere eine Kumulation der LC3-II-Proteinmenge im Vergleich zur unbehandelten Versuchsgruppe. (B) relative LC3-I-Proteinmenge. (C) relative LC3-II-Proteinmenge. (D) LC3-II/LC3-I Quotient. (E) Zellzahl als Marker der Toxizität. Es zeigten sich diskret erhöhte LC3-I- und exponentiell gesteigerte LC3-IIProteinmengen und daraus resultierend ein deutlich erhöhter LC3-II/LC3-I-Quotient in den mit Bafilomycin $A_{1}$ behandelten Zellen. Zusätzlich zeigte sich eine signifikante Reduktion der Zellzahl nach hochdosierter Bafilomycin $A_{1}$-Behandlung mit $50 \mathrm{nM}$. Primäre Mittelhirnneurone, alle Versuchsgruppen mit $\alpha$-Syn-WT transfiziert, DIV5, B-D: 1 Zellkultur, E: $n=6$ Gesichtsfelder in 20-facher Vergrößerung, „B.“ (in A): Bafilomycin $A_{1}$, Fehlerbalken: Standardfehler des Mittelwertes. ${ }^{*}: p<0,05$ in One-Way ANOVA gefolgt von Dunnett-Posthoc-Test. 
Aufgrund dieser Ergebnisse wurde sich für eine Dosis von $1 \mathrm{nM}$ Bafilomycin $\mathrm{A}_{1}$ für die folgenden Versuche entschieden, da es keine offensichtlichen toxischen Wirkungen auf die Zellkultur gab und dabei eine bestmögliche Blockade der Endstrecke der Makroautophagie im Vergleich zu den anderen getesteten Mengen erzielt wurde, wie aus der deutlichen Kumulation von LC3-II und dem erhöhten LC3-II/LC3-I-Quotienten ersichtlich wurde.

\subsubsection{Bafilomycin $A_{1}$-Behandlung der $\alpha$-Synuclein- und eGFP-transfizierten Mittelhirnneurone zur Bestimmung des Autophagie-Flusses im Western Blot}

Im Anschluss an die Vorversuche zur Ermittlung der optimalen Bafilomycin $\mathrm{A}_{1}$-Dosis von $1 \mathrm{nM}$ wurden nun auch mit den verschiedenen $\alpha$-Syn-Varianten sowie dem eGFPKontrollplasmid transfizierte Mittelhirnneurone mit Bafilomycin $A_{1}$ behandelt und mit den entsprechenden Versuchsgruppen ohne Bafilomycin $A_{1}$ verglichen. Zunächst erfolgte eine quantitative Analyse mittels Western Blot (s. Abb. 3.8 und 3.9).
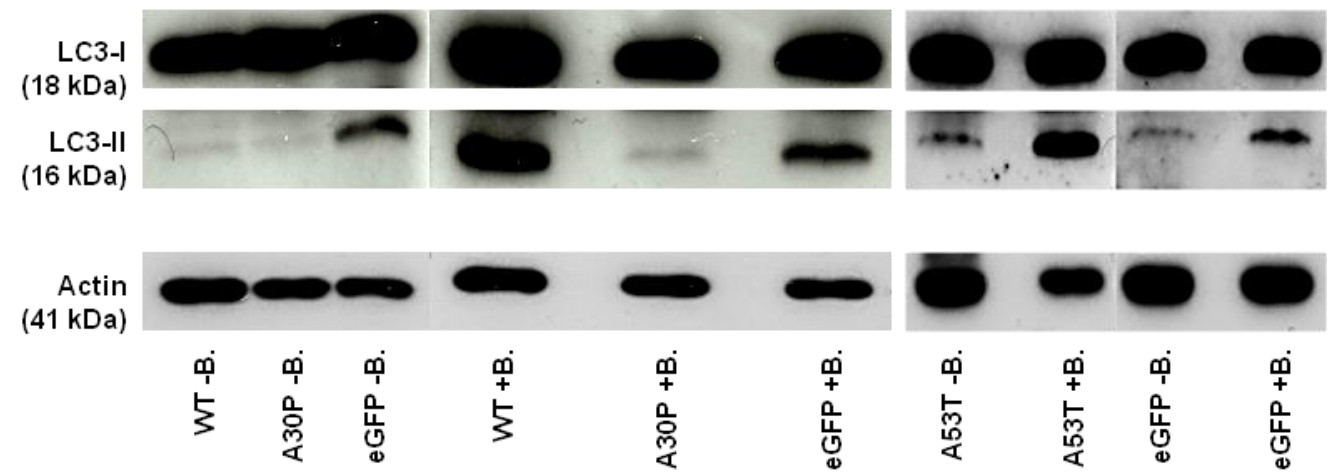

Abb. $3.8 \quad$ LC3-Analyse im Western Blot ohne (,-B.“) und mit (,,B.“) Bafilomycin $\mathrm{A}_{1}$-Behandlung nach Transfektion. Zu beobachten ist vor allem in der $\alpha$-Syn-WT- und A53T-Versuchsgruppe ein deutlicher LC3-II-Anstieg nach Bafilomycin $\mathrm{A}_{1}$-Behandlung im Vergleich zu den unbehandelten Populationen bei im Wesentlichen konstanter LC3-I-Proteinmenge sämtlicher Versuchsgruppen. Primäre Mittelhirnneurone, DIV5.

Für LC3-I konnten keine signifikanten Unterschiede ( $p=0,19$ in One-Way ANOVA) innerhalb des Gesamtversuches ermittelt werden. Da Bafilomycin $A_{1}$ erst nach der Bildung von Autophagosomen und der damit einhergehenden Konversion von LC3-I (zytosolisch) zu LC3-II (membrangebunden an Autophagosomen) die Inhibition der Makroautophagie bewirkt, ist dieses Ergebnis erwartungsgemäß eingetreten (s. Tab. 3.1 und Abb. 3.9 (A)).

Anders verhielt sich die Entwicklung der relativ zur unbehandelten eGFPKontrollgruppe ermittelten LC3-II-Proteinmengen nach Bafilomycin $\mathrm{A}_{1}$-Behandlung. Innerhalb der Kontrollgruppen ergab sich kein signifikanter Unterschied $(p=0,64$, One-Way ANOVA gefolgt von Tukey-Kramer-Post-hoc-Test) bei einer relativen Proteinmenge der Bafilomycin $A_{1}$ behandelten eGFP-Kontrolle des 1,16 \pm 0,34-Fachen im Vergleich zur unbehandelten Population. Dagegen konnte sowohl in der a-Syn-WT- als auch in der A53T-transfizierten 
Versuchsreihe ein signifikanter Anstieg der relativ zur unbehandelten eGFP-Kontrolle bestimmten LC3-II-Proteinmenge beobachtet werden. Hierbei kam es für den $\alpha$-Syn-WT zu einem Anstieg vom $0,35 \pm 0,17$-Fachen auf das 2,17 $\pm 0,72$-Fache $(p=0,049)$ und für A53T von 0,56 $\pm 0,20$ - auf 3,55 $\pm 0,82$-fach $(p=0,024)$. Diese Anstiege zeigten sich für A53T im Vergleich zu beiden eGFP-Kontrollen signifikant $(p=0,021$ zur unbehandelten eGFPKontrolle und $p=0,045$ zur Bafilomycin $A_{1}$ behandelten eGFP-Kontrolle) und für den $\alpha$-SynWT tendenziell erhöht. Die A30P-Mutation führte dahingegen weder innerhalb der A30Ptransfizierten Versuchsgruppen noch im Vergleich zu den eGFP-Kontrollen zu einem signifikanten Anstieg der relativen LC3-II-Proteinmenge (s. Tab. 3.1. und Abb 3.9 (B)). Dies spricht sowohl in der a-Syn-WT- als auch in der A53T-Versuchsgruppe für eine schnelle Degradation von LC3-II, die erst durch die Gabe von Bafilomycin $A_{1}$ erkennbar wurde.

Aufgrund der ermittelten Werte der LC3-I- und LC3-II-Proteinmengen konnte im Weiteren der LC3-II/LC3-I-Quotient berechnet werden. Hierbei ergaben sich sowohl für den $\alpha$-Syn-WT ( $p=0,0068$, One-Way ANOVA gefolgt von Tukey-Kramer-Post-hoc-Test) als auch für die A53T-Mutation ( $p=0,0069)$ signifikante Anstiege des LC3-II/LC3-I-Quotienten nach Bafilomycin $A_{1}$-Behandlung. Dagegen konnte in der Kontrollgruppe kein signifikanter Anstieg verzeichnet werden $(p=0,75)$ und auch die Transfektion mit der A30P-Mutation führte nach Bafilomycin $A_{1}$-Behandlung nicht zu einem signifikanten Anstieg des LC3-II/LC3-I-Quotienten im Vergleich zur unbehandelten A30P-Versuchsgruppe $(p=0,61)$. Darüber hinaus konnte ein signifikanter Unterschied zwischen der Bafilomycin $A_{1}$-behandelten a-Syn-WTVersuchsgruppe und der unbehandelten eGFP-Kontrolle $(p=0,036)$ sowie der unbehandelten A53T-Population $(p=0,015)$ ermittelt werden (s. Tab. 3.1 und Abb. $3.9(C)$ ).

Analog zu den unter 3.2.2.1 beschriebenen Ergebnissen konnte für den a-Syn-WT ( $p=0,0034)$ und die A53T-Mutation $(p=0,024)$ erneut eine signifikante Reduktion der LC3II-Proteinmenge und daraus resultierend ein signifikant erniedrigter LC3-II/LC3-I-Quotienten ( $\alpha$-Syn-WT: $p=0,012$, A53T: $p=0,034$ ) in den unbehandelten Versuchsgruppen gegenüber der Bafilomycin $A_{1}$-unbehandelten eGFP-Kontrolle gezeigt werden. Die A30P-Mutation zeigte sich im Rahmen dieser Versuchsreihe jedoch nicht signifikant verändert gegenüber der Kontrolle (LC3-II: $p=0,22$, LC3-II/LC3-I-Quotienten $p=0,58$ ). 


\begin{tabular}{|c|c|c|c|c|c|c|}
\hline & \multicolumn{2}{|c|}{ LC3-I-Proteinmenge } & \multicolumn{2}{|c|}{ LC3-II-Proteinmenge } & \multicolumn{2}{|c|}{ LC3-II/LC3-I-Quotient } \\
\hline & Mittelwert & s. e. m. & Mittelwert & s. e. $\mathbf{m}$. & Mittelwert & s. e. m. \\
\hline WT -B. & 1,08 & $\pm 0,33$ & 0,35 & $\pm 0,17$ & 0,088 & $\pm 0,021$ \\
\hline WT +B. & 1,19 & $\pm 0,38$ & 2,17 & $\pm 0,72$ & 0,605 & $\pm 0,126$ \\
\hline A30P -B. & 1,09 & $\pm 0,23$ & 0,71 & $\pm 0,29$ & 0,227 & $\pm 0,091$ \\
\hline $\mathrm{A} 30 \mathrm{P}+\mathrm{B}$ & 1,74 & $\pm 0,96$ & 1,44 & $\pm 0,65$ & 0,337 & $\pm 0,176$ \\
\hline A53T -B. & 1,30 & $\pm 0,14$ & 0,57 & $\pm 0,20$ & 0,107 & $\pm 0,025$ \\
\hline A53T +B. & 2,34 & $\pm 0,48$ & 3,55 & $\pm 0,82$ & 0,405 & $\pm 0,052$ \\
\hline eGFP -B. & 1 & \pm 0 & 1 & \pm 0 & 0,299 & $\pm 0,037$ \\
\hline eGFP +B. & 0,95 & $\pm 0,05$ & 1,16 & $\pm 0,34$ & 0,329 & $\pm 0,086$ \\
\hline
\end{tabular}

Tab. $\quad 3.1 \quad$ Zusammenfassung der Mittelwerte und jeweiligen Standardfehler (s. e. m.) der in Relation zur Bafilomycin A -unbehandelten eGFP-Kontrollgruppe gesetzten LC3-I- und -IIProteinmengen sowie des LC3-II/LC3-I-Quotienten. Primäre Mittelhirnneurone, DIV5, $\mathrm{n}=3$ unabhängige Zellkulturen, „-B.“: ohne Bafilomycin-Behandlung, „+B.“: mit Bafilomycin-Behandlung.

Aufgrund der Bafilomycin $\mathrm{A}_{1}$-induzierten Blockade der Autophagie und der damit einhergehenden Hemmung des LC3-II-Abbaus, wurde zur einzig validen Beurteilung des Autophagie-Flusses der Quotient aus der LC3-II-Proteinmenge der Bafilomycin $A_{1}$ behandelten und -unbehandelten Versuchsgruppe der jeweiligen Transfektionsgruppe bestimmt und miteinander verglichen. Hierbei spricht ein hoher Wert für einen schnellen Autophagie-Fluss, messbar an dem schnellen Abbau von LC3-II, der durch die Bafilomycin $A_{1}$-Behandlung erst sichtbar wird.

Es zeigte sich beim $\alpha$-Syn-WT ein Quotient von $8,47 \pm 2,46$, für A30P von 1,84 $\pm 0,24$ und für die A53T-Mutation von 7,42 $\pm 2,02 \mathrm{im}$ Vergleich zu 1,16 $\pm 0,34$ in der eGFP-Kontrollgruppe. Dabei ergab sich für den $\alpha-S y n-W T(p=0,011$, One-Way ANOVA gefolgt von TukeyKramer-Post-hoc-Test) und die A53T-Mutation $(p=0,042)$ ein signifikanter Unterschied zur eGFP-Kontrolle. Der Unterschied zwischen A30P und der eGFP-Versuchsgruppe war nicht signifikant $(p=0,98)$. Der Unterschied zur A30P-Mutation zeigte sich mit einem $p$-Wert zum a-Syn-WT von 0,072 und zur A53T-Mutation von 0,051 nicht signifikant (s. Abb. 3.9 (D)). 

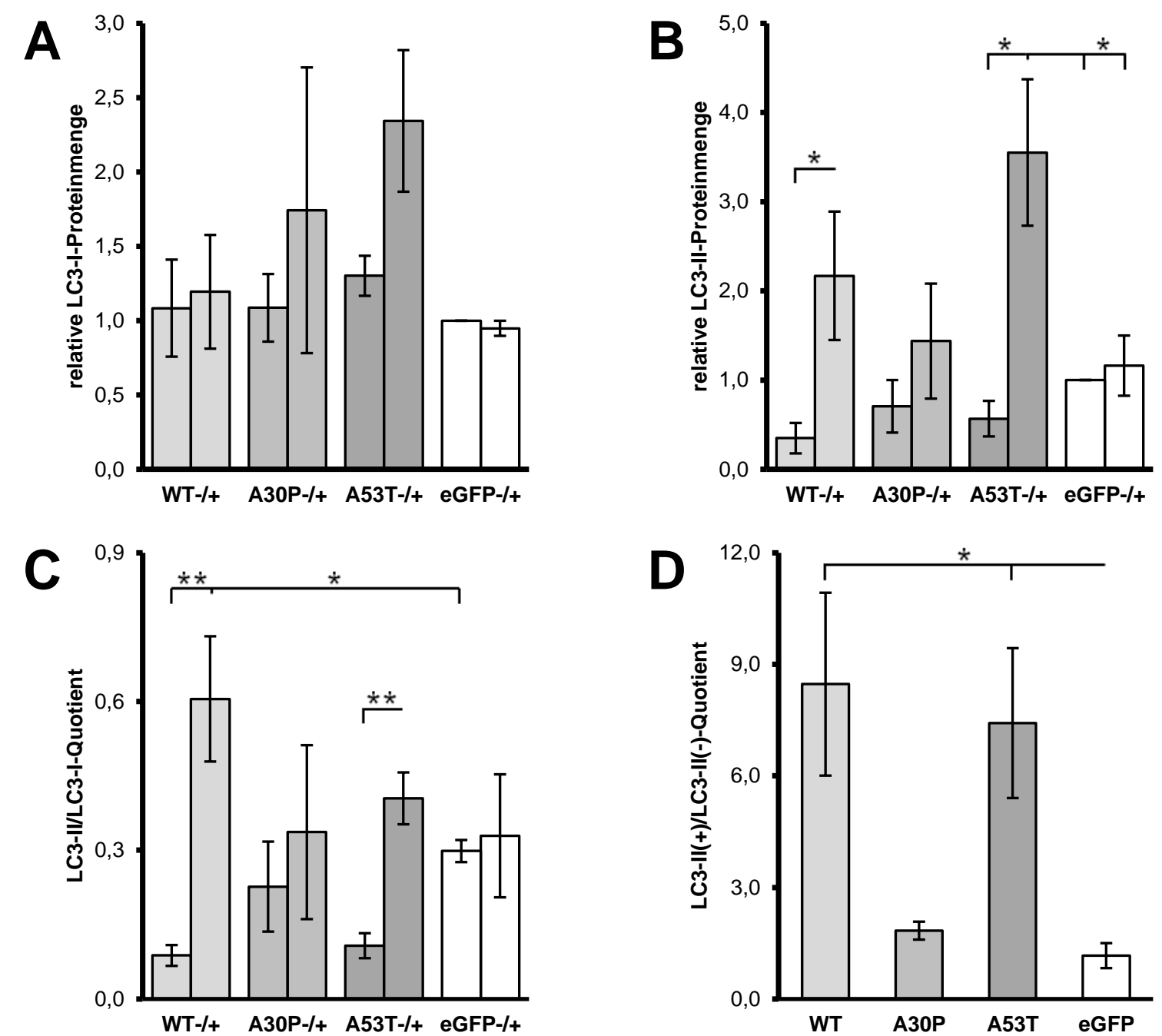

Abb. $\quad 3.9 \quad$ LC3-Analyse im Western Blot ohne und mit Bafilomycin $A_{1}$-Behandlung zur Analyse des Autophagie-Flusses. (A) relative LC3-I-Proteinmenge. (B) relative LC3-II-Proteinmenge. (C) LC3-II/LC3I-Quotient. (D) LC3-II(+)/LC3-II(-)-Quotient. Es zeigt sich eine signifikante Erhöhung der LC3-II-Proteinmenge nach Behandlung mit Bafilomycin $A_{1}$ in den $\alpha$-Syn-WT- und A53T-transfizierten Versuchsgruppen als Zeichen eines erhöhten Autophagie-Flusses und damit verbundener Steigerung der Autophagie, wohingegen die A30P-Mutation, wie die Kontrollgruppe auch, keine signifikante Veränderung der Autophagie zu verzeichnen hat. Primäre Mittelhirnneurone, DIV5, „-": ohne Bafilomycin $A_{1}, \ldots+$ : : mit Bafilomycin $A_{1}, n=3$ unabhängige Zellkulturen, Fehlerbalken: Standardfehler des Mittelwertes, ${ }^{*}: p<0,05,{ }^{* *}: p<0,01$ in One-Way ANOVA gefolgt von Tukey-Kramer-Post-hoc-Test.

\subsubsection{Analyse des Autophagie-Flusses mittels der Anzahl LC3-positiver Autophagosomen in immunzytochemischen Färbungen}

Zur weiteren Analyse der Makroautophagie wurden immunzytochemische Färbungen von LC3 durchgeführt. Dadurch ließen sich intrazelluläre Autophagosomen, die auf ihrer Oberfläche LC3-II enthalten, darstellen. Ein Vorteil dieser Methode war es, dass nun auch die spezifische Darstellung der dopaminergen Neurone durch eine zusätzliche Färbung gegen Tyrosinhydroxylase möglich wurde und hierdurch der Einfluss von $\alpha$-Syn direkt auf die Autophagie in dopaminergen Mittelhirnneuronen betrachtet werden konnte (s. Abb. 3.11). Des Weiteren konnten auch nicht-dopaminerge Neurone spezifisch analysiert werden. 
Zu diesem Zweck wurden Zellkulturen mit und ohne Bafilomycin $A_{1}$ behandelt und im Anschluss immunzytochemisch gefärbt. Mikroskopisch stellten sich die durch LC3-Färbung sichtbar gemachten Autophagosomen als kleine, zytoplasmatisch gelegene Punkte dar, welche automatisiert quantifiziert werden konnten (s. auch 2.3.4.1)

\subsubsection{Tyrosinhydroxylase-positive (dopaminerge) Neurone}

Zunächst wurde die Fläche der dopaminergen Neurone in den einzelnen Analysegruppen miteinander verglichen. Diese Untersuchung war nötig, um die gemessenen LC3positiven Autophagosomen der einzelnen Gruppen untereinander auch adäquat, auf eine Zellfläche standardisiert vergleichen zu können (Klionsky et al. 2012).

Im Rahmen der Analyse der durchschnittlichen Zellkörperfläche dopaminerger Neurone konnten keine signifikanten Unterschiede zwischen den Versuchsgruppen festgestellt werden ( $p>0,064$ in One-Way ANOVA und Tukey-Kramer-Post-hoc-Test) (s. Abb. 3.10).

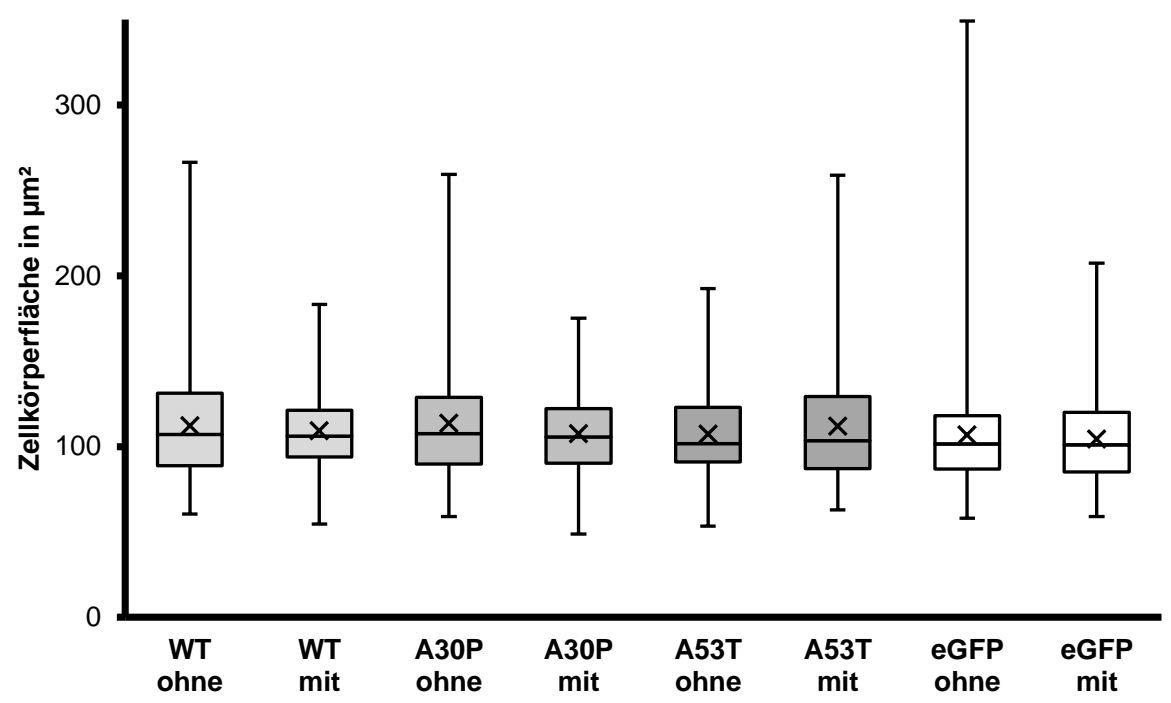

Abb. $\quad 3.10$ Durchschnittliche Zellkörperfläche eines dopaminergen Neurons. Es zeigten sich keine signifikanten Unterschiede in der durchschnittlichen Zellkörperfläche zwischen den einzelnen Versuchsgruppen. Transfizierte dopaminerge Mittelhirnneurone ohne und mit Bafilomycin $A_{1}$-Behandlung, DIV5, $\mathrm{n}=180$ aus 3 unabhängigen Zellkulturen. Darstellung als Box Plot: Box-Reichweite: von 1. bis 3. Quartile, innere Bande: Median (2. Quartile), Kreuz: arithmetischer Mittelwert, oberer Whisker: Maximum, unterer Whisker: Minimum. 

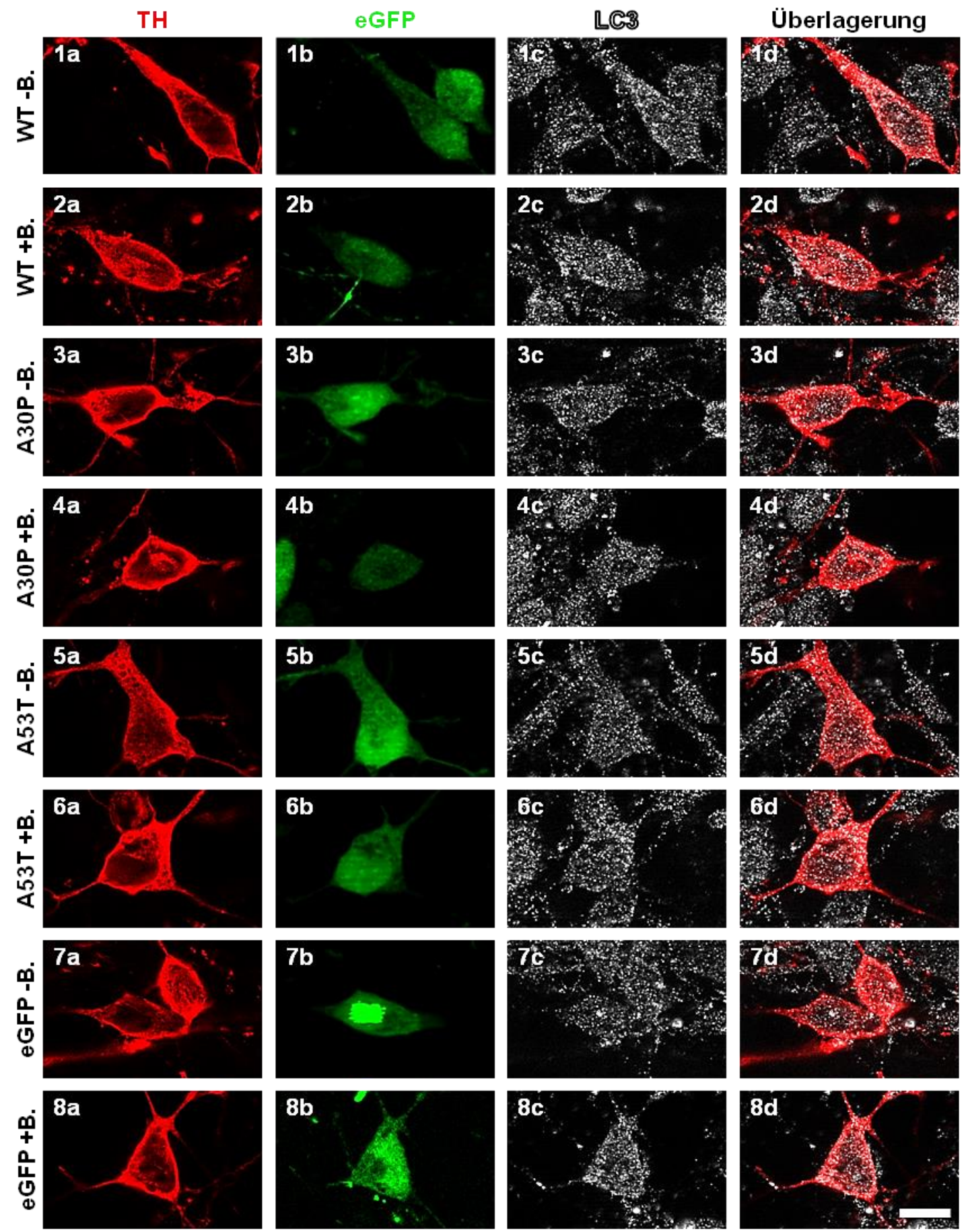
somen dopaminerger Mittelhirnneurone ohne und mit Bafilomycin $A_{1}$-Behandlung. (a) TH-Färbung, (b) eGFP-Fluoreszenz, (c) LC3-Färbung, (d) Überlagerung von a und c; 1(a-d) a-Syn-WT ohne Bafilomycin $A_{1}$-Behandlung, 2(a-d) a-Syn-WT mit Bafilomycin $A_{1}$-Behandlung, 3(a-d) A30P ohne Bafilomycin $A_{1}$ Behandlung, 4(a-d) A30P mit Bafilomycin $A_{1}$-Behandlung, 5(a-d) A53T ohne Bafilomycin $A_{1}$-Behandlung, 6(ad) A53T mit Bafilomycin $A_{1}$-Behandlung, 7(a-d) eGFP-Kontrollgruppe ohne Bafilomycin $A_{1}$-Behandlung, 8(a-d) eGFP-Kontrollgruppe mit Bafilomycin $A_{1}$-Behandlung. Primäre dopaminerge Mittelhirnneurone, DIV5, „-B.“: ohne Bafilomycin $A_{1}$, „B. 
Zur adäquaten Beurteilung der LC3-positiven Autophagosomen zwischen den Versuchsgruppen erfolgte trotz fehlender signifikanter Unterschiede der Zellkörperfläche die Berechnung auf die als Standardgrösse definierte Zellkörperfläche der Bafilomycin $A_{1}$ unbehandelten eGFP-Kontrollgruppe.

Es konnte gezeigt werden, dass in den a-Syn-WT-transfizierten Versuchsgruppen ein signifikanter Anstieg der immunzytochemisch gefärbten LC3-positiven Autophagosomen durch die Behandlung mit Bafilomycin $A_{1}$ von 38,68 \pm 1,57 auf 49,48 \pm 1,93 zu verzeichnen war ( $p=2,39 \times 10^{-5}$, One-Way ANOVA gefolgt von Tukey-Kramer-Post-hoc-Test). Auch in den mit A53T-transfizierten dopaminergen Mittelhirnneuronen konnte ein signifikanter Anstieg von 35,43 \pm 1,27 (ohne Bafilomycin $A_{1}$-Behandlung) auf 40,62 \pm 1,76 Autophagosomen ermittelt werden $(p=0,017)$. Dagegen blieb in den A30P-transfizierten Versuchsgruppen ein signifikanter Anstieg der LC3-positiven Autophagosomen nach Bafilomycin $A_{1}$ Behandlung aus, ähnlich den Ergebnissen der quantitativen LC3-II-Analyse mittels Western Blot (ohne Bafilomycin $A_{1}: 41,04 \pm 1,59$, mit Bafilomycin $A_{1}: 44,50 \pm 1,55 ; p=0,12$ ). In den Kontrollgruppen, welche lediglich mit $5 \mu \mathrm{g}$ eGFP transfiziert wurden, konnte ein signifikanter, aber geringerer Anstieg von 33,27 $\pm 1,19$ auf 38,47 \pm 1,33 in der Bafilomycin $A_{1}$ behandelten Population ermittelt werden ( $p=0,0037$ ) (s. Tab. 3.2 und Abb. 3.12). Ergänzend wurde, ähnlich zu den Auswertungen im Western Blot, zur Beurteilung des Autophagie-Flusses der Quotient der Autophagosomenanzahl mit Bafilomycin $A_{1}$-Behandlung zu der Autophagosomenanzahl ohne Bafilomycin $A_{1}$-Behandlung ermittelt. Hierfür erfolgte eine Ordnung der gemessenen Neurone nach ihrer Anzahl der Autophagosomen der einzelnen Versuchsgruppen. In dem so entstandenen Ranking erfolgte die Zuordnung der Bafilomycin $A_{1}$ behandelten zu den unbehandelten Neuronen entsprechend ihrer Ordnungszahl und die anschließende Quotientenbildung. Hierbei ergab sich in der a-Syn-WT-Population ein zu sämtlichen Versuchgruppen signifikant erhöhter Quotient von 1,29 $\pm 0,006$ ( $p=1,62 \times 10^{-6} \mathrm{zu}$ eGFP, A30P und A53T, One-Way ANOVA gefolgt von Tukey-Kramer-Post-hoc-Test), in der A30P-Versuchsgruppe zusätzlich eine signifikante Reduktion zur Kontrollgruppe sowie der A53T-Mutation von 1,11 $\pm 0,016$ ( $p=0,0099$ zu eGFP und $p=0,0092$ zu A53T). Für die A53T-Mutation mit 1,16 $\pm 0,009$ ergab sich kein signifikanter Unterschied zur Kontrollgruppe mit $1,16 \pm 0,009$ ( $p=1,00$ ) (s. Abb. 3.13). Somit zeigt sich für den $\alpha$-Syn-WT ein erhöhter Autophagie-Fluss und bei den mit A30P-tranfizierten Neuronen ein reduzierter AutophagieFluss. Die A53T-Mutation zeigt sich hingegen unverändert zur Kontrollgruppe. 


\begin{tabular}{|c|c|c|c|c|c|c|c|c|}
\hline & $\begin{array}{c}\text { WT } \\
\text {-B. }\end{array}$ & $\begin{array}{c}\text { WT } \\
\text { +B. }\end{array}$ & $\begin{array}{c}\text { A30P } \\
\text {-B. }\end{array}$ & $\begin{array}{c}\text { A30P } \\
\text { +B. }\end{array}$ & $\begin{array}{c}\text { A53T } \\
\text {-B. }\end{array}$ & $\begin{array}{c}\text { A53T } \\
\text { +B. }\end{array}$ & $\begin{array}{c}\text { eGFP } \\
\text {-B. }\end{array}$ & $\begin{array}{c}\text { eGFP } \\
\text { +B. }\end{array}$ \\
\hline Mittelwert & 38,68 & 49,48 & 41,04 & 44,50 & 35,43 & 40,62 & 33,27 & 38,47 \\
\hline $\begin{array}{c}\text { Standardfehler } \\
\text { des Mittelwertes }\end{array}$ & $\pm 1,57$ & $\pm 1,93$ & $\pm 1,59$ & $\pm 1,55$ & $\pm 1,27$ & $\pm 1,76$ & $\pm 1,19$ & $\pm 1,33$ \\
\hline
\end{tabular}

Tab. $\quad 3.2 \quad$ Anzahl LC3-positiver Autophagosomen transfizierter dopaminerge Mittelhirnneurone ohne (,-B.“) und mit (,+B.“) Bafilomycin A 1 -Behandlung. DIV5, $n=180$ aus 3 unabhängigen Zellkulturen.

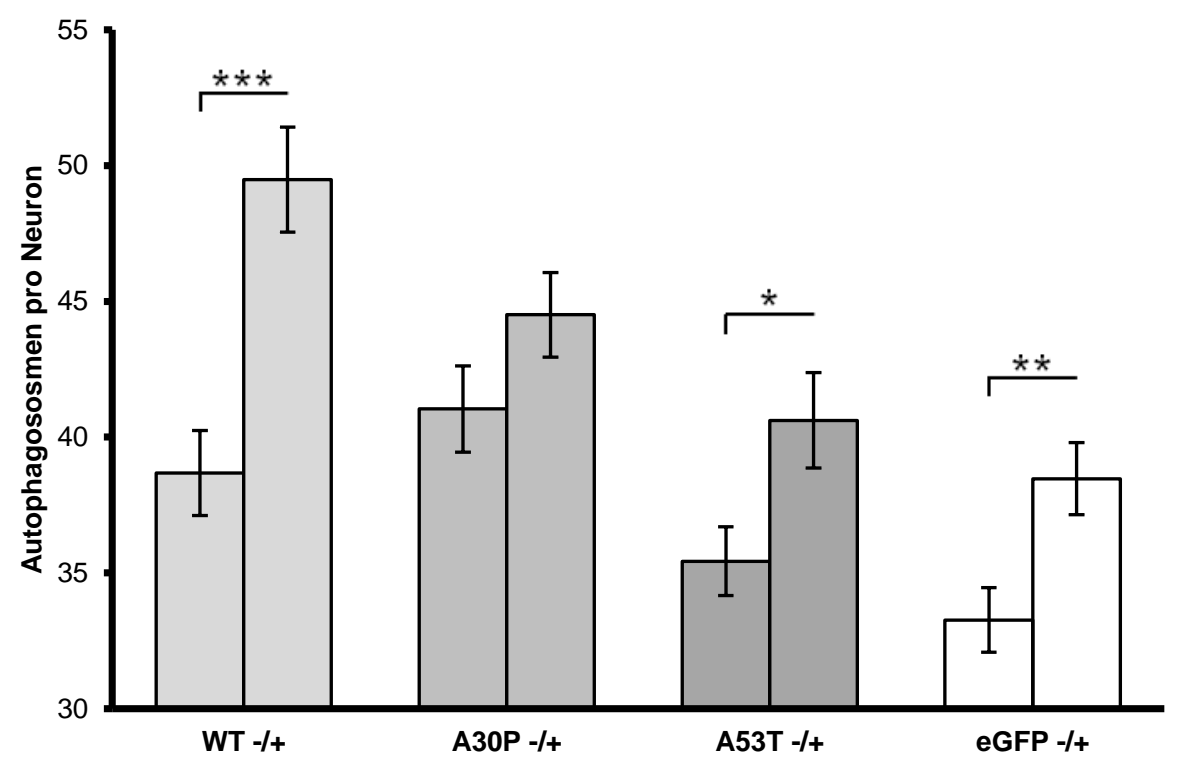

Abb. 3.12 Anzahl der LC3-positiven Autophagosomen. Es zeigt sich ein signifikanter Anstieg der LC3-positiven Autophagosomen nach Bafilomycin $A_{1}$-Behandlung im Vergleich zur unbehandelten Population in der a-Syn-WT-, A53T- und auch in der eGFP-Kontrollgruppe, wohingegen die A30P-Mutation keinen signifikanten Anstieg zu verzeichnen hat. Transfizierte dopaminerge Mittelhirnneurone ohne (,,“) und mit (,,+) Bafilomycin $\mathrm{A}_{1}$-Behandlung, DIV5, $\mathrm{n}=180$ aus 3 unabhängigen Zellkulturen, Fehlerbalken: Standardfehler des Mittelwertes, ${ }^{*}: p<0,05,{ }^{* *}: p<0,01,{ }^{* *}: p<0,001$ in One-Way ANOVA gefolgt von Tukey-Kramer-Posthoc-Test.

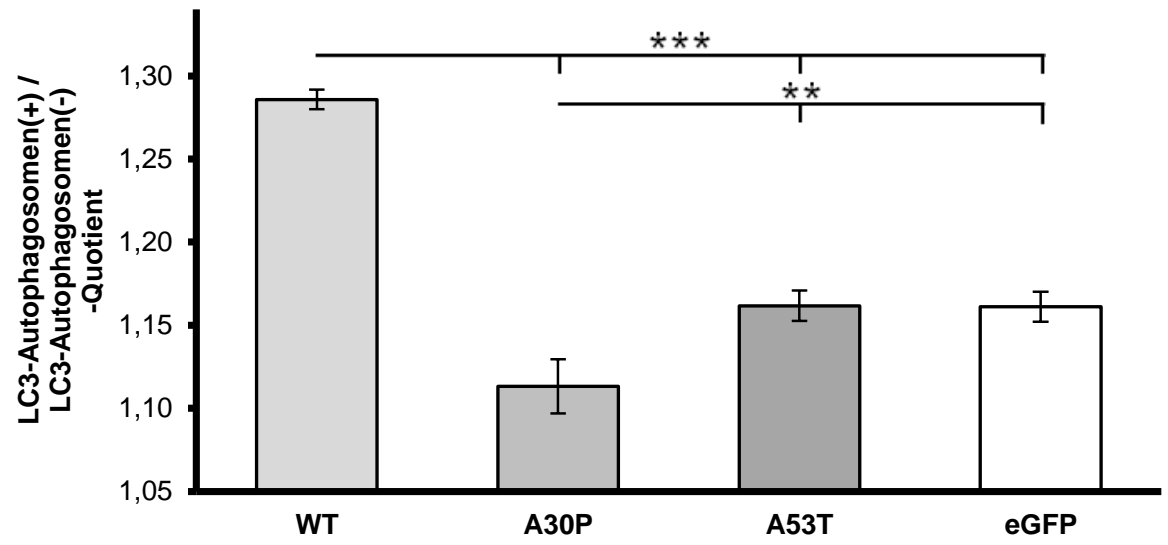

Abb. 3.13 Analyse des Autophagie-Flusses dopaminerger Mittelhirnneurone mittels LC3Autophagosomen(+)-LC3-Autophagosomen(-)-Quotient in immunzytochemischer Färbung. Es zeigt sich ein signifikant erhöhter Autophagie-Fluss der mit $\alpha$-Syn-WT-transfizierten Neurone im Vergleich zur eGFP-Kontrollgruppe. Dagegen ist bei den A30P-transfizierten Neuronen eine signifikante Reduktion zu verzeichnen. Für die A53T-Mutation ergab sich kein Unterschied. Transfizierte dopaminerge Mittelhirnneurone ohne (,-“) und mit (,+“) Bafilomycin $A_{1}$-Behandlung, DIV5, $n=180$ aus 3 unabhängigen Zellkulturen, Fehlerbalken: Standardfehler des Mittelwertes, ${ }^{*}: p<0,05,{ }^{* *}: p<0,01,{ }^{* \star *}: p<0,001$ in One-Way ANOVA gefolgt von Tukey-Kramer-Post-hoc-Test. 
Sämtliche $p$-Werte und die dadurch ermittelten signifikanten Unterschiede zwischen den jeweiligen transfizierten Versuchsgruppen sind in der anschließenden Tabelle dargestellt (s. Tab. 3.3).

\begin{tabular}{|c|c|c|c|c|c|c|c|c|}
\hline & $\begin{array}{l}\text { WT } \\
\text { mit }\end{array}$ & $\begin{array}{l}\text { A30P } \\
\text { ohne }\end{array}$ & $\begin{array}{c}\text { A30P } \\
\text { mit }\end{array}$ & $\begin{array}{l}\text { A53T } \\
\text { ohne }\end{array}$ & $\begin{array}{c}\text { A53T } \\
\text { mit }\end{array}$ & $\begin{array}{l}\text { eGFP } \\
\text { ohne }\end{array}$ & $\begin{array}{c}\text { eGFP } \\
\text { mit }\end{array}$ \\
\hline & & \multicolumn{7}{|c|}{ Bafilomycin-Behandlung } \\
\hline $\begin{array}{c}\text { WT } \\
\text { ohne }\end{array}$ & \multirow{7}{*}{ 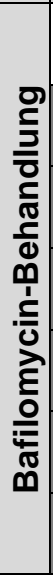 } & $\begin{array}{c}2,39 x \\
10^{-5}\end{array}$ & 0,96 & 0,13 & 0,81 & 0,99 & 0,019 & 1,00 \\
\hline $\begin{array}{l}\text { WT } \\
\text { mit }\end{array}$ & & & 0,0028 & 0,30 & $\begin{array}{c}2,19 x \\
10^{-6}\end{array}$ & 0,0013 & $\begin{array}{c}2,18 x \\
10^{-6}\end{array}$ & $\begin{array}{c}1,55 x \\
10^{-5}\end{array}$ \\
\hline $\begin{array}{l}\text { A30P } \\
\text { ohne }\end{array}$ & & & & 0,12 & 0,17 & 0,99 & 0,0089 & 0,94 \\
\hline $\begin{array}{c}\text { A30P } \\
\text { mit }\end{array}$ & & & & & $8,7 \times 10^{-4}$ & 0,63 & $\begin{array}{c}1,01 x \\
10^{-5}\end{array}$ & 0,028 \\
\hline $\begin{array}{l}\text { A53T } \\
\text { ohne }\end{array}$ & & & & & & 0,017 & 0,57 & 0,86 \\
\hline $\begin{array}{c}\text { A53T } \\
\text { mit }\end{array}$ & & & & & & & 0,017 & 0,68 \\
\hline $\begin{array}{l}\text { eGFP } \\
\text { ohne }\end{array}$ & & & & & & & & 0,0037 \\
\hline
\end{tabular}

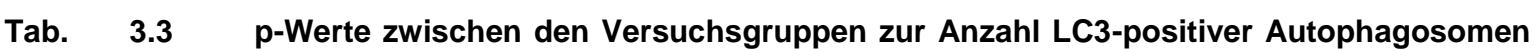
in dopaminergen Mittelhirnneuronen ohne und mit Bafilomycin $\mathbf{A}_{1}$-Behandlung. $n=180$ aus 3 unabhängigen Zellkulturen, DIV5, signifikante Unterschiede hervorgehoben.

\subsubsection{Tyrosinhydroxylase-negative Mittelhirnneurone}

Die gleichen immunzytochemischen Versuche und mikroskopischen Auswertungen bezüglich der LC3-positiven Autophagosomen wurden ergänzend auch mit transfizierten nicht-dopaminergen Mittelhirnneuronen, die insgesamt ca. $90 \%$ einer primären Mittelhirnzellkultur ausmachen, durchgeführt.

Hier erfolgte ebenso zunächst die Ermittlung der Zellkörperfläche der Neurone der einzelnen Versuchsgruppen, um auch bei nicht signifikantem Unterschied $(p=0,60$, OneWay ANOVA) die Autophagosomenanzahl der Zellfläche anzupassen (s. Abb. 3.14).

Im Vergleich mit den dopaminergen Neuronen, die im Mittel eine Zellkörperfläche von $109,18 \pm 0,77 \mu \mathrm{m}^{2} \quad(\mathrm{n}=1440$ dopaminerge Neurone aus 3 unabhängigen Zellkulturen) aufwiesen, zeigte sich die durchschnittlichen Zellkörperfläche nicht-dopaminerger Neurone mit $89,39 \pm 0,72 \mu \mathrm{m}^{2} \quad(\mathrm{n}=1440$ nicht-dopaminerge Neurone aus 3 unabhängigen Zellkulturen) signifikant kleiner ( $p=3,09 \times 10^{-74} \mathrm{im}$ Students t-Test). 


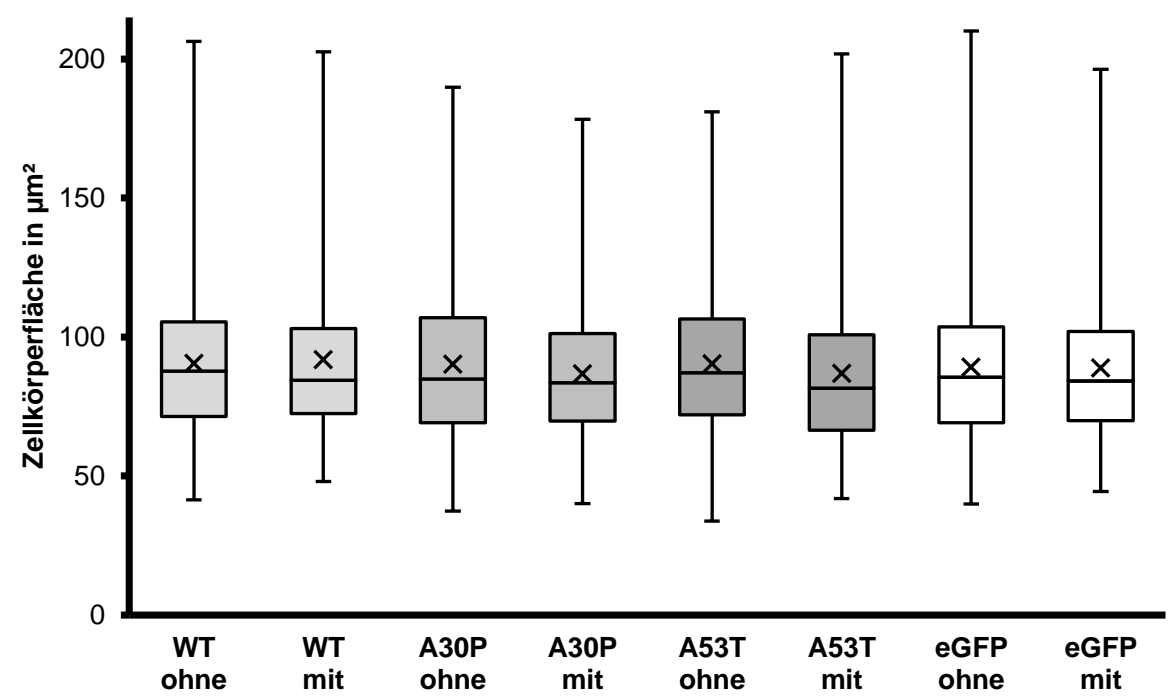

Abb. 3.14 Durchschnittliche Zellkörperfläche eines nicht-dopaminergen Neurons. Es zeigten sich keine signifikanten Unterschiede in der Zellkörperfläche zwischen den einzelnen Versuchsgruppen. Transfizierte nicht-dopaminerge Mittelhirnneurone ohne und mit Bafilomycin $A_{1}$-Behandlung, DIV5, $n=180$ aus 3 unabhängigen Zellkulturen. Darstellung als Box Plot: Box-Reichweite: von 1. bis 3. Quartile, innere Bande: Median (2. Quartile), Kreuz: arithmetischer Mittelwert, oberer Whisker: Maximum, unterer Whisker: Minimum.

Im Weiteren erfolgte die Ermittlung der LC3-positiven Autophagosomen nichtdopaminerger Neurone und auch hierbei wurde eine Flächenkorrektur mit Standardisierung auf die Bafilomycin $A_{1}$ unbehandelte eGFP-Kontrollgruppe vorgenommen.

Es zeigten sich auch bei den nicht-dopaminergen Neuronen ähnliche Ergebnisse wie bei den dopaminergen Mittelhirnneuronen. Die Transfektion mit dem a-Syn-WT führte zu einer signifikant höheren Anzahl LC3-positiver Autophagosomen mit 40,54 1,60 in der Bafilomycin $A_{1}$ behandelten Gruppe zu lediglich 30,83 $\pm 1,27$ in der unbehandelten Population ( $p=0,00054$, One-Way ANOVA gefolgt von Tukey-Kramer-Post-hoc-Test). Bei A53T konnte ebenso ein Anstieg von 31,90 \pm 1,48 auf 44,89 $\pm 2,41$ beobachtet werden $\left(p=2,55 \times 10^{-6}\right)$. Dagegen war in der A30P-transfizierten Versuchsreihe sogar ein leichter, insgesamt jedoch nicht signifikanter Abfall von 38,05 \pm 1,52 auf 35,97 \pm 1,32 nach Bafilomycin $A_{1}$-Behandlung zu verzeichnen $(p=0,98)$. Im Gegensatz zu den dopaminergen Neuronen zeigte sich zwar auch bei den nicht-dopaminergen Mittelhirnneuronen ein Anstieg der Autophagosomen von 34,71 \pm 1,41 auf 39,66 \pm 1,56 nach Bafilomycin $A_{1}$-Behandlung innerhalb der mit eGFP-transfizierten Kontrollversuchsgruppen, jedoch war dieser nicht signifikant $(p=0,36)$ (s. Abb 3.15 sowie Tab. 3.4 und 3.5 ). Ergänzend wurde für die nichtdopaminergen Neurone ebenso die Bestimmung des Quotienten der Bafilomycin $A_{1}$ behandelten zu unbehandelten Autophagosomenanzahl analog zur Bestimmung bei den dopaminergen Neuronen zur Analyse des Autophagie-Flusses durchgeführt. Hierbei ergab sich im Unterschied zu den dopaminergen Neuronen sowohl für den a-Syn-WT mit $1,36 \pm 0,013$ als auch für die A53T-Mutation mit 1,38 $\pm 0,14$ eine signifikante Erhöhung des Autophagie-Flusses im Vergleich zur eGFP-Kontrollgruppe mit 1,14 $\pm 0,005$ ( $p=1,62 \times 10^{-6}$ 
zum a-Syn-WT und zu A53T, One-Way ANOVA gefolgt von Tukey-Kramer-Post-hoc-Test). Die mit der A30P-Mutation transfizierten Neurone zeigten mit einem Quotienten von $0,96 \pm 0,005$ einen signifikant reduzierten Autophagie-Fluss gegenüber der Kontrollgruppe $\left(p=1,62 \times 10^{-6}\right)(s$. Abb. 3.17).

\begin{tabular}{|c|c|c|c|c|c|c|c|c|}
\hline & $\begin{array}{c}\text { WT } \\
\text {-B. }\end{array}$ & $\begin{array}{c}\text { WT } \\
\text { +B. }\end{array}$ & $\begin{array}{c}\text { A30P } \\
\text {-B. }\end{array}$ & $\begin{array}{c}\text { A30P } \\
\text { +B. }\end{array}$ & $\begin{array}{c}\text { A53T } \\
\text {-B. }\end{array}$ & $\begin{array}{c}\text { A53T } \\
\text { +B. }\end{array}$ & $\begin{array}{c}\text { eGFP } \\
\text {-B. }\end{array}$ & $\begin{array}{c}\text { eGFP } \\
\text { +B. }\end{array}$ \\
\hline Mittelwert & 30,83 & 40,54 & 38,05 & 35,97 & 31,90 & 44,89 & 34,71 & 39,66 \\
\hline $\begin{array}{c}\text { Standardfehler } \\
\text { des Mittelwertes }\end{array}$ & $\pm 1,27$ & $\pm 1,60$ & $\pm 1,52$ & $\pm 1,32$ & $\pm 1,48$ & $\pm 2,41$ & $\pm 1,41$ & $\pm 1,56$ \\
\hline
\end{tabular}

Tab. 3.4 Anzahl der LC3-positiven Autophagosomen transfizierter nicht-dopaminerger Mittelhirnneurone ohne (,-B.“) und mit (,+B.“) Bafilomycin A1-Behandlung. DIV5, $n=180$ aus 3 unabhängigen Zellkulturen.

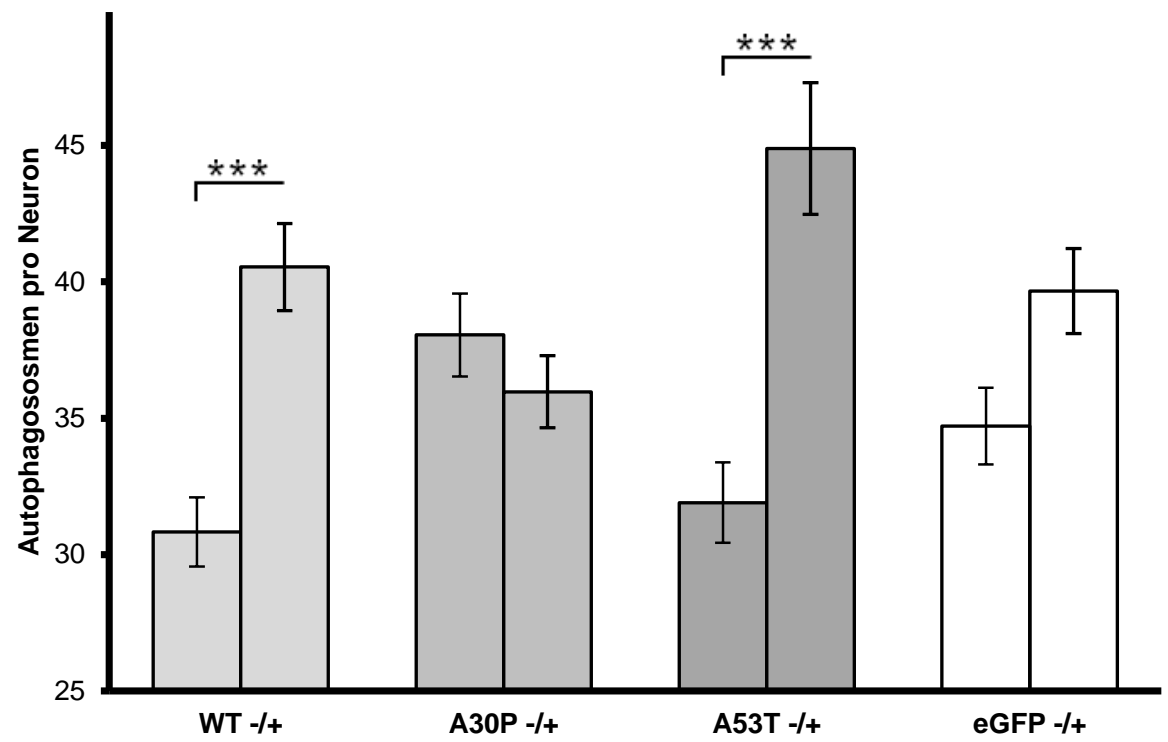

Abb. 3.15 Anzahl der LC3-positiven Autophagosomen transfizierter nicht-dopaminerger Mittelhirnneurone ohne (-) und mit (+) Bafilomycin $A_{1}$-Behandlung. Es zeigt sich ein signifikanter Anstieg der LC3-positiven Autophagosomen nach Bafilomycin $A_{1}$-Behandlung im Vergleich zur unbehandelten Population in der a-Syn-WT- und A53T-Versuchsgruppe. DIV5, $\mathrm{n}=180$ aus 3 unabhängigen Zellkulturen, "-“: ohne Bafilomycin A $A_{1}$-Behandlung, „+“: mit Bafilomycin $A_{1}$-Behandlung, Fehlerbalken: Standardfehler des Mittelwertes; ${ }^{* * *}: p<0,001$ in One-Way ANOVA gefolgt von Tukey-Kramer-Post-hoc-Test.

Die folgende Abbildung soll beispielhaft die Unterschiede in der immunzytochemischen Färbung der Autophagosomen zwischen a-Syn-WT und eGFP als Kontrolle an transfizierten nicht-dopaminergen Neuronen ohne und mit Bafilomycin $A_{1}$-Behandlung darstellen (s. Abb. 3.16). Es zeigt sich hierbei deutlich der Anstieg der Anzahl LC3-positiver Autophagosomen nach der Bafilomycin $\mathrm{A}_{1}$-Behandlung und zusätzlich der Unterschied des a-Syn-WTs mit einem deutlich ausgeprägteren Anstieg im Vergleich zur eGFP-Kontrolle. 

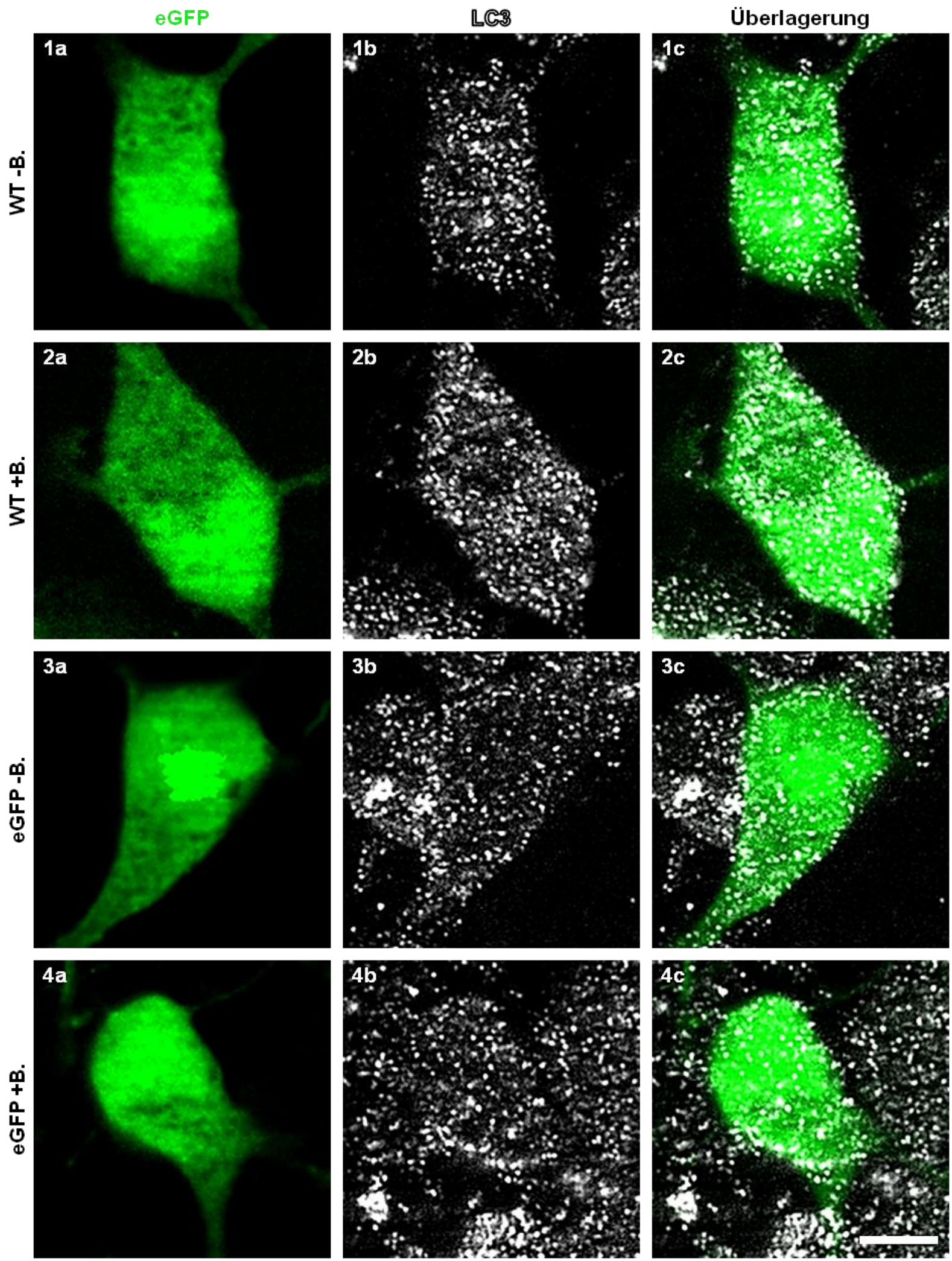

Abb. $\quad 3.16$ Repräsentative immunzytochemische Darstellung LC3-markierter Autophagosomen ohne und mit Bafilomycin $A_{1}$-Behandlung in nicht-dopaminergen Mittelhirnneuronen. (a) eGFPFluoreszenz, (b) LC3-Färbung, (c) Überlagerung von a und b; 1(a-c) a-Syn-WT ohne Bafilomycin $A_{1}-$ Behandlung, 2(a-c) $\alpha$-Syn-WT mit Bafilomycin $A_{1}$-Behandlung, 3(a-c) eGFP-Kontrollgruppe ohne Bafilomycin $\mathrm{A}_{1}$-Behandlung, 4(a-c) eGFP-Kontrollgruppe mit Bafilomycin $\mathrm{A}_{1}$-Behandlung. Primäre nicht-dopaminerge Mittelhirnneurone, DIV5, „-B.“: ohne Bafilomycin $A_{1}$, „+B.“: mit Bafilomycin $A_{1}$, Maßbalken: $5 \mu$ m, 63x-ÖlObjektiv. 


\begin{tabular}{|c|c|c|c|c|c|c|c|c|}
\hline & $\begin{array}{l}\text { WT } \\
\text { mit }\end{array}$ & $\begin{array}{l}\text { A30P } \\
\text { ohne }\end{array}$ & $\begin{array}{c}\text { A30P } \\
\text { mit }\end{array}$ & $\begin{array}{l}\text { A53T } \\
\text { ohne }\end{array}$ & $\begin{array}{c}\text { A53T } \\
\text { mit }\end{array}$ & $\begin{array}{l}\text { eGFP } \\
\text { ohne }\end{array}$ & $\begin{array}{c}\text { eGFP } \\
\text { mit }\end{array}$ \\
\hline & & \multicolumn{7}{|c|}{ Bafilomycin-Behandlung } \\
\hline $\begin{array}{c}\text { WT } \\
\text { ohne }\end{array}$ & \multirow{7}{*}{ 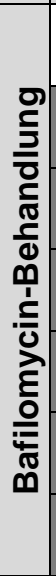 } & $5,4 \times 10^{-4}$ & 0,032 & 0,32 & 0,99 & $\begin{array}{c}2,21 x \\
10^{6}\end{array}$ & 0,68 & 0,0027 \\
\hline $\begin{array}{l}\text { WT } \\
\text { mit }\end{array}$ & & & 0,96 & 0,47 & 0,0037 & 0,54 & 0,17 & 0,99 \\
\hline $\begin{array}{l}\text { A30P } \\
\text { ohne }\end{array}$ & & & & 0,98 & 0,12 & 0,054 & 0,82 & 0,99 \\
\hline $\begin{array}{c}\text { A30P } \\
\text { mit }\end{array}$ & & & & & 0,63 & 0,0023 & 0,99 & 0,73 \\
\hline $\begin{array}{l}\text { A53T } \\
\text { ohne }\end{array}$ & & & & & & $\begin{array}{c}2,55 x \\
10^{-6}\end{array}$ & 0,92 & 0,015 \\
\hline $\begin{array}{c}\text { A53T } \\
\text { mit }\end{array}$ & & & & & & & $\begin{array}{c}2,14 x \\
10^{-4}\end{array}$ & 0,29 \\
\hline $\begin{array}{l}\text { eGFP } \\
\text { ohne }\end{array}$ & & & & & & & & 0,36 \\
\hline
\end{tabular}

Tab. $\quad 3.5 \quad p$-Werte zwischen den Versuchsgruppen zur Anzahl LC3-positiver Autophagosomen transfizierter nicht-dopaminerger Mittelhirnneuronen ohne und mit Bafilomycin $A_{1}$-Behandlung. Signifikante Unterschiede hervorgehoben.

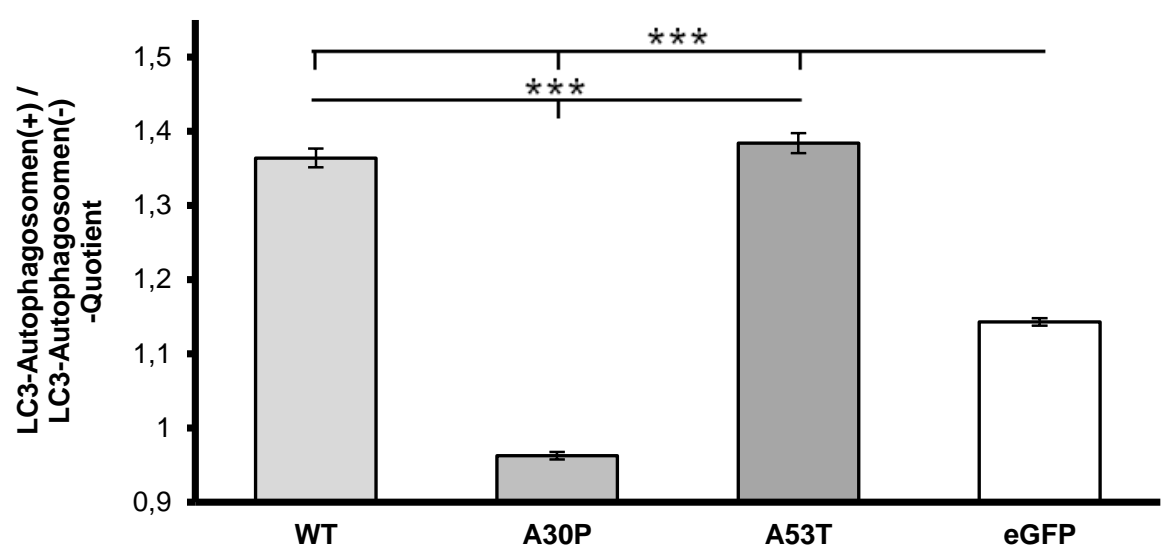

Abb. $\quad 3.17$ Analyse des Autophagie-Flusses transfizierter nicht-dopaminerger Mittelhirnneurone mittels LC3-Autophagosomen(+)-LC3-Autophagosomen(-)-Quotient in immunzytochemischer Färbung. Es zeigt sich ein signifikant erhöhter Autophagie-Fluss der mit a-Syn-WT- und A53T-transfizierten Neurone im Vergleich zur eGFP Kontrollgruppe. Dagegen ist bei den A30P-transfizierten Neuronen eine signifiikante Reduktion zu verzeichnen. Transfizierte nicht-dopaminerge Mittelhirnneurone ohne $($,-“) und mit (, ,+ B) Bafilomycin $\mathrm{A}_{1}$-Behandlung, DIV5, $\mathrm{n}=180$ aus 3 unabhängigen Zellkulturen, Fehlerbalken: Standardfehler des Mittelwertes, ${ }^{* * *}: p<0,001$ in One-Way ANOVA gefolgt von Tukey-Kramer-Post-hoc-Test.

\subsection{Chaperon-vermittelte Autophagie in primären dopaminer- gen Mittelhirnneuronen}

\subsubsection{LAMP-2A}

Im Rahmen der Chaperon-vermittelten Autophagie (CMA) dient LAMP-2A als Rezeptor, über den zu degradierende Proteine, welche mit dem Chaperon heat shock cognate protein of $70 \mathrm{kDa}$ (hsc70) an einer Pentapeptid-Sequenz (KFERQ) verbunden und somit markiert sind, in Lysosomen transportiert und dort enzymatisch abgebaut werden (s. auch 1.3.2). Hierbei kommt es zu einer Verschiebung der lysosomalen Strukturen in die 
Nähe des Zellkerns, sodass eine zellkernnahe Akkumulation von LAMP-2A-positiven Lysosomen für eine Steigerung der CMA spricht (Cuervo und Dice 2000).

Zur Untersuchung der Effekte von a-Syn auf die CMA wurden die primären Mittelhirnneurone daher immunzytochemisch gegen LAMP-2A gefärbt (s. Abb. 3.18) und die Akkumulation von Lysosomen in Nähe des Zellkerns gemessen.
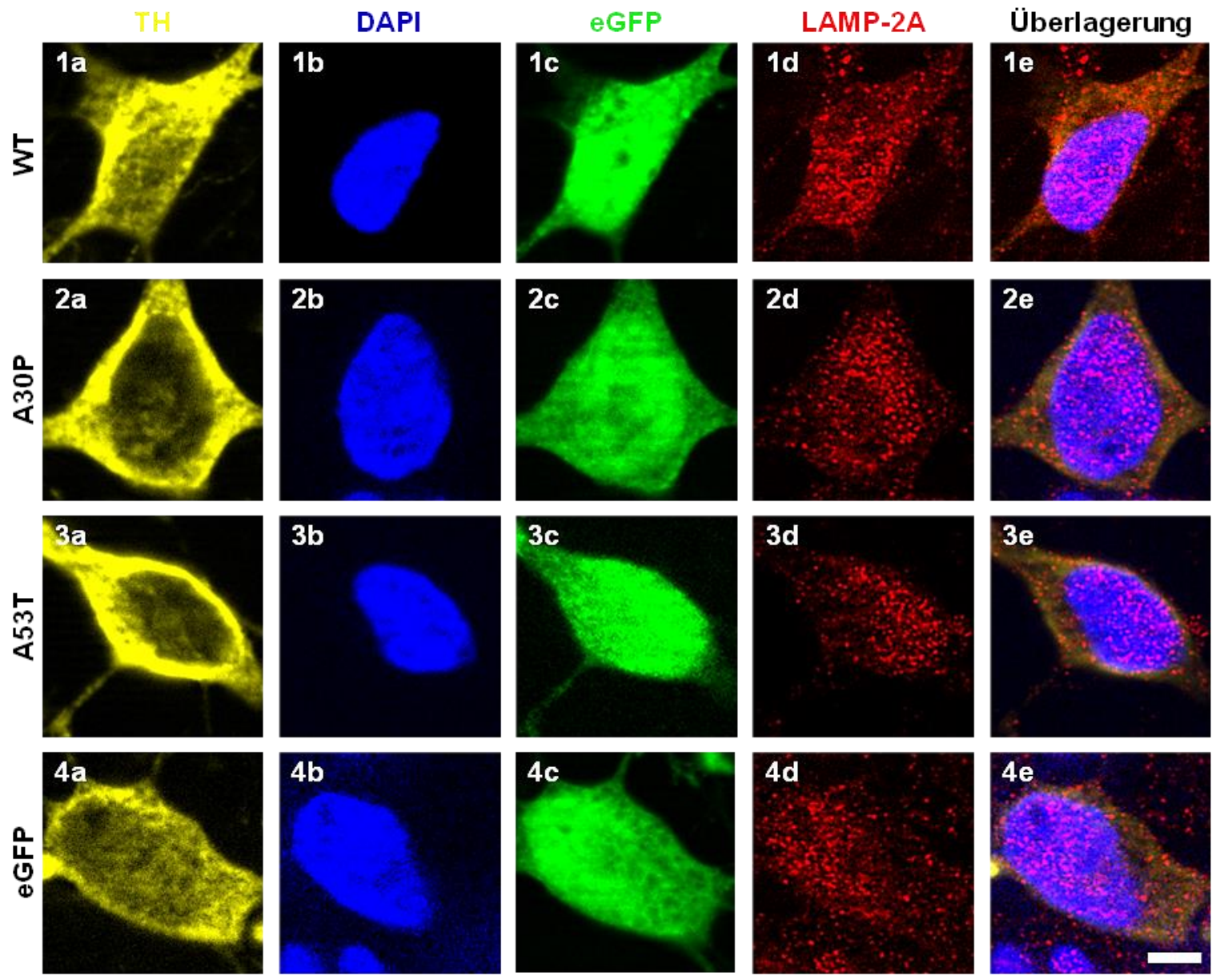

Abb. 3.18 Exemplarische Darstellung der immunzytochemisch gegen LAMP-2A markierten Lysosomen. (a) TH-Färbung, (b) eGFP-Fluoreszenz, (c) LAMP-2A-Färbung, (d) DAPI-Zellkernfärbung, (e) Überlagerung von a, b und d. Primäre dopaminerge Mittelhirnneurone, DIV5, Maßbalken: $5 \mu \mathrm{m}, 63 x-O ̈ l-$ Objektiv.

Zur Quantifizierung der CMA wurde die Anzahl LAMP-2A-positiver Lysosomen in Relation zum Abstand vom Zellnukleus ermittelt, um hierüber Aussagen über die Aktivität der CMA zu erlangen, da, wie bereits erwähnt, die Akkumulation LAMP-2A-positiver Lysosomen in Richtung Nukleus für eine gesteigerte CMA spricht. Hierbei zeigte sich bei den mit $\alpha$-SynWT transfizierten dopaminergen Neuronen eine signifikant höhere Anzahl an nukleusnahen LAMP-2A-positiven Lysosomen. Die übrigen Versuchsgruppen einschließlich der eGFPKontrolle wiesen keine Unterschiede auf. Dies legt eine gesteigerte Aktivität der CMA bei den a-Syn-WT-transfizierten Neuronen nahe. 
Die folgende Graphik (s. Abb. 3.19) und Tabelle (s. Tab. 3.6) sollen die Anzahl der LAMP-2A-positiven Lysosomen im jeweiligen Radiusbereich der einzelnen Versuchsgruppen darstellen und anschließend werden sämtliche Signifikanzvergleiche zur a-Syn-WTVersuchsgruppe an den einzelnen Abstandsbereichen gezeigt.

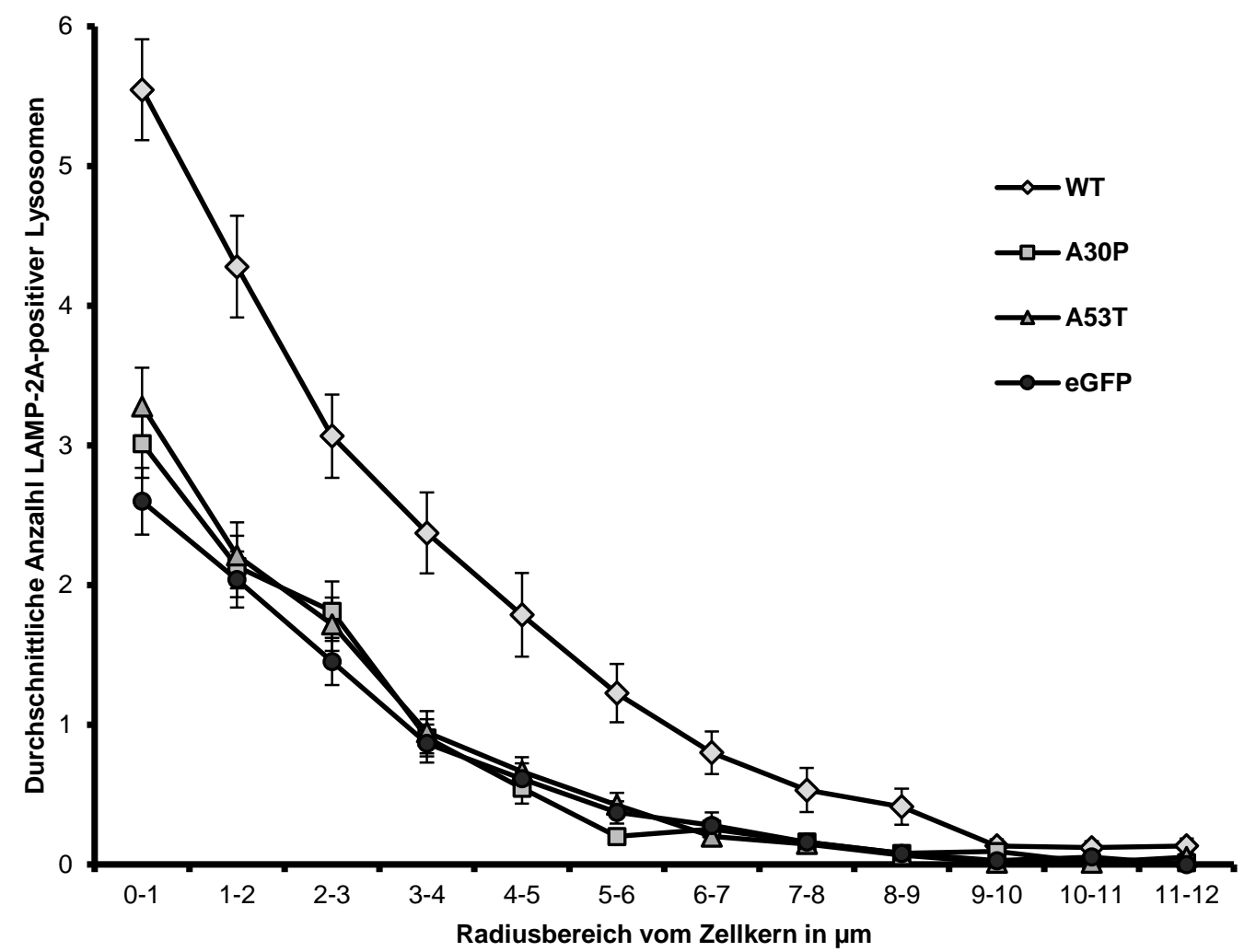

Abb. 3.19 Durchschnittliche Anzahl der LAMP-2A-positiven Lysosomen in verschiedenen Abstandsradien zum Nukleus. Es zeigt sich eine gesteigerte Chaperon-vermittelte Autophagie beim a-SynWT im Vergleich zu den anderen Gruppen (s. Tab. 3.6). Transfizierte dopaminerge Mittelhirnneurone, DIV5, $\mathrm{n}=450$ Einzelmessungen an 75 Neuronen aus 3 unabhängigen Zellkulturen. Die einzelnen Messpunkte wurden zur besseren Visualisierung miteinander verbunden. 


\begin{tabular}{|c|c|c|c|c|}
\hline & \multicolumn{4}{|c|}{$\begin{array}{c}\text { Durchschnittliche Anzahl LAMP-2A-positiver Lysosomen } \\
\text { (Mittelwert } \pm \text { Standardfehler des Mittelwertes) }\end{array}$} \\
\hline Abstandsbereich & $\mathbf{W T}$ & $\mathbf{A 3 0 P}$ & A53T & eGFP \\
\hline $\mathbf{0 - 1} \boldsymbol{\mu m}$ & $5,5 \pm 0,36$ & $3,01 \pm 0,25$ & $3,28 \pm 0,28$ & $2,60 \pm 0,24$ \\
\hline $\mathbf{1 - 2} \boldsymbol{\mu m}$ & $4,28 \pm 0,36$ & $2,13 \pm 0,22$ & $2,21 \pm 0,24$ & $2,04 \pm 0,20$ \\
\hline $\mathbf{2 - 3} \boldsymbol{\mu m}$ & $3,07 \pm 0,30$ & $1,81 \pm 0,21$ & $1,72 \pm 0,19$ & $1,45 \pm 0,17$ \\
\hline $\mathbf{3 - 4} \boldsymbol{\mu m}$ & $2,37 \pm 0,29$ & $0,91 \pm 0,13$ & $0,95 \pm 0,15$ & $0,87 \pm 0,14$ \\
\hline $\mathbf{4 - 5} \boldsymbol{\mu m}$ & $1,79 \pm 0,30$ & $0,55 \pm 0,11$ & $0,67 \pm 0,10$ & $0,61 \pm 0,11$ \\
\hline $\mathbf{5 - 6} \boldsymbol{\mu m}$ & $1,23 \pm 0,21$ & $0,20 \pm 0,05$ & $0,43 \pm 0,09$ & $0,37 \pm 0,08$ \\
\hline $\mathbf{6 - 7} \boldsymbol{\mu m}$ & $0,80 \pm 0,15$ & $0,25 \pm 0,07$ & $0,20 \pm 0,062$ & $0,28 \pm 0,09$ \\
\hline $\mathbf{7 - 8} \boldsymbol{\mu m}$ & $0,53 \pm 0,16$ & $0,16 \pm 0,05$ & $0,15 \pm 0,06$ & $0,16 \pm 0,05$ \\
\hline $\mathbf{8 - 9} \boldsymbol{\mu m}$ & $0,41 \pm 0,13$ & $0,08 \pm 0,03$ & $0,07 \pm 0,04$ & $0,08 \pm 0,04$ \\
\hline $\mathbf{9 - 1 0} \boldsymbol{\mu m}$ & $0,13 \pm 0,05$ & $0,09 \pm 0,04$ & $0,01 \pm 0,01$ & $0,03 \pm 0,02$ \\
\hline $\mathbf{1 0 - 1 1} \boldsymbol{\mu m}$ & $0,12 \pm 0,05$ & $0,01 \pm 0,01$ & $0,01 \pm 0,01$ & $0,05 \pm 0,04$ \\
\hline $\mathbf{1 1 - 1 2} \boldsymbol{\mu m}$ & $0,13 \pm 0,05$ & $0,01 \pm 0,01$ & $0,05 \pm 0,04$ & $0 \pm 0$ \\
\hline
\end{tabular}

Tab. $\quad 3.6 \quad$ Anzahl der LAMP-2A-positiven Lysosomen in den verschiedenen Abstandsradien vom Nukleus.

\begin{tabular}{|c|c|c|c|c|c|c|}
\hline & \multicolumn{6}{|c|}{ Signifikanzlevel (p-Wert) zur $\alpha$-Syn-WT-Versuchsgruppe } \\
\hline $\begin{array}{c}\text { Abstandsbereich } \\
\text { vom Nukleus }\end{array}$ & $0-1 \mu \mathrm{m}$ & $1-2 \mu \mathrm{m}$ & 2-3 $\mu \mathrm{m}$ & 3-4 $\mu \mathrm{m}$ & 4-5 $\mu \mathrm{m}$ & 5-6 $\mu \mathrm{m}$ \\
\hline A30P & $1,65 \times 10^{-6}$ & $1,76 \times 10^{-6}$ & 0,00052 & $2,18 \times 10^{-6}$ & $8,53 \times 10^{-6}$ & $1,70 \times 10^{-6}$ \\
\hline A53T & $1,90 \times 10^{-6}$ & $2,00 \times 10^{-6}$ & 0,00016 & $2,80 \times 10^{-6}$ & $6,27 \times 10^{-5}$ & $3,80 \times 10^{-5}$ \\
\hline eGFP & $1,65 \times 10^{-6}$ & $1,68 \times 10^{-6}$ & $5,10 \times 10^{-6}$ & $1,89 \times 10^{-6}$ & $2,53 \times 10^{-5}$ & $1,06 \times 10^{-5}$ \\
\hline & \multicolumn{6}{|c|}{ Signifikanzlevel (p-Wert) zur $\alpha$-Syn-WT-Versuchsgruppe } \\
\hline $\begin{array}{l}\text { Abstandsbereich } \\
\text { vom Nukleus }\end{array}$ & 6-7 $\mu \mathrm{m}$ & 7-8 $\mu \mathrm{m}$ & 8-9 $\mu \mathrm{m}$ & 9-10 $\mu \mathrm{m}$ & $10-11 \mu \mathrm{m}$ & $11-12 \mu \mathrm{m}$ \\
\hline A30P & 0,00082 & 0,023 & 0,0074 & 0,84 & 0,098 & 0,061 \\
\hline A53T & 0,00018 & 0,017 & 0,0048 & 0,065 & 0,098 & 0,34 \\
\hline eGFP & 0,0017 & 0,023 & 0,0074 & 0,12 & 0,47 & 0,029 \\
\hline
\end{tabular}

Tab. 3.7 p-Werte der A30P-, A53T- und eGFP-Versuchsgruppe zur $\alpha$-Syn-WTVersuchspopulation zur Anzahl LAMP-2A-positiver Lysosomen in verschiedenen Abstandsradien vom Nukleus. Es zeigt sich eine signifikante Erhöhung der Anzahl nukleusnaher LAMP-2A-positiver Lysosomen in der a-Syn-WT-Versuchsgruppe verglichen mit den weiteren Populationen, als Zeichen einer gesteigerten CMA der $\alpha$-Syn-WT-Versuchsgruppe. Transfizierte dopaminerge Mittelhirnneurone, DIV5, $\mathrm{n}=450$ Einzelmessungen an 75 Neuronen aus 3 unabhängigen Zellkulturen, signifikante Unterschiede $(p<0,05$ in OneWay ANOVA gefolgt von Tukey-Kramer-Post-hoc-Test) hervorgehoben. 


\subsection{Axonaler Transport}

Ein weiterer Mechanismus, der für die neuronale Funktionsfähigkeit und Integrität neuronaler Strukturen von besonderer Bedeutung ist, ist der axonale Transport von Zellsubstraten, Organellen oder Vesikeln in die peripher gelegenen Axonabschnitte bzw. der Rücktransport dieser in das Soma einer Zelle (s. auch 1.4).

\subsubsection{Visualisierung des axonalen Transportes - Synaptophysin}

Ein wesentliches Protein und neben Synaptobrevin mit $7 \%$ der Gesamtproteinmenge eines synaptischen Vesikels (McMahon et al. 1996) das zweithäufigste Oberflächenprotein synaptischer Vesikel ist Synaptophysin. Das Protein selbst wird vom SYP-Gen (X-Chromosom) codiert und besteht aus 313 Aminosäuren mit einem Molekulargewicht von ca. 38 kDa. Es hat vier Transmembrandomänen, mit welchen es in die Membran der synaptischen Vesikel integriert wird und hierbei einen Komplex aus vier Synaptophysin-Proteinen in Verbindung mit einem Synaptobrevin ausbilden kann (Khvotchev und Südhof 2004, Edelmann et al. 1995, Calakos und Scheller 1994, Johnston und Südhof 1990).

Synaptophysin erfült eine wesentliche Rolle im Rahmen der Wiederaufnahme (Endozytose) exozytierter synaptischer Vesikel und ist darüber hinaus an der Regulation dieses Prozesses beteiligt (Rajappa et al. 2016, Edelmann et al. 1995). Dabei ist im Rahmen der Endozytose Neurotransmitter-haltiger Vesikel, deren Inhalt durch den SNAREProteinkomplex in den synaptischen Spalt ausgeschüttet wurde (Jahn und Scheller 2006, Söllner et al. 1993a und 1993b), die Interaktion mit Synaptobrevin von wesentlicher Bedeutung (Khvotchev und Südhof 2004, Becher et al. 1999, Washbourne et al. 1995, Calakos und Scheller 1994).

Aufgrund dieser Zusammenhänge und des daraus resultierenden ubiquitären Vorkommens von Synaptophysin in synaptischen Vesikeln, ist die Darstellung von Synaptophysin - bspw. mittels Kopplung an eigenfluoreszierende Proteine wie eGFP - in lebenden Organismen oder Zellkulturen eine elegante Möglichkeit zur Visualisierung des axonalen Transportes. Daher wurden die Mittelhirnneurone zur Analyse des axonalen Transportes mit einem Synaptophysin-eGFP-exprimierenden AAV behandelt.

\subsubsection{Optimierung des Versuchsaufbaus}

\subsubsection{Virusdosis}

Zunächst musste eine geeignete Virusdosis gefunden werden, die ausreichend Neurone transfizierte und eine optimale Menge an Vesikeln sichtbar machte, ohne toxisch zu wirken. Hierfür wurde eine Konzentrationsreihe mit verschiedenen Mengen an Virus 
durchgeführt. Es wurden pro Well einer 24-Lochzellkulturplatte die jeweiligen Virusdosen nach dem unter 2.2.4.2 beschriebenen Protokoll zur Zellkultur hinzugegeben.

Bei der geringsten Dosis von 0,5 Virus-Transduktionseinheiten (=TU) konnten pro $0,147 \mathrm{~mm}^{2}$ (entspricht einem Gesichtsfeld in 20-facher Vergrößerung) durchschnittlich $14,5 \pm 1,41$ Virus-transfizierte Zellen gezählt werden. Mit Steigerung der Virusdosis auf 1,5 TU wurde die Anzahl Virus-transfizierter Zellen auf 23,73 $\pm 1,67$ erhöht und der Unterschied zu 0,5 TU war signifikant $(p=0,0058$, One-Way ANOVA gefolgt von TukeyKramer-Post-hoc-Test). Durch weitere Erhöhung der Virusdosis auf 3,0 TU konnte eine weitere Steigerung auf 38,12 $\pm 2,79$ Virus-transfizierte Zellen erreicht werden. Dieser Unterschied war sowohl zur 0,5 TU Versuchsgruppe $(p=0,0000016)$ als auch zur 1,5 TU Versuchsgruppe $(p=0,000013)$ signifikant.

Des Weiteren wurde die Toxizität der Virusbehandlung durch Quantifizierung der durchschnittlichen Zellzahl pro $0,147 \mathrm{~mm}^{2}$ für jede Versuchsgruppe ermittelt. Dabei wurden jeweils 13 Einzelmessungen durchgeführt. Es zeigte sich hierbei eine signifikant reduzierte Gesamtzellzahl in der mit 3,0 TU Virus-behandelten Versuchsgruppe von $383 \pm 25$ Zellen im Vergleich zur 0,5 TU Gruppe mit $570 \pm 15$ Zellen $(p=0,0000032)$ und zur mit 1,5 TU behandelten Versuchsgruppe mit durchschnittlich $567 \pm 28$ Zellen $(p=0,000056)$ (s. Abb. 3.20 und 3.21 A und B).
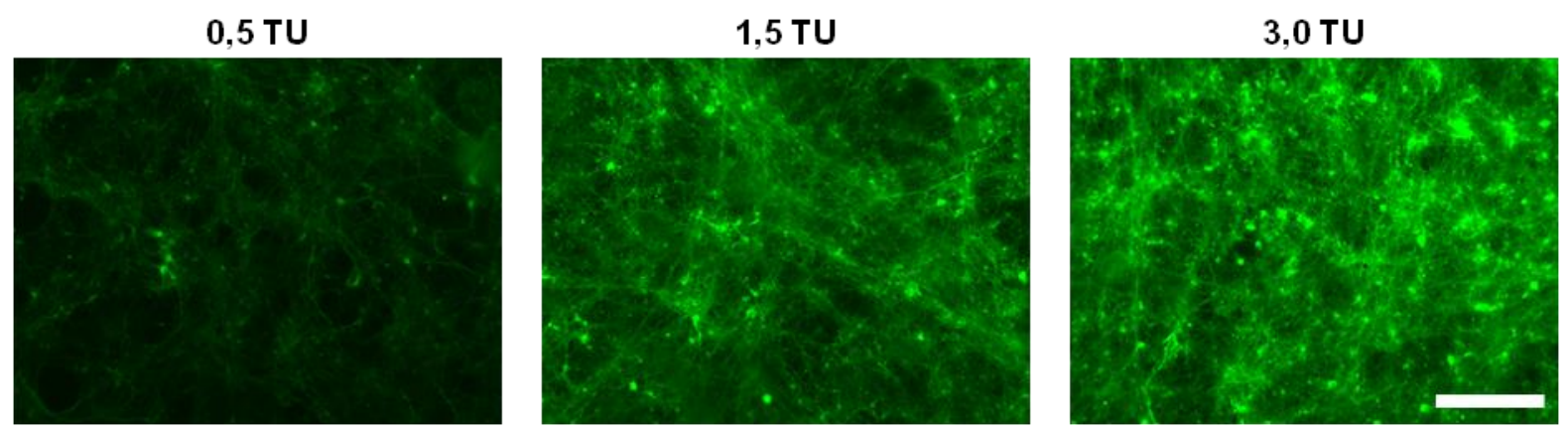

Abb. $\quad 3.20 \quad$ Synaptophysin-eGFP-transduzierte Zellen in Abhängigkeit von der eingesetzten Virusmenge von 0,5, 1,5 oder 3,0 TU. Zu erkennen ist die Steigerung der Synaptophysin-eGFP-Fluoreszenz mit Erhöhung der Virusdosis. Primäre Mittelhirnneurone, DIV5, Maßbalken: 200 m, 10x-Objektiv. 

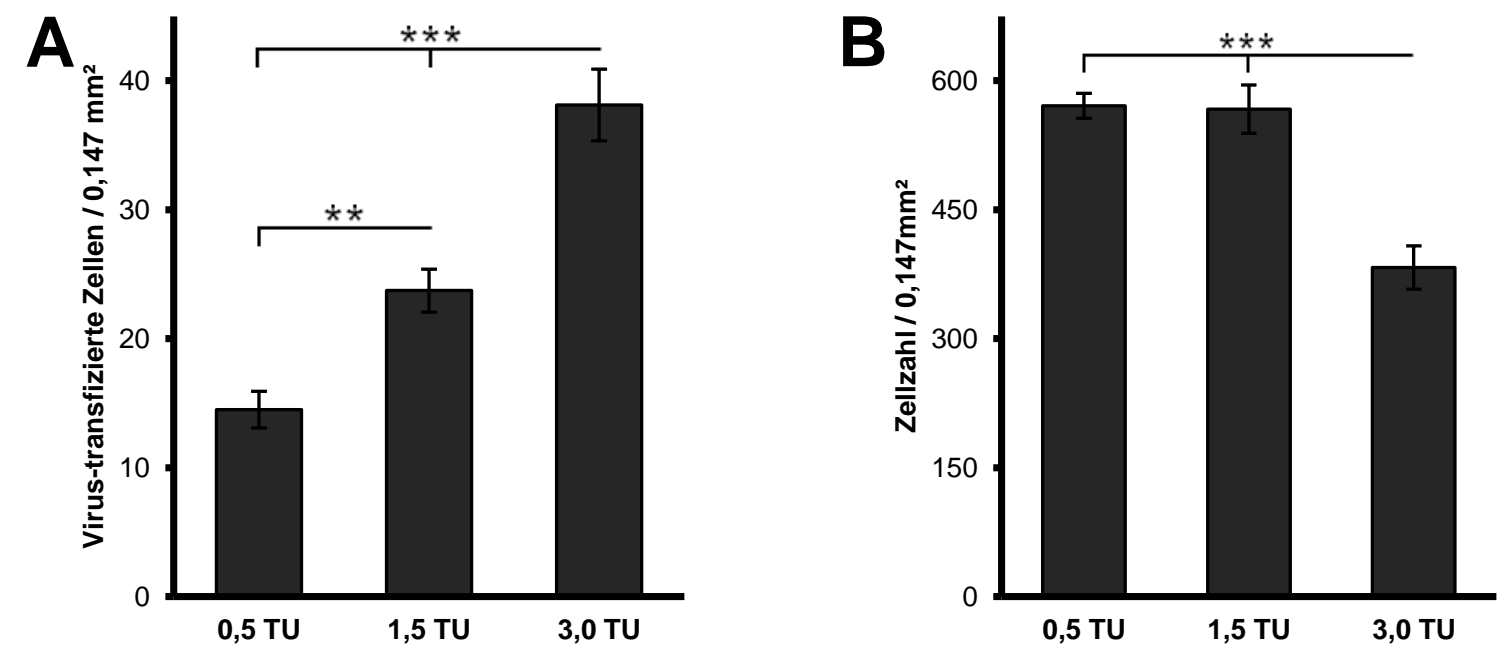

Abb. $\quad 3.21 \quad$ Optimierung der Synaptophysin-eGFP-Virustransduktion zur Analyse des axonalen Transportes in Mittelhirnneuronen. (A) Anzahl der Synaptophysin-eGFP-transduzierten Mittelhirnneurone bei unterschiedlicher Viruskonzentration. (B) Quantifizierung des Virus-induzierten Zelltodes bei unterschiedlicher Viruskonzentration. Es konnte eine signifikante Steigerung der Transduktionsrate sowie des Zelltodes mit zunehmender Virusmenge gezeigt werden. Primäre Mittelhirnneurone, DIV5, $n=13$ Gesichtsfelder in A und 26 Gesichtsfelder in B bei 10x-Vergrößerung, „TU“: Transduktionseinheiten, Fehlerbalken: Standardfehler des Mittelwertes; ${ }^{* *}: p<0,01,{ }^{* * *}: p<0,001$ in One-Way ANOVA gefolgt von Tukey-Kramer-Post-hoc-Test.

Aufgrund dessen wurde für die folgenden Versuche eine Synaptophysin-Virusdosis von 1,5 TU genutzt, da diese eine gute Transduktionsrate aufwies ohne einen anhand des Zelltodes ermittelten toxischen Effekt auf die Zellkultur auszuüben.

\subsubsection{Co-Transfektion von $\alpha$-Synuclein und DsRed}

Da das transduzierte Synaptophysin mit eGFP gekoppelt war, musste zur Visualisierung der a-Syn-Transfektion ein anderes Plasmid als eGFP, wie es in den vorhergehenden Versuchen genutzt wurde, co-transfiziert werden. Hierbei wurde sich für ein DsRed-exprimierendes Plasmid entschieden, da das Protein selbst rot fluoresziert. Der Ablauf der Transfektion sowie die Kultivierung der Zellen erfolgte analog zu allen anderen Versuchen mit dem Unterschied, dass die Zellen nicht in gewöhnlichen 24-Lochzellkulturplatten sondern in speziellen Zellkulturglaskammern kultiviert wurden, da diese die Fluoreszenzmikroskopie nicht beeinflussten. Zunächst wurde die Effizienz der CoTransfektion zwischen $\alpha$-Syn und DsRed untersucht. Hierbei zeigte sich eine 100\%ige CoTransfektion beider Plasmide, wie auf den folgenden Bildern beispielhaft für A53T und DsRed sowie der folgenden Quantifizierung ersichtlich wird. (s. Abb. 3.22 und 3.23). 

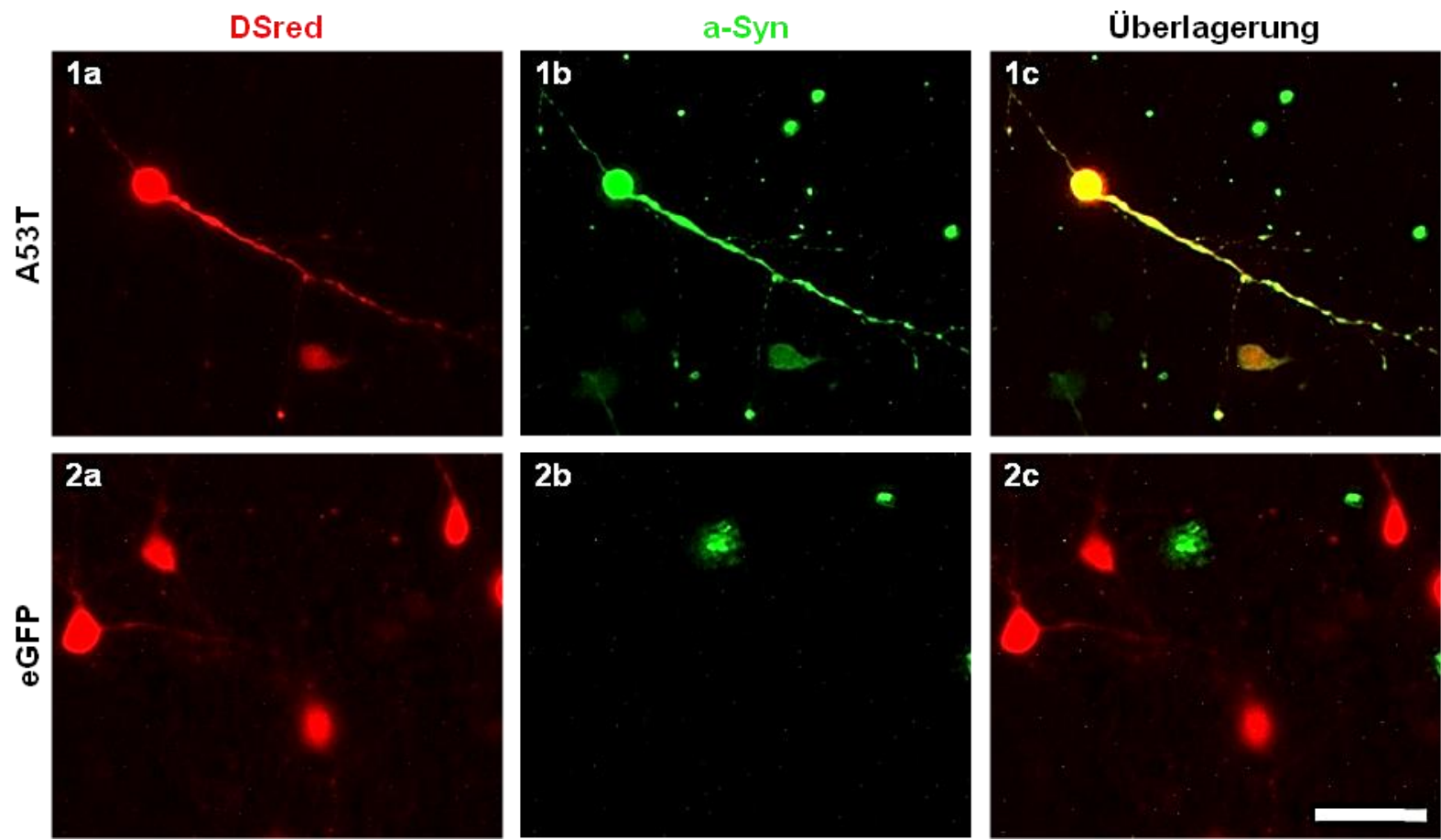

Abb. 3.22 Co-Transfektion und Expression von $\alpha$-Synuclein und DsRed in immuncytochemischer Färbung. (a) DsRed-Fluoreszenz, (b) $\alpha$-Syn-Färbung, (c) Überlagerung von a und b. Primäre Mittelhirnneurone, DIV5, Maßbalken: $25 \mu \mathrm{m}, 20 x-O b j e k t i v$.

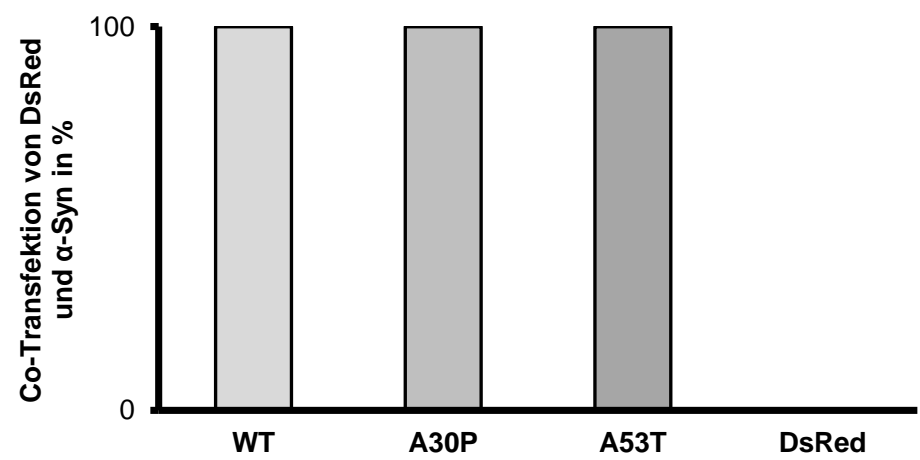

Abb. $\quad 3.23$ Quantifizierung der Co-Transfektion von $\alpha$-Synuclein und DsRed in Immunzytochemie. Es zeigt sich eine 100\%ige Co-Transfektion von DsRed und $\alpha$-Syn in den mit $\alpha$-Syn- und DsRedPlasmiden co-transfizierten Versuchsgruppen. In der Kontrollgruppe konnte a-Syn nicht nachgewiesen werden, sodass sich auch keine Co-Transfektion ergab. Primäre Mittelhirnneurone, DIV5, $\mathrm{n}=49$ (WT), 36 (A30P), 54 (A53T), 171 (DsRed) aus 3 unabhängigen Zellkulturen, Fehlerbalken: Standardfehler des Mittelwertes, ${ }^{* *}: p<0,001$ in One-Way ANOVA gefolgt von Tukey-Kramer-Post-hoc-Test.

\subsubsection{Vesikeltransport in $\alpha$-Synuclein-transfizierten Mittelhirnneuronen}

Die Auswertung der verschiedenen Parameter des Vesikeltransportes erfolgte, wie im Methodenteil dargestellt (s. auch 2.4 .2 und 2.4.3). Bei der Beurteilung der einzelnen Versuchsgruppen wurden verschiedene Parameter erhoben, die die Bewegung der Vesikel näher charakterisieren sollten, wobei in drei unabhängigen Versuchskulturen mehr als 400 Vesikel pro Gruppe gemessen wurden (WT: $n=460$, A30P: $n=444$, A53T: $n=462$, DsRed: $\mathrm{n}=597)$. Zum einen wurde die Durchschnittsgeschwindigkeit sämtlicher sich bewegenden und ruhenden Vesikel ermittelt und untereinander verglichen, zum anderen speziell die 
Geschwindigkeit sich bewegender Vesikel berechnet. Als Bewegung wurde eine Positionsänderung des Vesikels um mindestens $1 \mu \mathrm{m}$ innerhalb der aufgenommenen Zeitspanne von $10 \mathrm{~s}$ definiert, entsprechend einer Durchschnittsgeschwindigkeit von mindestens $0,1 \mu \mathrm{m} / \mathrm{s}$.

Dabei zeigte sich in der Kontrollgruppe eine durchschnittliche Vesikelgeschwindigkeit von $0,158 \pm 0,008 \mu \mathrm{m} / \mathrm{s}$. In den $\alpha$-Syn-transfizierten Versuchsgruppen war diese signifikant zur DsRed-Kontrolle reduziert. So zeigte sich für den $\alpha$-Syn-WT eine Geschwindigkeit von $0,085 \pm 0,006 \mu \mathrm{m} / \mathrm{s}\left(\mathrm{p}=1,64 \times 10^{-6}\right.$, One-Way ANOVA gefolgt von Tukey-Kramer-Post-hocTest), bei der A30P-Mutation von 0,120 $\pm 0,011 \mu \mathrm{m} / \mathrm{s}(\mathrm{p}=0,005)$ und für die A53T Mutation eine Durchschnittsgeschwindigkeit von $0,095 \pm 0,007 \mu \mathrm{m} / \mathrm{s}\left(\mathrm{p}=1,75 \times 10^{-6}\right)$. Der Unterschied zwischen A30P und $\alpha$-Syn-WT zeigte sich auch signifikant $(p=0,015)$ (s. Abb. $3.24(A))$.

Des Weiteren konnte auch ein Unterschied der Prozentzahl der sich bewegenden Vesikel zwischen den Versuchsgruppen festgestellt werden. Beim a-Syn-WT waren $25,91 \pm 4,45 \%$ der Vesikel in Bewegung, was gegenüber 44,24 $\pm 3,36 \%$ in der DsRedKontrollgruppe einen signifikanten Unterschied $(p=0,016$, One-Way ANOVA gefolgt von Tukey-Kramer-Post-hoc-Test) ausmachte. Auch bei der A30P-Mutation mit 33,06 $\pm 0,62 \%$ $(p=0,031)$ und der A53T-Mutation mit 26,15 $\pm 3,20 \%(p=0,018)$ konnten signifikant weniger bewegliche Vesikel gegenüber der Kontrolle festgestellt werden (s. Abb. 3.24 (B)).

Von diesen sich bewegenden Vesikeln wurden die durchschnittlichen Geschwindigkeiten ermittelt. Hierbei ergaben sich keine signifikanten Unterschiede ( $p=0,055$ in OneWay ANOVA) (s. Tab. 3.8 und Abb. 3.24 (C)).

\begin{tabular}{|c|c|}
\hline & Durchschnittsgeschwindigkeit in $\mu \mathrm{m} / \mathbf{s}$ \\
\hline WT & $0,25 \pm 0,015$ \\
\hline A30P & $0,31 \pm 0,025$ \\
\hline A53T & $0,28 \pm 0,018$ \\
\hline DsRed & $0,31 \pm 0,013$ \\
\hline
\end{tabular}

Tab. $\quad 3.8 \quad$ Durchschnittsgeschwindigkeit sich bewegender Vesikel (Geschwindigkeit $>\mathbf{0 , 1} \boldsymbol{\mu \mathrm { m }} / \mathrm{s}$ ). Es zeigten sich keine signifikanten Unterschiede zwischen den Versuchsgruppen. Primäre Mittelhirnneurone, DIV5, $n=460$ (WT), 444 (A30P), 462 (A53T), 597 (DsRed) aus 3 unabhängigen Zellkulturen.

Ein letzter Untersuchungspunkt war der Einfluss von a-Syn auf die durchschnittliche Anzahl an Geschwindigkeitsänderungen eines Vesikels. Hierdurch sollten Rückschlüsse auf die Beweglichkeit der Vesikel und der damit verbundenen Funktionsfähigkeit gewonnen werden. Beim a-Syn-WT konnten durchschnittlich 2,63 $\pm 0,08$, bei der A30P-Mutation 2,73 $\pm 0,08$ und bei der A53T-Mutation 2,70 $\pm 0,08$ Geschwindigkeitsänderungen gegenüber der DsRed-Kontrollgruppe mit 3,47 $\pm 0,09$ beobachtet werden. Dabei ergab sich eine signifikante Reduktion des $\alpha$-Syn-WTs $\left(p=2,63 \times 10^{-7}\right)$, der A30P-Mutation $\left(p=2,65 \times 10^{-7}\right)$ und der A53T-Mutation $\left(p=2,64 \times 10^{-7}\right)$ zur Kontrolle. Zwischen den mit $\alpha$-Syn-transfizierten 
Versuchsgruppen konnten keine signifikanten Unterschiede ermittelt werden (s. Abb $3.24(\mathrm{D}))$.
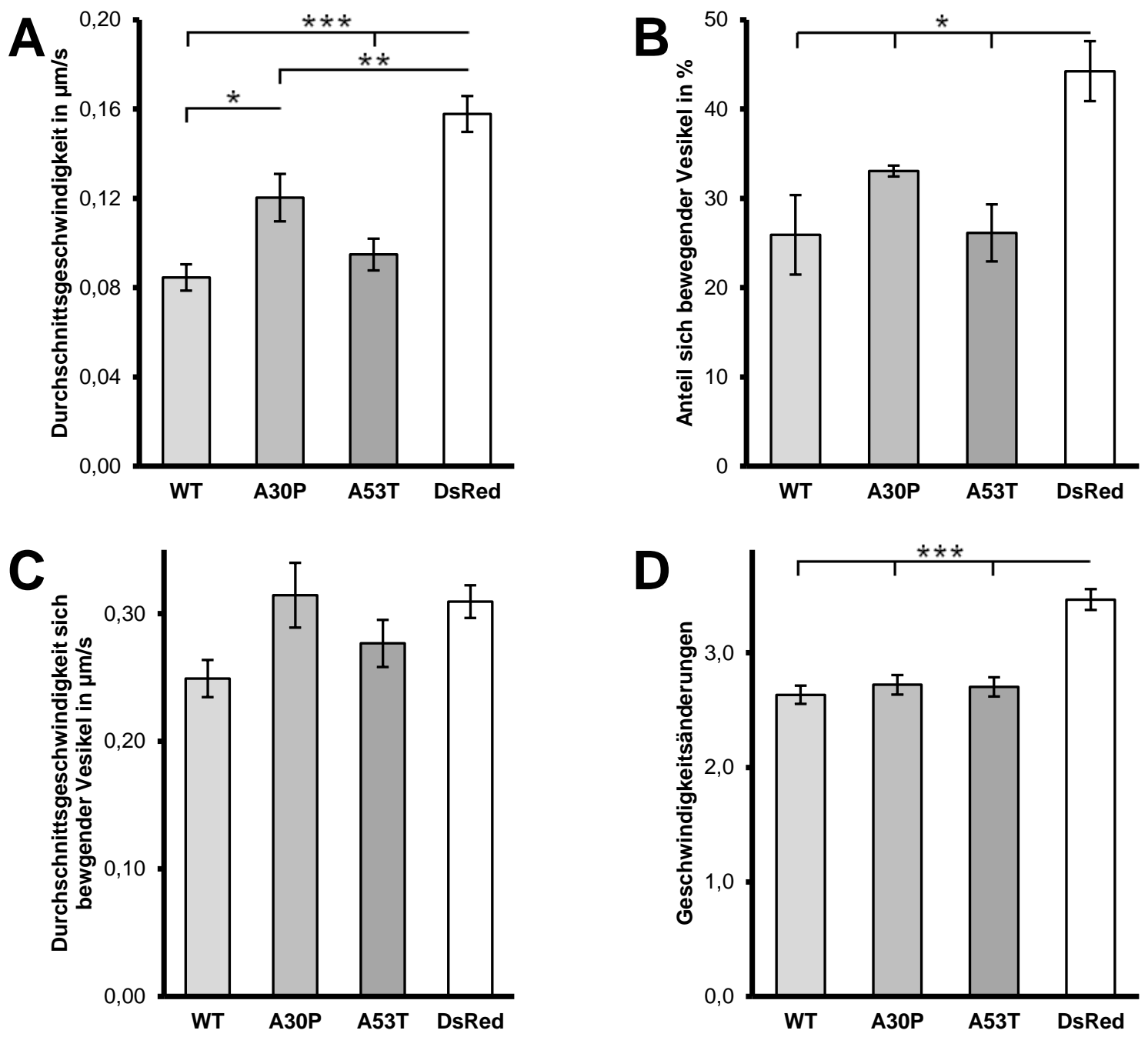

Abb. $\quad 3.24 \quad$ Analyseparameter des axonalen Transportes. (A) Durchschnittsgeschwindigkeit aller Vesikel. (B) Anteil sich bewegender Vesikel (Geschwindigkeit $>0,1 \mu \mathrm{m} / \mathrm{s}$ ). (C) Durchschnittsgeschwindigkeit der sich bewegenden Vesikel. (D) Geschwindigkeitsänderungen. Es zeigt sich eine signifikant reduzierte Gesamtdurchschnittsgeschwindigkeit aller Vesikel, bedingt durch eine deutlich verringerte Anzahl sich bewegender Vesikel mit weniger Geschwindigkeitsänderungen aller Vesikel in den a-Syn-transfizierten Versuchsgruppen im Vergleich zur DsRed-Kontrolle. Sofern nur sich bewegende Vesikel betrachtet werden, ergibt sich kein Unterschied in der Durchschnittsgeschwindigkeit. Primäre Mittelhirnneurone, $n=460$ (WT), 444 (A30P), 462 (A53T), 597 (DsRed), Fehlerbalken: Standardfehler des Mittelwertes, *: $p<0,05,{ }^{* *}: p<0,01$, $* * *: p<0,001$ in One-Way ANOVA gefolgt von Tukey-Kramer-Post-hoc-Test. 


\section{$4 \quad$ Diskussion}

Bislang ist die Pathogenese des iPS nur unzureichend verstanden. Wie bereits einleitend erwähnt, werden diverse Faktoren, darunter oxidativer Stress, Funktionsstörungen der zellulären Energiegewinnung (mitochondriale Dysfunktion), Fehlfunktionen des intrazellulären Proteinabbaus, pathologische Ausbreitung von Proteinaggregaten oder aber auch gestörte zelluläre Transportmechanismen, diskutiert. Letztlich führt das Zusammenspiel dieser veränderten zellulären Abläufe zum Absterben dopaminerger Neurone im Bereich der Substantia nigra im Mittelhirn, aber auch anderer nicht-dopaminerger Neurone des zentralen Nervensystems, wodurch die beschriebenen extrapyramidal-motorischen und die nichtmotorischen Symptome des iPS entstehen.

Es wurden daher verschiedene wissenschaftliche Modelle in-vitro und in-vivo entwickelt, die der näheren Charakterisierung der veränderten zellulären Abläufe dienen. Auf Grundlage der besonderen Bedeutung des Proteins $\alpha$-Synuclein und eines beschriebenen Gen-Dosis-Effektes in Parkinsonsyndromen (Tan et al. 2003), wurde in der vorliegenden Arbeit die Methode der Transfektion mit human- $\alpha$-Syn-exprimierenden Plasmiden gewählt, um eine Mittelhirnzellkultur zu erstellen, die dieses Protein in seiner WT-Form sowie den pathogenetischen Mutationen A30P und A53T überexprimiert, um anschließend die hierdurch entstandenen Dysfunktionen im Bereich der Autophagie sowie des axonalen Transportes synaptischer Vesikel zu untersuchen. Aufgrund des von Tan et al. diskutierten Gen-Dosis-Effektes, der durch die Verdopplung oder Verdreifachung des a-Syn-Gens und damit einhergehender 2-3-facher Gesamtproteinmenge von a-Syn ein Parkinsonsyndrom verursacht, war es wichtig, dass die Überexpression keine übermäßige $\alpha$-SynProteinmenge, sondern lediglich eine milde Steigerung auf das 2-3-Fache der nativen a-Syn-Expression bewirkt, um ein realitätsnahes Modell der Parkinsonerkrankung zur weiteren Analyse zu nutzen. Im Rahmen von Western Blot-Analysen zeigte sich eine durchschnittlich 2,11-fache Überexpression von $\alpha$-Syn nach Transfektion der human- $\alpha$-Synexprimierenden Plasmide (s. auch 3.1), wodurch der grundlegende Versuchsaufbau dieser Arbeit neben den pathogenetischen Mutationen auch den Gen-Dosis-Effekt adäquat widerspiegelt und zur In-vitro-Simulation des Parkinsonsyndroms geeignet ist.

\subsection{Autophagie}

Ein wesentlicher intrazellulärer Prozess zum Erhalt der zellulären Homöostase ist der Abbau sowie das damit einhergehende Recycling zu degradierender Proteine. Ist dieser Prozess gestört, kommt es zur Akkumulation und Aggregation von Proteinen in der Zelle, was langfristig toxische Effekte haben kann, wobei auch protektive Effekte der höhermolekularen Aggregate diskutiert wurden. Aggregiertes a-Syn findet sich als Haupt- 
bestandteil von Lewy-Körperchen, die das wesentliche histopathologische Korrelat des iPS sind. Daher ist eine Störung des intrazellulären Proteinabbaus von $\alpha$-Syn naheliegend. Zunächst wurde das Proteasomen-System, worüber ubiquitinierte Proteine abgebaut werden, als primärer Abbauprozess für a-Syn angesehen (Imai et al. 2000, Bennett et al. 1999), jedoch verdichtete sich im Verlauf aktuellerer Forschungsarbeiten die Evidenz dafür, dass die Degradation von $\alpha$-Syn hauptsächlich mittels lysosomaler Strukturen geschieht (Batelli et al. 2011, Cuervo et al. 2004, Lee et al. 2004, Webb et al. 2003). So konnte durch die spezifische Blockade der Makroautophagie mittels 3-Methyladenin sowohl eine Akkumulation von überexprimierten humanem $\alpha$-Syn als auch von endogenem Ratten- $\alpha$-Syn in Zellkulturexperimenten bewirkt werden (Vogiatzi et al. 2008). Passend hierzu führte die Behandlung von $\alpha$-Syn-überexprimierenden Zellkulturen mittels der Makroautophagie steigernden Substanz Rapamycin zu einem signifikant gesteigerten Abbau von aggregiertem a-Syn (Lee et al. 2004). Neben diesen pharmakologischen Modulationen der Makroautophagie konnten auch genetische Alterationen aufgezeigt werden, die eine Veränderung der Makroautophagie zur Folge haben und letztlich in einer vererbbaren Form des Parkinsonsyndroms enden. So zeigten Zavodszky et al., dass eine Mutation im PARK17-Gen (D620N), welches das Protein VPS35 (vacuolar protein sorting-associated protein 35) codiert, die Initiation der Autophagie und somit die Proteindegradation hemmt (Zavodszky et al. 2014). Darüber hinaus fand sich ein gestörter Abbau von $\alpha$-Syn sowie eine erhöhte Neurotoxizität ausgelöst durch dysfunktionelles VPS35 im Drosophila-Parkinsonmodell (Miura et al. 2014). Ebenso führen Mutationen des PARK9-Gens (codiert die lysosomale ATPase Atp13a2) zu einer lysosomalen Dysfunktion und können hierüber ein autosomalrezessiv vererbtes Parkinsonsyndrom auslösen (Ramirez et al. 2006).

Neben diesen zellkulturellen Versuchen ergaben sich in postmortalen Gehirnanalysen von Patienten mit einem Parkinsonsyndrom oder einer Lewy-Körperchen-Demenz Hinweise auf Veränderungen der Autophagosomen-Bildung bzw. der Proteindegradation (Anglade et al. 1997). In weiterführenden Studien konnte eine Akkumulation von LC3-II, die als Hinweis auf eine gesteigerte Autophagosomen-Bildung gedeutet wurde, gesehen werden (Kong et al. 2014, Klucken et al. 2012, Dehay et al. 2010, Chu et al. 2009, Webb et al. 2003, Zhu et al. 2003). So zeigten quantitative Proteinanalysen an postmortalem humanen Hirngewebe eine signifikante Erhöhung des endogenen Makroautophagie-Inhibitors mTOR (mechanistic target of rapamycin) und folgende Reduktion des Autophagie-induzierenden Proteins ATG7. Anschließende immunzytochemische Analysen an humanem Hirngewebe und an transgenen Mäusen zeigten eine deutliche Erhöhung LC3-positiver Puncta (entsprechend LC3-positiver Autophagosomen) sowie von a-Syn in den Zellen mit erhöhter mTOR-Proteinmenge, sodass eine Dysfunktion des Autophagie-Flusses mit folgender Akkumulation a-Syn-haltiger Autophagosomen postuliert wurde (Crews et al. 2010). 
Ergänzend hierzu durchgeführte Analysen an neokortikalen Neuronen a-Syn-transgener Mäuse nach Behandlung mit Rapamycin zeigten ebenso eine Erhöhung LC3-positiver Strukturen (Crews et al. 2010).

Im Gegensatz dazu zeigten Untersuchungen an A53T-überexprimierenden Zellkulturen (PC12-Zelllinie und Mittelhirnneurone) einen gesteigerten Autophagie-Fluss, welcher letztlich zu einem Anstieg LC3-positiver Autophagosomen sowie Autolysosomen und somit der Degradationspotenz der Makroautophagie führt (Choubey et al. 2011, Xilouri et al. 2009, Cuervo et al. 2004). Dies konnte auch in Versuchsreihen mit dem $\alpha$-Syn-WT, wenn auch in geringerer Ausprägung im Vergleich zur Mutationsform, gezeigt werden (Choubey et al. 2011, Spencer B et al. 2009, Xilouri et al. 2009).

Quantitative Proteinanalysen zeigten ebenso diskrepante Ergebnisse. So konnte invivo und in-vitro für den $\alpha$-Syn-WT und die A53T-Mutation eine Reduktion der p62Gesamtproteinmenge in kortikalen Neuronen der Maus und Ratte gezeigt werden (Choubey et al. 2011, Ebrahimi-Fakhari et al. 2011). Widersprechend hierzu wurde durch Winslow et al. 2010 eine Steigerung der p62-Proteinmenge gezeigt und daraus eine Hemmung der Autophagie durch den $\alpha$-Syn-WT abgleitet (Winslow et al. 2010). Hinsichtlich der LC3-IProteinmenge ergaben sich, passend zu den in dieser Arbeit beschriebenen Ergebnissen, keine signifikanten Unterschiede, ausgelöst durch die verschiedenen $\alpha$-Syn-Varianten (Chew et al. 2011, Choubey et al. 2011, Ebrahimi-Fakhari et al. 2011, Winslow et al. 2010, Spencer B et al. 2009). Dagegen wurden für die LC3-II-Proteinmenge sowohl Steigerungen (Choubey et al. 2011, Spencer B et al. 2009, Xilouri et al. 2009), gleichbleibende Proteinmengen (Chew et al. 2011, Ebrahimi-Fakhari et al. 2011, Winslow et al. 2010), aber auch reduzierte Werte gefunden (Winslow et al. 2010) und daraus sowohl AutophagieSteigerungen (Ebrahimi-Fakhari et al. 2011, Spencer B et al. 2009) als auch unveränderte (Chew et al. 2011) bis erniedrigte Autophagie-Prozesse (Winslow et al. 2010) abgeleitet. Auch durch die Behandlung mit Bafilomycin $A_{1}$ konnten insbesondere für den $\alpha$-Syn-WT keine einheitlichen Auswirkungen auf die LC3-II-Proteinmengen gesehen werden. So beschrieben Ebrahimi-Fakhari et al. und Spencer B et al. deutliche Kummulationen von LC3II, wohingegen Winslow et al. eine Erniedrigung festgestellt haben.

Da diese Arbeiten jedoch aufgrund der gewählten Methodik größtenteils keine adäquate Beurteilung des Autophagie-Flusses und damit des eigentlichen AutophagieStatus erlauben, ist anhand der daraus teils widersprüchlichen Ergebnisse bezüglich Makroautophagie-induzierender bzw. -inhibierender Proteine nicht abschließend zu beantworten, ob es sich, allein gemessen an der Menge LC3-II-positiver Autophagosomen, um eine Steigerung der Makroautophagie oder doch um einen gestörten Autophagie-Fluss und die damit verbundene Abbaustörung von LC3 handelt. 
Aufgrund dieser diskrepanten Ergebnisse, deren Aussagekraft durch die gewählten Versuchsanordnungen zum Teil nicht ausreichend zur Bewertung vor allem der Makroautophagie ist, wurde sich im Rahmen der vorliegenden Arbeit daher primär auf den Prozess der Makroautophagie konzentriert und erstmals eine Versuchsreihe mit adäquaten Kontrollgruppen ausgewertet, die eine valide Aussage über den Funktionsstatus der Makroautophagie in primären dopaminergen und nicht-dopaminergen Mittelhirnneuronen der Ratte erlaubt. Zusätzlich erfolgte eine ergänzende Auswertung des CMA-Funktionsstatus in diesem Zellkulturmodell.

\subsubsection{Makroautophagie}

Grundlegender Mechanismus der Makroautophagie ist die Ausbildung von Autophagosomen, welche die zu degradierenden Proteine umschließen. Nach Verschmelzung mit Lysosomen kommt es zum Abbau der Substrate durch die lysosomalen Proteasen (s. auch 1.3).

\subsubsection{Veränderungen der Proteinmenge von SQSTM1 (p62)}

Abzubauende poly-ubiquitinierte Proteine werden unter anderem über die Bindung an das Adaptorprotein p62 und die dadurch mögliche Interaktion mit dem AutophagosomRezeptor LC3 der lysosomalen Proteindegradation zugänglich gemacht. Hierbei kommt es sowohl zum Abbau des eigentlichen Zielproteins als auch des Vermittlers p62 selbst. Veränderungen der p62-Proteinmenge sind daher ein erster Anhaltspunkt für den Funktionsstatus der Makroautophagie, wobei reduzierte Werte primär auf eine gesteigerte Proteindegradation hindeuten.

Es konnte in der vorliegenden Arbeit anhand von quantitativen Western BlotAnalysen nach 5-tägiger Kultivierung der Mittelhirnneurone gezeigt werden, dass die Überexpression von a-Syn - sowohl des a-Syn-WTs als auch der beiden Mutationsformen A30P und A53T - in einer Mittelhirnneuronenzellkultur der Ratte die Proteinmenge von p62 im Vergleich zur eGFP-Kontrollgruppe signifikant um ca. 50 \% reduziert (s. auch 3.2.1), was zunächst auf eine gesteigerte Makroautophagie unter diesen Konditionen hindeutet. Ähnliches konnte zuvor bereits an kortikalen Neuronen der Ratte nach Plasmid-getriggerter Transfektion der a-Syn-A53T-Mutation gezeigt werden (Choubey et al. 2011). Allerdings werden die p62-Level in einer Zelle auch von der Produktion des Proteins und - neben der Autophagie - dem Abbau über das Ubiquitin-Proteasom-System beeinflusst, sodass eine direkte Korrelation mit der Autophagie nicht immer zutreffend ist. 


\subsubsection{Veränderungen von LC3-I und -II}

$\mathrm{Da}$ die alleinige Bestimmung der p62-Proteinmenge keine ausreichend valide Aussage über die aktuelle Aktivität der Makroautophagie erbringen kann, schließlich könnte dies auch Folge einer verringerten Proteinexpression sein, erfolgte die quantitative Analyse von LC3-I und -II sowohl im Western Blot als auch mittels Auszählung LC3-positiver Autophagosomen in immunzytochemischen Färbungen. Darüber hinaus erlaubte die Immunzytochemie eine differenzierte Untersuchung von dopaminergen und nichtdopaminergen Neuronen, wodurch eine mögliche spezifische Vulnerabilität der dopaminergen Neurone gegenüber der a-Syn-Überexpression untersucht werden konnte.

Im Rahmen der quantitativen LC3-Proteinanalyse der Mittelhirnneurone mittels Western Blot konnte eine signifikante Reduktion der LC3-II-Proteinmenge in den a-Syntransfizierten Neuronenpopulationen, welche nicht mit dem Makroautophagie-Inhibitor Bafilomycin $A_{1}$ behandelt wurden, gesehen werden. Ob es sich hierbei jedoch um eine Störung der Autophagosomen-Bildung, also eine inhibierte Makroautophagie, oder um einen gesteigerten Autophagie-Fluss mit beschleunigtem Abbau der Autophagosomen handelte, konnte erst nach Zugabe von Bafilomycin $A_{1}$ näher definiert werden. Hiernach zeigte sich ein überproportionaler Anstieg der LC3-II-Proteinmenge in den a-Syn-WT- und A53Ttransfizierten Versuchsgruppen. Die A30P-Mutation hingegen zeigte keine wesentliche Veränderung im Vergleich zur Kontrollgruppe. Da sich die LC3-I-Proteinmenge sowohl in den Bafilomycin $A_{1}$ unbehandelten als auch behandelten Versuchsgruppen nicht signifikant unterschied, spiegelte sich die beschriebene Änderung der LC3-II-Proteinmenge der einzelnen Versuchsgruppen auch in den LC3-II/LC3-I-Quotienten wider. Zusammengefasst werden diese Effekte letztlich durch den Quotienten aus Bafilomycin $A_{1}$ behandelter LC3-IIund unbehandelter LC3-II-Proteinmenge, wobei ein hoher Wert, wie er in der $\alpha$-Syn-WT- und A53T-Versuchsgruppe zu finden ist, für einen schnellen Auf- und Abbau von LC3-II-positiven Autophagosomen spricht, ein niedriger Quotient hingegen für einen langsamen Auf- und Abbau von Autophagosomen respektive auch einer langsamen Proteindegradation. Hierbei ergab sich ein signifikanter Unterschied in der a-Syn-WT- und A53T-Versuchsgruppe gegenüber der Kontrollpopulation, wohingegen die A30P Mutation keinen Unterschied aufwies, sodass letztlich die Überexpression der a-Syn-WT-Form sowie der A53T-Mutation einen gesteigerten Autophagie-Fluss bewirkt, wohingegen die A30P-Mutation keine Veränderung zur Folge hat.

Im Weiteren erfolgte die immunzytochemische Betrachtung der LC3-positiven Autophagosomen. Aufgrund der zusätzlichen TH-Färbung konnten dopaminerge Neurone separat betrachtet werden.

Es zeigten sich bei den dopaminergen Neuronen bereits ohne Bafilomycin $A_{1}$ Behandlung deutlich mehr LC3-positive Autophagosomen im Vergleich zur Kontrollgruppe, 
jedoch konnte sowohl beim a-Syn-WT und der A53T-Mutation als auch bei der Kontrollpopulation ein signifikanter Anstieg der LC3-Puncta nach der Bafilomycin $A_{1}$ Behandlung beobachtet werden. Der relative Anstieg war hierbei insbesondere in der $\alpha$-SynWT-Versuchsgruppe signifikant stärker ausgeprägt, wohingegen bei der A53T-Mutation der Anstieg dem der Kontrollgruppe entsprach. Einzig die A30P Mutation zeigte keine signifikante Veränderung der Anzahl LC3-positiver Autophagosomen.

Eine mögliche Interpretation dieser Ergebnisse ist, dass die verstärkte Induktion der Autophagie in den mit $\alpha$-Syn-WT- und A53T-transfizierten Neuronen im Vergleich zur Kontrollgruppe eine physiologische Reaktion der Neurone darstellt, um die erhöhten Proteinmengen von $\alpha$-Syn zu degradieren. Dies würde auch die gesteigerte Anzahl an Autophagosomen in den nativen, also Bafilomycin $A_{1}$ unbehandelten, mit $\alpha$-Syntransfizierten Neuronen erklären. Es zeigt sich in Verbindung mit den Western BlotAnalysen, dass in der Kontrollgruppe lediglich ein geringer Autophagie-Fluss, also ein geringes Ausmaß an autophagischer Proteindegradation, besteht. Dahingegen führen der a-Syn-WT und die A53T-Mutation zu einer signifikanten Steigerung des Autophagie-Flusses und der damit verbundenen Proteindegradation, wie zum einen aus der ausgeprägten Erhöhung der LC3-positiven Autophagosomen in der Immunzytochemie nach Bafilomycin $A_{1}$-Behandlung und zum anderen aus dem erhöhten LC3-II(Bafilomycin $A_{1}$ behandelt) / LC3II(Bafilomycin $A_{1}$ unbehandelt)-Quotienten im Western Blot zu entnehmen ist.

Im Unterschied zum a-Syn-WT und der A53T-Mutation ist in der A30PVersuchsgruppe weder eine Steigerung der Autophagosomenzahl nach Bafilomycin $A_{1}$ Behandlung noch eine Erhöhung des LC3-II(Bafilomycin $A_{1}$ behandelt)/LC3-II(Bafilomycin $A_{1}$ unbehandelt)-Quotienten erkennbar. Dies spricht im Vergleich zu den übrigen Versuchsgruppen für eine reduzierte Proteindegradation bzw. einen verminderten Autophagie-Fluss. Da sich aber in den nativen, also Bafilomycin $A_{1}$ unbehandelten Neuronen, nach Transfektion mit A30P, wie beim a-Syn-WT und A53T auch, eine im Vergleich zur Kontrollgruppe deutlich gesteigerte Anzahl an Autophagosomen findet, ist anzunehmen, dass auch hier eine verstärkte Induktion von Autophagie aufgrund der gesteigerten intrazellulären Proteinmenge stattfindet, dass diese aber auf der Ebene der Degradation von Autophagosomen blockiert wird und dadurch nicht effizient ablaufen kann. Hierin ist ein zuvor nicht beschriebener spezifischer Pathomechanismus der A30P-Mutation zu sehen.

Bei den nicht-dopaminergen Neuronen, welche ca. $90 \%$ der Gesamtzellkultur ausmachen, zeigte sich ein ähnliches Bild wie bei den Western Blot-Analysen der Gesamtzellkultur. Die initiale Autophagosomenzahl ohne Bafilomycin $A_{1}$-Behandlung zeigte sich zumindest beim a-Syn-WT und der A53T-Mutation reduziert, und nach der Behandlung mit Bafilomycin $A_{1}$ konnte ein signifikanter Anstieg verzeichnet werden. Wohingegen bei der A30P-Mutation keine signifikante Veränderung zur Kontrolle festgestellt werden konnte. Dies 
bedeutet wiederum einen gesteigerten Autophagie-Fluss in der $\alpha$-Syn-WT- und A53TVersuchsgruppe, wie anhand des signifikant gesteigerten Autophagsomen-Quotienten aus Bafilomycin $A_{1}$ behandelter und unbehandelter Subpopulation beider Versuchsgruppen zur eGFP-Kontrollgruppe zu erkennen ist. Vergleichend mit dem Quotienten der nichtdopaminergen Neurone kann den dopaminergen Neuronen somit eine höhere Vulnerabilität gegenüber der $\alpha$-Syn-Mutanten-Überexpression unterstellt werden und lediglich in der a-Syn-WT-Versuchsgruppe ist durch eine Steigerung des Autophagie-Flusses eine Kompensation gegenüber der Toxizität der $\alpha$-Syn-Überexpression möglich. Bei den nichtdopaminergen Neuronen ist auch für die A53T-Mutation aufgrund der ausgeprägten signifikanten Steigerung der Autophagosomenzahl nach Bafilomycin $A_{1}$-Behandlung in Verbindung mit dem daraus resultierend signifikant erhöhtem Quotienten der Autophagosomenzahl eine kompensatorische Steigerung zu erkennen, die den pathogenetischen Einfluss der A53T-Mutation positiv beeinflussen soll. Dass die A30PMutation sowohl in den dopaminergen als auch den nicht-dopaminergen eine reduzierte Autophagie zeigt, ist als mögliche spezifische Ursache der neuropathogenen Wirkung zu werten. Als Ursache dieser Wirkung ist bspw. die reduzierte Kolokalisation von $\alpha$-Syn-A30P und LC3 zu diskutieren (Koch et al. 2015), siehe unten.

Zusammenfassend konnte im Rahmen dieser Arbeit gezeigt werden, dass eine milde Überexpression des $\alpha$-Syn-WTs eine höchstwahrscheinlich als kompensatorische Wirkung auf die höhere $\alpha$-Syn-WT-Gesamtproteinmenge zu interpretierende Steigerung des Autophagie-Flusses sowohl in dopaminergen als auch nicht-dopaminergen Neuronen bewirkt, wogegen die a-Syn-A53T-Mutation lediglich in nicht-dopaminergen Mittelhirnneuronen eine Steigerung des Autophagie-Flusses zur Folge hat und in dopaminergen Neuronen der Autophagie-Fluss lediglich auf dem Niveau der Kontrollgruppe erhalten ist, wie anhand der immunzytochemischen Messung mit Ermittlung des AutophagosomenQuotienten aus Bafilomycin $A_{1}$ behandelter zu unbehandelter Versuchsgruppe vergleichend mit den Western Blot-Analysen zu entnehmen ist. Dies legt eine höhere Toxizität der A53TMutation in dopaminergen Neuronen nahe. Dahingegen konnte für die A30P-Mutation sowohl in den dopaminergen als auch nicht-dopaminergen Neuronen eine signifikante Reduktion des Autophagie-Flusses und damit der Proteindegradation beobachten werden.

Ähnlich wurde dies bereits an Zellkulturen bspw. von kortikalen Neuronen der Ratte und SH-SY5Y-Zellen für den a-Syn-WT und die A53T-Mutation demonstriert (Chew et al. 2011, Choubey et al. 2011, Xilouri et al. 2009, Cuervo et al. 2004) ohne dabei über den gleichzeitigen Vergleich mit einer Versuchsgruppe, deren Autophagie gänzlich blockiert wurde, eine valide Aussage über den tatsächlichen Autophagie-Fluss und damit den Funktionsstatus der Makroautophagie machen zu können. Daneben konnte gezeigt werden, dass die durch a-Syn induzierte Steigerung der Makroautophagie auch von dessen 
intrazellulärer Gesamtproteinmenge abhängt (Ebrahimi-Fakhari et al. 2011) und daher in dem gewählten Modell ggf. die alleinige Überexpression - zumindest des WTs und der A53T-Mutation - zu den beschriebenen Veränderungen führt. Entsprechende Studien bezüglich der A30P-Mutation bestehen zum jetzigen Zeitpunkt nicht, sodass eine vergleichende Aussage hierzu nicht getroffen werden kann. Da die A30P-Mutation jedoch keine Steigerung des Autophagie-Flusses bewirkt, ist hierin ein spezifischer pathogenetischer Mechanismus dieser Mutation zu sehen.

Ursächlich dafür kann eine reduzierte Fähigkeit zur Membranbindung der A30PMutation sein (Jo et al. 2002, Jensen PH et al. 1998). Dies konnte anhand quantitativer Proteinanalysen von Hirnlysaten der Ratte festgestellt werden. Hierbei wurden diese Lysate nach der Größe in zytosolische und vesikuläre Fraktionen separiert und anschließend die Proteinmenge von zuvor eingebrachtem Human- $\alpha-S y n$ (in verschiedenen Varianten: WT, A30P, A53T, $\alpha-S y n[30-140]$ und $\alpha-S y n[55-140])$ mittels Western Blot in den einzelnen Gruppen bestimmt. Hierbei zeigte sich eine fehlende Bindung des a-Syn-A30P zu vesikulären Membranstrukturen, wohingegen der a-Syn-WT und die A53T-Mutation keine veränderte Bindungsfähigkeit aufwiesen. Begründet liegt dies in der Membranbindungsdomäne, die durch die A30P-Mutation gestört wird (Jensen PH et al. 1998). In späteren Forschungsarbeiten konnte dieser Zusammenhang bestätigt werden (Jo et al. 2002). Zudem konnte in Co-Lokalisationsanalysen von $\alpha$-Syn und LC3 in dopaminergen Neuronen gezeigt werden, dass eine Interaktion von $\alpha$-Syn auch mit Membrananteilen der Autophagosomen stattfindet und sich diese bei der A30P-Mutation reduziert zeigte (Koch et al. 2015). Da trotz des reduzierten bzw. nicht gesteigerten Autophagie-Flusses die p62-Proteinmenge in der A30P-Versuchsgruppe reduziert ist, ist ggf. in der Negativregulation Autophagie-assoziierter Proteine wie bspw. p62 ein weiterer Pathomechanismus zu sehen.

Die zukünftige Entwicklung therapeutischer Konzepte basierend auf diesen Veränderungen der Makroautophagie bedarf sicherlich noch weiterer, vor allem pathomechanistischer Klärung. So sollten bspw. Analysen Autophagie-regulierender Proteine durchgeführt werden, um einen gezielten Therapiemechanismus entwickeln zu können. Anhand der in dieser Arbeit gewonnenen Erkenntnisse über die Auswirkungen der a-SynÜberexpression auf die Autophagie, die je nach $\alpha$-Syn-Variante und Zelltyp sowohl gesteigert als auch inhibiert sein kann und bekanntermaßen diese Veränderungen im Rahmen eines Parkinsonsyndroms zu finden sind, ist nicht allein die Hemmung respektive die Steigerung der Autophagie therapeutisch wichtig, sondern die Modulation der Autophagie auf das physiologische Maß. So könnte bspw. die Steuerung des Atg/ULKKomplexes (s. auch 1.3.1), welcher an der initialen Induktion der Autophagosomen-Bildung als einleitender Prozess der Makroautophagie beteiligt ist, als therapeutische Zielstruktur 
genutzt werden und je nach Notwendigkeit sowohl inhibierend als auch disinhibierend hierauf eingewirkt werden.

\subsubsection{Chaperon-vermittelte Autophagie}

Da die Autophagie aus drei Mechanismen, der Makro- und Mikroautophagie sowie der CMA, besteht, wurden zusätzlich Untersuchungen der CMA durchgeführt, um Hinweise auf eine kompensatorische Veränderung dieser weiteren lysosomalen Degradationsform zu erhalten.

Es wurde zuvor gezeigt, dass a-Syn-WT mittels der CMA degradiert werden kann, wohingegen die Parkinson-relevanten Mutationen A30P und A53T zwar wesentlich stärker an LAMP-2A (lysosomaler Rezeptor der CMA) binden können (Cuervo et al. 2004), anschließend jedoch keine Aufnahme in das Lysosom und somit auch keine Degradation erfolgt.

Durch die Blockade der CMA, bspw. mittels interferierender RNA gegen LAMP-2A oder durch eine mutationsbedingte Veränderung des CMA-Erkennungsmotivs des $\alpha$-Syns, wurde an humanen neuronalen Zelllinien und in primären Neuronenzellkulturen beobachtet, dass $\alpha$-Syn in seiner WT-Form wesentlich durch die CMA degradiert wird. So führte die Hemmung der CMA zur Ausbildung unlöslicher oder hochmolekularer a-Syn-Oligomere, sodass eine CMA-Dysfunktion als Auslöser einer Synucleinopathie diskutiert wird (AlvarezErviti et al. 2010, Vogiatzi et al. 2008). Darüber hinaus kann mittels CMA nur eine Degradation von $\alpha$-Syn-Monomeren oder -Dimeren erfolgen und posttranslationelle Veränderungen, wie Oxidation, Phosphorylierung oder Dopamin-bedingte Modifikationen von $\alpha$-Syn, verhindern teilweise nahezu komplett die Degradation des Proteins mittels CMA (Martinez-Vicente et al. 2008). Hierin ist - neben der fehlenden Einschleusung mutanten a-Syns in die Lysosomen - eine weitere Ursache der gestörten Proteindegradation zu sehen, da sowohl die A30P- als auch die A53T-Mutation zu einer gesteigerten Oligomerisierung des Proteins führen (Conway et al. 2000).

Dass die Hemmung der CMA, bspw. durch dysfunktionelles/mutiertes a-Syn (Xilouri et al. 2009, Martinez-Vicente et al. 2008, Cuervo et al. 2004), auch weitreichende Folgen für das zelluläre Überleben und somit neurodegenerative Toxizität hat, zeigen Studien, in denen die Überexpression von $\alpha$-Syn-WT oder -A53T und der hierdurch gestörte Abbau mittels CMA zu einer Fehlverteilung und damit einhergehenden Funktionsverlustes des Überlebensbzw. Apoptose-regulierenden Transkriptionsfaktors Mef2d (myocyte enhancer factor-2d) führt (Yang $Q$ et al. 2009). Zusätzlich konnte gezeigt werden, dass die $\alpha$-Syn-getriggerte Neurotoxizität auch durch Aufhebung der beschriebenen CMA-Störung rückgängig gemacht werden kann (Xilouri et al. 2009). Diese in Zellkulturmodellen gewonnenen Ergebnisse konnten in-vivo in a-Syn-A53T-transgenen Mäusen reproduziert werden, sodass diese 
Pathomechanismen auch in-vivo relevant zu sein scheinen (Murphy KE et al. 2015, Yang Q et al. 2009). So konnten in postmortalen Untersuchungen von Parkinsonpatienten reduzierte Proteinmengen der CMA-Schlüsselproteine LAMP-2A und Hsc70 zum Teil in zellulärer Korrelation mit a-Syn-Aggregaten gefunden werden. Darüber hinaus wurden auch erhöhte zytosolische Werte für Mef2d und IKBa (nuclear factor of kappa light polypeptide gene enhancer in B-cells inhibitor alpha), einem weiteren Zellproliferations- und Apoptoseregulierendem Protein, beobachtet (Murphy KE et al. 2015 und 2014, Alvarez-Erviti et al. 2010).

Demgegenüber sind jedoch auch Studien veröffentlicht, die an LAMP-2-KnockoutMäusen oder LAMP-2-defizienten Neuroblastomzellen keine Störung der CMA und somit auch keine Akkumulation von a-Syn oder anderer CMA-Substrate zeigen (Eskelinen et al. 2004) und dem gegenüber sogar erhöhte LAMP-2A-Werte in Gehirnen von LewyKörperchen-Demenzpatienten beschrieben wurden (Rothaug et al. 2015, Klucken et al. 2012).

Durch die Aktivierung der CMA erfolgt eine Verschiebung LAMP-2A-positiver Lysosomen in Richtung des Zellkerns, sodass immunzytochemisch eine perinukleäre Anreicherung LAMP-2A-positiver Lysosomen beobachtet werden kann, die einer Funktionssteigerung der CMA entspricht (Cuervo und Dice 2000). Dies zeigte sich spezifisch bei der a-Syn-WT-Form, wohingegen sich sowohl bei der A30P- als auch bei der A53T-Mutation keine Veränderung gegenüber der Kontrollgruppe fand. An PC12-Zellen, welche $\alpha$-Syn-WT oder eine der Mutationsformen A30P und A53T in äquivalenter Menge exprimierten, konnte eine deutlich erhöhte Affinität der $\alpha$-Syn-Mutationen im Vergleich zur a-Syn-WT-Form im Rahmen von Co-Immunopräzipitations-Analysen von LAMP-2A und $\alpha$-Syn beobachtet werden. Darüber hinaus wurde an isolierten Lysosomen eine verringerte Internalisierung der a-Syn-Mutationen im Vergleich zum a-Syn-WT verifiziert, weshalb zum einen der Abbau von a-Syn selbst, bedingt durch die stärkere Affinität zum lysosomalen Rezeptor LAMP-2A, aber auch der Abbau anderer CMA-Substrate, wie bspw. GAPDH (Glycerinaldehyd-3-phosphatDehydrogenase), inhibiert wird (Cuervo et al. 2004). Aufgrund dieser Ergebnisse ist die lediglich in der a-Syn-WT-Versuchsgruppe zu verzeichnende Steigerung der CMA nachvollziehbar. Ursächlich für die Steigerung der CMA beim a-Syn-WT könnte ein kompensatorischer Mechanismus, ausgelöst durch die erhöhte a-Syn-WT-Proteinmenge in den Neuronen, sein. Da a-Syn-WT selbst ein Substrat der CMA ist, führt dieses gesteigerte Substratangebot zu einer Aktivitätszunahme der CMA, um hierüber die toxischen Wirkungen zu reduzieren.

Eine Inhibition der CMA durch die A53T-Mutation, wie sie bspw. durch Xilouri et al. 2009 oder Martinez-Vicente et al. 2008 beschrieben wurde, konnte in dieser Versuchsreihe an primären dopaminergen Mittelhirnneuronen nicht verifiziert werden. Im Unterschied zu 
den hier analysierten primären dopaminergen Mittelhirnneuronen wurden durch Xilouri et al. Untersuchungen an Zellreihen (PC12 und SH-SY5Y) und primären kortikalen Neuronen durchgeführt, sodass allein der gewählte Zelltypus den Unterschied bedingen kann. Darüber hinaus erfolgte die Messung der CMA anhand des Umsatzes radioaktivmarkierter CMASubstrate (pulse-chase-Methode) und nicht über die perinukleäre Verschiebung lysosomaler Strukturen, sodass auch ein methodischer Unterschied besteht.

Es bleibt zu erwähnen, dass die Verschiebung der lysosomalen Strukturen in Richtung des Zellkerns zwar für eine Aktivitätszunahme der CMA spricht, jedoch quantitative Untersuchungen spezifischer CMA-Substrate [z. B. Ribonuklease A (Kaushik und Cuervo 2009) oder GAPDH (Cuervo et al. 2004)] folgen sollten, um auch Aussagen über die Abbaukapazität der CMA zu machen. Schließlich ist die Aufnahme der Substrate in die Lysosomen auch von der LAMP-2A-Proteinmenge abhängig, sodass quantitative Veränderungen, die im Rahmen einer immunzytochemischen Untersuchung methodisch bedingt nicht miterfasst werden können, die Abbaukapazität der CMA beeinflussen. Dies wiederum zeigt, dass weitere Analysen der CMA folgen sollten, um die Funktionsfähigkeit der CMA in a-Syn-überexprimierenden dopaminergen Mittelhirnneuronen noch weiter zu charakterisieren.

Insgesamt spiegeln die im Rahmen dieser Arbeit erhobenen Beobachtungen die bisherigen Forschungsergebnisse bezüglich der Auswirkungen von $\alpha$-Syn auf die CMAAktivität sehr gut wider, und ergänzende Untersuchungen, bspw. zum Substratabbau [z. B. mittels Western Blot-Analysen oder radioaktivmarkierten Substraten (Kaushik und Cuervo 2009)] oder der Funktionsfähigkeit und des quantitativen Vorhandenseins von LAMP-2A in der lysosomalen Membran [z. B. mittels Elektronenmikroskopie (Kaushik und Cuervo 2009)], können zur weiteren Klärung auch hinsichtlich pathomechanistischer Veränderungen beitragen.

Aufgrund der vorliegenden Ergebnisse ist anzunehmen, dass Störungen der Autophagie, ob Steigerung ( $\alpha$-Syn-WT und bedingt A53T) oder Inhibition (A30P), ausgelöst durch überexprimiertes und/oder mutiertes a-Syn kausal an der Entwicklung eines Parkinsonsyndroms beteiligt sein können. Es gilt jedoch in zukünftigen Experimenten zu evaluieren, ob es sich bei der Autophagiesteigerung des a-Syn-WTs und bedingt der A53TMutation um einen protektiven Mechanismus handelt, wodurch toxische Aggregationen, wie bspw. von a-Syn selbst, ihren neurodegenerativen Einfluss verlieren oder ob durch die gesteigerte Autophagie auch neuroprotektive Faktoren vermehrt abgebaut werden und sich hierdurch negative Effekte auf das Überleben dopaminerger Neurone ergeben. Auch A30Püberexprimierende Zellen sollten hinsichtlich positiver oder negativer Konsequenzen auf die neuronale Integrität und Funktionsfähigkeit durch weitere Modulation der Autophagie (Steigerung oder Inhibition) untersucht werden. Schließlich wurde bereits gezeigt, dass 
sowohl eine übermäßige Autophagie als auch eine inhibierte Proteindegradation neuronales Überleben bzw. neuronalen Zelltod beeinflussen können (Codogno und Meijer 2005). Sinnvoll und physiologisch erscheint eine Reduktion der Toxizität in Verbindung mit einem verbesserten Überleben. Hierfür muss jedoch grundlegende Evidenz zur Unterstützung dieser These gefunden werden, um anschließend darauf basierend auch gezielte therapeutische Strategien entwickeln zu können.

Eine in diesem Zusammenhang interessante weitere Beobachtung, die bisher jedoch nur an einer anderen Synucleinopathie - der Multisystematrophie - getroffen wurde und die Autophagie als therapeutisches Ziel weiter verkompliziert, ist ein sich im Verlauf der Erkrankung verändernder Funktionsstatus der Makroautophagie und damit verbunden eine Änderung der Auswirkung auf die zelluläre Homöostase. So konnte mehrfach gezeigt werden, dass eine initiale Steigerung der Proteindegradation zur Detoxifikation des zellulären Milieus beiträgt, im Verlauf hierdurch aber auch essentielle Proteine abgebaut werden, woraus eine Schwächung der Autophagie entsteht und toxische Substrate, wie bspw. $\alpha$-Syn, nicht mehr adäquat entfernt werden und so ein voranschreiten der Erkrankung bedingt wird (Tanji et al. 2013, Chiba et al. 2012, Schwarz et al. 2012). Hieraus ergibt sich die Möglichkeit, dass eine zeitlich angepasste Modulation der autophagischen Prozesse den Krankheitsverlauf positiv beeinflussen könnte, wobei die größte Herausforderung sein wird, den tatsächlichen Funktionsstatus der Autophagie vor allem in präsymptomatischen Menschen zu diagnostizieren, um daran angepasst neuroprotektiv zu therapieren.

\subsection{Axonaler Transport}

Neben dem Recycling aberranter Proteine und dysfunktioneller Zellbestandteile durch die Autophagie trägt der Transport verschiedener Zellkomponenten, bspw. entlang axonaler Strukturen von Neuronen, einen wesentlichen Teil zum Erhalt der zellulären Integrität bei. Insbesondere für Nervenzellen, aufgrund ihrer im Vergleich zu anderen Zelltypen ausgeprägten Polarität und der immensen Länge ihrer zellulären Ausläufer, ist ein funktionsfähiger Transport von distal benötigten aber auch von distal entstandenen und im Zellkörper abzubauenden Proteinen zwingend erforderlich.

Es wurde schon 1998 durch Jensen $\mathrm{PH}$ et al. die pathogenetische Akkumulation von a-Syn als Folge eines $\alpha$-Syn-getriggerten Defektes des axonalen Transportes diskutiert. Postmortale histologische Hirngewebsuntersuchungen von Parkinsonpatienten konnten bereits in frühen Stadien der Erkrankung eine signifikante Reduktion der Motorproteine Kinesin und auch Dynein zeigen, noch bevor ein zerebraler Dopaminmangel zu verzeichnen war. Durch Bestätigung dieser Erkenntnisse an human- $\alpha$-Syn-überexprimierenden Ratten ist sowohl die Beteiligung des axonalen Transportes an sich als auch die pathologische 
Wirkung von a-Syn auf den Transport an neurodegenerativen Vorgängen nahe liegend (Chu et al. 2012).

Zuvor wurden bereits mehrere Arbeiten an In-vitro-Modellen durchgeführt, die insgesamt teils widersprüchliche Auswirkungen von a-Syn auf den axonalen Transport beobachteten. So zeigten Li W et al. 2004 an spinalen Motorneuronen transgener Mäuse, die humanes $\alpha$-Syn-WT sowie die Mutantenformen A30P und A53T exprimierten, dass der axonale Transport von a-Syn mittels der langsamen Komponente des axonalen Transportes nicht verändert sei. Vielmehr beschreiben sie Störungen im axonalen Transport von $\alpha$-Syn als sehr späte, erst im symptomatischen Stadium auftretende pathologische Veränderung. Dennoch wird von innen bereits eine altersabhängige Verlangsamung des $\alpha$-SynTransportes beschrieben. Im Gegensatz hierzu wurde durch Saha et al. 2004 an primären kortikalen Neuronen der Ratte nach deren Transfektion mit a-Syn-WT, A30P oder A53T eine signifikante Reduktion der Geschwindigkeit des a-Syn-Transportes in den Mutationsversuchsgruppen gegenüber der $\alpha$-Syn-WT-Population gezeigt, wobei es im weiteren zeitlichen Verlauf der Untersuchung zu einer Angleichung der Geschwindigkeiten des a-SynTransportes in den verschiedenen Versuchsgruppen kam, die durch eine „altersbedingte“ weitere Verlangsamung der Geschwindigkeit in der a-Syn-WT-Versuchsgrupe erklärt wurde. Die Ätiologie dieser Angleichung der Transportgeschwindigkeiten aller Versuchsgruppen kann dabei nicht eindeutig geklärt werden. So ist einerseits eine Zunahme der pathologischen Wirkung des a-Syn-WTs denkbar, andererseits wäre auch eine Reduktion der pathologischen Wirkung der Mutationsformen eine mögliche Ursache. Klärung hätte hier die Beobachtung der Transportgeschwindigkeit in einer unbehandelten Kontrollgruppe erbringen können. Hätte sich in der Kontrollgruppe ebenfalls eine „altersabhängige“ Reduktion der Transportgeschwindigkeit gezeigt, spräche dies eher für eine Reduktion der Auswirkung der Mutationen. Eine gleichbleibende Geschwindigkeit in der Kontrolle würde dagegen für eine Zunahme der Pathogenität des $\alpha$-Syn-WTs sprechen, auch wenn aufgrund dieser Beobachtung keine Aussage über den auslösenden Mechanismus getroffen werden kann. In einer weiteren In-vitro-Untersuchung an primären hippocampalen Neuronen der Ratte durch Yang ML et al. 2010 konnte hingegen lediglich eine reduzierte Transportgeschwindigkeit für die A53T-Mutation gegenüber dem $\alpha$-Syn-WT beobachtet werden, die A30P-Mutation wies keine Veränderung auf.

Allen Studien gemeinsam ist die fehlende Negativkontrolle, also eine gänzlich unveränderte Population als Kontrollgruppe, sodass letztlich keine abschließende Aussage über die Auswirkung einer Überexpression des a-Syn-WT hinsichtlich des axonalen Transportes gemacht werden kann. Darüber hinaus wurde stets der Transport von a-Syn selbst untersucht und kein Augenmerk auf unabhängige Transportsubstrate, wie zum Beispiel synaptische Vesikel, gelegt. Da $\alpha$-Syn jedoch primär über den langsamen axonalen 
Transport intrazellulär bewegt wird, können Auswirkungen auf den schnellen Anteil des Transportes, wie er bspw. zum Transport synaptischer Vesikel und anderer präsynaptisch benötigter Substrate genutzt wird, nicht getätigt werden. Wenn man jedoch bedenkt, dass das iPS sich primär auf Grundlage einer synaptisch beginnenden Dysfunktion einschließlich eines Mangels an Neurotransmitter-haltigen Vesikeln ausbildet (Nikolaus et al. 2009, Linazasoro 2007), was erst in der Folge zu einem rückwärts gerichteten Absterben (dying back) dopaminerger Neurone der Substantia nigra führt (Burke und O'Malley 2013), wird klar, dass insbesondere der schnelle Transport vesikulärer Strukturen einen entscheidenden Pathomechanismus des Parkinsonsyndroms darstellen könnte, den es weiter zu untersuchen gilt.

Aufgrund dieser entscheidenden pathogenetischen Charakteristik des Parkinsonsyndroms wurden im Rahmen dieser Arbeit die Auswirkungen der milden a-Syn-Überexpression sowohl der a-Syn-WT-Form als auch der Mutationen A30P und A53T auf den schnellen axonalen Transport Synaptophysin-haltiger synaptischer Vesikel in primären Mittelhirnneuronen betrachtet. Ergänzend erfolgte der Vergleich mit einer unbehandelten Kontrollgruppe, um auch Veränderungen durch den a-Syn-WT verifizieren zu können.

Detailliert zeigte sich vor allem ein deutlich reduzierter Anteil an sich bewegenden Vesikeln in den a-Syn-transfizierten Neuronen. So sind in den $\alpha$-Syn-tranfizierten Versuchsgruppen lediglich 25-30\% aller Vesikel in Bewegung, wohingegen sich in der Kontrollgruppe annähernd jedes 2. Vesikel (ca. $45 \%$ ) bewegt. Wie bereits 2000 von Roy et al. und Wang $L$ et al. unabhängig voneinander gezeigt werden konnte, setzt sich die Durchschnittsgeschwindigkeit eines Vesikels nicht aus einer konstant linearen Bewegung in Richtung des Zieles zusammen, sondern ist vielmehr das Produkt von Phasen relativ hoher Geschwindigkeit im Wechsel mit Pausen unterschiedlicher Länge, sodass der beobachtete erhöhte Anteil an pausierenden Vesikeln wiederum entscheidend dazu beiträgt, dass sich auch die durchschnittliche Geschwindigkeit aller Vesikel in den mit $\alpha$-Syn-transfizierten Neuronen signifikant im Vergleich zur Kontrollgruppe reduziert zeigt. Neben dieser erhöhten Anzahl pausierender Vesikel in den a-Syn-transfizierten Neuronen mit der Folge einer reduzierten Gesamtdurchschnittsgeschwindigkeit zeigt sich zusätzlich auch eine verringerte Variabilität der Vesikelgeschwindigkeit. So verändern die Vesikel der Kontrollgruppe signifikant häufiger ihre Geschwindigkeit. Dies könnte zu einer höheren Flexibilität der Kontrollneurone bezüglich lokal entlang des Axons benötigten Nachschubs an Vesikeln führen, sodass auf veränderte Bedürfnisse im Substrattransport auch einfacher und effektiver reagiert werden kann und ggf. somit auch toxische Einflüsse besser kompensiert werden können. Darüber hinaus fand sich auch zwischen der A30P-Versuchsgruppe und den a-Syn-WT-transfizierten Neuronen eine signifikant reduzierte Durchschnittsgeschwindigkeit beim a-Syn-WT und in der Tendenz zeigte sich dies auch zwischen A30P und A53T. 
Ursächlich könnte ggf. auch hier die reduzierte Bindungsfähigkeit der A30P-Mutation zu membranösen Strukturen sein (Perrin et al. 2000, Jensen PH et al. 1998), sodass sich die Pathogenität verglichen mit dem a-Syn-WT und A53T aufgrund einer geringeren bindungsassoziierten Toxizität reduziert zeigt. Da jedoch auch die A30P-Mutation im Vergleich zur Kontrollgruppe sowohl eine reduzierte Durchschnittsgeschwindigkeit als auch eine verringerte Anzahl sich bewegender Vesikel aufweist, muss es weitere, bisher nicht verstandene negativ-regulatorische Signalwege oder toxische Wirkungen von a-Syn allgemein geben, die dieses pathologische Ergebnis bewirken. Sofern jedoch allein die sich bewegenden Vesikel betrachtet wurden, konnten keine Unterschiede der Durchschnittsgeschwindigkeiten zwischen allen Versuchspopulationen festgestellt werden. Die Hauptwirkung von $\alpha$-Syn auf den vesikulären Transport ist insgesamt vor allem eine Störung des Transportbeginns/der Bewegungsinitiation, wie anhand der prozentual deutlich mehr pausierenden Vesikel in den $\alpha$-Syn-Populationen zu erkennen ist. So lässt sich eine Interaktion von a-Syn bspw. mit Adaptorproteinen der Motorproteine vermuten, die zu einer gestörten Bindungsfähigkeit der Vesikel an die Motorproteine führt. Anhand der anschließend unauffälligen Transportgeschwindigkeit, sofern sich die Vesikel bewegen, ist jedoch zu entnehmen, dass der eigentliche Transport, also letztlich die energieabhängige Funktion der Motorproteine nach Bindung der Transportsubstrate, nicht beeinflusst wird. Dies spiegelt sich auch in der erniedrigten Anzahl von Geschwindigkeitsänderungen wider. So sind diese häufig Wechsel zwischen einer hinsichtlich der Geschwindigkeit unauffälligen Bewegung und Transportpausen. Auch der signifikante Unterschied der Durchschnittsgeschwindigkeit zwischen a-Syn-WT und A30P mit scheinbar etwas geringerer Pathogenität der Mutation könnte hierin begründet liegen. Sofern a-Syn als Regulator des axonalen Transportes fungiert, ist als Ursache für die etwas geringere Toxizität der A30P-Mutation im Vergleich zum a-Syn-WT und der A53T-Mutation bspw. die reduzierte Fähigkeit zur Membranbindung von A30P zu nennen. Durch die Bindung von a-Syn an synaptische Vesikel könnte die Interakton der synaptischen Vesikel mit Adaptorproteinen des axonalen Transportes, also die Bindung der Vesikel an die Motorproteine der Kinesin- und Dyneinfamilie, und somit in letzter Konsequenz der axonale Transport der Vesikel negativ beeinflusst werden. Folglich wären die Vesikel immobil, wie im Rahmen der vorliegenden Arbeit auch signifikant gezeigt werden konnte.

Daneben ist anzunehmen, dass der zeitliche Aspekt der Beobachtung wesentlich zu den dargestellten Ergebnissen, insbesondere eines fehlenden Unterschiedes zwischen dem a-Syn-WT und den Mutationen, beiträgt. Da sämtliche Untersuchungen nach 5-tägiger Kultivierung der primären Mittelhirnneurone erfolgten, besteht die Möglichkeit, dass sich in dieser Zeit bereits eine pathologische Toxizitätsangleichung zwischen den unterschiedlichen a-Syn-Varianten in diesem In-vitro-Modell ergeben hat, sodass eine initial bestehende 
höhere Pathogenität der Mutanten gegenüber dem a-Syn-WT, wie aufgrund der Ergebnisse von Saha et al. 2004 zu vermuten, nicht mehr verifiziert werden kann. Inwieweit dies eine realistische Annahme ist bedarf weiterer Testungen. Hier könnten zeitlich abgestufte Analysen dazu beitragen, diese Vermutung zu untermauern und ggf. den genauen Zeitpunkt dieser Pathogenitätszunahme des $\alpha$-Syn-WTs zu bestimmen, um weitere Untersuchungen bspw. bezüglich einer geänderten Genexpression von Transport-regulierenden oder am Transport-beteiligten Proteine, wie Kinesin oder Dynein, die bekanntermaßen im Rahmen des Parkinsonsyndroms vermindert sind (Chu et al. 2012), festzustellen. Andererseits ist eine Zunahme der Pathogenität der Mutationen zu einem späteren Zeitpunkt ebenso denkbar, sodass auch prospektive Untersuchungen ergänzt werden sollten, um diese Möglichkeit zu evaluieren.

Weiterhin ursächlich für den defekten Transport könnte eine Störung im Zusammenspiel von a-Syn mit wesentlichen für den Transport notwendigen Proteinen sein. So konnte gezeigt werden, dass $\alpha$-Syn Proteine des anterograden, Mikrotubuli-assoziierten axonalen Transportes wie KIF5A, Tubulin, Mikrotubuli, MAP2 und Tau bindet und dabei bspw. die Axon-spezifische Tau-vermittelte Bildung von Mikrotubuli beeinflusst (Prots et al. 2013). Zudem verlangsamen a-Syn-Oligomere den Kinesin-abhängigen Transport entlang der Mikrotubuli durch eine Störung der Tubulin-Polymerisierung (Prots et al. 2013). Die Proteine $\alpha$-Syn und Tau können gemeinsam aggregieren (Geddes et al. 2005, Giasson et al. 2003), wodurch der pathologische Effekt auf die Mikrotubuli noch verstärkt werden könnte. Auslöser der reduzierten axonalen Mikrotubuli-Bildung durch Tau scheint zum einen die Bindung von $\alpha$-Syn an die Mikrotubuli-Bindungsdomäne des Tau-Proteins sowie eine Verstärkung der Tau-Phosphorylierung zu sein (Duka et al. 2009, Jensen PH et al. 1999), was beides zu einer Dissoziation von Tau und Mikrotubuli führt. Daneben führt $\alpha$-Syn auch zu einer Destabilisierung von Mikrotubuli (Zhou et al. 2010, Lee et al. 2006,) indem vor allem die a-Syn-WT-Form über die verminderte Acetylierung von Tubulin die Stabilität der Mikrotubuli reduziert (Prots et al. 2013).

Interessanterweise konnte in einem weiteren Versuchsmodell, basierend auf einem neurotoxisch mittels MPTP [Vorstufe des Neurotoxins 1-Methyl-4-phenyl-pyridin $\left(\mathrm{MPP}^{+}\right)$] induzierten Parkinsonsyndrom, gezeigt werden, dass neben der Verlangsamung des Kinesin-abhängigen anterograden Transportes der retrograde Dynein-vermittelte Transport beschleunigt ist (Morfini et al. 2007). Dies wiederum kann in Verbindung mit einer anfänglich gesteigerten Makroautophagie, wie sie ähnlich bei der Multisystematrophie bereits gezeigt wurde (Tanji et al. 2013, Chiba et al. 2012, Schwarz et al. 2012), neben der Unterversorgung der Präsynapse zu einem gesteigerten Rücktransport und Abbau axonal-präsynaptisch noch benötigter Proteine führen und ggf. sogar eine weitere Ursache der initial gesteigerten Makroautophagie im Sinne einer Substrat-getriggerten positiven Rückkopplung sein. 
Hierdurch könnte sich im weiteren Verlauf eine Dekompensation der autophagischen Prozesse einstellen und so zum Fortschreiten der Toxizität mit Folge der weiteren Hemmung des Transportes beitragen. Letztlich könnte in diesem Zusammenhang eine Ursache für das präsynaptisch beginnende und nach proximal fortschreitende Absterben dopaminerger Neurone liegen (Morfini et al.2007).

Die gewählten Methoden zur Darstellung sowohl der Autophagie als auch des axonalen Transportes erlauben es nicht, diese Verknüpfung zu belegen, da beide Zellkompartimente getrennt voneinander analysiert wurden und keine Darstellung des Somas mit dem dazugehörigen Axon erfolgte. Eine mögliche Lösungsstrategie und Ausblick auf ein folgendes Experiment wäre die Benutzung sog. microfluid chambers, die eine separate Beobachtung von Axonen und den Zellkörpern ermöglichen (Park et al. 2006, Taylor AM et al. 2005). So wäre hierdurch eine gezielte Beobachtung der Axone und der dazugehörigen Zellkörper möglich, und es könnten in-vitro an lebenden Zellen sowohl der axonale Transport (Veränderung der Transportparameter wie Geschwindigkeit oder Bewegungsänderungen) als auch die Folgen auf die Makroautophagie (Veränderung der Autophagosomenzahl) direkt beobachtet und miteinander korreliert werden. 


\section{$5 \quad$ Zusammenfassung}

Die motorische Symptomatik der neurodegenerativen Erkrankung iPS wird durch einen Dopaminmangel in strategisch relevanten Hirnarealen ausgelöst. Bevor dies jedoch klinisch zu beobachten ist, tragen viele verschiedene zelluläre Ereignisse zur Degeneration der dopaminergen Neurone im Bereich der Substantia nigra und deren Axone bei. So werden bspw. oxidativer Stress oder toxische Stoffe als ätiologische Ereignisse diskutiert. Dass diese Veränderungen ein Parkinsonsyndrom bedingen, ist unumstritten, jedoch sind die pathomechanistischen Zusammenhänge noch unverstanden. Wenn zukünftig aber Therapiestrategien entwickelt werden sollen, die nicht mehr nur die Besserung der Symptomatik, sonden eine kurative Intention im Vordergrund sehen, ist ein grundlegendes Verständnis des Pathomechanismus notwendig.

Im Rahmen der vorliegenden Dissertation wurden in primären Mittelhirnneuronenzellkulturen der Ratte die Auswirkungen einer milden, mittels Plasmid-Transfektion erzielten a-Syn-Überexpression sowohl des $\alpha$-Syn-WTs als auch der pathogenetischen Mutationen A30P und A53T auf primäre dopaminerge und nicht-dopaminerge Mittelhirnneurone analysiert.

Hierbei konnte mittels Western Blot und immunzytochemischen Analysen typischer Makroautophagie-Marker (LC3-I und -II, p62) eine signifikant erhöhte Makroautophagie nach Überexpression von a-Syn-WT und der A53T-Mutation in nicht-dopaminergen Mittelhirnneuronen gezeigt werden. Dagegen fand sich für die A30P-Mutation eine signifikant erniedrigte Makroautophagie. Im Gegensatz hierzu konnte in den dopaminergen Neuronen lediglich in der a-Syn-WT-Versuchsgruppe eine gesteigerte Makroautophagie verifiziert werden. Die A53T-Mutation zeigte eine dem physiologischen Maß entsprechende Autophagie im Vergleich zur Kontrollgruppe und die A30P-Mutation ebenso wie in den dopaminergen Neuronen eine reduzierte Autophagie. So kann anhand der vorliegenden Ergebnisse postuliert werden, dass abhängig von der genetischen Variante des Proteins a-Synuclein eines Parkinsonpatienten die Modulation der Makroautophagie unterschiedlich sein kann und somit eine Patienten-spezifische Therapie erfolgen sollte. Dementsprechend könnte in der a-Syn-WT-Versuchsgruppe, die eine Steigerung der Makroautophagie zeigte, ggf. eine Inhibition, jedoch in der A30P-Population mit inhibierter Makroautophagie eine Steigerung der Makroautophagie, eine Besserung erzielen, was anhand von In-vivoExperimenten untersucht werden könnte. Um diese Erkenntnisse auch im Rahmen der Therapie eines iPS anwenden zu können, wird es ferner notwendig sein, für jeden einzelnen Parkinsonpatienten den aktuellen Status der Autphagie zu ermitteln und hierfür geeignete Biomarker zur laborchemischen Diagnostik auszumachen. 
Auch die gezeigten Veränderungen des axonalen Transportes vesikulärer Strukturen fügen sich insgesamt sehr gut in die bislang bekannten Pathomechanismen ein und bestärken die Beobachtung, dass der Beginn der neurodegenertiven Vorgänge beim iPS im Zerfall der axonalen Ausläufer zu sehen ist. So konnte im Rahmen dieser Arbeit gezeigt werden, dass eine Überexpression von humanem a-Syn eine signifikante Reduktion der Anzahl sich bewegender Vesikel zur Folge hat, was wiederum zu einer Senkung der durchschnittlichen Vesikelgeschwindigkeit führt. Daraus ist eine Störung der Transportinitiation entlang der axonalen Strukturen synaptischer Vesikel abzuleiten, was letztlich in einer Unterversorgung der synaptischen Strukturen mit den notwendigen Substraten resultiert.

Durch zukünftige Analysen der molekularen Hintergründe dieser Vorgänge, die diese Veränderungen durch pathogenes $\alpha$-Syn vermitteln, besteht die Möglichkeit, therapeutische Strategien zu entwickeln, die zu einer Modulation sowohl der autophagischen Prozesse als auch des axonalen Transportes führen und hierdurch spezifisch für jeden Patienten bspw. die Autophagie inhibieren oder verstärken, um so ein Angleichen an den physiologischen Status zu gewährleisten. Hierfür wird in Zukunft jedoch nicht nur das molekuläre Verständnis des iPS nötig sein, sondern zusätzlich müssen Testsysteme entwickelt werden, die Aufschluss darüber geben, welche Therapie im Einzelfall anzuwenden ist. Bspw. könnten hier klinische Studien zu Biomarkern der Autophagie aus Liquorpunktaten einen ersten Ansatz zur qualitativen und quantitativen Charakterisierung der Autophagie im einzelnen Individuum liefern. 


\section{$6 \quad$ Literaturverzeichnis}

Abeliovich A, Schmitz Y, Fariñas I, Choi-Lundberg D, Ho WH, Castillo PE, Shinsky N, Verdugo JM, Armanini M, Ryan A et al. (2000): Mice lacking alpha-synuclein display functional deficits in the nigrostriatal dopamine system. Neuron $\underline{25}(1)$, 239-252

Agarraberes FA, Dice JF (2001): A molecular chaperone complex at the lysosomal membrane is required for protein translocation. J Cell Sci 114(Pt 13), 2491-2499

Ali MY, Krementsova EB, Kennedy GG, Mahaffy R, Pollard TD, Trybus KM, Warshaw DM (2007): Myosin Va maneuvers through actin intersections and diffuses along microtubules. Proc Natl Acad Sci U S A 104(11), 4332-4336

Allen RD, Metuzals J, Tasaki I, Brady ST, Gilbert SP (1982): Fast axonal transport in squid giant axon. Science 218(4577), 1127-1129

Alvarez-Erviti L, Rodriguez-Oroz MC, Cooper JM, Caballero C, Ferrer I, Obeso JA, Schapira AH (2010): Chaperonemediated autophagy markers in Parkinson disease brains. Arch Neurol $\underline{67}(12), 1464-1472$

Andersen JK (2004): Oxidative stress in neurodegeneration: cause or consequence? Nat Med $\underline{10}, 18-25$

Anglade P, Vyas S, Javoy-Agid F, Herrero MT, Michel PP, Marquez J, Mouatt-Prigent A, Ruberg M, Hirsch EC, Agid Y (1997): Apoptosis and autophagy in nigral neurons of patients with Parkinson's disease. Histol Histopathol $\underline{12}(1), 25-31$

Appel-Cresswell S, Vilarino-Guell C, Encarnacion M, Sherman H, Yu I, Shah B, Weir D, Thompson C, Szu-Tu C, Trinh J (2013): Alpha-synuclein p.H50Q, a novel pathogenic mutation for Parkinson's disease. Mov Disord 28(6), 811-813

Arias E, Cuervo AM (2011): Chaperone-mediated autophagy in protein quality control. Curr Opin Cell Biol $\underline{23}(2), 184-189$

Axe EL, Walker SA, Manifava M, Chandra P, Roderick HL, Habermann A, Griffiths G, Ktistakis NT (2008): Autophagosome formation from membrane compartments enriched in phosphatidylinositol 3-phosphate and dynamically connected to the endoplasmic reticulum. J Cell Biol 182(4), 685-701

Azzouz M, Hottinger A, Paterna JC, Zurn AD, Aebischer P, Büeler H (2000): Increased motoneuron survival and improved neuromuscular function in transgenic ALS mice after intraspinal injection of an adeno-associated virus encoding Bcl-2. Hum Mol Genet $\underline{9}(5), 803-811$

Bandyopadhyay U, Cuervo AM (2007): Chaperone-mediated autophagy in aging and neurodegeneration: lessons from alphasynuclein. Exp Gerontol $\underline{42}(1-2), 120-128$

Bandyopadhyay U, Kaushik S, Varticovski L, Cuervo AM (2008): The chaperone-mediated autophagy receptor organizes in dynamic protein complexes at the lysosomal membrane. Mol Cell Biol $\underline{28}(18), 5747-5763$

Baron JA (1986): Cigarette smoking and Parkinson's disease. Neurology $\underline{36}, 1490-1496$

Bartels T, Choi JG, Selkoe DJ (2011): $\alpha$-Synuclein occurs physiologically as a helically folded tetramer that resists aggregation. Nature 477(7362), 107-110

Bartlett BJ, Isakson P, Lewerenz J, Sanchez H, Kotzebue RW, Cumming RC, Harris GL, Nezis IP, Schubert DR, Simonsen A et al. (2011): p62, $\operatorname{Ref}(2) P$ and ubiquitinated proteins are conserved markers of neuronal aging, aggregate formation and progressive autophagic defects. Autophagy $\underline{7}(6), 572-583$

Batelli S, Peverelli E, Rodilossi S, Forloni G, Albani D (2011): Macroautophagy and the proteasome are differently involved in the degradation of alpha-synuclein wild type and mutated A30P in an in-vitro inducible model (PC12/TetOn). Neuroscience $195,128-137$

Becher A, Drenckhahn A, Pahner I, Margittai M, Jahn R, Ahnert-Hilger G (1999): The synaptophysin-synaptobrevin complex: a hallmark of synaptic vesicle maturation. J Neurosci $\underline{19}(6), 1922-1931$

Bennett MC, Bishop JF, Leng Y, Chock PB, Chase TN, Mouradian MM (1999): Degradation of alpha-synuclein by proteasome. J Biol Chem 274(48), 33855-33858

Berg D, Niwar M, Maass S, Zimprich A, Moller JC, Wuellner U, Schmitz-Hubsch T, Klein C, Tan EK, Schols L, et al. (2005): Alpha-synuclein and Parkinson's disease: implications from the screening of more than 1,900 patients. Mov Disord $\underline{20}$, 1191-1194

Berman SB, Hastings TG (1999): Dopamine oxidation alters mitochondrial respiration and induces permeability transition in brain mitochondria: implications for Parkinson's disease. J Neurochem $\underline{73}, 1127-1137$ 
Betarbet R, Sherer TB, MacKenzie G, Garcia-Osuna M, Panov AV, Greenamyre JT (2000): Chronic systemic pesticide exposure reproduces features of Parkinson's disease. Nat Neurosci $\underline{3}, 1301-1306$

Beyer K (2006): Alpha-synuclein structure, posttranslational modification and alternative splicing as aggregation enhancers. Acta Neuropathol $\underline{112(3), 237-251}$

Bjørkøy G, Lamark T, Brech A, Outzen H, Perander M, Overvatn A, Stenmark H, Johansen T (2005): p62/SQSTM1 forms protein aggregates degraded by autophagy and has a protective effect on huntingtin-induced cell death. J Cell Biol $\underline{171}(4), 603-614$

Blaszczyk JW (1998): Motor deficiency in Parkinson's disease. Acta Neurobiol Exp (Wars) $\underline{58}(1), 79-93$

Bloem BR, Van Dijk JG, Beckley DJ, Roos RA, Remler MP, Bruyn GW (1992): Altered postural reflexes in Parkinson's disease: a reverse hypothesis. Med Hypotheses $\underline{39}, 243-247$

Bodis-Wollner I, Tagliati M (1993): The visual system in Parkinson's disease. Adv Neurol $\underline{60}, 390-394$

Braak H, Del Tredici K (2008): Invited Article: Nervous system pathology in sporadic Parkinson disease. Neurology $\underline{70}$, 1916-1925

Braak H, Del Tredici K (2009): Neuroanatomy and pathology of sporadic Parkinson's disease. Adv Anat Embryol Cell Biol 201, $1-119$

Braak H, Müller CM, Rüb U, Ackermann H, Bratzke H, de Vos RA, Del Tredici K (2006): Pathology associated with sporadic Parkinson's disease--where does it end? J Neural Transm Suppl. (70), 89-97

Brady ST, Lasek RJ, Allen RD (1982): Fast axonal transport in extruded axoplasm from squid giant axon. Science 218(4577), 1129-1131

Brooks DJ (1998): The early diagnosis of Parkinson's disease. Ann Neurol 44, 10-18

Büning H, Perabo L, Coutelle O, Quadt-Humme S, Hallek M (2008): Recent developments in adeno-associated virus vector technology. J Gene Med $\underline{10}(7), 717-733$

Buller RM, Janik JE, Sebring ED, Rose JA (1981): Herpes simplex virus types 1 and 2 completely help adenovirus-associated virus replication. J Virol $\underline{40}(1), 241-247$

Burke RE, O'Malley K (2013): Axon degeneration in Parkinson's disease. Exp Neurol 246, 72-83

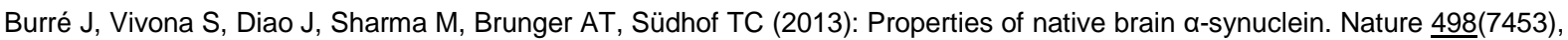
E4-6, discussion E6-7

Calakos N, Scheller RH (1994): Vesicle-associated membrane protein and synaptophysin are associated on the synaptic vesicle. J Biol Chem 269(40), 24534-24537

Cao TT, Chang W, Masters SE, Mooseker MS (2004): Myosin-Va binds to and mechanochemically couples microtubules to actin filaments. Mol Biol Cell $\underline{15}(1), 151-161$

Carboni E, Lingor P (2015): Insights on the interaction of alpha-synuclein and metals in the pathophysiology of Parkinson's disease. Metallomics $\underline{7}(3)$, 395-404

Carlsson A (1964): Evidence for a role of dopamine in extrapyramidal functions. Acta Neuroveg (Wien) $\underline{26}, 484-493$

Chalfie M, Tu Y, Euskirchen G, Ward WW, Prasher DC (1994): Green fluorescent protein as a marker for gene expression. Science $\underline{263}(5148), 802-805$

Chandra S, Gallardo G, Fernandez-Chacon R, Schluter OM, Sudhof TC (2005): Alpha-synuclein cooperates with CSPalpha in preventing neurodegeneration. Cell $\underline{123}, 383-396$

Chartier-Harlin MC, Kachergus J, Roumier C, Mouroux V, Douay X, Lincoln S, Levecque C, Larvor L, Andrieux J, Hulihan M (2004): Alpha-synuclein locus duplication as a cause of familial Parkinson's disease. Lancet 364(9440), 1167-1169

Chaudhuri KR, Schapira AH (2009): Non-motor symptoms of Parkinson's disease: dopaminergic pathophysiology and treatment. Lancet Neurol $\underline{8}, 464-474$

Chauhan NB, Siegel GJ, Lee JM (2001): Depletion of glial cell line-derived neurotrophic factor in substantia nigra neurons of Parkinson's disease brain. J Chem Neuroanat 21 (4), 277-288 
Chen L, Feany MB (2005): Alpha-synuclein phosphorylation controls neurotoxicity and inclusion formation in a Drosophila model of Parkinson disease. Nat Neurosci $\underline{8}(5), 657-663$

Chew KC, Ang ET, Tai YK, Tsang F, Lo SQ, Ong E, Ong WY, Shen HM, Lim KL, Dawson VL et al. (2011): Enhanced autophagy from chronic toxicity of iron and mutant A53T a-synuclein: implications for neuronal cell death in Parkinson disease. J Biol Chem 286(38), 33380-33389

Chia PH, Li P, Shen K (2013): Cell biology in neuroscience: cellular and molecular mechanisms underlying presynapse formation. J Cell Biol 203(1), 11-22

Chiang HL, Dice JF (1988): Peptide sequences that target proteins for enhanced degradation during serum withdrawal. J Biol Chem $\underline{263}(14), 6797-6805$

Chiba Y, Takei S, Kawamura N, Kawaguchi Y, Sasaki K, Hasegawa-Ishii S, Furukawa A, Hosokawa M, Shimada A (2012): Immunohistochemical localization of aggresomal proteins in glial cytoplasmic inclusions in multiple system atrophy. Neuropathol Appl Neurobiol $\underline{38}(6), 559-571$

Choi HS, Lee SH, Kim SY, An JJ, Hwang SI, Kim DW, Yoo KY, Won MH, Kang TC, Kwon HJ et al. (2006): Transduced Tatalpha-synuclein protects against oxidative stress in-vitro and in-vivo. J Biochem Mol Biol $\underline{39}(3), 253-262$

Choubey V, Safiulina D, Vaarmann A, Cagalinec M, Wareski P, Kuum M, Zharkovsky A, Kaasik A (2011): Mutant A53T alphasynuclein induces neuronal death by increasing mitochondrial autophagy. J Biol Chem $\underline{286}(12), 10814-10824$

Chu Y, Dodiya H, Aebischer P, Olanow CW, Kordower JH (2009): Alterations in lysosomal and proteasomal markers in Parkinson's disease: relationship to alpha-synuclein inclusions. Neurobiol Dis $\underline{35}(3), 385-398$

Chu Y, Morfini GA, Langhamer LB, He Y, Brady ST, Kordower JH (2012): Alterations in axonal transport motor proteins in sporadic and experimental Parkinson's disease. Brain 135(Pt 7), 2058-2073

Codogno P, Meijer AJ (2005): Autophagy and signaling: their role in cell survival and cell death. Cell Death Differ 12 Suppl 2 , 1509-1518

Colapinto M, Mila S, Giraudo S, Stefanazzi P, Molteni M, Rossetti C, Bergamasco B, Lopiano L, Fasano M (2006): alphaSynuclein protects SH-SY5Y cells from dopamine toxicity. Biochem Biophys Res Commun $\underline{349}, 1294-1300$

Conway KA, Harper JD, Lansbury PT (1998): Accelerated in-vitro fibril formation by a mutant alpha-synuclein linked to earlyonset Parkinson disease. Nat Med $\underline{4}, 1318-1320$

Conway KA, Lee SJ, Rochet JC, Ding TT, Williamson RE, Lansbury PT Jr. (2000): Acceleration of oligomerization, not fibrillization, is a shared property of both alpha-synuclein mutations linked to early-onset Parkinson's disease: implications for pathogenesis and therapy. Proc Natl Acad Sci U S A $\underline{97}(2), 571-576$

Cookson MR (2009): alpha-Synuclein and neuronal cell death. Mol Neurodegener $\underline{4}, 9$

Cooper JM, Daniel SE, Marsden CD, Schapira AH (1995): L-dihydroxyphenylalanine and complex I deficiency in Parkinson's disease brain. Mov Disord 10, 295-297

Crews L, Spencer B, Desplats P, Patrick C, Paulino A, Rockenstein E, Hansen L, Adame A, Galasko D, Masliah E (2010): Selective molecular alterations in the autophagy pathway in patients with Lewy body disease and in models ofalphasynucleinopathy. PLoS One $\underline{5}(2)$, e9313

Cuervo AM (2004): Autophagy: many paths to the same end. Mol Cell Biochem 263(1-2), 55-72

Cuervo AM, Dice JF (2000): Unique properties of lamp2a compared to other lamp2 isoforms. J Cell Sci 113 Pt 24, 4441-4450

Cuervo AM, Stefanis L, Fredenburg R, Lansbury PT, Sulzer D (2004): Impaired degradation of mutant alpha-synuclein by chaperone-mediated autophagy. Science $\underline{305}(5688), 1292-1295$

Cui J, Bai XY, Shi S, Cui S, Hong Q, Cai G, Chen X (2012): Age-related changes in the function of autophagy in rat kidneys. Age (Dordr) 34(2), 329-339

Dauer W, Przedborski S (2003): Parkinson's disease: mechanisms and models. Neuron $\underline{39}(6), 889-909$

de Lau LM, Koudstaal PJ, Hofman A, Breteler MM (2006): Serum cholesterol levels and the risk of Parkinson's disease. Am J Epidemiol 164(10), 998-1002 
de Rijk MC, Launer LJ, Berger K, Breteler MM, Dartigues JF, Baldereschi M, Fratiglioni L, Lobo A, Martinez-Lage J, Trenkwalder C, et al. (2000): Prevalence of Parkinson's disease in Europe: A collaborative study of population-based cohorts. Neurologic Diseases in the Elderly Research Group. Neurology $\underline{54}, 21-23$

Decressac M, Kadkhodaei B, Mattsson B, Laguna A, Perlmann T, Björklund A (2012): $\alpha$-Synuclein-induced down-regulation of Nurr1 disrupts GDNF signaling in nigral dopamine neurons. Sci Transl Med 4(163), 163ra156

Deffieu M, Bhatia-Kissová I, Salin B, Galinier A, Manon S, Camougrand N (2009): Glutathione participates in the regulation of mitophagy in yeast. J Biol Chem 284(22), 14828-14837

Dehay B, Bové J, Rodríguez-Muela N, Perier C, Recasens A, Boya P, Vila M (2010): Pathogenic lysosomal depletion in Parkinson's disease. J Neurosci $\underline{30}(37), 12535-12544$

Desplats P, Lee HJ, Bae EJ, Patrick C, Rockenstein E, Crews L, Spencer B, Masliah E, Lee SJ (2009): Inclusion formation and neuronal cell death through neuron-toneuron transmission of \{alpha\}-synuclein. Proc Natl Acad Sci U S A $\underline{106}$, 1301013015

Deuschl G, Schade-Brittinger C, Krack P, Volkmann J, Schäfer H, Bötzel K, Daniels C, Deutschländer A, Dillmann U, Eisner W et al. (2006): A randomized trial of deep-brain stimulation for Parkinson's disease. N Engl J Med 355(9), 896-908

Dexter DT, Carter CJ, Wells FR, Javoy-Agid F, Agid Y, Lees A, Jenner P, Marsden CD (1989): Basal lipid peroxidation in substantia nigra is increased in Parkinson's disease. J Neurochem $\underline{52}, 381-389$

Dice JF (1990): Peptide sequences that target cytosolic proteins for lysosomal proteolysis. Trends Biochem Sci 15(8), $305-$ 309

Dong Z, Wolfer DP, Lipp HP, Büeler H (2005): Hsp70 gene transfer by adeno-associated virus inhibits MPTP-induced nigrostriatal degeneration in the mouse model of Parkinson disease. Mol Ther 11(1), 80-88

Dorsey ER, Constantinescu R, Thompson JP, Biglan KM, Holloway RG, Kieburtz K, Marshall FJ, Ravina BM, Schifitto G, Siderowf A, et al. (2007): Projected number of people with Parkinson disease in the most populous nations, 2005 through 2030. Neurology $\underline{68}, 384-386$

Driver JA, Logroscino G, Gaziano JM, Kurth T (2009): Incidence and remaining lifetime risk of Parkinson disease in advanced age. Neurology $\underline{72}, 432-438$

Duka T, Duka V, Joyce JN, Sidhu A (2009): Alpha-Synuclein contributes to GSK-3beta-catalyzed Tau phosphorylation in Parkinson's disease models. FASEB J $\underline{23}(9), 2820-2830$

Dunn WA Jr, Cregg JM, Kiel JA, van der Klei IJ, Oku M, Sakai Y, Sibirny AA, Stasyk OV, Veenhuis M (2005): Pexophagy: the selective autophagy of peroxisomes. Autophagy 1 (2), $75-83$

Ebrahimi-Fakhari D, Cantuti-Castelvetri I, Fan Z, Rockenstein E, Masliah E, Hyman BT, McLean PJ, Unni VK (2011): Distinct roles in-vivo for the ubiquitin-proteasome system and the autophagy-lysosomal pathway in the degradation of $\alpha$ synuclein. J Neurosci 31(41), 14508-14520

Edelmann L, Hanson PI, Chapman ER, Jahn R (1995): Synaptobrevin binding to synaptophysin: a potential mechanism for controlling the exocytotic fusion machine. EMBO J $\underline{14}(2), 224-231$

Eschbach J, Dupuis L (2011): Cytoplasmic dynein in neurodegeneration. Pharmacol Ther 130(3), 348-363

Eskelinen EL, Tanaka Y, Saftig P (2003): At the acidic edge: emerging functions for lysosomal membrane proteins. Trends Cell Biol $\underline{13}(3), 137-145$

Eskelinen EL, Schmidt CK, Neu S, Willenborg M, Fuertes G, Salvador N, Tanaka Y, Lüllmann-Rauch R, Hartmann D, Heeren J (2004): Disturbed cholesterol traffic but normal proteolytic function in LAMP-1/LAMP-2 double-deficient fibroblasts. Mol Biol Cell 15(7), 3132-3145

Fasano M, Bergamasco B, Lopiano L (2006): Modifications of the iron-neuromelanin system in Parkinson's disease. J Neurochem $\underline{96}, 909-916$

Fearnley JM, Lees AJ (1991): Ageing and Parkinson's disease: substantia nigra regional selectivity. Brain $\underline{114}(\mathrm{Pt}$ 5), 22832301

Feng Y, He D, Yao Z, Klionsky DJ (2014): The machinery of macroautophagy. Cell Res $\underline{24}(1), 24-41$

Flanagan LA, Rebaza LM, Derzic S, Schwartz PH, Monuki ES (2006): Regulation of human neural precursor cells by laminin and integrins. J Neurosci Res 83(5), 845-856 
Florence TM, Stauber JL (1988): Neurotoxicity of manganese. Lancet 1 (8581), 363

Follett KA, Weaver FM, Stern M, Hur K, Harris CL, Luo P, Marks WJ Jr., Rothlind J, Sagher O, Moy C et al. (2010): Pallidal versus subthalamic deep-brain stimulation for Parkinson's disease. N Engl J Med 362(22), 2077-2091

French IT, Muthusamy KA (2016): A Review of Sleep and Its Disorders in Patients with Parkinson's Disease in Relation to Various Brain Structures. Front Aging Neurosci $\underline{8}, 114$

Fujiwara H, Hasegawa M, Dohmae N, Kawashima A, Masliah E, Goldberg MS, Shen J, Takio K, Iwatsubo T (2002): alphaSynuclein is phosphorylated in synucleinopathy lesions. Nat Cell Biol $\underline{4}(2), 160-164$

Gassmann M, Grenacher B, Rohde B, Vogel J (2009): Quantifying Western blots: pitfalls of densitometry. Electrophoresis $\underline{30}(11), 1845-1855$

Gao X, Chen H, Choi HK, Curhan G, Schwarzschild MA, Ascherio A (2008): Diet, urate, and Parkinson's disease risk in men. Am J Epidemiol 167(7), 831-838

Gasser T (2001): Genetics of Parkinson's disease. J Neurol 248, 833-840

Geddes JW (2005): alpha-Synuclein: a potent inducer of tau pathology. Exp Neurol 192(2), 244-250

Geng J, Klionsky DJ (2008): The Atg8 and Atg12 ubiquitin-like conjugation systems in macroautophagy. 'Protein modifications: beyond the usual suspects' review series. EMBO Rep $\underline{9}(9), 859-864$

George JM (2002): The synucleins. Genome Biol $\underline{3}(1)$, REVIEWS3002

Germain M, Nguyen AP, Le Grand JN, Arbour N, Vanderluit JL, Park DS, Opferman JT, Slack RS (2011): MCL-1 is a stress sensor that regulates autophagy in a developmentally regulated manner. EMBO J $\underline{30}(2), 395-407$

Ghosh D, Mondal M, Mohite GM, Singh PK, Ranjan P, Anoop A, Ghosh S, Jha NN, Kumar A, Maji SK (2013): The Parkinson's disease-associated H50Q mutation accelerates $\alpha$-Synuclein aggregation in-vitro. Biochemistry $\underline{52}(40), 6925-6927$

Giasson BI, Forman MS, Higuchi M, Golbe LI, Graves CL, Kotzbauer PT, Trojanowski JQ, Lee VM (2003): Initiation and synergistic fibrillization of tau and alpha-synuclein. Science $\underline{300}(5619), 636-640$

Gibellini F, Smith TK (2010): The Kennedy pathway--De novo synthesis of phosphatidylethanolamine and phosphatidylcholine. IUBMB Life $\underline{62}(6), 414-428$

Goldberg MS, Lansbury PT Jr. (2000): Is there a cause-and-effect relationship between alpha-synuclein fibrillization and Parkinson's disease? Nat Cell Biol 2 , E115-119

Gonçalves S, Outeiro TF (2013): Assessing the subcellular dynamics of alpha-synuclein using photoactivation microscopy. Mol Neurobiol $\underline{47}(3), 1081-1092$

Good PF, Hsu A, Werner P, Perl DP, Olanow CW (1998): Protein nitration in Parkinson's disease. J Neuropathol Exp Neurol $\underline{57}, 338-342$

Gordon PB, Seglen PO (1988): Prelysosomal convergence of autophagic and endocytic pathways. Biochem Biophys Res Commun 151(1), 40-47

Gorell JM, Johnson CC, Rybicki BA, Peterson EL, Kortsha GX, Brown GG, Richardson RJ (1999): Occupational exposure to manganese, copper, lead, iron, mercury and zinc and the risk of Parkinson's disease. Neurotoxicology 20, 239-247

Grealish S, Diguet E, Kirkeby A, Mattsson B, Heuer A, Bramoulle Y, Van Camp N, Perrier AL, Hantraye P, Björklund A et al. (2014): Human ESC-derived dopamine neurons show similar preclinical efficacy and potency to fetal neurons when grafted in a rat model of Parkinson's disease. Cell Stem Cell 15(5), 653-665

Gstraunthaler G, Lindl T: Zell- und Gewebekultur: Allgemeine Grundlagen und spezielle Anwendungen. 7.Auflage; Springer-Verlag Berlin Heidelberg 2013, 91

Gunawardena S, Goldstein LS (2004): Cargo-carrying motor vehicles on the neuronal highway: transport pathways and neurodegenerative disease. J Neurobiol $\underline{58}(2), 258-271$

Haack J: Der Einfluss von humanem Wildtyp-Alpha-Synuclein und seinen Mutationen A30P und A53T auf Wachstum und Regeneration primärer dopaminerger Mittelhirnneurone der Ratte. Med. Diss. Göttingen (in Vorbereitung*) 2019

\footnotetext{
${ }^{*}$ mit freundlicher Genehmigung von Jessica Haack
} 
Hadjigeorgiou GM, Xiromerisiou G, Gourbali V, Aggelakis K, Scarmeas N, Papadimitriou A, Singleton A (2006): Association of alpha-synuclein Rep1 polymorphism and Parkinson's disease: influence of Rep1 on age at onset. Mov Disord 21(4), 534-539

Hallett PJ, Deleidi M, Astradsson A, Smith GA, Cooper O, Osborn TM, Sundberg M, Moore MA, Perez-Torres E, Brownell AL et al. (2015): Successful function of autologous iPSC-derived dopamine neurons following transplantation in a non-human primate model of Parkinson's disease. Cell Stem Cell 16(3), 269-274

Hammer JA 3rd, Sellers JR (2011): Walking to work: roles for class V myosins as cargo transporters. Nat Rev Mol Cell Biol $\underline{13}(1), 13-26$

Harding TM, Morano KA, Scott SV, Klionsky DJ (1995): Isolation and characterization of yeast mutants in the cytoplasm to vacuole protein targeting pathway. J Cell Biol 131(3), 591-602

Hashimoto M, Hsu LJ, Rockenstein E, Takenouchi T, Mallory M, Masliah E (2002): alpha-Synuclein protects against oxidative stress via inactivation of the c-Jun $\mathrm{N}$-terminal kinase stress-signaling pathway in neuronal cells. J Biol Chem 277(13), $11465-11472$

Hernán MA, Takkouche B, Caamaño-Isorna F, Gestal-Otero JJ (2002): A meta-analysis of coffee drinking, cigarette smoking, and the risk of Parkinson's disease. Ann Neurol $\underline{52}(3), 276-284$

Herting B, Schulze S, Reichmann H, Haehner A, Hummel T (2008): A longitudinal study of olfactory function in patients with idiopathic Parkinson's disease. J Neurol 255(3), 367-370

Hirokawa N, Takemura R (2005): Molecular motors and mechanisms of directional transport in neurons. Nat Rev Neurosci $\underline{6}(3), 201-214$

Hirokawa N, Noda Y (2008): Intracellular transport and kinesin superfamily proteins, KIFs: structure, function, and dynamics. Physiol Rev $\underline{88}(3), 1089-1118$

Hirokawa N, Niwa S, Tanaka Y (2010): Molecular motors in neurons: transport mechanisms and roles in brain function, development, and disease. Neuron $\underline{68}(4), 610-638$

Howells DW, Porritt MJ, Wong JY, Batchelor PE, Kalnins R, Hughes AJ, Donnan GA (2000): Reduced BDNF mRNA expression in the Parkinson's disease substantia nigra. Exp Neurol 166(1), 127-135

Huang JD, Brady ST, Richards BW, Stenolen D, Resau JH, Copeland NG, Jenkins NA (1999): Direct interaction of microtubuleand actin-based transport motors. Nature 397(6716), 267-270

Huang X, Alonso A, Guo X, Umbach DM, Lichtenstein ML, Ballantyne CM, Mailman RB, Mosley TH, Chen H (2015): Statins, plasma cholesterol, and risk of Parkinson's disease: a prospective study. Mov Disord 30(4), 552-559

Huynh KK, Eskelinen EL, Scott CC, Malevanets A, Saftig P, Grinstein S (2007): LAMP proteins are required for fusion of lysosomes with phagosomes. EMBO J $\underline{26}(2), 313-324$

Imai Y, Soda M, Takahashi R (2000): Parkin suppresses unfolded protein stress-induced cell death through its E3 ubiquitinprotein ligase activity. J Biol Chem $\underline{275}(46)$, 35661-35664

Iwai A, Masliah E, Yoshimoto M, Ge N, Flanagan L, de Silva HA, Kittel A, Saitoh T (1995): The precursor protein of non-A beta component of Alzheimer's disease amyloid is a presynaptic protein of the central nervous system. Neuron 14(2), 467-75

Jahn R, Scheller RH (2006): SNAREs--engines for membrane fusion. Nat Rev Mol Cell Biol $\underline{7}(9), 631-643$

Jahreiss L, Menzies FM, Rubinsztein DC (2008): The itinerary of autophagosomes: from peripheral formation to kiss-and-run fusion with lysosomes. Traffic $\underline{9}(4), 574-587$

Jensen PH, Nielsen MS, Jakes R, Dotti CG, Goedert M (1998): Binding of alpha-synuclein to brain vesicles is abolished by familial Parkinson's disease mutation. J Biol Chem 273(41), 26292-26294

Jensen PH, Hager H, Nielsen MS, Hojrup P, Gliemann J, Jakes R (1999): alpha-synuclein binds to Tau and stimulates the protein kinase A-catalyzed tau phosphorylation of serine residues 262 and 356. J Biol Chem 274(36), 25481-25489

Jensen PJ, Alter BJ, O'Malley KL (2003): Alpha-synuclein protects naive but not dbcAMP-treated dopaminergic cell types from 1-methyl-4-phenylpyridinium toxicity. J Neurochem $\underline{86}, 196-209$

Jha N, Jurma O, Lalli G, Liu Y, Pettus EH, Greenamyre JT, Liu RM, Forman HJ, Andersen JK (2000): Glutathione depletion in PC12 results in selective inhibition of mitochondrial complex I activity. Implications for Parkinson's disease. J Biol Chem $\underline{275}(34), 26096-26101$ 
Jin M, Klionsky DJ (2014): Regulation of autophagy: modulation of the size and number of autophagosomes. FEBS Lett $\underline{588}(15), 2457-2463$

Jo E, Fuller N, Rand RP, St George-Hyslop P, Fraser PE (2002): Defective membrane interactions of familial Parkinson's disease mutant A30P alpha-synuclein. J Mol Biol $\underline{315}(4), 799-807$

Johnston PA, Südhof TC (1990): The multisubunit structure of synaptophysin. Relationship between disulfide bonding and homo-oligomerization. J Biol Chem $\underline{265}(15), 8869-8873$

Kamel F, Hoppin JA (2004): Association of pesticide exposure with neurologic dysfunction and disease. Environ Health Perspect $112,950-958$

Kapitein LC, Hoogenraad CC (2011): Which way to go? Cytoskeletal organization and polarized transport in neurons. Mol Cell Neurosci $\underline{46}(1), 9-20$

Karpinar DP, Balija MB, Kügler S, Opazo F, Rezaei-Ghaleh N, Wender N, Kim HY, Taschenberger G, Falkenburger BH, Heise H (2009): Pre-fibrillar alpha-synuclein variants with impaired beta-structure increase neurotoxicity in Parkinson's disease models. EMBO J $\underline{28}(20), 3256-3268$

Kaur D, Yantiri F, Rajagopalan S, Kumar J, Mo JQ, Boonplueang R, Viswanath V, Jacobs R, Yang L, Beal MF, et al. (2003): Genetic or pharmacological iron chelation prevents MPTP-induced neurotoxicity in-vivo: a novel therapy for Parkinson's disease. Neuron $\underline{37}(6)$, 899-909

Kaushik S, Bandyopadhyay U, Sridhar S, Kiffin R, Martinez-Vicente M, Kon M, Orenstein SJ, Wong E, Cuervo AM (2011): Chaperone-mediated autophagy at a glance. J Cell Sci $\underline{124}$ (Pt 4), 495-499

Kaushik S, Cuervo AM (2009): Methods to monitor chaperone-mediated autophagy. Methods Enzymol 452, 297-324

Keeney PM, Xie J, Capaldi RA, Bennett JP Jr. (2006): Parkinson's disease brain mitochondrial complex I has oxidatively damaged subunits and is functionally impaired and misassembled. J Neurosci $\underline{26}, 5256-5264$

Khalaf O, Fauvet B, Oueslati A, Dikiy I, Mahul-Mellier AL, Ruggeri FS, Mbefo MK, Vercruysse F, Dietler G, Lee SJ et al. (2014): The H50Q mutation enhances $\alpha$-synuclein aggregation, secretion, and toxicity. J Biol Chem 289(32), 21856-21876

Khvotchev MV, Südhof TC (2004): Stimulus-dependent dynamic homo- and heteromultimerization of synaptobrevin/VAMP and synaptophysin. Biochemistry $\underline{43}(47), 15037-15043$

Kim HY, Cho MK, Kumar A, Maier E, Siebenhaar C, Becker S, Fernandez CO, Lashuel HA, Benz R, Lange A et al. (2009): Structural properties of pore-forming oligomers of alpha-synuclein. J Am Chem Soc 131(47), 17482-17489

Klionsky DJ (2005): Autophagy. Curr Biol 15(8), R282-283

Klionsky DJ, Cregg JM, Dunn WA Jr, Emr SD, Sakai Y, Sandoval IV, Sibirny A, Subramani S, Thumm M, Veenhuis M et al. (2003): A unified nomenclature for yeast autophagy-related genes. Dev Cell $\underline{5}(4), 539-545$

Klionsky DJ, Cuervo AM, Seglen PO (2007): Methods for monitoring autophagy from yeast to human. Autophagy $\underline{3}(3)$, 181-206

Klionsky DJ, Elazar Z, Seglen PO, Rubinsztein DC (2008): Does bafilomycin A1 block the fusion of autophagosomes with lysosomes? Autophagy $\underline{4}(7), 849-850$

Klionsky DJ, Abdalla FC, Abeliovich H, Abraham RT, Acevedo-Arozena A, Adeli K, Agholme L, Agnello M, Agostinis P, AguirreGhiso JA et al. (2012): Guidelines for the use and interpretation of assays for monitoring autophagy. Autophagy $\underline{8}(4)$, 445-544

Klionsky DJ, Abdelmohsen K, Abe A, Abedin MJ, Abeliovich H, Acevedo Arozena A, Adachi H, Adams CM, Adams PD, Adeli K (2016): Guidelines for the use and interpretation of assays for monitoring autophagy (3rd edition). Autophagy 12 (1), 1-222

Klucken J, Poehler AM, Ebrahimi-Fakhari D, Schneider J, Nuber S, Rockenstein E, Schlötzer-Schrehardt U, Hyman BT, McLean PJ, Masliah E et al. (2012): Alpha-synuclein aggregation involves a bafilomycin A 1-sensitive autophagy pathway. Autophagy $\underline{8}(5), 754-766$

Koch JC, Barski E, Lingor P, Bähr M, Michel U (2011): Plasmids containing NRSE/RE1 sites enhance neurite outgrowth of retinal ganglion cells via sequestration of REST independent of NRSE dsRNA expression. FEBS J 278(18), 3472-3483

Koch JC, Bitow F, Haack J, d'Hedouville Z, Zhang JN, Tönges L, Michel U, Oliveira LM, Jovin TM, Liman J et al. (2015): AlphaSynuclein affects neurite morphology, autophagy, vesicle transport and axonal degeneration in CNS neurons. Cell Death Dis $\underline{6}$, e1811 
Komatsu M, Kageyama S, Ichimura Y (2012): p62/SQSTM1/A170: physiology and pathology. Pharmacol Res $\underline{66}(6), 457-462$

Kong SM, Chan BK, Park JS, Hill KJ, Aitken JB, Cottle L, Farghaian H, Cole AR, Lay PA, Sue CM et al. (2014): Parkinson's disease-linked human PARK9/ATP13A2 maintains zinc homeostasis and promotes a-Synuclein externalization via exosomes. Hum Mol Genet $\underline{23}(11), 2816-2833$

Krieglstein K, Suter-Crazzolara C, Fischer WH, Unsicker K (1995): TGF-beta superfamily members promote survival of midbrain dopaminergic neurons and protect them against MPP+ toxicity. EMBO J $\underline{14}(4), 736-742$

Krüger R, Kuhn W, Müller T, Woitalla D, Graeber M, Kösel S, Przuntek H, Epplen JT, Schöls L, Riess O (1998): Ala30Pro mutation in the gene encoding alpha-synuclein in Parkinson's disease. Nat Genet $\underline{18}(2), 106-108$

Kutzing MK, Firestein BL (2008): Altered uric acid levels and disease states. J Pharmacol Exp Ther $\underline{324}(1), 1-7$

Larsen KE, Schmitz Y, Troyer MD, Mosharov E, Dietrich P, Quazi AZ, Savalle M, Nemani V, Chaudhry FA, Edwards RH et al. (2006): Alpha-synuclein overexpression in PC12 and chromaffin cells impairs catecholamine release by interfering with a late step in exocytosis. J Neurosci $\underline{26}(46), 11915-11922$

Lee HJ, Khoshaghideh F, Lee S, Lee SJ (2006): Impairment of microtubule-dependent trafficking by overexpression of alphasynuclein. Eur J Neurosci 24 (11), 3153-3162

Lee HJ, Khoshaghideh F, Patel S, Lee SJ (2004): Clearence of alpha-synuclein oligomeric intermediates via the lysosomal degradation pathway. J Neurosci 24(8), 1888-1896

Lesage S, Anheim M, Letournel F, Bousset L, Honoré A, Rozas N, Pieri L, Madiona K, Dürr A, Melki R (2013): G51D asynuclein mutation causes a novel parkinsonian-pyramidal syndrome. Ann Neurol 73(4), 459-471

Levine CB, Fahrbach KR, Siderowf AD, Estok RP, Ludensky VM, Ross SD (2003): Diagnosis and treatment of Parkinson's disease: a systematic review of the literature. Evid Rep Technol Assess (Summ) $\underline{57}$, 1-4

Li JY, Englund E, Holton JL, Soulet D, Hagell P, Lees AJ, Lashley T, Quinn NP, Rehncrona S, Bjorklund A et al. (2008): Lewy bodies in grafted neurons in subjects with Parkinson's disease suggest host-to-graft disease propagation. Nat Med $\underline{14}$, 501-503

Li W, Hoffman PN, Stirling W, Price DL, Lee MK (2004): Axonal transport of human alpha-synuclein slows with aging but is not affected by familial Parkinson's disease-linked mutations. J Neurochem $\underline{88(2), ~ 401-410 ~}$

Li W, West N, Colla E, Pletnikova O, Troncoso JC, Marsh L, Dawson TM, Jäkälä P, Hartmann T, Price DL, Lee MK (2005): Aggregation promoting C-terminal truncation of alpha-synuclein is a normal cellular process and is enhanced by the familial Parkinson's disease-linked mutations. Proc Natl Acad Sci U S A 102(6), 2162-2167

Linazasoro G (2007): Pathophysiology of motor complications in Parkinson disease: postsynaptic mechanisms are crucial. Arch Neurol $\underline{64}(1), 137-140$

Loos B, du Toit A, Hofmeyr JH (2014): Defining and measuring autophagosome flux-concept and reality. Autophagy $\underline{10}(11)$, 2087-2096

Lv L, Li D, Zhao D, Lin R, Chu Y, Zhang H, Zha Z, Liu Y, Li Z, Xu Y et al. (2011): Acetylation targets the M2 isoform of pyruvate kinase for degradation through chaperone-mediated autophagy and promotes tumor growth. Mol Cell $\underline{42(6), 719-730}$

Maasho K, Marusina A, Reynolds NM, Coligan JE, Borrego F (2004): Efficient gene transfer into the human natural killer cell line, NKL, using the Amaxa nucleofection system. J Immunol Methods 284(1-2), 133-140

Maeder Cl, Shen K, Hoogenraad CC (2014): Axon and dendritic trafficking. Curr Opin Neurobiol 27, 165-170

Malik JM, Shevtsova Z, Bähr M, Kügler S (2005): Long-term in-vivo inhibition of CNS neurodegeneration by Bcl-XL gene transfer. Mol Ther 11(3), 373-381

Mari M, Griffith J, Rieter E, Krishnappa L, Klionsky DJ, Reggiori F (2010): An Atg9-containing compartment that functions in the early steps of autophagosome biogenesis. J Cell Biol 190(6), 1005-1022

Maroteaux L, Scheller RH (1991): The rat brain synucleins; family of proteins transiently associated with neuronal membrane. Brain Res Mol Brain Res 11(3-4), 335-343

Martinez-Vicente M, Talloczy Z, Kaushik S, Massey AC, Mazzulli J, Mosharov EV, Hodara R, Fredenburg R, Wu DC, Follenzi A et al. (2008): Dopamine-modified alpha-synuclein blocks chaperone-mediated autophagy. J Clin Invest 118(2), 777-788 
Massey AC, Kaushik S, Sovak G, Kiffin R, Cuervo AM (2006): Consequences of the selective blockage of chaperonemediated autophagy. Proc Natl Acad Sci U S A $\underline{103}(15), 5805-5810$

McMahon HT, Bolshakov VY, Janz R, Hammer RE, Siegelbaum SA, Südhof TC (1996): Synaptophysin, a major synaptic vesicle protein, is not essential for neurotransmitter release. Proc Natl Acad Sci U S A 93(10), 4760-4764

McPherson RA, Rosenthal LJ, Rose JA (1985): Human cytomegalovirus completely helps adeno-associated virus replication. Virology $\underline{47}(1), 217-222$

Meléndez A, Levine B (2009): Autophagy in C. elegans. WormBook 2009, 1-26

Millecamps S, Julien JP (2013): Axonal transport deficits and neurodegenerative diseases. Nat Rev Neurosci 14(3), 161-176

Miura E, Hasegawa T, Konno M, Suzuki M, Sugeno N, Fujikake N, Geisler S, Tabuchi M, Oshima R, Kikuchi A (2014): VPS35 dysfuncti nimpairs lysosomal degradation of $\alpha$-synuclein and exacerbates neurotoxicity in a Drosophila model of Parkinson's disease. Neurobiol Dis $\underline{71}, 1-13$

Mizushima N (2007): Autophagy: process and function. Genes Dev 211(22), 2861-2873

Mizushima N, Yoshimori T (2007): How to interpret LC3 immunoblotting. Autophagy $\underline{3}(6), 542-545$

Mizushima N, Yoshimori T, Ohsumi Y (2011): The role of Atg proteins in autophagosome formation. Annu Rev Cell Dev Biol $\underline{27}, 107-132$

Modler AJ, Gast K, Lutsch G, Damaschun G (2003): Assembly of amyloid protofibrils via critical oligomers--a novel pathway of amyloid formation. J Mol Biol $\underline{325}(1), 135-148$

Mogi M, Togari A, Kondo T, Mizuno Y, Komure O, Kuno S, Ichinose H, Nagatsu T (1999): Brain-derived growth factor and nerve growth factor concentrations are decreased in the substantia nigra in Parkinson's disease. Neurosci Lett $\underline{270}(1)$, $45-48$

Monti B, Polazzi E, Batti L, Crochemore C, Virgili M, Contestabile A (2007): Alpha-synuclein protects cerebellar granule neurons against 6-hydroxydopamine-induced death. J Neurochem $\underline{103}, 518-530$

Morfini G, Pigino G, Opalach K, Serulle Y, Moreira JE, Sugimori M, Llinás RR, Brady ST (2007): 1-Methyl-4-phenylpyridinium affects fast axonal transport by activation of caspase and protein kinase C. Proc Natl Acad Sci U S A 104(7), 2442-2447

Mülhardt C: Molekularbiologie/Genomics. in: Der Experimentator, 6. Auflage; Spektrum, Heidelberg 2009

Murphy DD, Rueter SM, Trojanowski JQ, Lee VM (2000): Synucleins are developmentally expressed, and alpha-synuclein regulates the size of the presynaptic vesicular pool in primary hippocampal neurons. J Neurosci 20(9), 3214-3220

Murphy KE, Gysbers AM, Abbott SK, Tayebi N, Kim WS, Sidransky E, Cooper A, Garner B, Halliday GM (2014): Reduced glucocerebrosidase is associated with increased $\alpha$-synuclein in sporadic Parkinson's disease. Brain 137(Pt 3), 834-848

Murphy KE, Gysbers AM, Abbott SK, Spiro AS, Furuta A, Cooper A, Garner B, Kabuta T, Halliday GM (2015): Lysosomalassociated membrane protein 2 isoforms are differentially affected in early Parkinson's disease. Mov Disord $\underline{30}$ (12), 1639-1647

Muzyczka N (1992): Use of adeno-associated virus as a general transduction vector for mammalian cells. Curr Top Microbiol Immunol. 158, 97-129

Narayanan NS, Rodnitzky RL, Uc EY (2013): Prefrontal dopamine signaling and cognitive symptoms of Parkinson's disease. Rev Neurosci 24(3), 267-278

Nemani VM, Lu W, Berge V, Nakamura K, Onoa B, Lee MK, Chaudhry FA, Nicoll RA, Edwards RH (2010): Increased expression of alpha-synuclein reduces neurotransmitter release by inhibiting synaptic vesicle reclustering after endocytosis. Neuron $\underline{65}(1), 66-79$

Nezis IP, Simonsen A, Sagona AP, Finley K, Gaumer S, Contamine D, Rusten TE, Stenmark H, Brech A (2008): Ref(2)P, the Drosophila melanogaster homologue of mammalian $\mathrm{p} 62$, is required for the formation of protein aggregates in adult brain. J Cell Biol $\underline{180}(6), 1065-1071$

Nikolaus S, Antke C, Müller HW (2009): In vivo imaging of synaptic function in the central nervous system: I. Movement disorders and dementia. Behav Brain Res 204(1), 1-31

Ohsumi Y (2014): Historical landmarks of autophagy research. Cell Res $\underline{24}(1), 9-23$ 
Okada Y, Yamazaki H, Sekine-Aizawa Y, Hirokawa N (1995): The neuron-specific kinesin superfamily protein KIF1A is a unique monomeric motor for anterograde axonal transport of synaptic vesicle precursors. Cell 1 1(5), 769-780

Palfi S, Gurruchaga JM, Ralph GS, Lepetit H, Lavisse S, Buttery PC, Watts C, Miskin J, Kelleher M, Deeley S et al. (2014): Long-term safety and tolerability of ProSavin, a lentiviral vector-based gene therapy for Parkinson's disease: a dose escalation, open-label, phase 1/2 trial. Lancet $\underline{383}$ (9923), 1138-1146

Park JW, Vahidi B, Taylor AM, Rhee SW, Jeon NL (2006): Microfluidic culture platform for neuroscience research. Nat Protoc $1(4), 2128-2136$

Parkinson J: An essay on the shaking palsy. Sherwood, Neely, und Jones, London 1817

Parkinson Study Group (2004): Levodopa and the progression of Parkinson's disease. N Engl J Med $\underline{351}$, 2498-2508

Pearce RK, Owen A, Daniel S, Jenner P, Marsden CD (1997): Alterations in the distribution of glutathione in the substantia nigra in Parkinson's disease. J Neural Transm 104, 661-677

Peelaerts W, Bousset L, Van der Perren A, Moskalyuk A, Pulizzi R, Giugliano M, Van den Haute C, Melki R, Baekelandt V

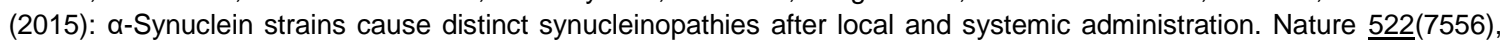
340-344

Perlson E, Maday S, Fu MM, Moughamian AJ, Holzbaur EL (2010): Retrograde axonal transport: pathways to cell death? Trends Neurosci 33(7), 335-344

Perrin RJ, Woods WS, Clayton DF, George JM (2000): Interaction of human alpha-Synuclein and Parkinson's disease variants with phospholipids. Structural analysis using site-directed mutagenesis. J Biol Chem 275(44), 34393-34398

Polymeropoulos MH, Lavedan C, Leroy E, Ide SE, Dehejia A, Dutra A, Pike B, Root H, Rubenstein J, Boyer R et al. (1997): Mutation in the alpha-synuclein gene identified in families with Parkinson's disease. Science 276(5321), 2045-2047

Postuma RB, Gagnon JF, Vendette M, Fantini ML, Massicotte-Marquez J, Montplaisir J (2009): Quantifying the risk of

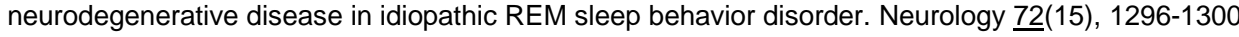

Powers KM, Kay DM, Factor SA, Zabetian CP, Higgins DS, Samii A, Nutt JG, Griffith A, Leis B, Roberts JW, et al. (2008): Combined effects of smoking, coffee, and NSAIDs on Parkinson's disease risk. Mov Disord $\underline{23}, 88-95$

Priyadarshi A, Khuder SA, Schaub EA, Priyadarshi SS (2001): Environmental risk factors and Parkinson's disease: a metaanalysis. Environ Res $\underline{86}, 122-127$

Prots I, Veber V, Brey S, Campioni S, Buder K, Riek R, Böhm KJ, Winner B (2013): a-Synuclein oligomers impair neuronal microtubule-kinesin interplay. J Biol Chem $\underline{288(30), ~ 21742-21754 ~}$

Przedborski S, Kostic V, Jackson-Lewis V, Naini AB, Simonetti S, Fahn S, Carlson E, Epstein CJ, Cadet JL (1992): Transgenic mice with increased $\mathrm{Cu} / \mathrm{Zn}$-superoxide dismutase activity are resistant to $\mathrm{N}$-methyl-4-phenyl-1,2,3,6-tetrahydropyridineinduced neurotoxicity. J Neurosci 12 (5), 1658-1667

Puschmann A, Ross OA, Vilariño-Güell C, Lincoln SJ, Kachergus JM, Cobb SA, Lindquist SG, Nielsen JE, Wszolek ZK, Farrer $\mathrm{M}$ et al. (2009): A Swedish family with de novo alpha-synuclein A53T mutation: evidence for early cortical dysfunction. Parkinsonism Relat Disord 15(9), 627-632

Quik M, O'Leary K, Tanner CM (2008): Nicotine and Parkinson's disease: implications for therapy. Mov Disord $\underline{23}$, 1641-1652

Quintavalle C, Di Costanzo S, Zanca C, Tasset I, Fraldi A, Incoronato M, Mirabelli P, Monti M, Ballabio A, Pucci P et al. (2014): Phosphorylation-regulated degradation of the tumor-suppressor form of PED by chaperone-mediated autophagy in lung cancer cells. J Cell Physiol 229(10), 1359-1368

Rajappa R, Gauthier-Kemper A, Böning D, Hüve J, Klingauf J (2016): Synaptophysin 1 Clears Synaptobrevin 2 from the Presynaptic Active Zone to Prevent Short-Term Depression. Cell Rep 14(6), 1369-1381

Ramirez A, Heimbach A, Gründemann J, Stiller B, Hampshire D, Cid LP, Goebel I, Mubaidin AF, Wriekat AL, Roeper J (2006): Hereditary parkinsonism with dementia is caused by mutations in ATP13A2, encoding a lysosomal type 5 P-type ATPase. Nat Genet $\underline{38}(10), 1184-1191$

Rao MV, Mohan PS, Kumar A, Yuan A, Montagna L, Campbell J, Veeranna, Espreafico EM, Julien JP, Nixon RA (2011): The myosin $V a$ head domain binds to the neurofilament-L rod and modulates endoplasmatic reticulum (ER) content and distribution within axons. PLoS One $\underline{6}(2)$, e17087 
Reed NA, Cai D, Blasius TL, Jih GT, Meyhofer E, Gaertig J, Verhey KJ (2006): Microtubule acetylation promotes kinesin-1 binding and transport. Curr Biol $\underline{16}(21), 2166-2172$

Reggiori F, Klionsky DJ (2013): Autophagic processes in yeast: mechanism, machinery and regulation. Genetics 194(2), 341-361

Riederer P, Sofic E, Rausch WD, Schmidt B, Reynolds GP, Jellinger K, Youdim MB (1989): Transition metals, ferritin, glutathione, and ascorbic acid in parkinsonian brains. J Neurochem. $\underline{52}, 515-520$

Rodnitzky RL (1998): Visual dysfunction in Parkinson's disease. Clin Neurosci. $\underline{5(2)}, 102-106$

Rothaug M, Stroobants S, Schweizer M, Peters J, Zunke F, Allerding M, D'Hooge R, Saftig P, Blanz J (2015): LAMP-2 deficiency leads to hippocampal dysfunction but normal clearance of neuronal substrates of chaperone-mediated autophagy in a mouse model for Danon disease. Acta Neuropathol Commun $\underline{3}, 6$

Roy S, Coffee P, Smith G, Liem RK, Brady ST, Black MM (2000): Neurofilaments are transported rapidly but intermittently in axons: implications for slow axonal transport. J Neurosci 므(18), 6849-6861

Saal KA, Koch JC, Tatenhorst L, Szegö EM, Ribas VT, Michel U, Bähr M, Tönges L, Lingor P (2015): AAV.shRNA-mediated downregulation of ROCK2 attenuates degeneration of dopaminergic neurons in toxin-induced models of Parkinson's disease in-vitro and in-vivo. Neurobiol Dis $\underline{73}, 150-162$

Saha AR, Hill J, Utton MA, Asuni AA, Ackerley S, Grierson AJ, Miller CC, Davies AM, Buchman VL, Anderton BH et al. (2004): Parkinson's disease alpha-synuclein mutations exhibit defective axonal transport in cultured neurons. J Cell Sci $\underline{117}$ (Pt 7), 1017-1024

Sambrook JF, Russell DW: Molecular Cloning. A laboratory manual. 3. Auflage; Cold Spring Harbor Laboratory Press, Cold Spring Harbor, New York 2001

Schlager MA, Hoogenraad CC (2009): Basic mechanisms for recognition and transport of synaptic cargos. Mol Brain $\underline{2}, 25$

Schlesinger I, Schlesinger N (2008): Uric acid in Parkinson's disease. Mov Disord 233(12), 1653-1657

Schwarz L, Goldbaum O, Bergmann M, Probst-Cousin S, Richter-Landsberg C (2012): Involvement of macroautophagy in multiple system atrophy and protein aggregate formation in oligodendrocytes. J Mol Neurosci $\underline{47}(2), 256-266$

Shen L, Ji HF (2013): Low uric acid levels in patients with Parkinson's disease: evidence from meta-analysis. BMJ Open $\underline{3}(11)$, e003620

Shimoda K, Sauve Y, Marini A, Schwartz JP, Commissiong JW (1992): A high percentage yield of tyrosine hydroxylase-positive cells from rat E14 mesencephalic cell culture. Brain Res $\underline{586(2), 319-331}$

Shintani T, Klionsky DJ (2004): Autophagy in health and disease: a double-edged sword. Science $\underline{306}$ (5698), 990-995

Simon KC, Chen H, Schwarzschild M, Ascherio A (2007): Hypertension, hypercholesterolemia, diabetes, and risk of Parkinson disease. Neurology $\underline{69}(17), 1688-1695$

Singleton AB, Farrer M, Johnson J, Singleton A, Hague S, Kachergus J, Hulihan M, Peuralinna T, Dutra A, Nussbaum R (2003): alpha-Synuclein locus triplication causes Parkinson's disease. Science 302(5646), 841

Singleton AB, Farrer MJ, Bonifati V (2013): The genetics of Parkinson's disease: progress and therapeutic implications. Mov Disord $\underline{28}(1), 14-23$

Slaughter JR, Slaughter KA, Nichols D, Holmes SE, Martens MP (2001): Prevalence, clinical manifestations, etiology, and treatment of depression in Parkinson's disease. J Neuropsychiatry Clin Neurosci 13(2), 187-196

Smith WW, Jiang H, Pei Z, Tanaka Y, Morita H, Sawa A, Dawson VL, Dawson TM, Ross CA (2005): Endoplasmic reticulum stress and mitochondrial cell death pathways mediate A53T mutant alpha-synuclein-induced toxicity. Hum Mol Genet 14(24), 3801-3811

Söllner T, Bennett MK, Whiteheart SW, Scheller RH, Rothman JE (1993a): A protein assembly-disassembly pathway in-vitro that may correspond to sequential steps of synaptic vesicle docking, activation, and fusion. Cell $\underline{75}(3), 409-418$

Söllner T, Whiteheart SW, Brunner M, Erdjument-Bromage H, Geromanos S, Tempst P, Rothman JE (1993b): SNAP receptors implicated in vesicle targeting and fusion. Nature $\underline{362}(6418), 318-324$

Sou YS, Tanida I, Komatsu M, Ueno T, Kominami E (2006): Phosphatidylserine in addition to phosphatidylethanolamine is an in-vitro target of the mammalian Atg8 modifiers, LC3, GABARAP, and GATE-16. J Biol Chem 281(6), 3017-3024 
Spatola M, Wider C (2014) Genetics of Parkinson's disease: the yield. Parkinsonism Relat Disord 20 Suppl 1, 35-48

Spencer B, Potkar R, Trejo M, Rockenstein E, Patrick C, Gindi R, Adame A, Wyss-Coray T, Masliah E (2009): Beclin 1 gene transfer activates autophagy and ameliorates the neurodegenerative pathology in alpha-synuclein models of Parkinson's and Lewy body diseases. J Neurosci $\underline{29}(43), 13578-13588$

Spencer DD, Robbins RJ, Naftolin F, Marek KL, Vollmer T, Leranth C, Roth RH, Price LH, Gjedde A, Bunney BS et al. (1992): Unilateral transplantation of human fetal mesencephalic tissue into the caudate nucleus of patients with Parkinson's disease. N Engl J Med 327(22), 1541-1548

Spencer JP, Jenner P, Daniel SE, Lees AJ, Marsden DC, Halliwell B (1998): Conjugates of catecholamines with cysteine and GSH in Parkinson's disease: possible mechanisms of formation involving reactive oxygen species. J Neurochem $\underline{71}$, 2112-2122

Spillantini MG, Schmidt ML, Lee VM, Trojanowski JQ, Jakes R, Goedert M (1997): Alpha-synuclein in Lewy bodies. Nature $\underline{388}$, 839-840

Stokin GB, Lillo C, Falzone TL, Brusch RG, Rockenstein E, Mount SL, Raman R, Davies P, Masliah E, Williams DS et al. (2005): Axonopathy and transport deficits early in the pathogenesis of Alzheimer's disease. Science $\underline{307}(5713)$, $1282-1288$

Suzuki K, Kubota Y, Sekito T, Ohsumi Y (2007): Hierarchy of Atg proteins in pre-autophagosomal structure organization. Genes Cells $\underline{12}(2), 209-218$

Takeda A, Hashimoto M, Mallory M, Sundsumo M, Hansen L, Sisk A, Masliah E (1998): Abnormal distribution of the non-Abeta component of Alzheimer's disease amyloid precursor/alpha-synuclein in Lewy body disease as revealed by proteinase $\mathrm{K}$ and formic acid pretreatment. Lab Invest $\underline{78}(9), 1169-1177$

Tan EK, Tan C, Shen H, Chai A, Lum SY, Teoh ML, Yih Y, Wong MC, Zhao Y (2003): Alpha synuclein promoter and risk of Parkinson's disease: microsatellite and allelic size variability. Neurosci Lett $\underline{336}, 70-72$

Tanaka Y, Guhde G, Suter A, Eskelinen EL, Hartmann D, Lüllmann-Rauch R, Janssen PM, Blanz J, von Figura K, Saftig P (2000): Accumulation of autophagic vacuoles and cardiomyopathy in LAMP-2-deficient mice. Nature 406(6798), 902-906

Tanji K, Odagiri S, Maruyama A, Mori F, Kakita A, Takahashi H, Wakabayashi K (2013): Alteration of autophagosomal proteins in the brain of multiple system atrophy. Neurobiol Dis $\underline{49}, 190-198$

Tanner CM, Ottman R, Goldman SM, Ellenberg J, Chan P, Mayeux R, Langston JW (1999): Parkinson disease in twins: an etiologic study. JAMA $\underline{281}, 341-346$

Taylor AM, Blurton-Jones M, Rhee SW, Cribbs DH, Cotman CW, Jeon NL (2005): A microfluidic culture platform for CNS axonal injury, regeneration and transport. Nat Methods $\underline{2}(8), 599-605$

Taylor R Jr, Chen PH, Chou CC, Patel J, Jin SV (2012): KCS1 deletion in Saccharomyces cerevisiae leads to a defect in translocation of autophagic proteins and reduces autophagosome formation. Autophagy $\underline{8}(9), 1300-1311$

Thomas B, Beal MF (2007): Parkinson's disease. Hum Mol Genet 16 Spec No. 2, 183-194

Thompson LM, Aiken CT, Kaltenbach LS, Agrawal N, Illes K, Khoshnan A, Martinez-Vincente M, Arrasate M, O'Rourke JG, Khashwji $\mathrm{H}$ et al. (2009): IKK phosphorylates Huntingtin and targets it for degradation by the proteasome and lysosome. J Cell Biol 187(7), 1083-1099

Thumm M, Egner R, Koch B, Schlumpberger M, Straub M, Veenhuis M, Wolf DH (1994): Isolation of autophagocytosis mutants of Saccharomyces cerevisiae. FEBS Lett 349(2), 275-280

Tsukada M, Ohsumi Y (1993): Isolation and characterization of autophagy-defective mutants of Saccharomyces cerevisiae. FEBS Lett $\underline{333}(1-2), 169-174$

Uéda K, Saitoh T, Mori H (1994): Tissue-dependent alternative splicing of mRNA for NACP, the precursor of non-A beta component of Alzheimer's disease amyloid. Biochem Biophys Res Commun 205(2), 1366-1372

Uversky VN, Li J, Fink AL (2001): Metal-triggered structural transformations, aggregation, and fibrillation of human alphasynuclein. A possible molecular NK between Parkinson's disease and heavy metal exposure. J Biol Chem $\underline{276}$, 4428444296

Vale RD (2003): The molecular motor toolbox for intracellular transport. Cell 112(4), 467-480 
van der Vaart A, Griffith J, Reggiori F (2010): Exit from the Golgi is required for the expansion of the autophagosomal phagophore in yeast Saccharomyces cerevisiae. Mol Biol Cell 21(13), 2270-2284

Vogiatzi T, Xilouri M, Vekrellis K, Stefanis L (2008): Wild type alpha-synuclein is degraded by chaperone-mediated autophagy and macroautophagy in neuronalcells. J Biol Chem 283(35), 23542-23556

Wang G, Mao Z (2014): Chaperone-mediated autophagy: roles in neurodegeneration. Transl Neurodegener $\underline{3}, 20$

Wang L, Brown A (2001): Rapid intermittent movement of axonal neurofilaments observed by fluorescence photobleaching. Mol Biol Cell 12(10), 3257-3267

Wang L, Ho CL, Sun D, Liem RK, Brown A (2000): Rapid movement of axonal neurofilaments interrupted by prolonged pauses. Nat Cell Biol $2(3), 137-141$

Wang QJ, Ding Y, Kohtz DS, Mizushima N, Cristea IM, Rout MP, Chait BT, Zhong Y, Heintz N, Yue Z (2006): Induction of autophagy in axonal dystrophy and degeneration. J Neurosci $\underline{26}(31), 8057-8068$

Washbourne P, Schiavo G, Montecucco C (1995): Vesicle-associated membrane protein-2 (synaptobrevin-2) forms a complex with synaptophysin. Biochem J $\underline{305}$ (Pt 3), 721-724

Webb JL, Ravikumar B, Atkins J, Skepper JN, Rubinsztein DC (2003): Alpha-Synuclein is degraded by both autophagy and the proteasome. J Biol Chem $\underline{278}(27), 25009-25013$

Wersinger C, Sidhu A (2003): Attenuation of dopamine transporter activity by alpha-synuclein. Neurosci Lett $\underline{340}(3), 189-192$

Wider C, Wszolek ZK (2008): Etiology and pathophysiology of frontotemporal dementia, Parkinson disease and Alzheimer disease: lessons from genetic studies. Neurodegener Dis $\underline{5}, 122-125$

Widner H, Tetrud J, Rehncrona S, Snow B, Brundin P, Gustavii B, Björklund A, Lindvall O, Langston JW (1992): Bilateral fetal mesencephalic grafting in two patients with parkinsonism induced by 1-methyl-4-phenyl-1,2,3,6-tetrahydropyridine (MPTP). N Engl J Med 327(22), 1556-1563

Wilfinger WW, Mackey K, Chomczynski P (1997): Effect of pH and ionic strength on the spectrophotometric assessment of nucleic acid purity. Biotechniques $\underline{22}(3), 474-476$ und $478-481$

Williams A, Gill S, Varma T, Jenkinson C, Quinn N, Mitchell R, Scott R, Ives N, Rick C, Daniels J et al. (2010): Deep brain stimulation plus best medical therapy versus best medical therapy alone for advanced Parkinson'sdisease (PD SURG trial): a randomised, open-label trial. Lancet Neurol $\underline{9}(6), 581-591$

Winslow AR, Chen CW, Corrochano S, Acevedo-Arozena A, Gordon DE, Peden AA, Lichtenberg M, Menzies FM, Ravikumar B, Imarisio $S$ et al. (2010): a-Synuclein impairs macroautophagy: implications for Parkinson's disease. J Cell Biol 190(6), 1023-1037

Xie Z, Klionsky DJ (2007): Autophagosome formation: core machinery and adaptations. Nat Cell Biol $\underline{9}(10), 1102-1109$

Xilouri M, Brekk OR, Stefanis L (2016): Autophagy and Alpha-Synuclein: Relevance to Parkinson's Disease and Related Synucleopathies. Mov Disord 31(2), 178-192

Xilouri M, Vogiatzi T, Vekrellis K, Park D, Stefanis L (2009): Abberant alpha-synuclein confers toxicity to neurons in part through inhibition of chaperone-mediatedautophagy. PLoS One $4(5)$, e5515

Xu Q, Park Y, Huang X, Hollenbeck A, Blair A, Schatzkin A, Chen H (2010): Physical activities and future risk of Parkinson disease. Neurology $\underline{75(4)}, 341-348$

Yamamoto A, Tagawa Y, Yoshimori T, Moriyama Y, Masaki R, Tashiro Y (1998): Bafilomycin A1 prevents maturation of autophagic vacuoles by inhibiting fusion between autophagosomes and lysosomes in rat hepatoma cell line, H-4-II-E cells. Cell Struct Funct $\underline{23}(1), 33-42$

Yang F, Trolle Lagerros Y, Bellocco R, Adami HO, Fang F, Pedersen NL, Wirdefeldt K (2015): Physical activity and risk of Parkinson's disease in the Swedish National March Cohort. Brain 138(Pt 2), 269-275

Yang ML, Hasadsri L, Woods WS, George JM (2010): Dynamic transport and localization of alpha-synuclein in primary hippocampal neurons. Mol Neurodegener $\underline{5}(1), 9$

Yang Q, She H, Gearing M, Colla E, Lee M, Shacka JJ, Mao Z (2009): Regulation of neuronal survival factor MEF2D by chaperone-mediated autophagy. Science $\underline{323}(5910), 124-127$ 
Yen WL, Shintani T, Nair U, Cao Y, Richardson BC, Li Z, Hughson FM, Baba M, Klionsky DJ (2010): The conserved oligomeric Golgi complex is involved in double-membrane vesicle formation during autophagy. J Cell Biol 188(1), 101-114

Yorimitsu T, Klionsky DJ (2005): Autophagy: molecular machinery for self-eating. Cell Death Differ 12 Suppl 2, 1542-1552

Yoshimori T, Yamamoto A, Moriyama Y, Futai M, Tashiro Y (1991): Bafilomycin A1, a specific inhibitor of vacuolar-type $H(+)$ ATPase, inhibits acidification and protein degradation in lysosomes of cultured cells $\underline{266}(26), 17707-17712$

Zarranz JJ, Alegre J, Gómez-Esteban JC, Lezcano E, Ros R, Ampuero I, Vidal L, Hoenicka J, Rodriguez O, Atarés B (2004): The new mutation, E46K, of alpha-synuclein causes Parkinson and Lewy body dementia. Ann Neurol $\underline{55}(2), 164-173$

Zavodszky E, Seaman MN, Moreau K, Jimenez-Sanchez M, Breusegem SY, Harbour ME, Rubinsztein DC (2014): Mutation in VPS35 associated with Parkinson's disease impairs WASH complex association and inhibitsautophagy. Nat Commun $\underline{5}$, 3828

Zeitelhofer M, Vessey JP, Thomas S, Kiebler M, Dahm R (2009): Transfection of cultured primary neurons via nucleofection. Curr Protoc Neurosci Chapter 4:Unit4, 32

Zhivotovsky B, Samali A, Gahm A, Orrenius S (1999): Caspases: their intracellular localization and translocation during apoptosis. Cell Death Differ $\underline{6}(7), 644-651$

Zhou RM, Huang YX, Li XL, Chen C, Shi Q, Wang GR, Tian C, Wang ZY, Jing YY, Gao C et al. (2010): Molecular interaction of $\alpha$-synuclein with tubulin influences on the polymerization of microtubule in-vitro and structure of microtubule in cells. Mol Biol Rep $\underline{37}(7), 3183-3192$

Zhu JH, Guo F, Shelburne J, Watkins S, Chu CT (2003): Localisation of phosphorylated ERK/MAP kinases to mitochondria and autophagosomes in Lewy body diseases. Brain Pathol $\underline{13}(4), 473-481$

Zolotukhin S, Byrne BJ, Mason E, Zolotukhin I, Potter M, Chesnut K, Summerford C, Samulski RJ, Muzyczka N (1999): Recombinant adeno-associated virus purification using novel methods improves infectious titer and yield. Gene Ther $\underline{6}(6), 973-985$ 
Teile dieser Arbeit wurden in folgendem Beitrag vorab veröffentlicht:

Koch JC, Bitow F, Haack J, d'Hedouville Z, Zhang JN, Tönges L, Michel U, Oliveira LM, Jovin TM, Liman J et al. (2015): Alpha-Synuclein affects neurite morphology, autophagy, vesicle transport and axonal degeneration in CNS neurons. Cell Death Dis $\underline{6}$, e1811 


\section{Danksagung}

Zu aller erst möchte ich mich bei Prof. Dr. med. M. Bähr für die Möglichkeit, in seiner Arbeitsgruppe unter besten Vorausseztungen diese Arbeit zu verfassen, bedanken.

Ganz besonderer Dank gilt an dieser Stelle Herrn PD Dr. med. Jan C. Koch, der zu jeder Zeit als Betreuer an meiner Seite die Weiterentwicklung der Experimente unterstützte und der nicht nur bei Rückschlägen es stets verstand, die Motiavtion zum Weitermachen hochzuhalten, sondern vielmehr aus negativen Ereignissen weitere Ideen kreierte und somit entscheidend zum Gelingen der Arbeit beitrug. Hieraus hat sich neben einer professionellen Zusammenarbeit auch ein freundschaftliches Verhältnis aufgebaut, welches ich zu keiner Zeit missen möchte.

Außerdem möchte ich mich bei Herrn Prof. Dr. med Paul Lingor als Leiter der AG Lingor für die Bereitsstellung des Dissertationsthemas und vor allem für die stets konstruktiven Anmerkungen, ohne die diese Arbeit nicht möglich gewesen wäre, bedanken.

Großen Dank möchte ich auch allen Mitgliedern der Arbeitsgruppe von Prof. Bähr, insbesondere der AG Lingor, aussprechen. Hierbei ist besonders Elisabeth Barski hervorzuheben, die zu jeder Zeit meiner Dissertation mit Rat zur Seite stand und vor allem zu Anfang die notwendigen praktischen Laborfertigkeiten lehrte. Gesonderter Dank gilt auch Dr. rer. nat. Sebastian Kügler für die Bereitsstellung der a-Syn-Plasmide sowie Prof. Uwe Michel für die Bereitstellung des eGFP- und des DsRed-Plasmids sowie des SynaptophysineGFP-Virus.

Ebenso möchte ich mich bei der Universitätsmedizin Göttingen für die Ermöglichung eines Forschungsfreisemesters bedanken.

$\mathrm{Zu}$ guter Letzt möchte ich mich herzlich bei meiner Mitdoktorandin und Lebensgefährtin Jessica Haack bedanken. Ohne sie wären viele Versuche nicht möglich gewesen. 
Lebenslauf 